\author{
UNIVERSIDADE DE SÃO PAULO \\ INSTITUTO DE ENERGIA E AMBIENTE \\ PROGRAMA DE PÓS-GRADUAÇÃO EM ENERGIA
}

JOSÉ EDUARDO PRATA

ESTIMATIVA E RECUPERAÇÃO DA ÁGUA PRESENTE NOS PRODUTOS DE COMBUSTÃO DE CENTRAIS TERMELÉTRICAS 
JOSÉ EDUARDO PRATA

\section{ESTIMATIVA E RECUPERAÇÃO DA ÁGUA PRESENTE NOS PRODUTOS DE COMBUSTÃO DE CENTRAIS TERMELÉTRICAS}

Tese apresentada ao Programa de PósGraduação em Energia do Instituto de Energia e Ambiente da Universidade de São Paulo para obtenção do título de Doutor em Ciências.

Orientador: Prof. Dr. José Roberto Simões Moreira

\section{Versão Corrigida}

(versão original disponível na Biblioteca do Instituto de Energia e Ambiente e na Biblioteca Digital de Teses e Dissertações da USP) 


\section{ESTIMATIVA E RECUPERAÇÃO DA ÁGUA PRESENTE NOS PRODUTOS DE COMBUSTÃO DE CENTRAIS TERMELÉTRICAS}

Tese apresentada ao Programa de PósGraduação em Energia do Instituto de Energia e Ambiente da Universidade de São Paulo para obtenção do título de Doutor em Ciências.

Aprovado em:

Banca Examinadora:

Prof. Dr.

Instituição:

Julgamento:

Assinatura:

Prof. Dr.

Instituição:

Julgamento:

Assinatura:

Prof. Dr.

Instituição:

Julgamento:

Assinatura:

Prof. Dr.

Instituição:

Julgamento:

Assinatura:

Prof. Dr.

Instituição:

Julgamento:

Assinatura: 


\section{Agradecimentos}

À minha família e amigos pelo incentivo permanente.

Ao Instituto de Pesquisas Tecnológicas do Estado de São Paulo pelo incentivo e disponibilização de tempo, sem o qual a realização deste trabalho não seria possível.

Ao Instituto de Energia e Ambiente da USP pelo suporte e subsídio de conhecimentos valiosos por meio de seu corpo docente.

Sou imensamente grato ao SISEA (Laboratório de Sistemas Energéticos Alternativos da USP) pelo acolhimento ao longo dos últimos 10 anos.

Por fim, deixo registrada minha profunda gratidão, respeito e admiração pelo professor José Roberto Simões Moreira, o qual me orienta ao longo dos últimos anos. 
Dedicatória

À minha esposa, Patrícia Aos meus pais, Eliana e José 


\section{Resumo}

Usinas Termelétricas (UTEs), compostas por ciclo simples a vapor e ciclo combinado, são instalações industriais que consomem elevadas quantidades de água, sobretudo por conta de suas operações de resfriamento e de geração de vapor. Paralelamente, tem-se observado a redução de oferta deste recurso em muitas regiões onde se encontram instaladas unidades termelétricas, fato que suscita a preocupação, o debate e a pesquisa acerca do desenvolvimento de tecnologias e estratégias direcionadas à mitigação do consumo e reaproveitamento de água em UTEs. Em contrapartida, do mesmo modo que UTEs são intensivas no consumo de água, esta é também produzida na forma de vapor em escalas significativas como resultado do processo de combustão. Contudo, a parcela de água produzida é lançada para a atmosfera juntamente com os demais gases produzidos $\left(\mathrm{CO}_{2}, \mathrm{~N}_{2}, \mathrm{O}_{2}, \mathrm{SO}_{2}\right)$. Frente a esse contexto, este trabalho se divide em duas etapas distintas. A primeira voltada à estimativa da quantidade de água $\mathrm{e}$ demais componentes presentes nos gases de combustão de trinta e seis UTEs brasileiras, dentre as quais vinte e duas são movidas a gás natural (ciclos simples e combinados) e quatorze a carvão mineral (ciclos simples). Tais estimativas levam em conta as condições ambientais do local de operação, a eficiência típica do ciclo e a composição do combustível empregado. A segunda etapa trata da modelagem e da simulação, sob diferentes condições operacionais (pressão, temperatura de resfriamento e porcentagem de vapor de água nos gases), de um condensador duplo tubo vertical operando sob regime de convecção natural no lado do resfriamento, a partir do qual se estuda o processo de condensação do vapor de água na presença dos demais gases produzidos, estes conhecidos como gases não condensáveis (GNC). Tais simulações tem o propósito de avaliar as taxas de recuperação de água capazes de serem obtidas por meio do condensador/processo idealizado.

Palavras Chave: Usinas Termelétricas, Recuperação de água, Condensação, Combustão, Gases não condensáveis. 


\begin{abstract}
Single and combined steam cycle thermoelectric plants are power plants that consume high amounts of water, mainly from the cooling and steam generation operations. At the same time, there have been a reduction in the supply of this resource in many regions where thermoelectric units are installed. This fact increases the concern, discussion, and research on the development of technologies and new strategies directed to the mitigation of the consumption and reutilization of water. On the other hand, likewise UTEs are intensive in water consumption, they also produce it at significant amounts of steam from the combustion process, and that amount of water produced is released to the atmosphere together with gases produced $\left(\mathrm{CO}_{2}, \mathrm{~N}_{2}, \mathrm{O}_{2}\right.$, $\mathrm{SO}_{2}$ ). In this sense, this work is divided into two distinct parts. The first one is aimed at estimating the amount of water and other components present in the flue gases of thirty Brazilian thermal power plants, of which twenty-two are powered by natural gas (single and combined cycles) and eight moved by coal (single cycles). Such estimates consider environmental conditions of the operation site, typical cycle efficiency, and fuel composition employed. The second part deals with a numerical modeling and simulation, at different operating conditions (pressure, cooling temperature, and water vapor content in the gases), of a double vertical tube condenser operating by natural convection on the cooling side, from which the condensation process of the water vapor is studied in the presence of the other gases produced (known as non-condensable gases, NCG). These simulations have the fundamental purpose of evaluating the rates of condensate that can be recovered by means of the condenser/idealized process.
\end{abstract}

Keywords: Thermal Power Plants, Water recovery, Condensation, Combustion, Noncondensable gases. 


\section{Lista de Ilustrações}

Figura 2.1 - Esquema de um ciclo Brayton aberto. Fonte: Elaboração própria............................ 30

Figura 2.2 - Esquema de um ciclo Brayton fechado. Fonte: Elaboração própria........................ 31

Figura 2.3 - Diagrama T-s para ciclo Brayton ideal e real. Fonte: Moran \& Shapiro (2006) .... 32

Figura 2.4 - Eficiência térmica do ciclo Brayton em função da razão de pressão. Fonte:

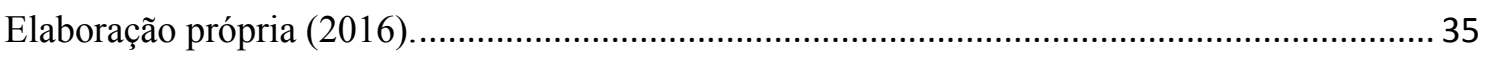

Figura 2.5 - Componentes básicos de uma turbina a gás. Fonte: EPE (2008)........................... 37

Figura2.6 - Turbina a gás aeroderivativa modelo LM6000, 50 MW da GE. Fonte:

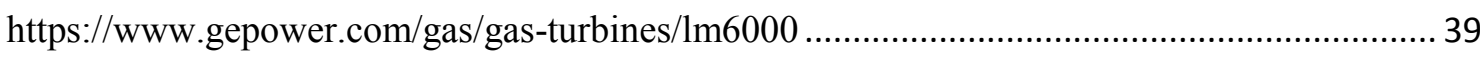

Figura 2.7 - Turbina a gás heavy duty modelo 9F03, 132MW da GE. Fonte:

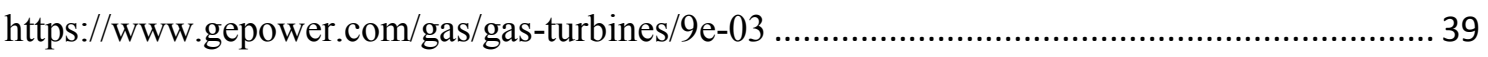

Figura 2.8 - Esquema genérico de um ciclo Rankine simples. Fonte: Elaboração própria. ........ 42

Figura 2.9 - Diagrama T-s do ciclo Rankine ideal. Fonte: Moran e Shapiro (2006).................. 43

Figura 2.10 - Diagrama T-s do ciclo Rankine real. Fonte: Moran e Shapiro (2006).................. 45

Figura 2.11 - Tipos de termelétricas de ciclo combinado: a) em série; b) em paralelo; c) em série/paralelo. Fonte: Lora e Do Nascimento (2004).

Figura 2.12 - Esquema de uma caldeira de recuperação com queima suplementar e um único nível de pressão. Fonte: Branco (2005).

Figura 2.13 - Sistema de resfriamento de passagem única (once-through). Fonte: Adaptado de

Rutberg (2003).

Figura 2.14 - Classificação das torres de resfriamento úmidas. Fonte: Adaptado de Rutberg (2003). 54

Figura 2.15 - Torre de resfriamento seca. Fonte: Adaptado de Rutberg (2003)......................... 55

Figura 2.16 - Modos de condensação. (a) Filme, (b) Gotas, (c) Condensação homogênea, (d) Contato direto. Fonte: Adaptado de Incropera e Dewitt (2011).

Figura 2.17 - Condensação de vapor em superfície vertical. (a) Gotas, (b) Filme. Fonte: Incropera e DeWitt (2011), cortesia de J.W. Westwater, University of Illinois at ChampaignUrbana.

Figura 2.18 - Formas de condensação em uma parede vertical de alumínio isotérmica na presença de 20\% em massa de gases não condensáveis. Fonte: Yi et al. (2016)........................ 58

Figura 2.19 - Superfície de condensação ondulada. Fonte: Adaptado de Carey (1992). 59

Figura 2.20 - Efeitos da camada limite relacionados à condensação em filme em uma superfície vertical, a) não considerando hipóteses de Nusselt; b) considerando as hipóteses de Nusselt. Fonte: Adaptado de Incropera e DeWitt (2011). 60 
Figura 2.21 - Perfis de concentração e temperatura na condensação de vapor na na presença de não condensáveis. Fonte: Elaboração própria.

Figura 2.22 - Captação e consumo de água para diferentes tipos de centrais termelétricas de acordo com o tipo de combustível, geração e sistema de resfriamento. Fonte: Adaptado de Scanlon et al. (2013).

Figura 2.23 - Aparato experimental para condensação de gases de combustão. Fonte: Adaptado de Levy et al. (2011).

Figura 2.24 - Permeabilidade do vapor de água vs. seletividade $\mathrm{H}_{2} \mathrm{O} / \mathrm{N}_{2}$ de várias membranas poliméricas a $30^{\circ} \mathrm{C}$. Fonte: Adaptado de Metz et al. (2005)

Figura 2.25 - Ilustração do aparato experimental utilizado por Chan et al. (1990). Fonte:

Adaptado de Chan et al. (1990).

Figura 2.26 - Resultados dos coeficientes locais de transferência de calor em função das frações mássicas de ar de Chan et al. (1990). Fonte: Adaptado de Chan et al. (1990). .75

Figura 2.27 - Comparação entre os resultados numéricos e experimentais de Siddique et al. (1993) e Siddique et al. (1994), para frações mássicas de ar iguais a 0,11 e 0,22. Adaptado de Siddique et al. (1994).

Figura 2.28 - Resultados de $\mathrm{h}_{\mathrm{cd}}, \mathrm{h}_{\mathrm{f}} \mathrm{e} \mathrm{h}_{\mathrm{g}}$ obtidos por Maheshwari et al. (2004). Fonte: Adaptado de Maheshwari et al. (2004).

Figura 2.29 - Resultados de fluxo de condensação de Fu et al. (2016). Fonte: Adaptado de Fu et al. (2016).

Figura 2.30 - Coeficientes locais de transferência de calor em função das frações mássicas de ar. Fonte: Fu et al. (2016).

Figura 3.1 - Fator de produção de água, $\mathrm{V}_{1}{ }_{1}$, das UTEs movidas a carvão mineral avaliadas. . 100 Figura 3.2 - Fator de produção de água, $\mathrm{V}_{1}$, das UTEs movidas a gás natural avaliadas. 101 Figura 3.3 - Porcentagem volumétrica de GNC das UTEs movidas a carvão mineral avaliadas.

Figura 3.4 - Temperatura de saturação do vapor de água, $\mathrm{T}_{\text {sat, }}$ das UTEs movidas a carvão mineral avaliadas 104

Figura 3.5 - Porcentagem volumétrica de GNC das UTEs movidas a gás natural avaliadas. .. 105 Figura 3.6 - Temperatura de saturação do vapor de água, $\mathrm{T}_{\text {sat, }}$ das UTEs movidas a gás natural avaliadas 106

Figura 4.1 - Condensador idealizado neste trabalho. Fonte: Elaboração prórpria 110

Figura 4.2 - Distribuição das temperaturas no condensador. Fonte: Elaboração própria 111

Figura 4.3 - Camada limite na convecção natural ao longo de uma placa vertical. Fonte: Adaptado de Holman (2010). 
Figura 4.4 - Perfis de temperatura, $\mathrm{T}_{\mathrm{si}}, \mathrm{T}_{\mathrm{g}}, \mathrm{T}_{\text {sat }}$ e $\mathrm{T}_{\mathrm{c}}$ para $\mathrm{T}_{\mathrm{ce}}=25,30$ e $35^{\circ} \mathrm{C}, \mathrm{P}_{\mathrm{o}}=101,32 \mathrm{kPa}$ e $\%$ Vol. v $=6,16 \%$.

Figura 4.5 - Números adimensionais e coeficientes convectivos de transferência de calor do

fluido de resfriamento, $\mathrm{P}_{\mathrm{o}}=101,32 \mathrm{kPa}, \% \mathrm{Vol} . \mathrm{v}=6,16, \mathrm{~T}_{\mathrm{ce}}=25,30$ e $35^{\circ} \mathrm{C}$

Figura 4.6 - Número de Grashof do fluido de resfriamento em função das diferenças de temperatura $\left(\mathrm{T}_{\mathrm{s}}-\mathrm{T}_{\infty}\right), \mathrm{P}_{\mathrm{o}}=101,32 \mathrm{kPa}, \% \mathrm{Vol} . \mathrm{v}=6,16, \mathrm{~T}_{\mathrm{ce}}=25,30$ e $35^{\circ} \mathrm{C}$

Figura 4.7 - Diferenças de temperatura $\left(\mathrm{T}_{\mathrm{se}}-\mathrm{T}_{\infty}\right)$ no lado do fluido de resfriamento, $\mathrm{P}_{\mathrm{o}}=101,32$

$\mathrm{kPa}, \%$ Vol. v $=6,16, \mathrm{~T}_{\mathrm{ce}}=25,30$ e $35^{\circ} \mathrm{C}$.

Figura 4.8 - Parâmetro adimensional $\mathrm{Gr}_{\mathrm{c}} / \mathrm{Re}_{\mathrm{c}}^{2}$ ao longo de $\mathrm{L}, \mathrm{P}_{\mathrm{o}}=101,32 \mathrm{kPa}, \% \mathrm{Vol} . \mathrm{v}=6,16$, $\mathrm{T}_{\mathrm{ce}}=25,30$ e $35^{\circ} \mathrm{C}$

Figura 4.9 - Densidades do fluido de resfriamento na superfície e ao longe. (a) $\mathrm{T}_{\mathrm{ce}}=25^{\circ} \mathrm{C}$, (b) $\mathrm{T}_{\mathrm{ce}}=30^{\circ} \mathrm{C},(\mathrm{c}) \mathrm{T}_{\mathrm{ce}}=35^{\circ} \mathrm{C}, \mathrm{P}_{\mathrm{o}}=101,32 \mathrm{kPa}$ e $\% \mathrm{Vol} . \mathrm{v}=6,16$.

Figura 4.10 - Coeficientes de transferência de calor de condensação $\left(\mathrm{h}_{\mathrm{cd}}\right)$, do filme líquido $\left(\mathrm{h}_{\mathrm{fl}}\right)$ e dos gases de combustão $\left(\mathrm{h}_{\mathrm{g}}\right), \mathrm{T}_{\mathrm{ce}}=25^{\circ} \mathrm{C}, \mathrm{P}_{\mathrm{o}}=101,32 \mathrm{kPa}$ e \%Vol. $\mathrm{v}=6,16$ 139

Figura 4.11 - Coeficientes de transferência de calor de condensação $\left(\mathrm{h}_{\mathrm{cd}}\right)$, do filme líquido $\left(\mathrm{h}_{\mathrm{fl}}\right)$ e dos gases de combustão $\left(\mathrm{h}_{\mathrm{g}}\right), \mathrm{T}_{\mathrm{ce}}=30^{\circ} \mathrm{C}, \mathrm{P}_{\mathrm{o}}=101,32 \mathrm{kPa}, \% \mathrm{Vol}$. v $=6,16$ 139

Figura 4.12 - Coeficientes de transferência de calor de condensação $\left(\mathrm{h}_{\mathrm{cd}}\right)$, do filme líquido $\left(\mathrm{h}_{\mathrm{fl}}\right)$ e dos gases de combustão $\left(\mathrm{h}_{\mathrm{g}}\right), \mathrm{T}_{\mathrm{ce}}=35^{\circ} \mathrm{C}, \mathrm{P}_{\mathrm{o}}=101,32 \mathrm{kPa}, \% \mathrm{Vol}$. v $=6,16$ 139

Figura 4.13 - Coeficientes globais de transferência de calor, $U, P_{o}=101,32 \mathrm{kPa}, \%$ Vol $v=6,16$, $T_{c e}=25,30$ e $35^{\circ} \mathrm{C}$.

Figura 4.14 - Coeficientes de transferência de massa nos GC, $\mathrm{k}_{\mathrm{g}}, \mathrm{P}_{\mathrm{o}}=101,32 \mathrm{kPa}, \% \mathrm{Vol} \mathrm{v}=$ $6,16, \mathrm{~T}_{\mathrm{ce}}=25,30$ e $35^{\circ} \mathrm{C}$.

Figura 4.15 - Diferença de fração mássica entre o GC e a interface $\left(\mathrm{x}_{\mathrm{v}, \mathrm{b}}-\mathrm{x}_{\mathrm{v}, \mathrm{i}}\right)$. (a) ao longo de $\mathrm{L}$. (b) em função de $\quad\left(\mathrm{T}_{\mathrm{g}}-\mathrm{T}_{\mathrm{i}}\right), \mathrm{P}_{\mathrm{o}}=101,32 \mathrm{kPa}, \% \mathrm{Vol} \mathrm{v}=6,16, \mathrm{~T}_{\mathrm{ce}}=25,30$ e $35^{\circ} \mathrm{C}$.

Figura 4.16 - Influência da pressão nos coeficientes de transferência de calor e de massa. (a) coeficiente convectivo de transferência de calor, (b) coeficiente convectivo de transferência de massa. $\mathrm{T}_{\mathrm{ce}}=25^{\circ} \mathrm{C}, \%$ Vol. v $=6,16$ e $\mathrm{P}_{\mathrm{o}}=101,32,105,110$ e $120 \mathrm{kPa}$. 145

Figura 4.17 - Coefcientes de difusividade do vapor ao longo do condensador, $\mathrm{T}_{\mathrm{ce}}=25^{\circ} \mathrm{C}, \% \mathrm{Vol}$. $\mathrm{v}=6,16, \mathrm{P}_{\mathrm{o}}=101,32,105,110$ e $120 \mathrm{kPa}$. 146

Figura 4.18 - Números de Schmidt ao longo do condensador, $\mathrm{T}_{\mathrm{ce}}=25^{\circ} \mathrm{C}, \% \mathrm{Vol}$. v $=6,16, \mathrm{P}_{\mathrm{o}}=$ $101,32,105,110$ e $120 \mathrm{kPa}$.

Figura 4.19 - Relações entre números de Nusselt e de Sherwood com e sem efeito de sucção, $\mathrm{T}_{\mathrm{ce}}=25^{\circ} \mathrm{C}, \%$ Vol. v $=6,16$, (a) $\mathrm{P}_{\mathrm{o}}=101,32 \mathrm{kPa}$; (b) $\mathrm{P}_{\mathrm{o}}=105 \mathrm{kPa}$; (c) $\mathrm{P}_{\mathrm{o}}=110 \mathrm{kPa}$; (c) $\mathrm{P}_{\mathrm{o}}=120 \mathrm{kPa}$

Figura 4.20 - Coeficientes convectivos de transferência de calor e de massa $\left(\mathrm{h}_{\mathrm{g}}\right.$ e $\left.\mathrm{k}_{\mathrm{g}}\right), \mathrm{P}_{\mathrm{o}}=$ $101,32 \mathrm{kPa}, \mathrm{T}_{\mathrm{ce}}=25^{\circ} \mathrm{C}, \%$ Vol. $\mathrm{v}=6,16 ; 10 ; 15 ; 20 ; 70$ e 90. 151 
Figura 4.21 - Taxas de condensação locais $\left(d \dot{m}_{c d}\right), \mathrm{P}_{\mathrm{o}}=101,32 \mathrm{kPa}, \mathrm{T}_{\mathrm{ce}}=25^{\circ} \mathrm{C}, \% \mathrm{Vol} . \mathrm{v}=6,16$; $10 ; 15 ; 20 ; 70$ e 90 . 


\section{Lista de Tabelas}

Tabela 2.1 - Características das turbinas a gás. Fonte: Simões-Moreira e Pimenta (2017)........ 40

Tabela 2.2 - Comparação entre captação e consumo de água em sistemas de circulação aberta e torre úmida com circulação fechada. Fonte: Adaptado de Feeley et al. (2008) e EPRI (2002). . 51 Tabela 2.3 - Consumo de água na geração termelétrica com utilização de torre de resfriamento úmida. Adaptado de Carney et al. (2008).

Tabela 2.4 - Consumo de água na geração termelétrica com utilização de torre de esfriamento úmida e sistema de absorção de $\mathrm{CO}_{2}$. Fonte: Adaptado de Carney et al. (2008).

Tabela 2.5 - Valores médios de captação e consumo de água em UTEs com torres de resfriamento evaporativas. Fonte: Adaptado de Chandel, Pratson e Jackson (2011).

Tabela 2.6 - Condições experimentais estabelecidas no trabalho de Chan et al. (1990). Adaptado de Chan et al., (1990).

Tabela 3.1 - Massa molecular e densidade $\left(0^{\circ} \mathrm{C}\right.$ e $\left.101,32 \mathrm{kPa}\right)$ dos componentes envolvidos nos processos de combustão de gás natural e carvão mineral. Fonte: Smith et al. (2000). 85

Tabela 3.2 - Eficiências típicas dos três tipos genéricos de UTEs avaliadas. Fontes:

Khartchenko e Kharchenko (2014), Mazurenko et al.(2013) e Lora e Do Nascimento (2004). . 93

Tabela 3.3 - Consumo e consumo específico de carvão mineral e vazões de água produzida pelas UTEs movidas a carvão mineral.

Tabela 3.4 - Consumo e consumo específico de gás natural e vazões de água produzida pelas UTEs movidas a gás natural.

Tabela 4.1 - Coeficientes C e m para obtenção do número de Nusselt em convecção natural ao longo de placas e cilindros verticais. Holman (2010).

Tabela 4.2 - Condições de simulação estabelecidas

Tabela 4.3 - Dimensões do condensador

Tabela 4.4 - Valores de $\mathrm{Gr}_{\mathrm{c}} / \mathrm{Re}_{\mathrm{c}}{ }^{2}$ na região de transição da convecção natural e

combinada/forçada

Tabela 4.5 - Resultados obtidos para avaliação da variação da temperatura de entrada do fluido de resfriamento, $\mathrm{T}_{\text {ce. }} \mathrm{P}_{\mathrm{o}}=101,32 \mathrm{kPa}$ e $\%$ Vol. $\mathrm{v}=6,16 \%$.

Tabela 4.6 - Resultados obtidos para avaliação da variação da pressão do sistema, $\mathrm{P}_{\mathrm{o}} \cdot \mathrm{T}_{\mathrm{ce}}=$ $25^{\circ} \mathrm{C}, \%$ Vol. $\mathrm{v}=6,16 \%$

Tabela 4.7 - Resultados obtidos para avaliação das porcentagens de vapor nos GC, \%Vol. v, $\mathrm{P}_{\mathrm{o}}=101,32 \mathrm{kPa}$ e $\mathrm{T}_{\mathrm{ce}}=25^{\circ} \mathrm{C}$. 


\section{Lista de Abreviaturas e Siglas}

$\begin{array}{ll}C E C & \text { Consumo específico de combustível } \\ C F D & \text { Computational Fluid Dynamics } \\ G C & \text { Gases de combustão } \\ G N C & \text { Gases não condensáveis } \\ M E A & \text { Monoethanolamina } \\ I N M E T & \text { Instituto nacional de meteorologia } \\ P C I & \text { Poder calorífico inferior } \\ P C S & \text { Poder calorífico superior } \\ \text { UTE } & \text { Usina Termelétrica } \\ \text { UTES } & \text { Usina Termelétricas }\end{array}$

$V B A \quad$ Visual Basic for Applications 


\section{Lista de símbolos}

\begin{tabular}{|c|c|}
\hline$A$ & Área $\left(m^{2}\right)$ \\
\hline$D$ & Diâmetro (m) \\
\hline Dif & Coeficiente de difusividade mássica $\left(\mathrm{m}^{2} / \mathrm{s}\right)$ \\
\hline$d \dot{m}_{c d}$ & Vazão mássica de condensado local (kg/s) \\
\hline$d A$ & Elemento diferencial de área $\left(\mathrm{m}^{2}\right)$ \\
\hline$d L$ & Elemento diferencial de comprimento (m) \\
\hline$f$ & Razão ar/combustível (-) \\
\hline$g$ & Aceleração da gravidade $\left(\mathrm{m} / \mathrm{s}^{2}\right)$ \\
\hline$h$ & Coeficiente de transferência de calor $\left(\mathrm{W} / \mathrm{m}^{2} . \mathrm{K}\right)$ \\
\hline$h_{l g}^{*}$ & Entalpia específica de condensação $(\mathrm{kJ} / \mathrm{kg} . \mathrm{K})$ \\
\hline$k$ & Coeficiente de transferência de massa $\left(\mathrm{kg} / \mathrm{m}^{2} . \mathrm{s}\right)$ \\
\hline$m$ & Massa (kg) \\
\hline$\dot{m}$ & Vazão mássica (kg/s) \\
\hline$n$ & Número de mols (-) \\
\hline$N$ & Fração molar (-) \\
\hline$L$ & Comprimento (m) \\
\hline$M M$ & Massa molecular (kg/kgmol) \\
\hline$P$ & Pressão (kPa) ou Potência (MW) \\
\hline$\dot{Q}$ & Taxa de transferência de calor (MW) \\
\hline$R$ & Resistência térmica $\left(\mathrm{m}^{2} \mathrm{~K} / \mathrm{W}\right)$ \\
\hline $\mathcal{R}$ & Constante universal dos gases perfeitos, $8,314 \mathrm{~kJ} / \mathrm{kgmol} . \mathrm{K}$ \\
\hline$T$ & Temperatura $\left({ }^{\circ} \mathrm{C}\right),(\mathrm{K})$ \\
\hline$U$ & Coeficiente global de transferência de calor, $\left(\mathrm{W} / \mathrm{m}^{2} . \mathrm{K}\right)$ \\
\hline$v$ & Velocidade, $(\mathrm{m} / \mathrm{s})$ \\
\hline$V$ & Volume por unidade de combustível $\left(\mathrm{m}^{3} / \mathrm{kg}\right)$ ou $\left(\mathrm{m}^{3} / \mathrm{m}^{3}\right)$ \\
\hline$\dot{V}$ & Vazão volumétrica $\left(\mathrm{m}^{3} / \mathrm{s}\right)$ \\
\hline$V^{\prime}$ & Fator volumétrico de produção de água ( $\left.\mathrm{m}^{3} / \mathrm{MWh}\right)$ \\
\hline$m^{\prime}$ & Fator mássico de produção de água (kg/MWh) \\
\hline
\end{tabular}


Fração mássica (-)

Fração volumétrica (-)

$z / L$

Comprimento adimensionalizado (-)

$\%$ Vol. $v$

Porcentagem volumétrica de vapor nos gases se combustão (\%)

\section{Símbolos gregos}

$\begin{array}{ll}\gamma & \text { Coeficiente de excesso de ar (-) } \\ \Gamma & \text { Vazão por unidade de comprimento da seção circular de } \\ \beta & \text { escoamento }(\mathrm{kg} / \mathrm{m} . \mathrm{s}) \\ \lambda & \text { Coeficiente de expansão volumétrica. } 1 / \mathrm{T}\left(\mathrm{K}^{-1}\right) \\ \mu & \text { Condutividade térmica }(\mathrm{W} / \mathrm{m} . \mathrm{K}) \\ \rho & \text { Viscosidade dinâmica }(\mathrm{kg} / \mathrm{m} . \mathrm{s}) \\ v & \text { Densidade }\left(\mathrm{kg} / \mathrm{m}^{3}\right) \\ \omega & \text { Viscosidade cinemática }\left(\mathrm{m}^{2} / \mathrm{s}\right) \\ \phi & \text { Umidade absoluta }(\mathrm{kg} \mathrm{vapor} / \mathrm{kg} \text { ar seco) } \\ \eta & \text { Umidade relativa }(-) \\ \delta & \text { Eficiência térmica e rendimento }\end{array}$

\section{Subscritos e sobrescritos}

$\begin{array}{ll}a & \text { Ar } \\ b & \text { Seio do fluido } \\ c & \text { Fluido de resfriamento } \\ c d & \text { Condensado } \\ c m & \text { Carvão mineral } \\ f & \text { Filme } \\ f r & \text { Filme rugoso } \\ f s & \text { Filme liso } \\ g & \text { Gases de combustão } \\ g n & \text { Gás Natural }\end{array}$




$\begin{array}{ll}i & \text { Interface } \\ l & \text { Líquido } \\ s a t & \text { Saturação } \\ v & \text { Vapor } \\ s i & \text { Superfície interna } \\ \text { se } & \text { Superfície externa }\end{array}$




\section{Lista de Números Adimensionais}

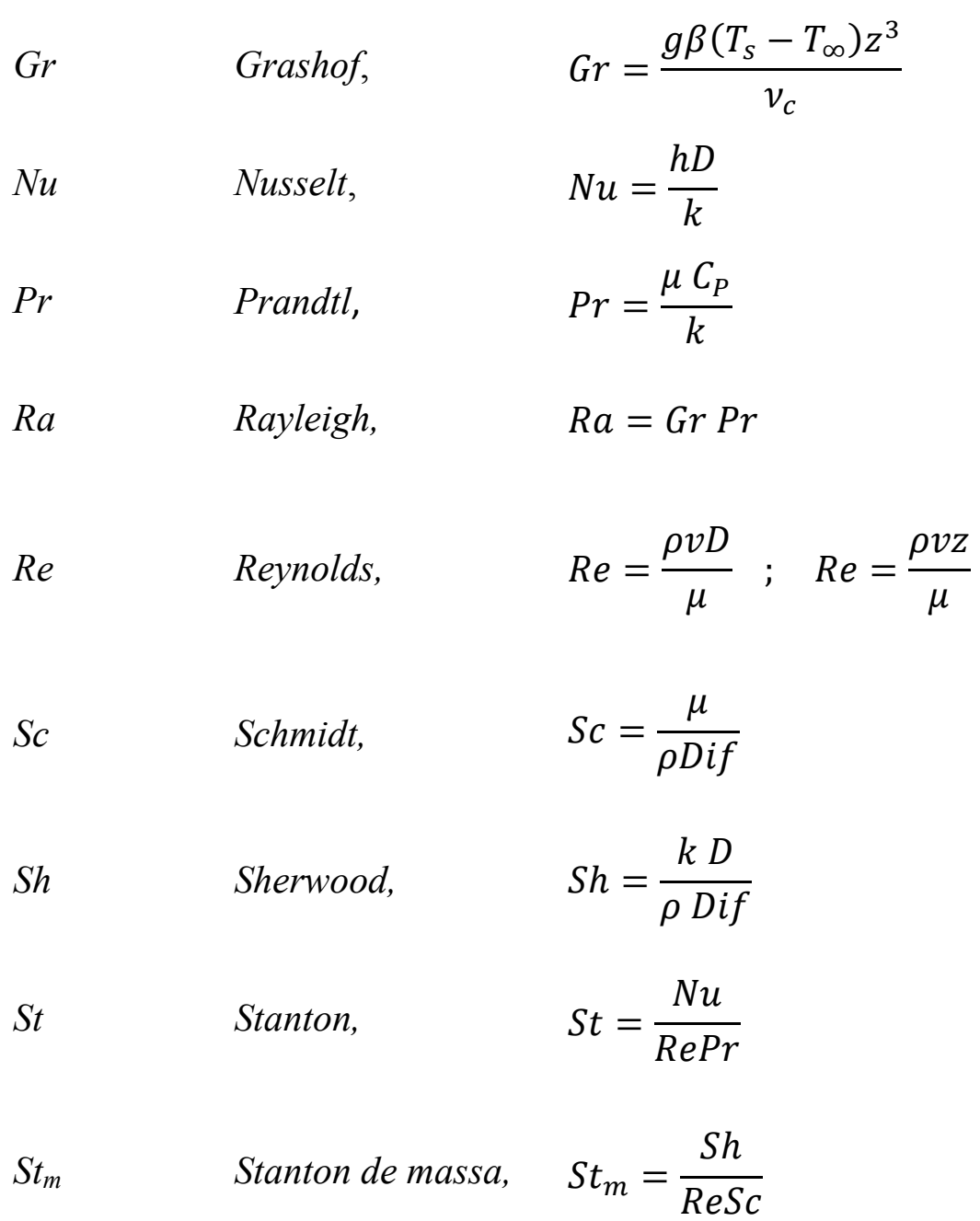




\section{Sumário}

1 Introdução

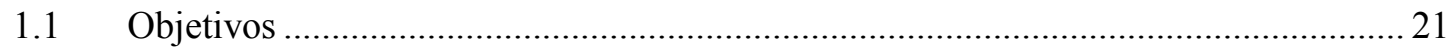

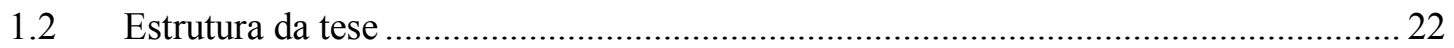

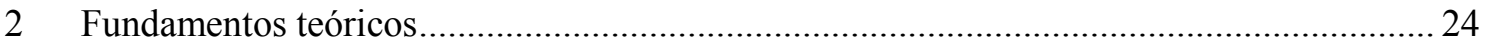

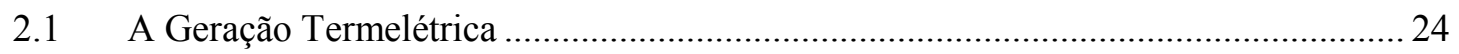

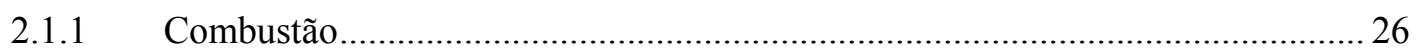

2.1.2 Reações e estequiometria da combustão .......................................................... 27

2.1.3 Ciclo Brayton (Turbina a gás): análise ideal e real ............................................. 30

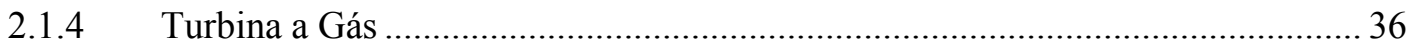

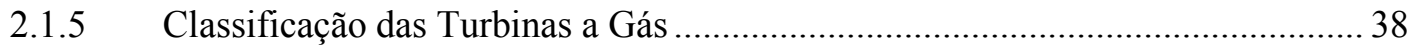

2.1.6 O ciclo Rankine: análises ideal e real ................................................................ 41

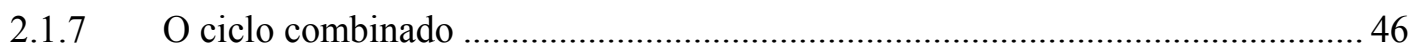

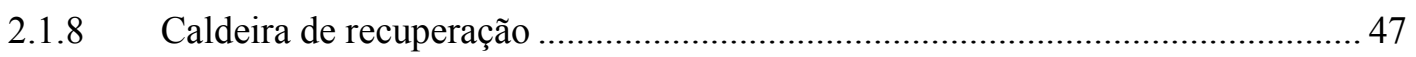

2.1.9 Resfriamento em centrais termelétricas ......................................................... 49

2.1.10 Sistemas de resfriamento de circulação aberta (Open Through) .......................... 51

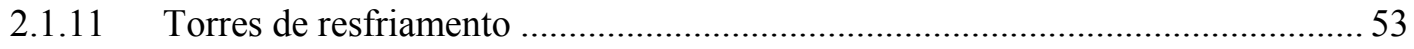

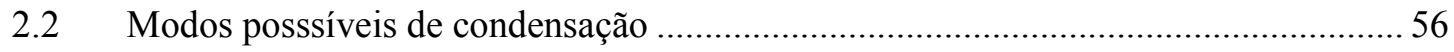

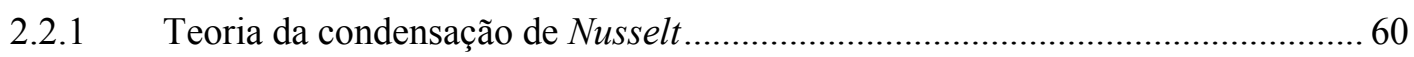

2.2.2 Análise teórica da condensação na presença de gases não condensáveis segundo

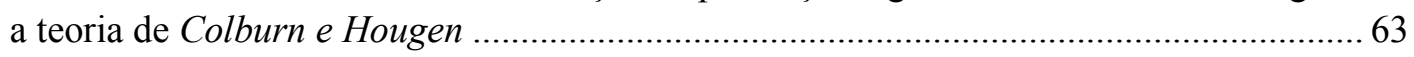

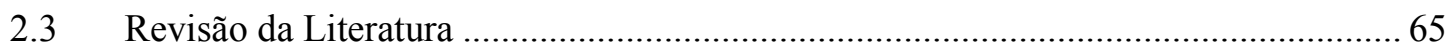

2.3.1 Captação e consumo de água em UTEs ................................................................ 65

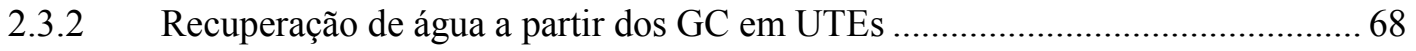

2.3.3 Condensação na presença de gases não condensáveis ......................................... 72

3 Estimativa do potencial de produção de água em determinadas centrais termelétricas

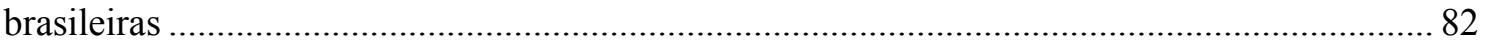

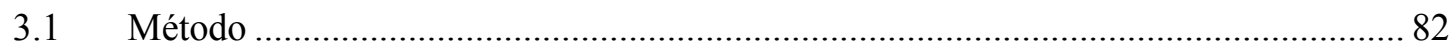

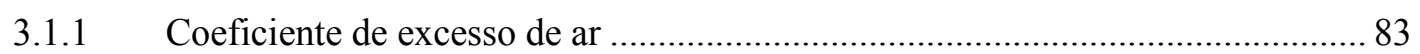

3.1.2 Quantificação dos produtos de combustão ........................................................ 84

3.1.3 Umidade absoluta do ar de combustão ............................................................. 87

3.1.4 Umidade relativa do ar de combustão .............................................................. 88

3.1.5 Frações volumétricas e temperatura de saturação ................................................ 89

3.1.6 Consumo de combustível e fator de produção de água ...................................... 90

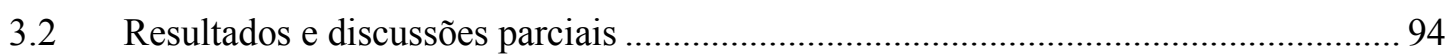


3.2.1 Consumo de combustível ( $\left.\dot{m}_{c m} e \dot{V}_{g n}\right)$, consumo específico de combustível

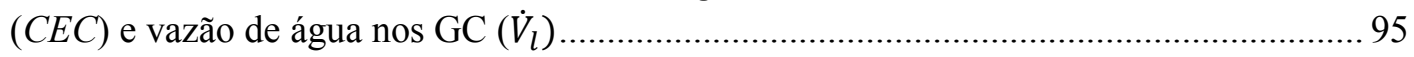

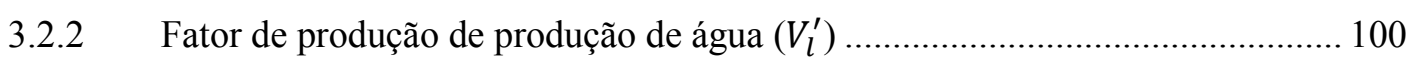

3.2.3 Gases não condensáveis (GNC) e temperatura de saturação do vapor $\left(T_{\text {sat }}\right) \ldots . .102$

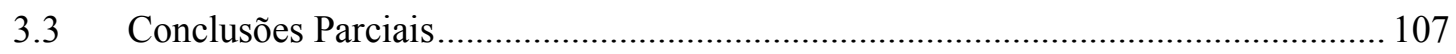

4 Recuperação da água presente nos gases de combustão ....................................................... 109

4.1 Idealização do condensador de superfície ................................................................. 109

4.2 Modelagem do processo de condensação................................................................. 112

4.2.1 Transferência de calor e massa nos GC (GNC/vapor de água) .......................... 117

4.2.2 Transferência de calor no filme de condensado ................................................. 118

4.2.3 Transferência de calor no fluido de resfriamento ............................................. 120

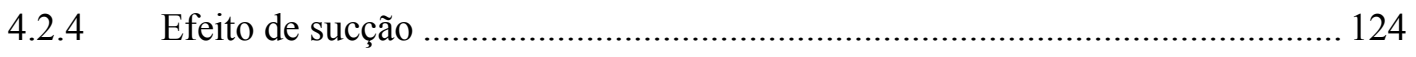

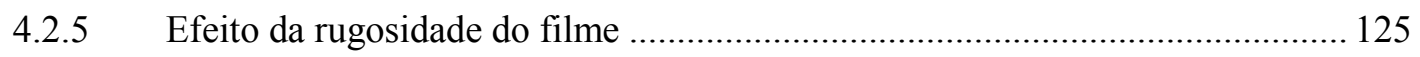

4.2.6 Rendimento do processo de condensação ...................................................... 127

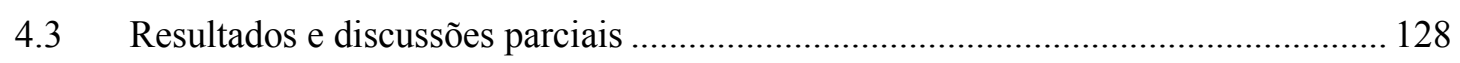

4.3.1 Temperatura de entrada do fluido de resfriamento (GNC/ar), $T_{c e}$...................... 130

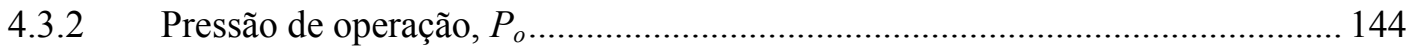

4.3.3 Porcentagem volumétrica de vapor de água no GC, \% Vol. v ............................. 150

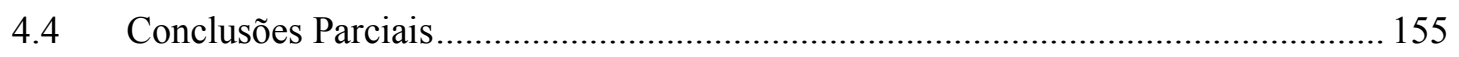

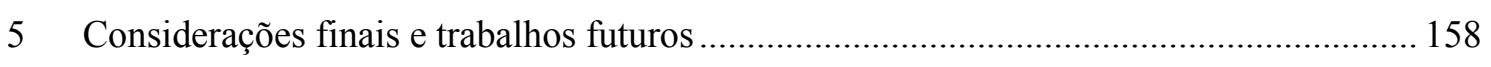

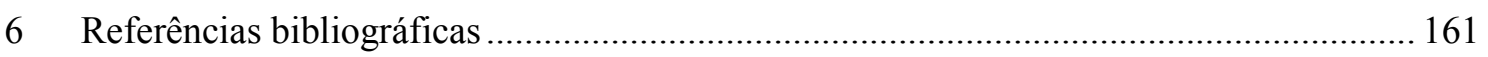

APÊNDICE A - Composições de Gás Natural e Carvão Mineral e Condições Ambientais

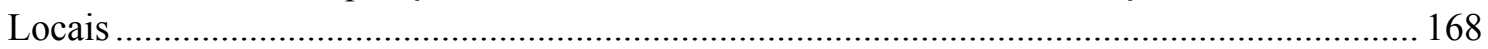

APÊNDICE B - Porcentagem volumétrica dos componentes dos gases de combustão............ 172

APÊNDICE C - Propriedades termofísicas dos fluidos e do material do condensador............. 183

APÊNDICE D - Método numérico das diferenças finitas e discretização das equações de

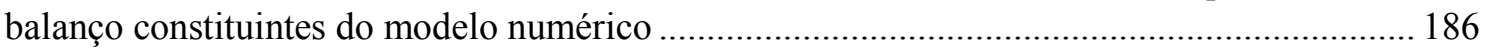

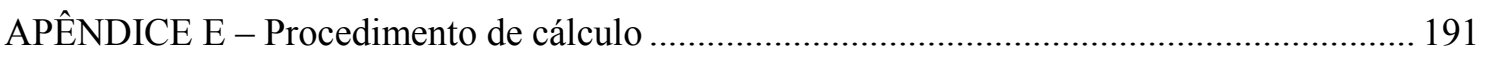




\section{Introdução}

O consumo mundial de energia elétrica, em crescimento contínuo ao longo dos anos, associado à crescente preocupação com as questões ambientais, propiciam que entidades governamentais, empresas privadas e pesquisadores busquem novas tecnologias, bem como instituam diretrizes para a utilização dos insumos empregados na produção industrial. A redução da oferta de água potável em vários continentes também traz preocupações com forma mais adequada de se empregar os recursos hídricos disponíveis. Novas tecnologias vêm sendo desenvolvidas, as quais incluem intensiva preocupação com o meio ambiente e com a escassez de recursos.

Com o aumento da população e o crescente desenvolvimento industrial, a água passou a ser cada vez mais utilizada como se fosse um recurso abundante e infinito. $\mathrm{O}$ conceito de abundância da água ainda é muito forte, principalmente no Brasil, um dos países que mais dispõem deste recurso, com cerca de $13 \%$ de toda a água doce do planeta. O problema associado à questão hídrica no Brasil refere-se à má distribuição. Sua escassez atinge áreas cuja climatologia é desfavorável e regiões altamente urbanizadas, como é o caso das principais regiões metropolitanas. Segundo Feeley et al. (2008) até 2025 mais de $25 \%$ da população mundial viverá em países com significante desequilíbrio entre oferta e necessidade de água, a maioria na Ásia, África e América Latina.

Estima-se que a agricultura seja responsável por $70 \%$ do consumo total de água do planeta e alcance, ao logo dos próximos anos, patamares acima de 90\% em países desenvolvidos, tendo como destinação básica a produção de alimentos, fibras naturais para indústria têxtil, biocombustíveis e outras matérias-primas advindas da agricultura. A utilização residencial e comercial corresponde a $8 \%$ do uso mundial, o que inclui ingestão, banho, cocção, saneamento e jardinagem. Já a atividade industrial e a geração de energia elétrica são responsáveis por aproximadamente $22 \%$ do consumo total (Macedônio et al. 2013).

Inúmeros estudos indicam que a evaporação de água de resfriamento seja responsável por mais da metade das perdas deste recurso em indústrias, o que denota ineficiência das estratégias de gerenciamento energético e de recursos. Toda indústria de transformação ou planta de geração de energia elétrica (termelétrica ou nuclear), mesmo 
aquelas com configurações orientadas à recuperação de calor e eficiência energética, necessitam de formas externas de dissipação de calor, de modo a controlar a temperatura dos fluidos envolvidos em seus processos, conforme as necessidades operacionais existentes. A água possui características que a coloca como principal fluido de trabalho no que se refere ao gerenciamento energético, tais como: relativa abundância, alta capacidade térmica, fluidez e custo razoavelmente baixo. Assim, grandes quantidades de água são demandadas na operação de plantas químicas, petroquímicas, centrais termelétricas, entre outras.

A elevada quantidade de água necessária para a operação de centrais termelétricas, sejam elas compostas por ciclos simples a vapor ou por ciclos combinados, tem sido e continuará sendo o principal fator de decisão no que se refere ao gerenciamento de recursos nesse tipo de indústria, ditando quais fontes de energia podem ou não ser empregadas em determinadas regiões (Badr et al., 2012). Uma grande fração da energia térmica consumida mundialmente na atualidade advém da queima de combustíveis fósseis e um dos principais subprodutos desse processo é vapor de água.

Em centrais movidas a carvão mineral, a quantidade vapor de água existente nos gases de exaustão gira em torno de 12 a 16\% em volume. De acordo com Carney (2015) a parcela de vapor de água presente nos gases de exaustão de uma planta termelétrica de 500MW movida a carvão betuminoso é de aproximadamente $227 \mathrm{~m}^{3} / \mathrm{h}$. Segundo Wang et al. (2013), os gases de exaustão produzidos pela queima de $1 \mathrm{~m}^{3}$ de gás natural geram, teoricamente, $1,5 \mathrm{~kg}$ de vapor de água que contêm cerca 3,6 MJ de entalpia. Se essa expressiva quantidade de energia for recuperada simultaneamente, a eficiência global da planta pode ser incrementada na ordem de $10 \%$.

Frente à importância deste recurso na geração termelétrica, aliada à questão da escassez que existe em determinadas regiões do país, a presente tese trata de estimar a quantidade de água presente nos gases de combustão de determinadas UTEs brasileiras movidas a carvão mineral e gás natural. Realizadas as estimativas, é também abordado o aspecto tecnológico que envolve o tema, tendo em vista a modelagem e a simulação de um equipamento/processo com objetivo de se avaliar a recuperação da quantidade de água existente nos gases de combustão. 


\subsection{Objetivos}

Com base na revisão da literatura, apresentada adiante, pode-se afirmar que UTEs de ciclo combinado e ciclo simples a vapor, além de consumir elevadas quantidades de água, também são sensivelmente dependentes da disponibilidade deste recurso para manutenção de suas operações. No entanto, do mesmo modo que são consumidoras intensivas deste recurso, também o produzem em escalas relevantes por meio de seus processos de combustão.

Posto isso, a primeira etapa do trabalho tem por objetivo fundamental realizar a estimativa da quantidade de água existente nos gases de combustão de determinadas UTEs brasileiras, cujas capacidades se situam acima de 50 MW e são movidas a carvão mineral e gás natural. Paralelamente, objetiva-se também estimar as quantidades dos demais componentes produzidos nos processos de combustão, quais sejam: $\mathrm{CO}_{2}, \mathrm{~N}_{2}, \mathrm{O}_{2}$ e $\mathrm{SO}_{2}$. De posse da fração de vapor de água existente na mistura de gases, foi possível estimar a sua temperatura de saturação e a quantidade de água que pode ser recuperada.

A segunda parte do trabalho tem como objetivo o desenvolvimento e a simulação do modelo de um condensador de superfície duplo tubo vertical, operando em contra-corrente, visando separar a parcela de água contida nos produtos de combustão de UTEs. O modelo de condensação idealizado não considera água como fluido de resfriamento, mas sim uma mistura de ar atmosférico e de GNC remanescente do próprio processo.

A partir das simulações, serão avaliadas as eficiências do processo de recuperação frente a determinadas condições específicas, tais como: pressão do sistema, temperatura de entrada do fluido de resfriamento e fração mássica de vapor de água nos produtos de combustão. Assim, busca-se estabelecer a relação entre os volumes de água produzidos e o quanto pode ser recuperado por meio do processo de condensação modelado.

Além de se verificar as taxas de condensação, tem-se o intuito de obter o comportamento dos coeficientes de transferência de calor e de massa ao longo do equipamento, tanto no lado dos GC como no lado do fluido de resfriamento, de modo a compreender quais são os principais fatores limitantes existentes no processo. 


\subsection{Estrutura da tese}

Este trabalho é constituído por duas partes um tanto quanto distintas, porém complementares. A primeira é voltada à estimativa da quantidade de água produzida pelo processo de combustão em determinadas UTEs brasileiras, cujas capacidades de geração se situam acima acima de $50 \mathrm{MW}$.

A segunda etapa aborda o aspecto tecnológico associado ao processo de recuperação da água existente nos GC (gases de combustão) por meio do processo de condensação.

A tese é subdividida de acordo com a sequência descrita a seguir:

No Capítulo 1, inicia-se a discussão acerca da preocupação crescente a respeito da escassez de água em todo o mundo, associada ao crescente consumo mundial deste recurso por conta, principalmente, da agricultura, das atividades industriais em geral e da geração de energia elétrica. É apresentada a questão central deste trabalho: Usinas termelétricas compostas por ciclos a vapor consomem elevadas quantidades de água, mas também as produzem por meio de seus processos de combustão.

O Capítulo 2 apresenta a fundamentação teórica que envolve a geração termelétrica por meio da abordagem dos ciclos simples Brayton (turbina a gás) e Rankine (turbina a vapor) e ciclo combinado. Neste capítulo é tratado o principal responsável pelo elevado consumo de água em plantas termelétricas que contenham ciclos a vapor: Torres de resfriamento. São também apresentadas as teorias de condensação de Nusselt e de Colburn e Hougen, além da revisão da literatura no que se refere aos dois aspectos do trabalho.

O Capítulo 3 é reponsável por apresentar o método utilizado para as estimativas de produção de água nas centrais termelétricas selecionadas, assim como os resultados, discussões e conclusões parciais obtidas.

No Capítulo 4 é apresentada a idealização de um condensador de superfície, assim como a modelagem do processo de condensação de vapor presença de gases não condensáveis que nele ocorre, com vistas a se avaliar a recuperação da parcela de água presente nos gases de combustão. São apresentados os resultados com base na avaliação de determinadas influências (Temperatura, Pressão e Porcentagem de Vapor), bem como as conclusões parciais acerca deste capítulo. 
Por fim, no Capítulo 5 são realizadas as considerações finais e discutidas as perspectivas de futuros trabalhos perante novas abordagens que possam complementar e comprovar os resultados encontrados nesta tese. 


\section{Fundamentos teóricos}

Neste capítulo são apresentados os fundamentos básicos alusivos à geração termelétrica. Considera-se que estes fundamentos sejam pertinentes à contextualização, bem como necessários para melhor compreensão do presente trabalho. São também apresentados, à luz da termodinâmica clássica, os equacionamentos dos ciclos Rankine e Brayton em suas abordagens ideal e real.

Com vistas ao aspecto tecnológico existente neste trabalho, também serão tratados os modos possíveis de condensação e os fundamentos associados aos processos de condensação de vapor puro, por meio da clássica teoria de Nusselt (1916), e condensação na presença de GNC, à luz do modelo de Colburn e Hougen (1934).

\subsection{A Geração Termelétrica}

A geração termelétrica baseia-se na conversão de energia térmica em energia mecânica e na conversão desta em energia elétrica. A energia térmica é obtida por meio da queima de combustíveis fósseis ou renováveis, ou pela fissão nuclear de combustíveis radioativos. Numa central termelétrica não nuclear, a combustão é o primeiro estágio na transformação da energia química do combustível em energia elétrica (EPE 2016).

Segundo Lora e Do Nascimento (2004) as UTEs podem ser classificadas de acordo com os seguintes critérios:

- Produto principal: Distingue as termelétricas cujo produto único é a eletricidade daquelas que produzem simultaneamente eletricidade e calor (centrais de cogeração);

- Tipo de combustível: O tipo de combustível é importante não apenas do ponto de vista técnico-econômico, como também da perspectiva ambiental. Os combustíveis usuais são o carvão mineral, gás natural e óleo diesel;

- Tipo de máquina térmica: Turbina a gás, turbina a vapor, motor a combustão interna, ciclo combinado, cogeração ou central nuclear (centrais nucleares também são consideradas centrais termelétricas);

- Tipo de caldeira: Classificação referente apenas aos ciclos a vapor; 
- Potência;

- Carga: As centrais podem operar continuamente com uma carga relativamente constante (operação em carga base) ou operar apenas algumas horas por dia (operação em carga pico);

A seguir, são apresentadas as características dos tipos mais difundidos de centrais termelétricas:

Central termelétrica de geração com ciclo vapor: possuem, como máquinas térmicas, turbinas a vapor com finalidade única de produção de eletricidade. A introdução de alternativas térmicas de recuperação de calor, tais como aquecimento regenerativo e reaquecimento, possibilita que a planta alcance maiores eficiências térmicas. Utilizam qualquer tipo de combustível e possuem como principal vantagem o alcance de elevadas potências;

Central termelétrica de cogeração: produzem, simultaneamente, energia elétrica e térmica a partir de um mesmo combustível, que pode ser um derivado de petróleo, gás natural, carvão ou biomassa. Geralmente possuem baixa capacidade, porém caracterizadas por alta eficiência térmica, podendo ser acionadas tanto por turbinas a vapor, turbinas a gás e motores de combustão interna;

Central termelétrica de turbina a gás operando em ciclo simples: seu único produto final é a eletricidade. A máquina térmica utilizada para tal é a turbina a gás. Possui partida rápida, motivo pelo qual pode ser utilizada para suprimento de eletricidade em períodos de pico. Utilizam combustíveis líquidos e gasosos, predominantemente diesel especial e gás natural. No entanto, atualmente existem turbinas capazes de operar com uma ampla gama de combustíveis, tais como etanol, syngas $^{1}$, biodiesel, querosene, dentre outros. Neste tipo de ciclo são adotadas diversas tecnologias de recuperação de calor, contudo, mesmo assim, a eficiência térmica destas plantas é menor que a das centrais de geração com ciclo a vapor;

Central de ciclo combinado: trata-se de um ciclo com turbina vapor acoplado termicamente a um ciclo com turbina a gás. Neste tipo de ciclo ocorre o aproveitamento da energia térmica dos gases de combustão a elevadas temperaturas em uma caldeira de

\footnotetext{
${ }^{1}$ Syngas ou "gás de síntese" é uma mistura de gases que consiste basicamente de hidrogênio, monóxido de carbono e dióxido de carbono produzida a partir de combustíveis como o gás natural, carvão, biomassa ou qualquer fonte de hidrocarbonetos em reação com vapor de água ou oxigênio (Rostrup-Nielsen e Christiansen, 2011)
} 
recuperação, cuja responsabilidade é geração de vapor de água a ser expandido nas turbinas a vapor;

Central de motores de combustão interna: utiliza motores de ciclo Diesel ou Otto a gás natural para geração de potência, sendo bastante utilizado em localidades isoladas;

Central nuclear: centrais nucleares podem ser consideradas centrais termelétricas que operam em um ciclo Rankine com vapor saturado, devido a restrições de temperatura decorrentes dos limites dos materiais construtivos do reator nuclear.

\subsubsection{Combustão}

Em uma UTE, o processo de combustão constitui o primeiro estágio na conversão da energia química do combustível em energia elétrica, incidindo sensivelmente na eficiência térmica do sistema.

Do ponto de vista teórico, a combustão é definida como uma reação química exotérmica autossustentada em que elementos combustíveis são oxidados. Na prática, entende-se a combustão como a reação dos elementos combustíveis com o oxigênio do ar, visando geração de energia térmica na forma de calor, satisfazendo os seguintes critérios para o alcance da combustão completa:

- Fornecimento de quantidade adequada de ar ao tipo de combustível;

- Mistura molecular do oxigênio do ar como o combustível na temperatura e pressão de ignição, ou seja, dentro dos limites de combustão da mistura;

- Garantia de boa miscibilidade ar/combustível;

- Volume da câmara de combustão (ou fornalha) suficiente para permitir um tempo de residência suficiente da mistura ar/combustível (Glassman e Yetter, 2008).

O processo de combustão é complexo e dinâmico, dependente do tempo em que as reações químicas ocorrem, dos níveis de energia moleculares e atômicos de ambos os fluidos (combustível e comburente) em movimento, do estado físico do combustível e do equipamento utilizado. Somado a esses fatores, destaca-se a relação entre as massas de combustível e comburente, estas determinantes para que o processo ocorra o mais próximo possível da oxidação completa de todos os compostos presentes no combustível liberando o máximo de energia possível (Dos Santos et al., 2017). 


\subsubsection{Reações e estequiometria da combustão}

As Eqs. (2.1), (2.2) e (2.3) representam as reações de combustão completa, ao passo que as Eqs. (2.4) e (2.5) correspondem às reações incompletas, cujas oxidações se completam conforme as Eqs. (2.6) e (2.7). Os termos $\Delta H_{i}$ representam a entalpia liberada por unidade de massa ou volume de combustível. Ressalta-se que inúmeros compostos e radicais intermediários são formados até que as reações principais entre o combustível e o comburente se completem e atinjam condições de equilíbrio, resultando na formação de dióxido de carbono $\left(\mathrm{CO}_{2}\right)$, dióxido de enxofre $\left(\mathrm{SO}_{2}\right)$ e água $\left(\mathrm{H}_{2} \mathrm{O}\right)$, os quais são formas de oxidação completa do carbono $(C)$, enxofre $(\mathrm{S})$ e hidrogênio $(H)$. (Dos Santos et al., 2017).

$$
\begin{gathered}
C+\mathrm{O}_{2} \rightarrow \mathrm{CO}_{2}+\Delta \mathrm{H}_{1} \\
\mathrm{H}_{2}+\frac{1}{2} \mathrm{O}_{2} \rightarrow \mathrm{H}_{2} \mathrm{O}+\Delta \mathrm{H}_{2} \\
\mathrm{~S}+\frac{3}{2} \mathrm{O}_{2} \rightarrow \mathrm{SO}_{3}+\Delta H_{3} \\
\mathrm{C}+\frac{1}{2} \mathrm{O}_{2} \rightarrow \mathrm{CO}^{2}+\Delta H_{4} \\
S+\mathrm{O}_{2} \rightarrow \mathrm{SO}_{2}+\Delta H_{5} \\
S O_{2}+\frac{1}{2} \mathrm{O}_{2} \rightarrow \mathrm{SO}_{3}+\Delta H_{6} \\
\mathrm{CO}+\frac{1}{2} \mathrm{O}_{2} \rightarrow \mathrm{CO}_{2}+\Delta H_{6}
\end{gathered}
$$


A oxidação completa de combustíveis constituídos por hidrocarbonetos simples origina dióxido de carbono $\left(\mathrm{CO}_{2}\right)$ e água $\left(\mathrm{H}_{2} \mathrm{O}\right)$, conforme o equacionamento básico abaixo:

$$
C_{n} H_{m}+\left(n+\frac{m}{4}\right) O_{2} \rightarrow n C O_{2}+\frac{m}{2} H_{2} O
$$

Mesmo em um caso ideal de combustão completa, a contabilização de todas as espécies presentes nos seus produtos vai além de medir as parcelas correspondentes ao $\mathrm{CO}_{2}$ e $\mathrm{H}_{2} \mathrm{O}$. Como a combustão, em geral, ocorre com ar atmosférico ao invés de oxigênio puro, o nitrogênio presente no ar pode participar da reação, produzindo óxidos de nitrogênio $\left(\mathrm{NO}_{\mathrm{x}}{ }^{2}\right)$. Além disso, muitos combustíveis contêm elementos diferentes do carbono, os quais podem se transformar durante a combustão.

Usualmente, o ar é utilizado como oxidante em uma reação de combustão, sendo, em algumas situações, enriquecido com oxigênio puro, de modo a atender as necessidades técnicas específicas do processo. Uma vez que o ar é composto por oxigênio, nitrogênio e pequenas quantidades de dióxido de carbono, argônio e traços de outras espécies, é perfeitamente razoável, para o propósito de avaliação quantitativa da reação de combustão do gás natural e do carvão mineral, considerar o ar como uma mistura composta - em base molar - por $20,9 \%$ de oxigênio e 79,1\% de nitrogênio. Assim, para cada mol de oxigênio necessário para a combustão, deve-se também considerar a inserção no sistema de 3,76 mols de nitrogênio.

Embora a parcela de nitrogênio presente na reação não altere significantemente o balanço de oxigênio, ela possui relevância quando se trata dos aspectos termodinâmicos e de cinética química da formação dos poluentes em sistemas de combustão. Sendo assim, assume-se o nitrogênio como uma espécie inerte e a relação estequiométrica da oxidação completa do hidrocarboneto de formulação genérica $C_{n} H_{m}$ se torna:

$$
C_{n} H_{m}+\left(n+\frac{m}{4}\right)\left(O_{2}+3,76 N_{2}\right) \rightarrow n C O_{2}+\frac{m}{2} H_{2} O+3,76\left(n+\frac{m}{4}\right) N_{2}
$$

\footnotetext{
${ }^{2} \mathrm{O}$ termo óxidos de nitrogênio geralmente refere-se a vários compostos químicos gasosos, formados pela combinação do oxigênio com o nitrogênio. $O$ processo mais habitual destes compostos inorgânicos é a combustão em altas temperaturas, processo no qual o ar é habitualmente o comburente. Os óxidos de nitrogênio, conhecidos como importantes poluentes da atmosfera, são emitidos na atmosfera pelos motores de combustão interna, fornos, caldeiras, estufas, incineradores, pelas indústrias químicas (na fabricação de ácido nítrico, de ácido sulfúrico, de corantes, vernizes, nitrocelulose, etc.), na indústria de explosivos e, também, pelos silos de cereais (os cereais contêm nitratos e nitritos que se decompõe liberando-o) (EPA, 1999).
} 
Desta forma, para cada mol de combustível queimado são necessários 4,76 $(n+$ $m / 4)$ mols de ar, sendo gerados $4,76(n+m / 4)+m / 4$ mols de produtos de combustão. A composição dos gases é geralmente apresentada em frações molares, posto que as mesmas não variam em função da temperatura e pressão do sistema ao contrário da concentração molar, dada em base volumétrica (mol/volume) (Glassman, 1977).

A quantidade mínima de ar que fornece o oxigênio para a combustão completa do carbono, hidrogênio e quaisquer outros elementos do combustível que possam se oxidar é conhecida como "ar teórico". Experimentalmente, é sabido que a combustão completa não é alcançada a menos que a quantidade de ar fornecida seja maior que a quantidade teórica necessária. Existem dois parâmetros importantes utilizados para expressar a relação entre o combustível e o ar: a relação ar/combustível $(A C)$ e seu recíproco, a relação combustível/ar $(C A)$. Tais relações são geralmente calculadas em base mássica, conforme Eq. 2.10, mas algumas vezes também podem ser expressas em base molar, Eq. 2.11.

$$
\begin{aligned}
A C_{\text {massa }} & =\frac{m_{\text {ar }}}{m_{\text {combustível }}} \\
A C_{\text {molar }} & =\frac{n_{\text {ar }}}{n_{\text {combustível }}}
\end{aligned}
$$

Também é possível representar a quantidade de ar realmente fornecida à reação em função da razão de equivalência, definida na Eq. 2.12. O subscrito $s$ é utilizado para indicar que a relação se refere a $100 \%$ do ar teórico, também conhecido como ar estequiométrico (Van Wylen et al., 1994).

$$
\Phi=\frac{C A}{C A_{s}}=\frac{A C_{s}}{A C}
$$




\subsubsection{Ciclo Brayton (Turbina a gás): análise ideal e real}

Existem basicamente dois tipos de ciclos de potência baseados em turbinas a gás: ciclo aberto, o mais utilizado, que emprega um processo de combustão interna e é composto pelo conjunto compressor/turbina a gás e câmara de combustão; e o ciclo fechado, também composto pelo conjunto compressor/turbina a gás, porém, neste caso, este conjunto se encontra associado a dois trocadores de calor. Esquemas representativos destes dois tipos de configuração são apresentados nas Figs. 2.1 e 2.2, respectivamente.

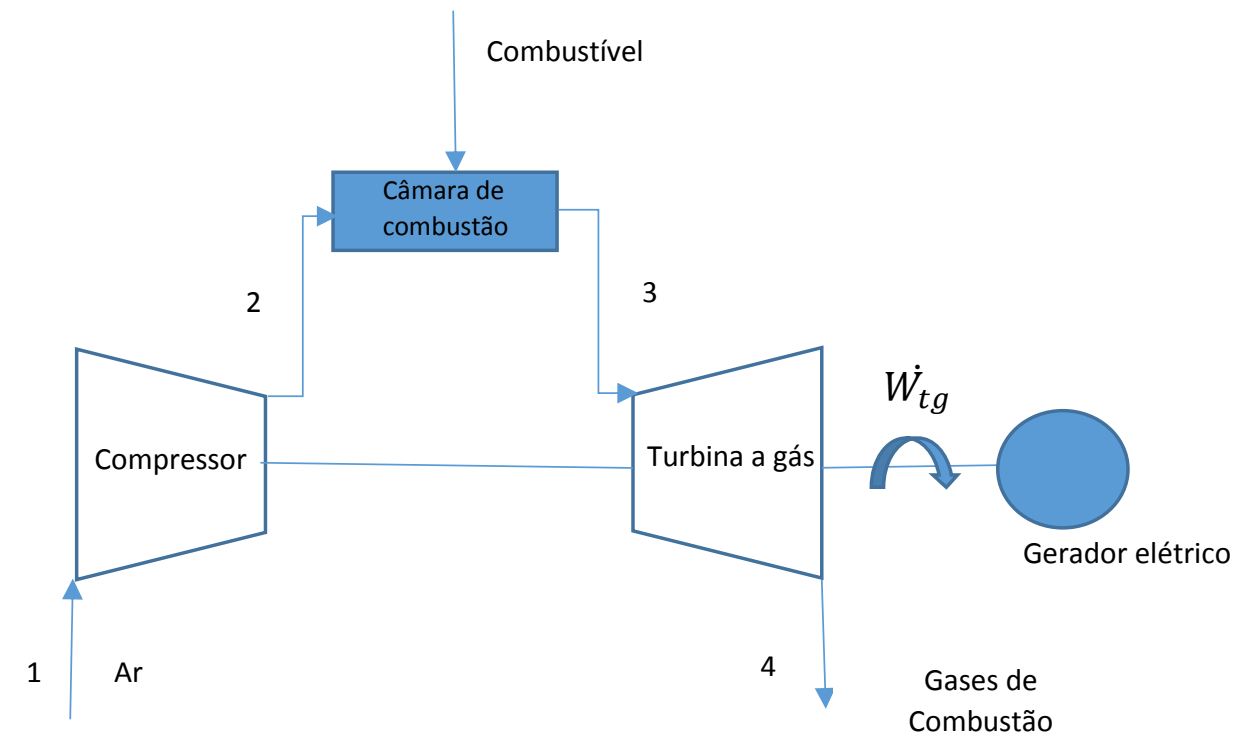

Figura 2.1 - Esquema de um ciclo Brayton aberto. Fonte: Elaboração própria. 


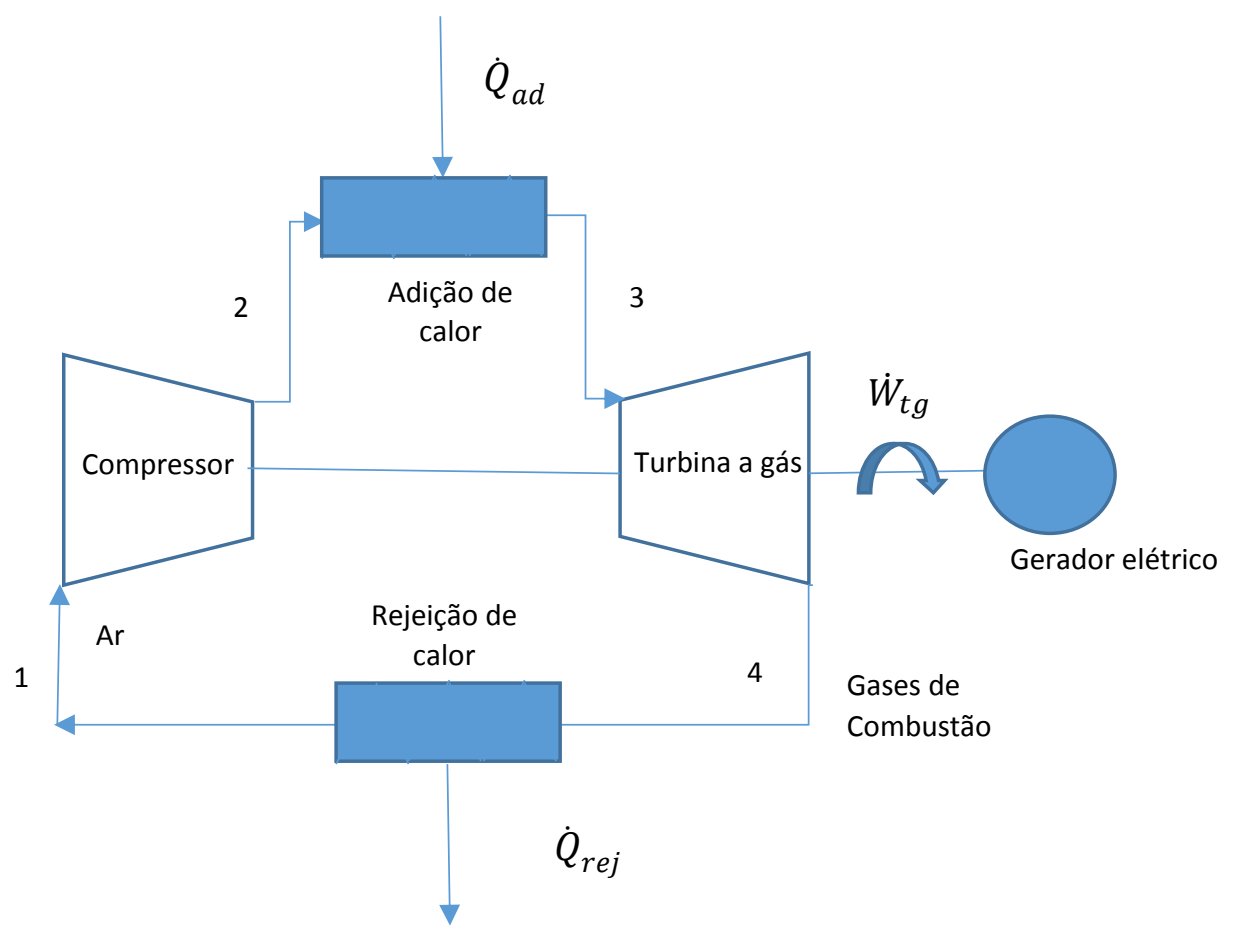

Figura 2.2 - Esquema de um ciclo Brayton fechado. Fonte: Elaboração própria.

O ciclo Brayton fechado, em sua forma ideal, é composto por dois processos isobáricos e dois processos isentrópicos, representados no diagrama temperaturaentropia, $T-s$, da Fig. 2.3. Os dois processos isobáricos correspondem à combustão e rejeição de calor, $(2 \mathrm{~s}-3)$ e $(4 \mathrm{~s}-1)$, e os dois processos isentrópicos se referem à compressão do ar e expansão dos gases de combustão, $(1-2 \mathrm{~s})$ e $(3-4 \mathrm{~s})$.

No caso de um ciclo Brayton real os processos que o compõem são irreversíveis, representados na Fig. 2.3 por $(1-2),(2-3),(3-4)$ e $(4-1)$, o que significa que os valores de eficiência térmica que podem ser atingidos são menores do que os alcançados na situação ideal. As principais causas de irreversibilidades no ciclo Brayton real, tanto nos ciclos abertos como nos fechados, são as seguintes:

- Quedas de pressão na câmara de combustão e trocadores de calor;

- Processo de compressão e expansão não isentrópicos no compressor e na turbina;

- Efetividade dos trocadores de calor inferior a $100 \% \mathrm{e}$;

- Calores específicos dos gases variando com a temperatura. 


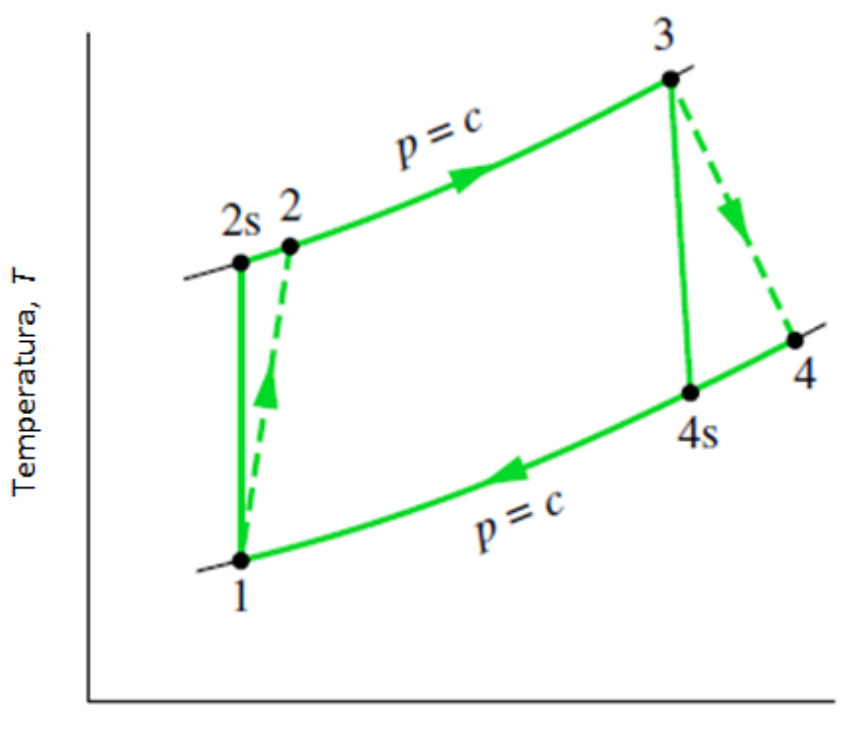

Entropia, s

Figura 2.3 - Diagrama T-s para ciclo Brayton ideal e real. Fonte: Moran \& Shapiro (2006)

De modo a contabilizar as irreversibilidades no compressor e na turbina, são empregadas as chamadas eficiências isentrópicas. Para o compressor a eficiência isentrópica é definida como sendo a razão entre o trabalho de compressão reversível e o trabalho de compressão irreversível (situação real), conforme a Eq. 2.13. Valores típicos de $\eta_{i c}$ variam entre 0,85 e 0,9 (Mazurenko et al., 2013).

$$
\eta_{i, c}=\frac{\left(\frac{\dot{W}_{12}}{\dot{m}}\right)_{s}}{\frac{\dot{W}_{12}}{\dot{m}}}=\frac{h_{2 s}-h_{1}}{h_{2}-h_{1}}=\frac{\left(T_{2 s}-T_{1}\right)}{\left(T_{2}-T_{1}\right)}
$$

A eficiência isentrópica da turbina a gás é dada pela razão entre trabalho irreversível e o trabalho reversível, dada pela Eq. 2.14. Os valores típicos de $\eta_{i t}$ variam de 0,9 quando a razão de pressão $(r)$ é igual a 30 e 0,93 quando a razão de pressão é igual a 6 (Mazurenko et al., 2013). 


$$
\eta_{i, t g}=\frac{\frac{\dot{W}_{34}}{\dot{m}}}{\left(\frac{\dot{W}_{34}}{\dot{m}}\right)_{s}}=\frac{h_{3}-h_{4}}{h_{3}-h_{4 s}}=\frac{\left(T_{3}-T_{4}\right)}{\left(T_{3}-T_{4 s}\right)}
$$

Os modelos termodinâmicos de um ciclo Brayton genérico, apresentados por Lora e Do Nascimento (2004) e Kartchenko \& Kartchenko (2014), são semelhantes e levam em conta as seguintes hipóteses simplificadoras:

- fluido de trabalho é o mesmo ao longo de todo o ciclo;

- $\quad$ os processos são todos ideais;

- o regime é permanente;

- não ocorrem perdas de pressão;

- os calores específicos dos fluidos envolvidos são constantes;

- as parcelas das energias cinética e potencial são desprezadas.

Aplicando-se o balanço de energia para cada um dos processos explicitados no esquema representativo do ciclo e no diagrama $T$-s, obtém-se o equacionamento descrito a seguir:

Compressão:

$$
\frac{\dot{W}_{c}}{\dot{m}}=h_{2}-h_{1}
$$

Adição de calor:

$$
\frac{\dot{Q}_{a d}}{\dot{m}}=h_{3}-h_{2}
$$

Expansão:

$$
\frac{\dot{W}_{t g}}{\dot{m}}=-\left(h_{4}-h_{3}\right)=h_{3}-h_{4}
$$


Rejeição de calor:

$$
\frac{\dot{Q}_{r e j}}{\dot{m}}=-\left(h_{1}-h_{4}\right)=h_{4}-h_{1}
$$

Trabalho do ciclo:

$$
\frac{\dot{W}_{\text {ciclo }}}{\dot{m}}=\frac{\dot{W}_{t}}{\dot{m}}-\frac{\dot{W}_{c}}{\dot{m}}
$$

Eficiência térmica:

$$
\begin{gathered}
\eta_{\text {ciclo }}=\frac{\dot{W}_{\text {ciclo }}}{\dot{Q}_{a d}}=\frac{\left(\frac{\dot{W}_{t}-\dot{W}_{c}}{\dot{m}}\right)}{\frac{\dot{Q}_{a d}}{\dot{m}}} \\
\text { ou } \\
\eta_{\text {ciclo }}=\frac{h_{3}-h_{4}-\left(h_{2}-h_{1}\right)}{h_{3}-h_{2}}=1-\frac{h_{4}-h_{1}}{h_{3}-h_{2}}
\end{gathered}
$$

Considerando que os gases de combustão possuam calor específico constante, obtém-se:

$$
\eta_{\text {ciclo }}=\frac{C_{p}\left(T_{3}-T_{4}\right)-C_{p g}\left(T_{2}-T_{1}\right)}{c_{p g}\left(T_{3}-T_{2}\right)}=1-\frac{T_{4}-T_{1}}{T_{3}-T_{2}}
$$

Sabendo que:

$$
\frac{T_{2}}{T_{1}}=\left(\frac{P_{2}}{P_{1}}\right)^{\frac{k-1}{k}}=\frac{T_{3}}{T_{4}}
$$


onde, $k$ é constante e dado pela razão dos calores específicos do gás de combustão a pressão constante e volume constante.

$$
k=\frac{C_{P}}{C_{v}}
$$

Desta forma, a eficiência do ciclo pode ser expressa pela Eq. 3.25.

$$
\eta_{\text {ciclo }}=1-\left(\frac{T_{1}}{T_{2}}\right)=1-\frac{1}{(r)^{\frac{k-1}{k}}}
$$

sendo que $r$ é a razão de pressões fornecida pela compressão, ou seja:

$$
r=\frac{P_{2}}{P_{1}}
$$

Pode-se observar o comportamento da eficiência térmica em função da razão de pressão para um ciclo Brayton padrão a ar $(k=1,4)$ na Fig. 2.4.

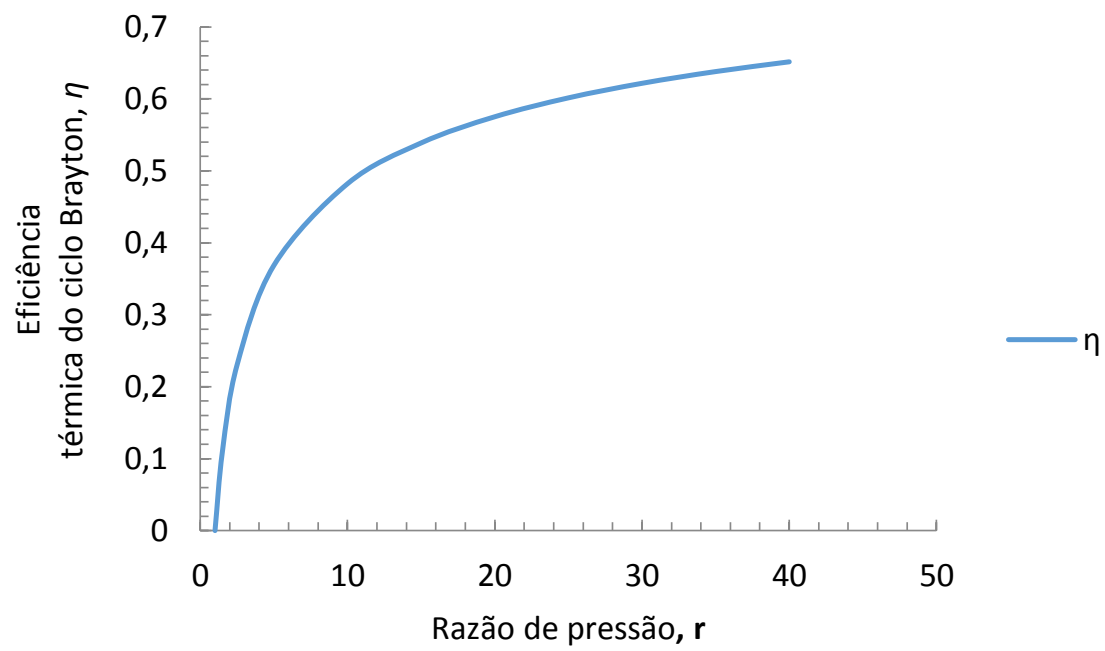

Figura 2.4 - Eficiência térmica do ciclo Brayton em função da razão de pressão. Fonte: Elaboração própria (2016). 
Simões-Moreira e Pimenta (2017) disponibilizam a Eq. 2.27 que fornece o rendimento térmico do ciclo levando em consideração os rendimentos das máquinas (turbina a gás e compressor).

$$
\eta_{\text {ciclo }}=\frac{\eta_{\text {turb }} \frac{T_{3}}{T_{1}}\left(1-\frac{1}{r^{(k-1) / k}}\right)-\frac{1}{\eta_{\text {comp }}}\left(r^{\frac{(k-1)}{k}}-1\right)}{\frac{T_{3}}{T_{1}}-\left(1+\frac{r^{\frac{(k-1)}{k}}-1}{\eta_{\text {comp }}}\right)}
$$

\subsubsection{Turbina a Gás}

A eletricidade é produto final das UTEs de turbina a gás operando em ciclo simples. Caracterizam-se por uma partida rápida, razão pela qual podem ser empregadas no atendimento da demanda em períodos de pico, podendo também serem adaptadas para utilizar combustíveis líquidos (diesel especial e óleo combustível) (Lora e Do Nascimento, 2004).

As turbinas a gás são máquinas motrizes de combustão interna divididas em três seções principais: compressor de ar, sistema de combustão e a turbina propriamente dita. O compressor tem a função de captar e pressurizar o ar atmosférico para alimentação da câmara de combustão. O sistema de combustão consiste em um conjunto de injetores que fornecem combustível na proporção especificada para a câmara de combustão e promover a mistura adequada para queima em elevadas temperaturas. A turbina propriamente dita consiste em um complexo conjunto de pás rotativas por onde passam os gases expandidos da combustão e que fazem girar o eixo do gerador responsável por produzir a energia eletromecânica. Na Fig. 2.5 são apresentados os componentes básicos de uma turbina a gás (EPE, 2008). 


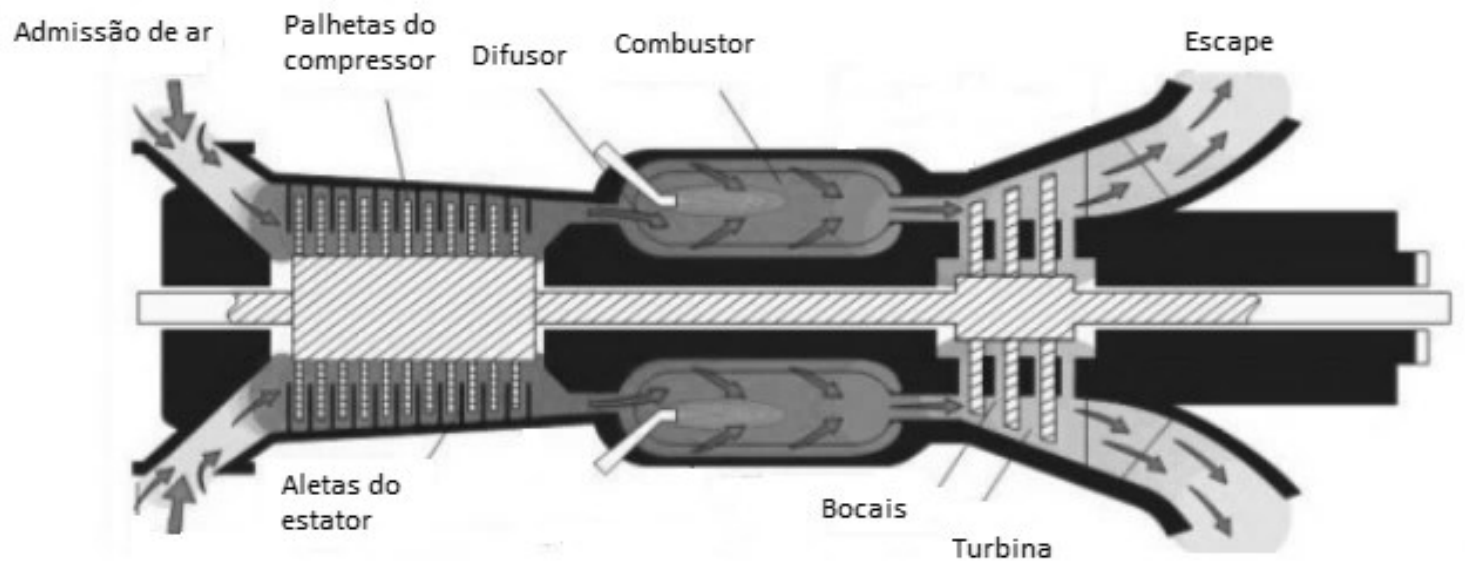

Figura 2.5 - Componentes básicos de uma turbina a gás. Fonte: EPE (2008).

Ao longo dos últimos vinte anos observou-se grande evolução na tecnologia envolvida no projeto e produção de turbinas a gás, o que se deve, principalmente, ao desenvolvimento de novos materiais, revestimentos e esquemas de resfriamento. Acrescenta-se ainda a elevação da razão de compressão alcançada pelos compressores, o que incrementou a eficiência térmica de cerca de $15 \%$ a valores superiores a $45 \%$ (Boyce, 2002).

As turbinas a gás possuem um longo histórico, iniciado a partir das pesquisas do inventor inglês John Barber (1734-1801), que desenvolveu a ideia de comprimir o ar e utilizar a sua energia como fluido de trabalho. Ao longo do século XIX, houve o avanço do desenvolvimento das turbinas a gás e apenas em 1939 foi construída a primeira turbina a gás dedicada à geração de energia elétrica, com $4 \mathrm{MW}$ de potência, na cidade de Neuchatel, na Suíça. As turbinas de aplicação aeronáutica tiveram o seu desenvolvimento independente na mesma década das turbinas industriais. Assim, existem dois tipos de turbinas a gás: as máquinas industriais (ou heavy duty) e as aeroderivativas. As turbinas industriais heavy duty são projetadas para a aplicação industrial e são caracterizadas pela robustez, flexibilidade no uso de combustível, alta confiabilidade e baixo custo. A maior aplicação dessas turbinas tem sido na geração de eletricidade operando na base. Já as turbinas aeroderivativas são oriundas de turbinas a gás aeronáuticas que sofreram algumas modificações no projeto para fins industriais (Tolmasquim 2005). 
Em outras áreas de atuação, a aplicação das turbinas a gás se desenvolveu de forma mais lenta, principalmente pelo seu baixo rendimento térmico e pelo seu alto custo de desenvolvimento, o que as tornava pouco competitivas em relação a outros sistemas de geração de potência para uso geral.

Na década de 1940, quando a turbina térmica a gás foi introduzida para a geração de energia elétrica, houve uma revolução nos processos de geração de energia a partir da utilização de combustíveis fósseis. Vinte anos mais tarde, as usinas termoelétricas com turbina a gás já estavam aptas para uso, mas não eram economicamente viáveis devido à indisponibilidade do gás natural como combustível, bem como aos baixos rendimentos. Próximo ao ano de 1990 a turbina a gás passou a ser responsável por uma parte da geração de eletricidade das novas usinas térmicas. A maior participação da turbina a gás se deve ao ciclo combinado. Outros fatores que propiciaram a popularização da turbina a gás para geração de energia foram: o desenvolvimento na aerodinâmica dos compressores e o aumento da resistência térmica do material associado à tecnologia de resfriamento (EPE 2016).

\subsubsection{Classificação das Turbinas a Gás}

Como já apresentado, usualmente as turbinas a gás industriais podem ser categorizadas em dois tipos: turbinas aeroderivativas e turbinas industriais (heavy duty).

As turbinas aeroderivativas são oriundas de turbinas aeronáuticas que passaram por modificação de projeto, haja vista que pode ser mais econômico modificá-las, objetivando finalidades industriais, do que projetar e desenvolver turbinas completamente novas. São caracterizadas por apresentar maior eficiência e alta confiabilidade, além de ocupar pouco espaço, possuir menor razão peso/potência e flexibilidade na manutenção. Podem atingir uma potência de cerca de $50 \mathrm{MW}$ sendo utilizadas principalmente em plataformas marítimas, atendendo à potências de pico em termelétricas e propulsão naval.

Como exemplo de turbinas a gás aeroderivativas, pode-se citar alguns modelos fabricados pela GE, tais como a LM1600, LM2500, LM5000 e LM6000 (Fig. 2.6), que fornecem potências de 13,2 MW a 40,7 MW. 


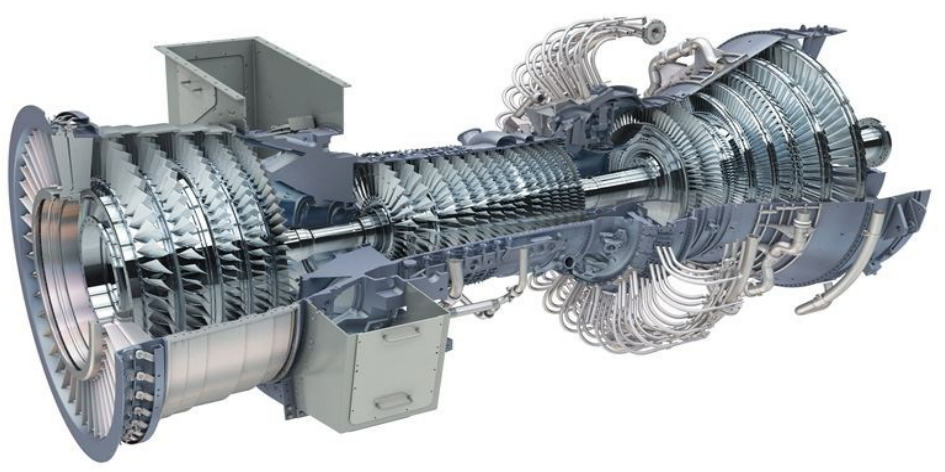

Figura2.6 - Turbina a gás aeroderivativa modelo LM6000, 50 MW da GE. Fonte: https://www.gepower.com/gas/gasturbines $/ \operatorname{lm} 6000$

Já as turbinas industriais (heavy duty) são projetadas especificamente para a aplicação industrial seguindo filosofia própria. Sendo caracterizadas pela robustez, flexibilidade no uso de combustível, alta confiabilidade e baixo custo. Podem atingir uma potência de cerca de $340 \mathrm{MW}$, sendo que a maior aplicação dessas turbinas tem sido na geração de eletricidade operando na base. São exemplos de turbinas a gás industriais os modelos da GE, 9F.03 (Fig. 2.7), 7F.05, 9E03 e 9E04.

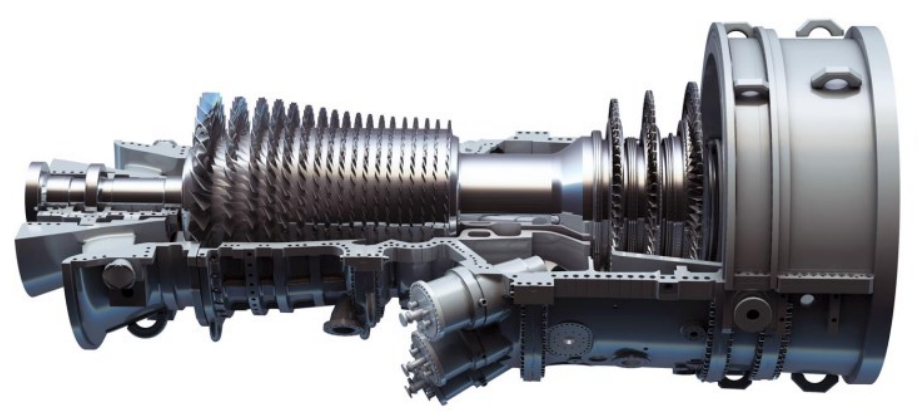

Figura 2.7 - Turbina a gás heavy duty modelo 9F03, 132MW da GE. Fonte: https://www.gepower.com/gas/gasturbines/9e-03 
Simões-Moreira e Pimenta (2017) disponibilizam as principais características das turbinas a gás industriais e aeroderivativas:

Tabela 2.1 - Características das turbinas a gás. Fonte: Simões-Moreira e Pimenta (2017).

Turbinas industriais

- São as mais empregadas na produção de potência $(0,5$ a $250 \mathrm{MW})$

- Grandes e pesadas, já que em geral, não existem restrições de peso ou tamanho

- Menos eficientes, porém de menor custo por quilowatt gerado do que as aeroderivativas

- Podem atingir temperaturas máximas de até $1260^{\circ} \mathrm{C}$

- Unidades modernas podem apresentar taxa de compressão de até 18:1

- Maior variedade de combustível em relação às aeroderivativas

\section{Turbinas aeroderivativas}

- Origem na indústria aeronáutica

- As maiores se situam na faixa de potência entre 40 e $50 \mathrm{MW}$

- Utilizam componentes mais leves e compactos

- São mais eficientes até $40 \%$ com taxas de compressão de 30:1

- Demandam investimentos mais elevados

Boyce (1982) classifica as turbinas a gás industriais de acordo com suas faixas de potência:

\section{- Pequeno porte (até 1 MW)}

As turbinas a gás de pequeno porte são aquelas cuja potência nominal é menor que $1 \mathrm{MW}$. Seu projeto é similar ao projeto das turbinas maiores, no entanto, há algumas unidades que contêm um compressor centrífugo ou uma combinação de compressor centrífugo e axial, bem como turbina de fluxo radial. Geralmente uma turbina a gás deste tipo é formada por um compressor centrífugo de simples estágio com uma razão de pressão de cerca de 4:1, uma câmara de combustão simples com cerca de $870{ }^{\circ} \mathrm{C}$ de temperatura máxima e uma turbina de fluxo radial. A eficiência das turbinas a gás de pequeno porte é normalmente muito menor que a eficiência das unidades de porte maior, por conta da limitação da temperatura de entrada da turbina e da baixa eficiência de seus componentes. 
Estas unidades são robustas e sua simplicidade de projeto garante muitas horas de operação sem problemas, sendo que algumas possuem regenerador para aumentar a eficiência térmica.

\section{- Médio porte: entre 1 MW a 15 MW}

Turbinas a gás de médio porte são aquelas com potência entre $1 \mathrm{MW}$ e $15 \mathrm{MW}$. Geralmente, são turbinas com dois eixos, as quais são mais eficientes em operações com carregamento parcial, pois nesta configuração de turbina o gerador de gás opera com eficiência máxima, enquanto a turbina de potência opera em uma faixa de velocidade menor. O compressor possui geralmente entre 10 e 16 estágios de compressão axial subsônico, o qual produz uma razão de pressão de cerca de 5 a 11. A turbina do gerador de gás tem geralmente de 2 a 3 estágios axiais, com resfriamento a ar das palhetas do primeiro estágio. A turbina de potência é geralmente de fluxo axial com um ou dois estágios. As turbinas de médio porte são usadas em plataformas offshore e estão em expansão em plantas petroquímicas. Nas plantas de processo, o gás de exaustão da turbina é usado para geração de vapor. As plantas de cogeração, que normalmente utilizam turbinas de médio porte, apresentam altos valores de eficiência e são a tendência do futuro.

\section{- Grande porte: acima de 15 MW}

As turbinas a gás de grande porte possuem potências acima de $15 \mathrm{MW}$ e podem ser aeroderivativas ou heavy-duty. As turbomáquinas são predominantemente axiais e podem ter vários estágios.

\subsubsection{O ciclo Rankine: análises ideal e real}

O princípio básico de um ciclo Rankine, ou ciclo vapor como também é conhecido, é a utilização de calor liberado por um processo de combustão para geração de vapor que é expandido em uma turbina, produzindo trabalho de eixo que por sua vez é convertido em energia elétrica em um gerador. Uma configuração simplificada do ciclo Rankine é apresentada na Fig. 2.8. Os componentes básicos são: gerador de vapor (caldeira), turbina a vapor, condensador, bomba de alimentação de água e gerador elétrico. 


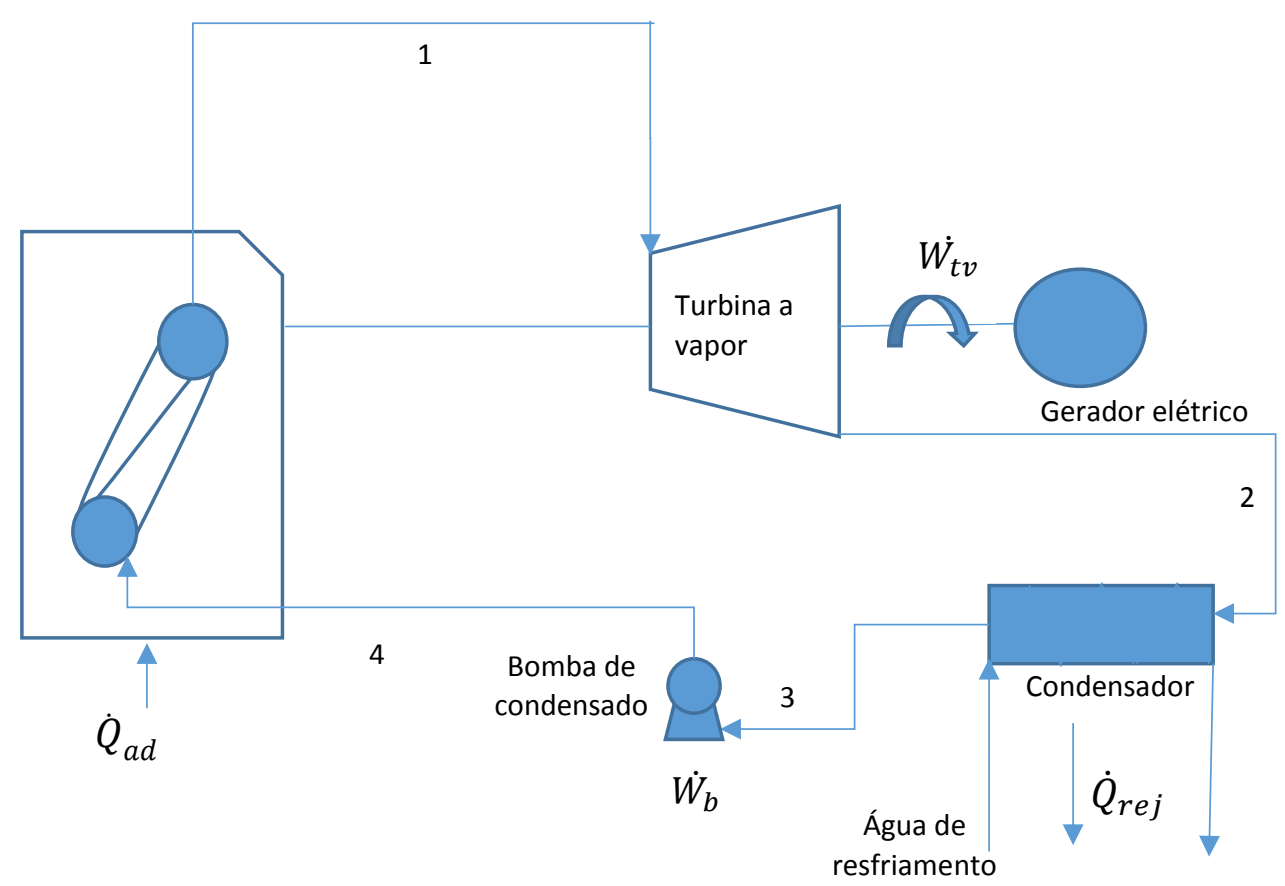

Figura 2.8 - Esquema genérico de um ciclo Rankine simples. Fonte: Elaboração própria.

O ciclo Rankine simples ideal abrange os seguintes processos reversíveis internos descritos no diagrama temperatura-entropia, $T$-s, da Fig. 2.9:

- $(1-2)$, expansão isentrópica do fluido de trabalho através da turbina, sendo vapor saturado no estado 1 e vapor a pressão do condensador no estado 2;

- $\quad(2-3)$, rejeição de calor do fluido de trabalho a pressão constante através do condensador com líquido saturado no estado 3;

- $\quad(3-4)$, compressão isentrópica do líquido;

- (4 - 1), transferência de calor para o fluido de trabalho a pressão constante no gerador de vapor completando o ciclo. 


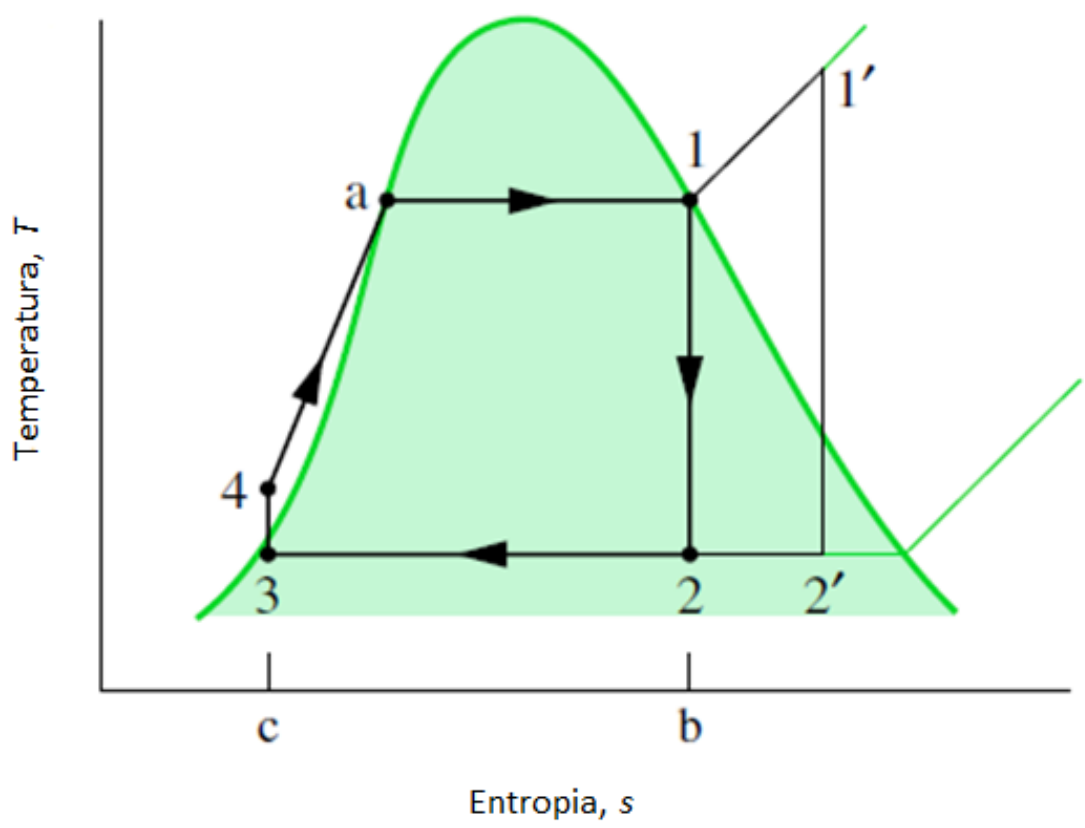

Figura 2.9 - Diagrama T-s do ciclo Rankine ideal. Fonte: Moran e Shapiro (2006).

O ciclo Rankine simples ideal também dispõe da possibilidade de emprego de vapor superaquecido, neste caso representado no diagrama temperatura-entropia, $T-S$, pela sequência de processos (1'- 2'- 3'- 4 -1'). A utilização de vapor superaquecido proporciona maior eficiência térmica à medida que a adição de calor é realizada em temperaturas médias mais elevadas. Complementarmente, o título do vapor na saída da turbina é aumentado, deste modo proporcionando melhor desempenho e prevenindo erosão das pás. Contudo, a máxima temperatura que pode ser empregada é fixada pelos limites metalúrgicos dos materiais que compõem os equipamentos. Algumas plantas térmicas modernas têm operado a temperaturas de vapor acima de $620^{\circ} \mathrm{C}$ por meio do emprego de aços especiais conhecidos como austenísticos ${ }^{3}$. No entanto, os custos de construção se elevam exponencialmente com a utilização de temperaturas acima de $540^{\circ} \mathrm{C}$. A prática geralmente limita a temperatura do vapor até $540^{\circ} \mathrm{C}$ e em alguns poucos casos até $565^{\circ} \mathrm{C}$ (Gupta, 2012).

Aplicando-se as equações de conservação de massa e de energia aos processos descritos nas Figs. 2.8 e 2.9 e negligenciando-se tanto os processos de transferência de

\footnotetext{
${ }^{3}$ Aços austeníticos são compostos por ferro, cromo e níquel e possuem excelente resistência à corrosão e alta ductibilidade. Em geral podem ser utilizados tanto em processos que requerem elevadas temperaturas (até $1150^{\circ} \mathrm{C}$ ) como em condições criogênicas (Arcelor Mittal, 2008).
} 
calor entre os componentes e suas redondezas, como as variações de energia cinética e potencial, obtêm-se as seguintes equações representativas dos processos, a seguir:

- Expansão na turbina a vapor:

$$
\frac{\dot{W}_{t}}{\dot{m}}=h_{1}-h_{2}
$$

- Rejeição de calor no condensador:

$$
\frac{\dot{Q}_{r e j}}{\dot{m}}=h_{2}-h_{3}
$$

- Bombeamento de líquido:

$$
\frac{\dot{W}_{b}}{\dot{m}}=h_{4}-h_{3}
$$

- Adição de calor no gerador de vapor:

$$
\frac{\dot{Q}_{a d}}{\dot{m}}=h_{1}-h_{4}
$$

- Eficiência térmica:

$$
\eta_{\text {ciclo }}=\frac{\dot{W}_{\text {ciclo }}}{\dot{Q}_{a d}}=\frac{\left(\frac{\dot{W}_{t}-\dot{W}_{b}}{\dot{m}}\right)}{\frac{\dot{Q}_{a d}}{\dot{m}}}
$$

Irreversibilidades e perdas estão associadas a cada um dos quatro subsistemas termodinâmicos da Fig. 2.8, sendo que em alguns deles a influência destas irreversibilidades e perdas é mais pronunciada do que em outros. Na turbina, a principal irreversibilidade observada está associada ao processo de expansão do vapor ao passar pelas pás da turbina. Conforme nota-se por meio do diagrama $T-s$ da Fig. 2.10, o 
processo real de expansão adiabática $(1-2)$ é acompanhado por um incremento de entropia. O trabalho realizado por unidade de massa neste processo é menor que o trabalho correspondente caso o processo fosse isentrópico $\left(1-2_{\mathrm{s}}\right)$.

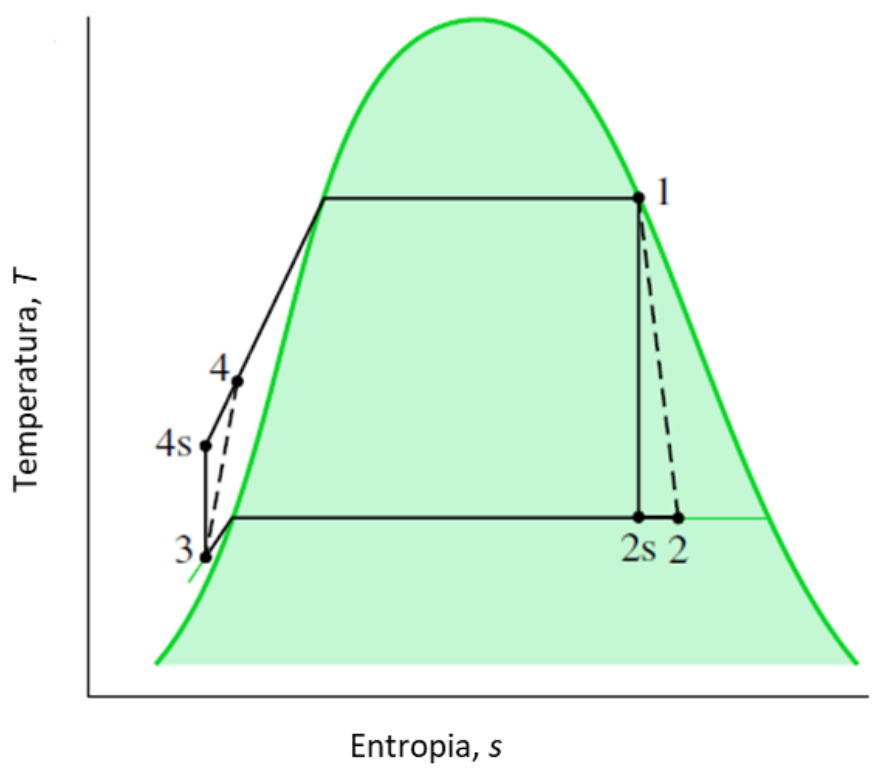

Figura 2.10 - Diagrama $T-s$ do ciclo Rankine real. Fonte: Moran e Shapiro (2006).

A eficiência isentrópica permite que os efeitos das irreversibilidades no interior da turbina a vapor sejam contabilizados em termos dos trabalhos reais e ideais, conforme Eq. 2.33.

$$
\eta_{i, t v}=\frac{\frac{\dot{W}_{12}}{\dot{m}}}{\left(\frac{\dot{W}_{12}}{\dot{m}}\right)_{s}}=\frac{h_{1}-h_{2}}{h_{1}-h_{2 s}}=\frac{\left(T_{1}-T_{2}\right)}{\left(T_{1}-T_{2 s}\right)}
$$

$\mathrm{Na}$ bomba de condensado o trabalho real necessário para superar os efeitos de atrito também reduz a potência líquida da planta térmica. Na Fig. 2.10, o processo $(3-4)$ representa o aumento de entropia no interior da bomba. Neste caso, o trabalho demandado é superior ao trabalho correspondente ao processo isentrópico $(3-4 \mathrm{~s})$ e sua eficiência isentrópica também pode ser expressa em termos dos trabalhos real e ideal, de acordo com a Eq. 2.34. 


$$
\eta_{i, b}=\frac{\left(\frac{\dot{W}_{34}}{\dot{m}}\right)_{s}}{\frac{\dot{W}_{34}}{\dot{m}}}=\frac{h_{4 s}-h_{3}}{h_{4}-h_{3}}=\frac{\left(T_{1}-T_{2}\right)}{\left(T_{1}-T_{2 s}\right)}
$$

\subsubsection{O ciclo combinado}

Segundo Horlock (1992) apud (Lora e Do Nascimento, 2004) existem três tipos de centrais de ciclos combinados para a geração de eletricidade. São eles:

- Em série, Figs. 2.11 a;

- Em paralelo, Fig. 2.11 b;

- Em série/paralelo, Fig. 2.11 c.

De acordo com a definição de Mazurenko et al. (2013), um ciclo combinado em série consiste numa cascata energética que tem como ciclo superior um ciclo Brayton e como ciclo inferior um ciclo Rankine, funcionando por meio da utilização da energia térmica dos gases de exaustão da turbina a gás para geração de vapor numa caldeira de recuperação.

Em um ciclo combinado em série, devido ao acoplamento térmico entre os dois ciclos, obtém-se maior aproveitamento da energia inicial contida no combustível, uma vez que os gases de exaustão da turbina a gás são utilizados numa caldeira de recuperação para geração do vapor que é fornecido para a turbina a vapor. Já em uma UTE de ciclo combinado em paralelo, o combustível é utilizado para gerar calor para os dois ciclos simultaneamente. Por fim, as centrais em série/paralelo são semelhantes às centrais em série, porém empregam, suplementarmente, a queima de combustível na caldeira de recuperação (Lora e Do Nascimento, 2004). 


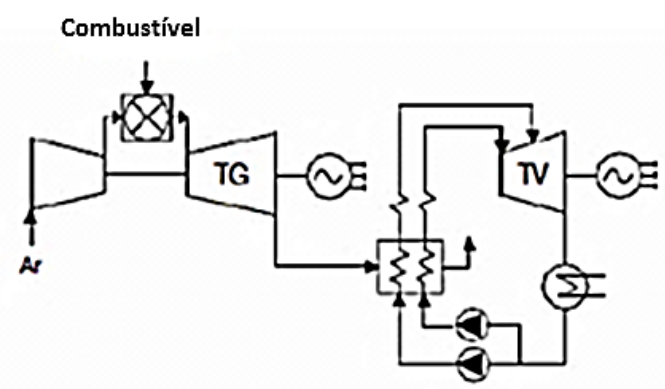

(a)

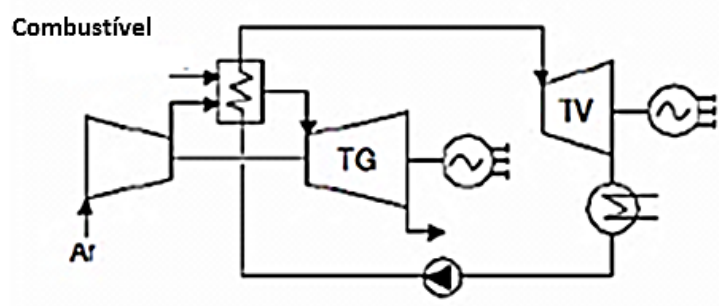

(b)

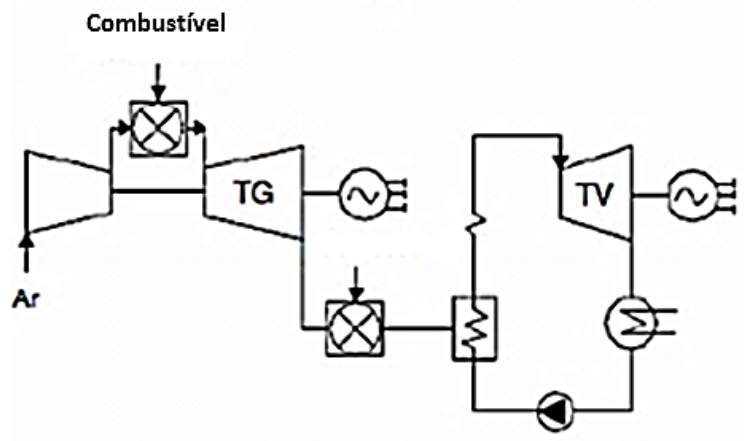

(c)

Figura 2.11 - Tipos de termelétricas de ciclo combinado: a) em série; b) em paralelo; c) em série/paralelo. Fonte: Lora e Do Nascimento (2004).

\subsubsection{Caldeira de recuperação}

Segundo Simões-Moreira e Pimenta (2017), a caldeira de recuperação ou HRSG (do inglês, heat recovery steam generator) é o equipamento que produz vapor de água pressurizado para acionar o ciclo Rankine mediante transferência de calor dos gases de combustão do ciclo Brayton, integrando, assim, os dois ciclos. A transferência de calor nas caldeiras de recuperação se dá por convecção, diferentemente das caldeiras comuns onde a radiação desempenha papel significativo. $\mathrm{O}$ vapor pode ser gerado em um ou mais níveis de pressão para alimentar a turbina a vapor, ou mesmo ser consumido em algum outro ponto do processo. Há situações em que a demanda de vapor é superior à 
quantidade que pode ser produzida pela simples recuperação da energia térmica dos gases de combustão, gerando a necessidade de uma queima adicional de combustível. É importante que a temperatura dos gases de exaustão não decresça demasiadamente de modo a se evitar condensação de vapor de água, evitando assim o processo de corrosão das tubulações.

De acordo com Branco (2005), diferentemente dos gases de exaustão de uma turbina a óleo ou de um motor diesel, os gases provenientes de uma turbina a gás contêm oxigênio, uma vez que estes equipamentos operam com coeficientes de excesso de ar elevados, o que permite a queima suplementar de combustível se houver a necessidade de vapor a temperaturas mais elevadas ou em maior quantidade. Na Fig. 2.12 são ilustrados os componentes principais e secundários de uma caldeira de recuperação empregada em um ciclo combinado, gerando vapor em um único nível de pressão.

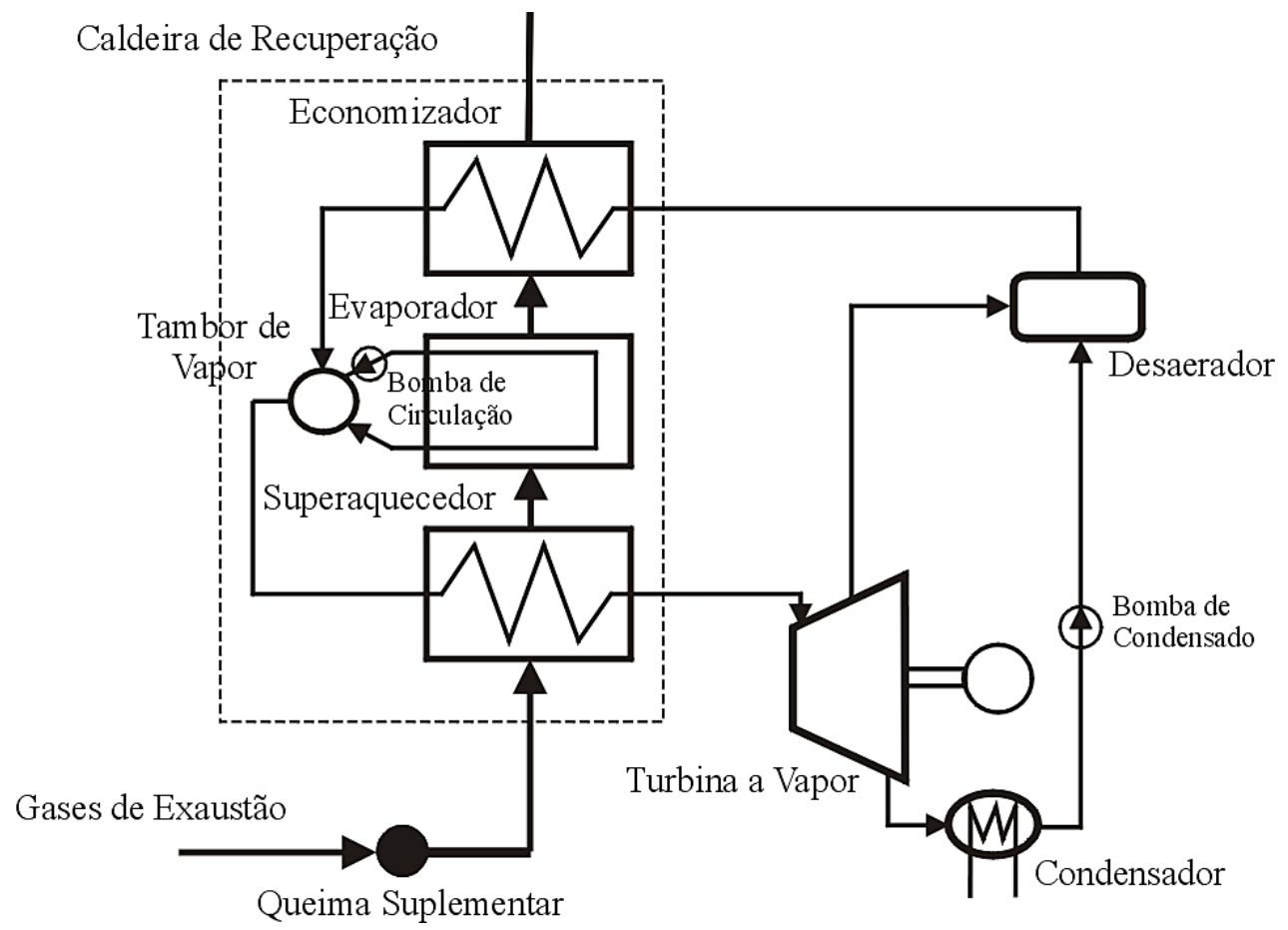

Figura 2.12 - Esquema de uma caldeira de recuperação com queima suplementar e um único nível de pressão. Fonte: Branco (2005).

A seguir, são descritos os principais componentes de uma caldeira de recuperação, conforme esquema da Fig. 2.12: 
- Economizador: responsável pelo pré-aquecimento da água antes da entrada no evaporador. A água é admitida no estado de líquido comprimido, no nível de pressão correspondente ao ciclo de potência, acrescido dos valores de perdas de carga que ocorrem até a entrada da turbina a vapor. Deve-se dar atenção especial à temperatura de operação do economizador, pois este parâmetro é importante para evitar a evaporação da água de alimentação nas conexões entre o economizador e o evaporador e a vaporização dentro do próprio economizador, durante a operação em carga parcial, fenômeno este que causa problemas de erosão e instabilidade devido ao escoamento bifásico.

- Evaporador: trata-se de um trocador de calor que aquece e vaporiza a água. A condição de saída desse equipamento sempre é vapor saturado.

- Superaquecedor: superaquece o vapor proveniente do evaporador até uma condição especificada. $\mathrm{O}$ vapor saturado é superaquecido até a temperatura de entrada da turbina a vapor, limitada pela diferença de temperatura com o gás na entrada deste trocador de calor. Esta diferença de temperatura é conhecida como diferença terminal ou aproach do superaquecedor.

- Tambor de vapor (steam-drum): situado no evaporador, tem a função de garantir a geração de vapor saturado para o superaquecedor e de separar este vapor da água não evaporada.

\subsubsection{Resfriamento em centrais termelétricas}

Centrais termelétricas que operam com turbinas a vapor, em ciclos simples ou combinados, demandam consideráveis volumes de água em sua operação, sobretudo em função da tecnologia empregada no resfriamento adjunto ao processo de condensação de vapor proveniente da exaustão da turbina. Ademais, além da perda por evaporação, perdas adicionais ocorrem por conta de arraste de líquido pela corrente de ar e também por meio da descarga de água (purga), cuja finalidade é manutenção da qualidade da água dentro de níveis aceitáveis de qualidade torre de resfriamento. Há ainda outros pontos relevantes de consumo de água em centrais térmicas, tais como a injeção de vapor na turbina a gás, purga em trocadores de calor, utilização de água de serviço e potável (Medeiros, 2003). Segundo Gupta (2012), a demanda por água para a geração 
de vapor em ciclos Rankine é da ordem de 3 a 4 toneladas/h/MW e a quantidade de água de reposição é de aproximadamente 2 a 3\% deste valor. Já a quantidade de água de resfriamento requerida para condensação é estimada em $50 \mathrm{~kg} / \mathrm{kg}$ vapor.

Gleick (1994) apud Yang e Dziegielewski (2007) estimaram que a demanda de água em centrais termelétricas movidas a carvão mineral, que utilizem circuitos de resfriamento de passagem única, é de aproximadamente 12,5 vezes a massa do carvão queimado. Essa intensa demanda de água pode exercer significantes impactos tanto nas reservas superficiais como nas subterrâneas, a depender da localidade onde a planta se encontra instalada.

A disponibilidade de água vem se tornando um fator relevante no licenciamento e implantação de UTEs. Segundo Macedonio et al. (2014) uma planta acionada a carvão mineral requer 1,6L água para cada $\mathrm{kWh}$ gerado, enquanto que uma central nuclear necessita de 2,3L por kWh. Conforme afirma Zhelev (2005), a título de exemplo da magnitude das perdas por meio de evaporação, uma planta termelétrica de 3600MW de potência perde para o ambiente aproximadamente $120.000 \mathrm{~m}^{3}$ de água por dia.

De forma geral, a tecnologia adotada para resfriamento em centrais termelétricas é fator preponderante na quantidade de água captada e consumida pelas plantas. Segundo Mallick (2014), a maioria das usinas movidas a turbina vapor ou ciclo combinado rejeita o calor de condensação via úmida, por meio de torres de resfriamento, ou via seca através de condensadores a ar, conhecidos também como torres de resfriamento secas. A escolha entre estes dois tipos de sistemas leva em conta os custos e as eficiências dos mesmos, uma vez que torres de resfriamento oferecem menor custo e melhor eficiência em dias quentes e condensadores a ar evitam o consumo e desperdício de água sendo capazes de economizar $60 \%$ do consumo de água em relação aos sistemas via úmida (Pan et al., 2012).

Na Tabela 2.2 são disponibilizados valores de captação e de consumo de água associados ao tipo de resfriamento adotado. Os dados foram extraídos dos trabalhos de Feeley III et al. (2008) e EPRI (2002). 
Tabela 2.2 - Comparação entre captação e consumo de água em sistemas de circulação aberta e torre úmida com circulação fechada. Fonte: Adaptado de Feeley et al. (2008) e EPRI (2002).

\begin{tabular}{ccccc}
\hline \multirow{2}{*}{ Tipo do sistema } & \multicolumn{2}{c}{ Feeley et al. (2008) } & \multicolumn{2}{c}{ EPRI (2002) } \\
\cline { 2 - 5 } & $\begin{array}{c}\text { Captação } \\
(1 / \mathrm{kWh})\end{array}$ & $\begin{array}{c}\text { Consumo } \\
(1 / \mathrm{kWh})\end{array}$ & $\begin{array}{c}\text { Captação } \\
(1 / \mathrm{kWh})\end{array}$ & $\begin{array}{c}\text { Consumo } \\
(1 / \mathrm{kWh})\end{array}$ \\
\cline { 2 - 5 } $\begin{array}{c}\text { Torre de } \\
\text { resfriamento úmida } \\
\text { Circulação aberta }\end{array}$ & 4,5 & 4,2 & $2,0-2,3$ & 2 \\
\hline
\end{tabular}

A taxa de evaporação prevista pelos projetistas de torres de resfriamento é da ordem de $1 \%$ da vazão de água circulante para cada $12,5^{\circ} \mathrm{C}$ de redução da temperatura da água durante o resfriamento (ASHRAE, 2007). Como referência, em ensaios de desempenho realizados pelo IPT (Instituto de Pesquisas Tecnológicas do Estado de São Paulo) em uma torre de resfriamento que operava em uma central termelétrica de ciclo combinado localizada na região de Belo Horizonte-MG, encontrou-se que a taxa de evaporação para um total de sete ensaios variou de $0,99 \%$ a $1,30 \%$ da vazão de água de entrada (Neves, 2013).

As centrais movidas a carvão possuem consumo de água superior ao usual quando equipadas com sistemas de captura de $\mathrm{CO}_{2}$ por meio de aminas, uma vez que o processo de captura empregado demanda elevadas quantidades de vapor de água para regeneração do solvente, no caso a monoetanolamina (MEA). Além disso, se faz necessária a produção adicional de energia elétrica de modo compensar o consumo associado ao processo de captura de $\mathrm{CO}_{2}$ (Chandel et al., 2011). Estima- se que esta carga adicional reduza a capacidade da planta em até 20-30\% (Rochell, 2009).

\subsubsection{Sistemas de resfriamento de circulação aberta (Open Through)}

Conforme discutido previamente, a tecnologia empregada para o resfriamento em UTEs é fator determinante na quantidade de recursos hídricos captados e efetivamente consumidos. Segundo Rutberg (2003), em sistemas cujo resfriamento se dá por circulação aberta, a água passa uma única vez pelo condensador, podendo ser captada a partir de diferentes fontes hídricas, tais como rios, lagos, lagoas, mares, águas subterrâneas, entre outros, conforme a Fig. 2.13. 
Cabe enfatizar que este tipo de processo de resfriamento requer maior quantidade de água a ser captada, contudo seu consumo total é menor, já que após absorver entalpia de condensação do vapor oriundo da turbina, a parcela de água captada é devolvida para os respectivos reservatórios com pouca ou nenhuma perda.

Apesar de simples e econômicos, se comparado a outros tipos de sistemas de resfriamento, os sistemas de circulação aberta são limitados pela capacidade do corpo hídrico de fornecer a vazão de água demandada. Além disso, o despejo de água a elevadas temperaturas - incremento em torno de 15 a $30^{\circ} \mathrm{C}$ - é bastante danoso ao ecossistema do corpo hídrico receptor. De acordo com Gallo (1997) os volumes de captação de água em sistemas de circulação aberta variam de $96 \mathrm{~m}^{3} / \mathrm{MWh}$, em ciclos simples, a $39,6 \mathrm{~m}^{3} / \mathrm{MWh}$, em ciclos combinados.

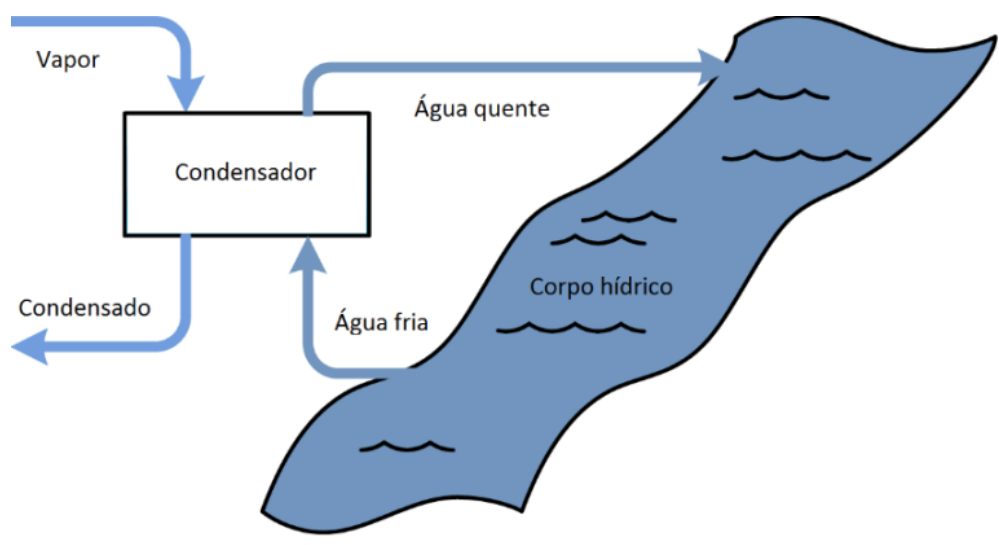

Figura 2.13 - Sistema de resfriamento de passagem única (once-through). Fonte: Adaptado de Rutberg (2003).

$\mathrm{O}$ retorno da água a elevadas temperaturas $\left(15^{\circ} \mathrm{C}\right.$ a $\left.30^{\circ} \mathrm{C}\right)$ ao corpo hídrico receptor pode originar pequenas perdas por evaporação (valores em torno de 1\%). Esse processo de evaporação indireta origina um consumo que, mesmo em pequenas quantidades, se torna relevante frente ao elevado volume requerido por esse tipo de resfriamento. Além do mais, do ponto de vista ambiental, a poluição térmica acarreta redução do oxigênio dissolvido na água, o que origina uma menor taxa de autodepuração dos corpos hídricos, e que consequentemente eleva a toxicidade de certas substâncias ameaçando, assim, a sobrevivência de determinadas espécies aquáticas (Arroyo, 2012). 


\subsubsection{Torres de resfriamento}

Em essência, as torres de resfriamento são grandes trocadores de calor em que um líquido, predominantemente água, é resfriado por meio de uma corrente de ar ambiente. Estes equipamentos possuem características específicas, com emprego restrito a uma estreita faixa de temperaturas de operação, posto que operam nas condições atmosféricas (Nunes, 2014). As torres de resfriamento podem ser divididas basicamente em duas categorias distintas: Torres úmidas (evaporativas) e Torres secas (trocadores de calor arrefecidos a ar).

As torres de resfriamento úmidas são aquelas em que a água e o ar estão em contato direto. O processo que ocorre em torres úmidas é conhecido como resfriamento evaporativo, o qual ocorre por meio da transferência de calor gerado pela evaporação de pequena parcela de água e também por meio de transferência de calor sensível decorrente do diferencial de temperatura entre as correntes de ar e água. À medida que parte da água que ingressa no sistema é evaporada, uma quantidade equivalente de água é reposta no sistema (make up). Assim, a vazão de água fria que retorna ao condensador é sempre igual a vazão de água quente que alimenta a torre de resfriamento. O grau de resfriamento nas torres de resfriamento úmidas depende fundamentalmente da umidade relativa e da temperatura de bulbo úmido do ar atmosférico, sendo a temperatura de bulbo úmido a mínima temperatura teórica que pode ser obtida pelo processo.

De forma genérica, tanto nas torres úmidas como nas secas, a dinâmica de funcionamento pode se dar por duas formas distintas: convecção natural ou forçada. Adicionalmente, o modo de escoamento das vazões de ar e água se divide em: contracorrente e correntes cruzadas. Tais classificações podem ser melhor compreendidas por meio da Fig. 2.14. 


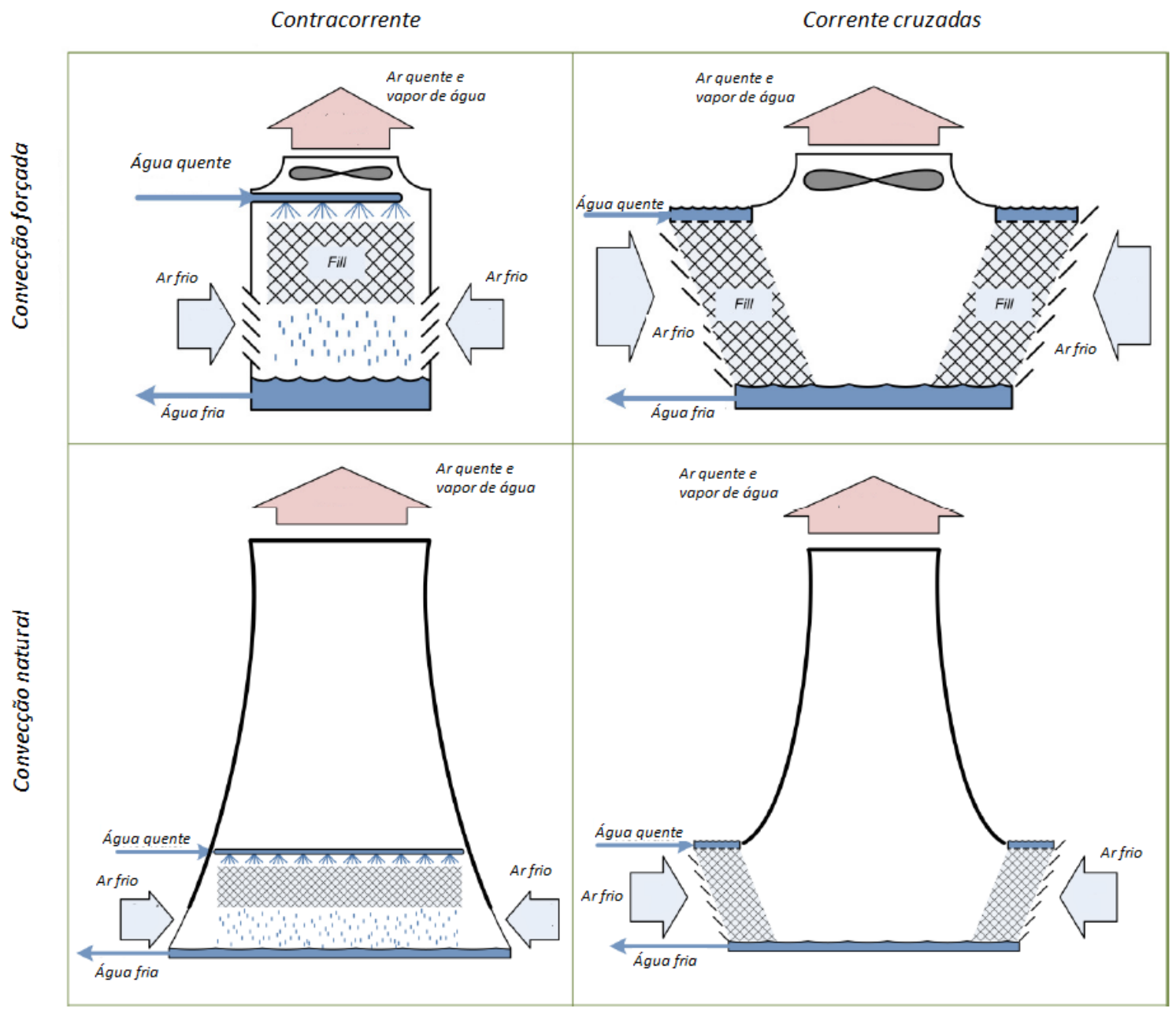

Figura 2.14 - Classificação das torres de resfriamento úmidas. Fonte: Adaptado de Rutberg (2003).

As torres de resfriamento de convecção natural não dependem de ventiladores e possuem baixos custos operacionais. Nelas, o fluxo de ar ascendente se estabelece devido à diferença de pressão, ocasionada pela desigualdade de densidade entre o ar frio, localizado na região externa do equipamento, e o ar quente em seu interior. A água quente descendente transfere calor para o ar o qual uma vez aquecido se torna mais leve e consequentemente ascende ao longo do equipamento. A diferença de densidade é relativamente pequena, e faz com que torres de tiragem natural necessitem de grandes alturas para gerar a diferença de pressão necessária para superar a perda de carga no interior do equipamento e manter o escoamento.

Em torres de convecção forçada o escoamento do ar é realizado por meio de um ventilador que pode estar localizado tanto na base como no topo da torre de resfriamento. Neste caso, as principais vantagens estão relacionadas à menor altura do equipamento, menores custos de capital e flexibilidade operacional, uma vez que a 
vazão de ar pode ser regulada por meio de um inversor de frequência associado ao ventilador.

Nas torres secas, como o próprio nome sugere, a água a ser resfriada não entra contato direto com o ar, uma vez que circula no interior de serpentinas dispostas na corrente de ar no interior da torre. Assim, a capacidade de resfriamento é inferior a de torres evaporativas. Por necessitar de maiores superfícies de troca de calor, este tipo de equipamento torna-se, na maioria das vezes, maior e mais custoso. Contudo, o aspecto vantajoso se refere ao fato de que nas torres secas não ocorrem perdas de água por evaporação, logo a reposição do ciclo se dá em escala infinitamente inferior ao existente em torres úmidas. Desta forma, o emprego de torres secas é vantajoso em localidades onde não existe abundância de água.

As torres secas podem ser categorizadas como de resfriamento direto e indireto. No resfriamento direto o equipamento atua como se fosse o próprio condensador do vapor, conforme ilustrado na Fig.2.15, onde o ar, por meio de um ventilador, é forçado através de tubos aletados no interior dos quais o vapor é condensado. Já no resfriamento indireto, o vapor é substituído pela água de resfriamento do condensador (Gupta, 2012).

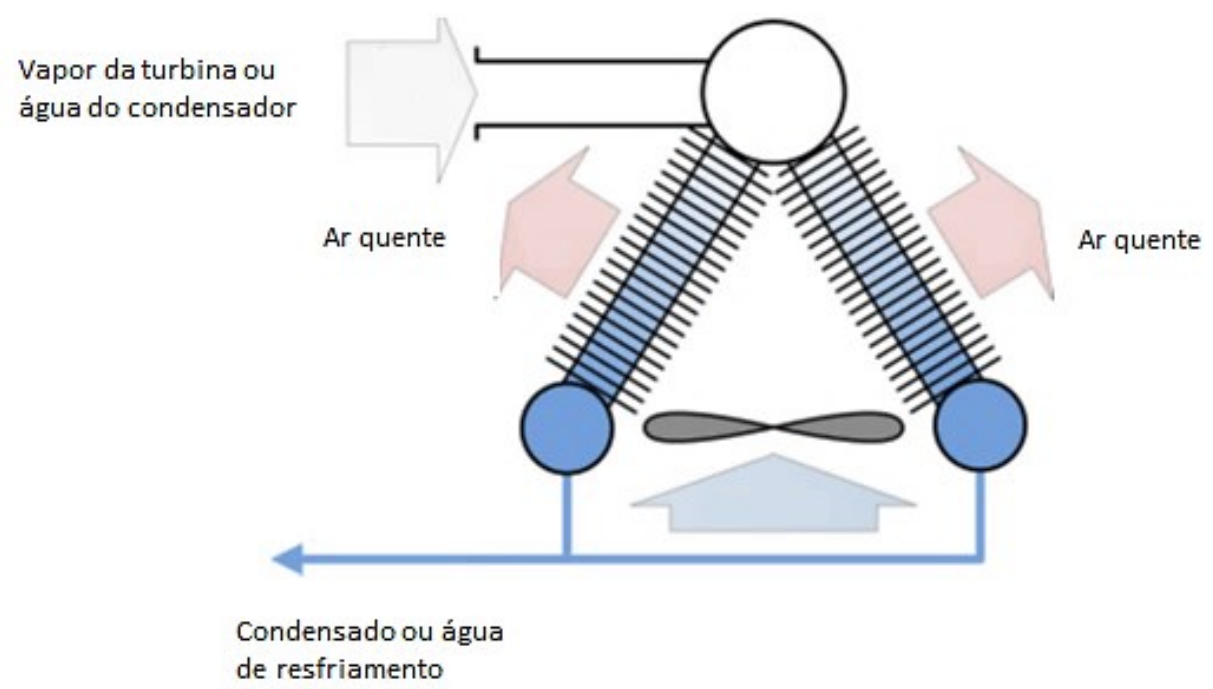

Figura 2.15 - Torre de resfriamento seca. Fonte: Adaptado de Rutberg (2003). 


\subsection{Modos posssíveis de condensação}

A condensação ocorre quando a temperatura do vapor é reduzida abaixo de sua temperatura de saturação. De acordo com Incropera e Dewitt (2011), o processo geralmente resulta do contato entre o vapor e uma superfície resfriada, conforme o exposto na Fig. 2.16 (a e b). Ao longo da condensação, o fluxo de calor resultante da mudança de fase é transferido na direção da superfície e o condensado é formado.

Outros modos comuns de ocorrência da condensação são o homogêneo, no qual o vapor condensa em suspensão na fase gasosa formando uma névoa resultante de uma expansão, conforme Fig. 2.16 (c); e a condensação em contato direto, que ocorre quando o vapor é misturado diretamente com um fluido de resfriamento, Fig. 2.16 (d).

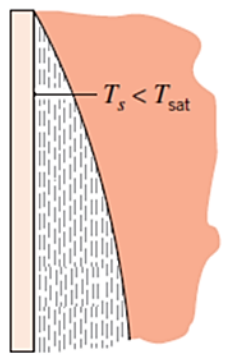

(a) Filme

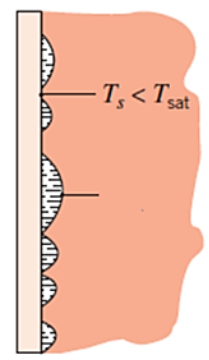

(b) Gotas

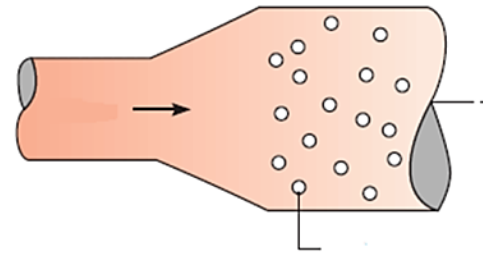

(c) Névoa
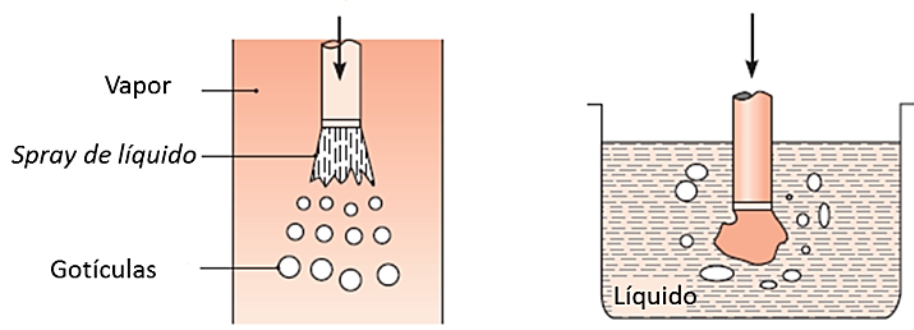

(d)

Figura 2.16 - Modos de condensação. (a) Filme, (b) Gotas, (c) Condensação homogênea, (d) Contato direto. Fonte: Adaptado de Incropera e Dewitt (2011).

De acordo com o exposto na Fig. 2.16 (a) e (b), a condensação pode acontecer de duas formas distintas, a depender das condições da superfície empregada. A forma predominante de ocorrência é aquela na qual o líquido forma um filme, o qual sob efeito da gravidade, escoa continuamente ao longo da totalidade da superfície resfriada. A condensação em regime de filme geralmente ocorre quando a superfície se encontra 
limpa e não contaminada. Contudo, caso a superfície esteja recoberta com alguma substância que iniba sua "molhabilidade", é possível que o regime de gotas prevaleça. As gotas se formam em rachaduras, pequenos orifícios e cavidades existentes na superfície podendo crescer e se coalescerem no decorrer do processo.

Imagens da condensação de vapor de água em filme e em gotas em uma superfície vertical de cobre são apresentadas na Fig. 2.17. Para promoção da condensação em gotas a superfície foi revestida por uma fina camada de oleato de cobre.

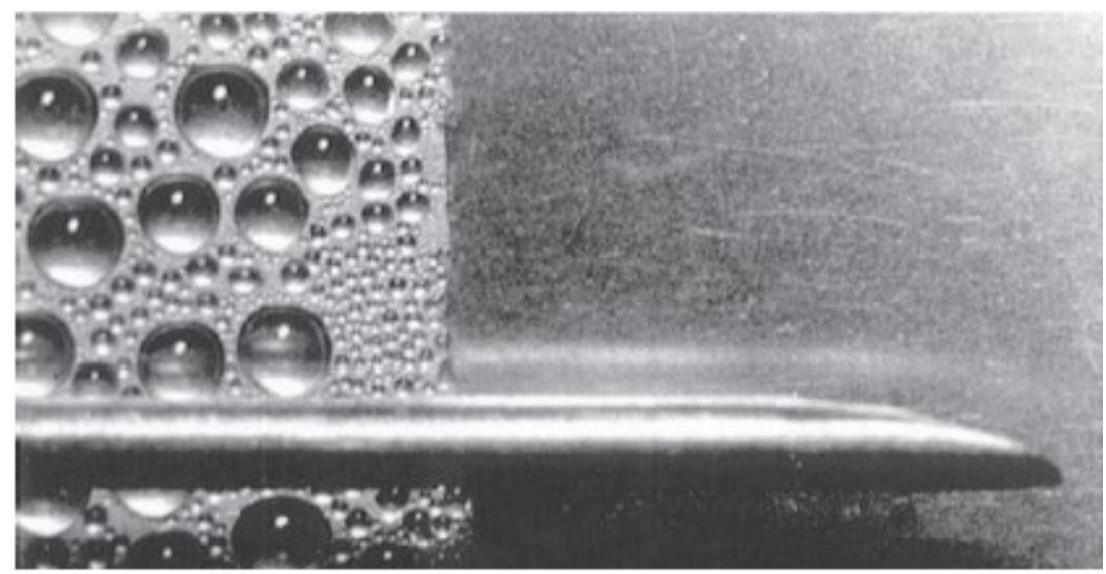

Figura 2.17 - Condensação de vapor em superfície vertical. (a) Gotas, (b) Filme. Fonte: Incropera e DeWitt (2011), cortesia de J.W. Westwater, University of Illinois at Champaign-Urbana.

Na Fig. 2.18 são apresentadas imagens de modos distintos de condensação sobre uma parede vertical de alumínio na presença de uma fração de mássica de $20 \%$ de gases não condensáveis obtidas por Yi et al. (2016). O modo de condensação variou em razão de fatores como sub-resfriamento superficial, velocidade do fluxo de vapor e assim por diante. Quando o sub-resfriamento da superfície é baixo (15K), Fig. 2.18 (a), ocorre a formação de um grande número de gotículas de água com 0,1-3mm de diâmetro distribuídos de forma relativamente uniforme em toda a superfície de condensação. A Fig. 2.18 (b) mostra que conforme ocorre o aumento do subresfriamento $(25 \mathrm{~K})$, ocorre também o aumento das gotas de água, as quais se coalescem e se tornam maiores formando pequenos "riachos" (streams) pela superfície. Os diâmetros das gotas de condensado que se formavam na placa tornavam-se obviamente maiores, e escoavam mais rápidamente, o que os autores denominaram de "Drop streak-form". Já a Fig. 2.18 (c) ilustra a característica do filme que se forma com 
subresfriamento de $45 \mathrm{~K}$. Observa-se que o filme ocupa aproximadamente $2 / 3$ da superfície e que as gotículas de água se encontram distribuídas nas extremidades da superfície de condensação. Na Fig. 2.18 (d), onde o subresfrimento se encontra em 50K, verifica-se nitidamente que ocorre mudança no modo de condensação em relação a Fig. 2.18 (c). Torna-se mais difícil a diferenciação entre filme e gota, de forma que as gotas caem na forma irregular e constituem um filme estreito, o que é chamado de streamlet form pelos autores.

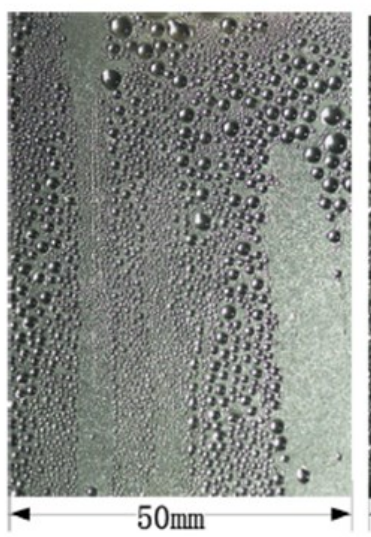

(a) $\left(T_{s}-T_{w}\right)=15 \mathrm{~K}$

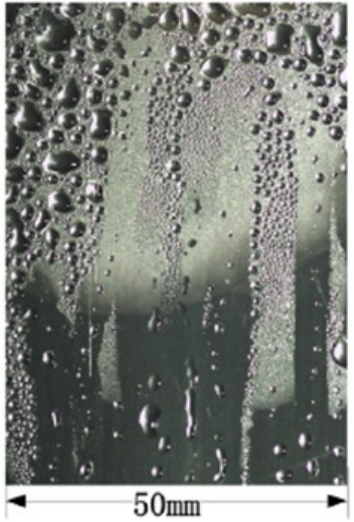

(b) $\left(\mathrm{T}_{\mathrm{s}}-\mathrm{T}_{\mathrm{w}}\right)=25 \mathrm{~K}$

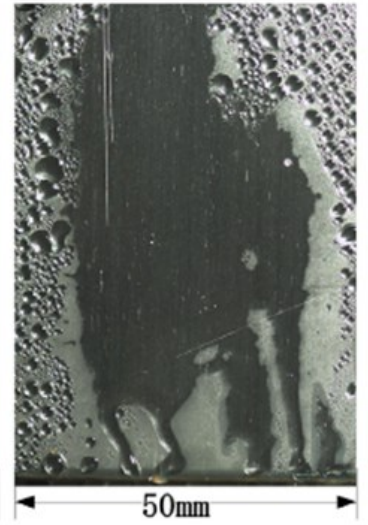

(c) $\left(T_{-}-T_{w}\right)=45 \mathrm{~K}$

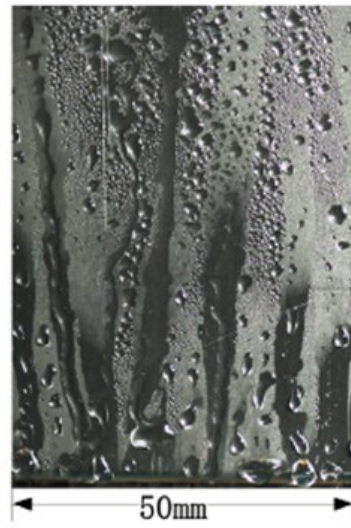

(d) $\left(\mathrm{T}_{\mathrm{s}}-\mathrm{T}_{\mathrm{w}}\right)=50 \mathrm{~K}$

Figura 2.18 - Formas de condensação em uma parede vertical de alumínio isotérmica na presença de $20 \%$ em massa de gases não condensáveis. Fonte: Yi et al. (2016).

Segundo Yi et al. (2016) o regime de condensação em gotas proporciona o alcance de coeficientes de transferência de calor e taxas de condensação bastante superiores aos encontrados no regime de filme, uma vez que a maioria do calor transferido ocorre através das gotas, que em geral possuem diâmetros menores do que $100 \mu \mathrm{m}$. Portanto, é uma prática comum na indústria a utilização de superfícies revestidas por silicones, teflon, ceras e ácidos graxos de modo a inibir a formação de filme e promover a formação de gotas. No entanto, as camadas dos inibidores tendem a perder sua efetividade gradualmente, em decorrência de processos de oxidação, degradação e incrustração. Consequentemente, o modo de condensação tende a se modificar para filme.

Tendo em vista que a condensação em gotas é muito difícil de ser realizada na prática, muitos pesquisadores dedicam-se a melhorar a transferência de calor na condensação pelicular. Para o processo de condensação de vapor puro, observa-se que a 
maior resistência térmica se encontra na transferência de calor através da espessura do filme condensado. Assim, busca-se diminuir a espessura do filme de condensado desta camada. Neste sentido, de acordo com Carey (1992), as superfícies onduladas, que são também conhecidas como superfícies de Gregorig (primeiramente estudas por Gregorig em 1954), possuem a característica de aumentar a transferência de calor quando comparadas às superfícies lisas. A Fig. 2.19 ilustra o formato típico destas superfícies.

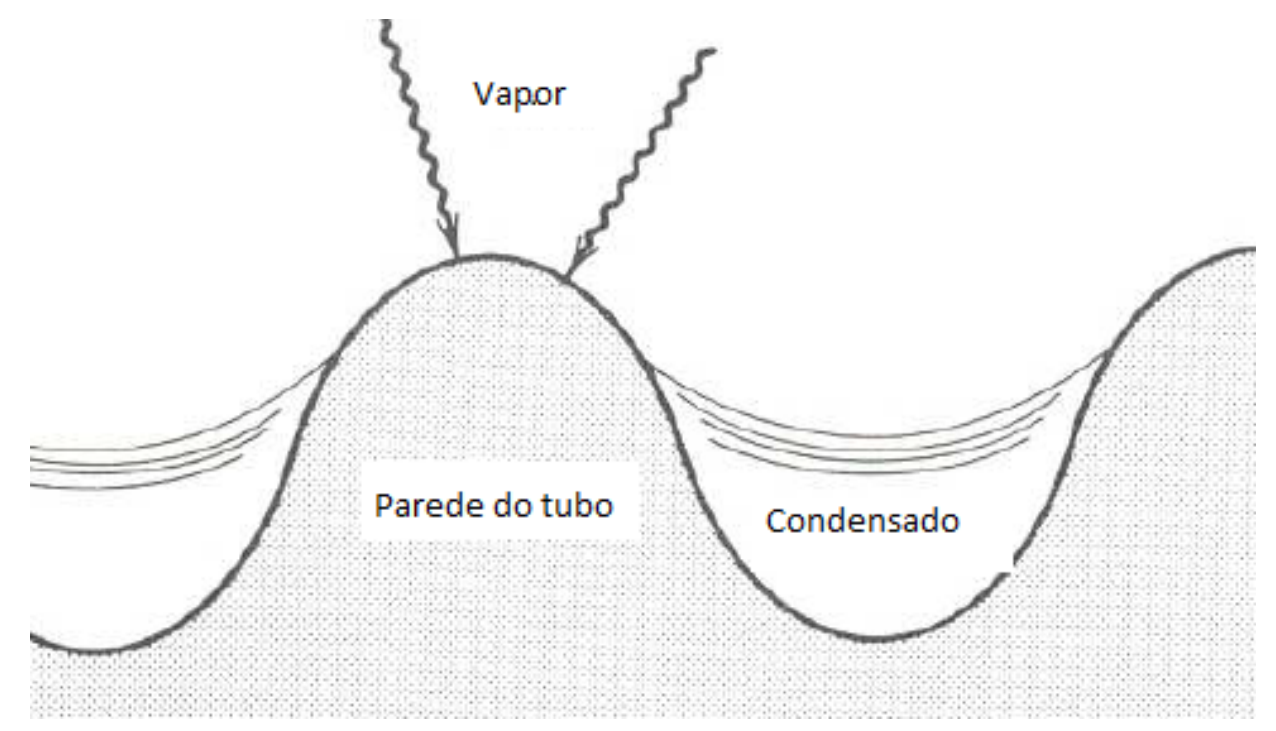

Figura 2.19 - Superfície de condensação ondulada. Fonte: Adaptado de Carey (1992).

Como o formato da película acompanha o formato da superfície na crista, devido ao raio de curvatura do menisco, a pressão interna tende a exceder a pressão do vapor; por outro lado, no vale destas "ranhuras", também devido ao raio de curvatura do líquido, a pressão interna do líquido tende a ser menor que a pressão do vapor. Devido ao gradiente de pressão do líquido condensado induzido pela tensão superficial, ocorre a migração do líquido na direção dos vales, diminuindo a espessura da camada de líquido condensado nesta região Carey (1992). 


\subsubsection{Teoria da condensação de Nusselt}

Tomando-se como referência a Fig. 2.20 (a), nota-se que o filme líquido se origina no topo da placa e escoa descendentemente pela influência da gravidade. A espessura do filme e a vazão mássica de condensado aumentam ao longo de $x$, por conta da contínua condensação na região interfacial entre o líquido e o vapor, que se encontra na temperatura de saturação, $T_{\text {sat }}$.

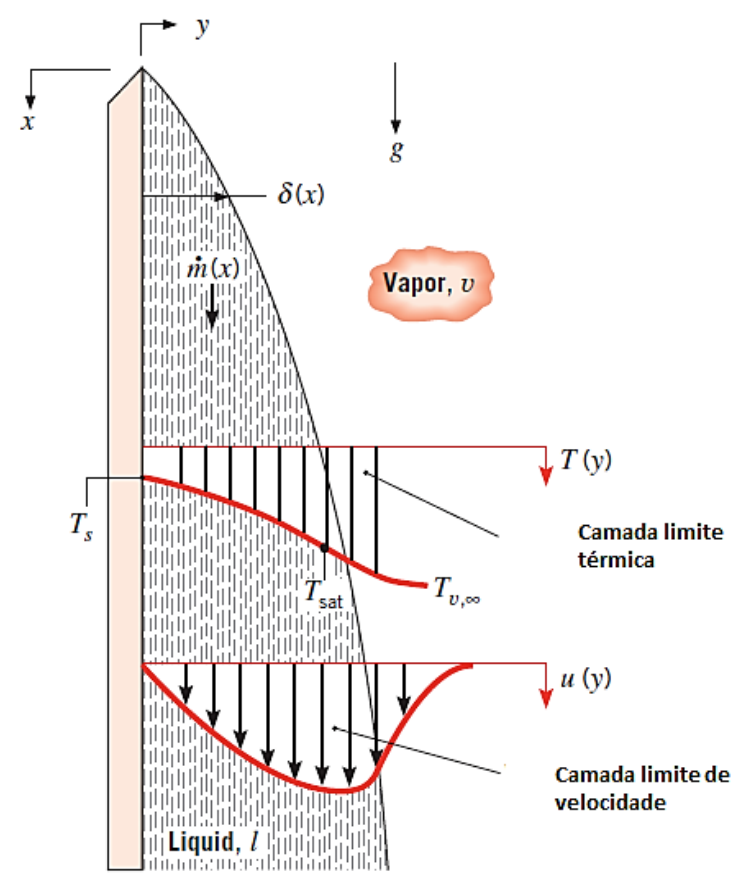

(a)

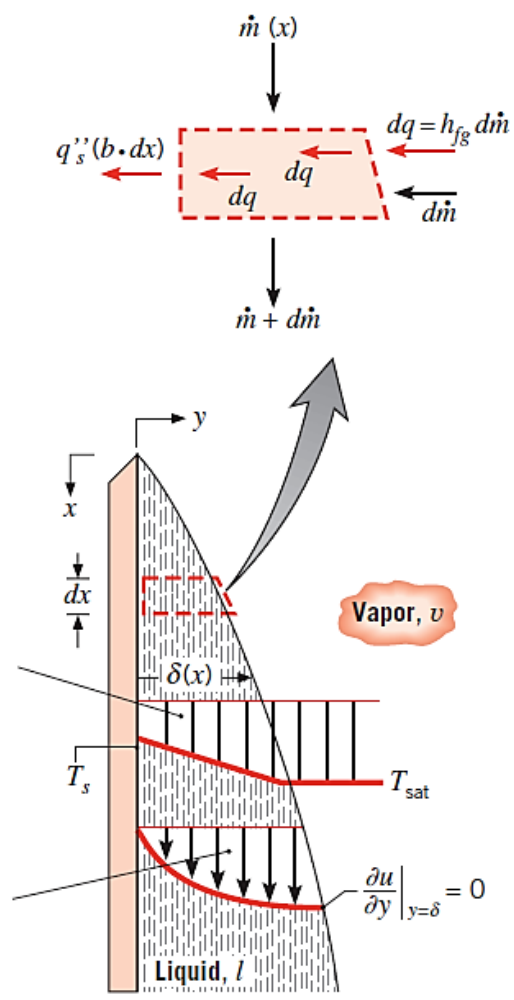

(b)

Figura 2.20 - Efeitos da camada limite relacionados à condensação em filme em uma superfície vertical, a) não considerando hipóteses de Nusselt; b) considerando as hipóteses de Nusselt. Fonte: Adaptado de Incropera e DeWitt (2011).

A relação analítica para o coeficiente de transferência de condensação em regime de filme líquido, realizada por Nusselt em 1916, considera as seguintes hipóteses simplificadoras, representadas na Fig 2.20 (b):

- A superfície de condensação e o vapor são mantidos a temperaturas constantes, $T_{s}$ e $T_{\text {sat }}$;

- A fase gasosa é composta apenas por vapor puro; 
- A temperatura do filme de condensado varia linearmente desde a interface líquido-vapor até a superfície;

- A transferência de calor através da película de líquido se dá por condução;

- A velocidade do vapor é baixa, de forma a não haver arrasto de condensado;

- O escoamento do condensado se dá em regime laminar $(0<\operatorname{Re}<30)$, sendo que as propriedades do líquido são consideradas constantes;

- A aceleração da camada de condensado é desprezível.

Conforme as hipóteses descritas acima, a equação de quantidade de movimento para filme de condensado pode ser expressa da seguinte forma:

$$
\frac{\partial^{2} u}{\partial y^{2}}=-\frac{g}{\mu}\left(\rho_{l}-\rho_{v}\right)
$$

O perfil de velocidade do filme condensado pode ser obtido por meio da integração da Eq. 2.35.

$$
u(y)=\frac{g\left(\rho_{l}-\rho_{v}\right) \delta^{2}}{\mu}\left[\frac{y}{\delta}-\frac{1}{2}\left(\frac{y}{\delta}\right)^{2}\right]
$$

A partir das Eqs. 2.35 e 2.36, a vazão mássica de condensado pode ser obtida como sendo:

$$
\dot{m}_{c d}=\int_{0}^{\delta(x)} \rho_{l} u(y) d y=\frac{g \rho_{l}\left(\rho_{l}-\rho_{v}\right) \delta^{3}}{3 \mu}
$$

A variação de $\delta$ em função de $x$ é determinada primeiramente pela aplicação da conservação de energia ao elemento diferencial da Fig. 2.21 (b). 


$$
\begin{gathered}
d q=h_{f g} d \dot{m}_{c d}=\frac{k_{l}}{\delta}\left(T_{s a t}-T_{s}\right) d x \\
\frac{d \dot{m}_{c d}}{d x}=\frac{k_{l}\left(T_{s a t}-T_{s}\right)}{\delta h_{f g}}
\end{gathered}
$$

Diferenciando a Eq. 2.37 obtém-se que:

$$
\frac{d \dot{m}_{c d}}{d x}=\frac{g \rho_{l}\left(\rho_{l}-\rho_{v}\right) \delta^{2}}{\mu} \frac{d \delta}{d x}
$$

Combinando as Eqs. 2.39 e 2.40 e integrando a expressão resultante, obtém-se a expressão da espessura do filme:

$$
\delta(x)=\left[\frac{4 k_{l} \mu_{l}\left(T_{s a t}-T_{s}\right) x}{g \rho_{l}\left(\rho_{l}-\rho_{v}\right) h_{f g}}\right]^{1 / 4}
$$

Uma vez definida a espessura da película, pode-se encontrar o coeficiente convectivo local de transferência de calor, conforme Eq. 2.42.

$$
h_{x}=\frac{k_{l}}{\delta(x)}=\left[\frac{g \rho_{l}\left(\rho_{l}-\rho_{v}\right) k_{l}^{3} h_{l g}}{4 \mu_{l}\left(T_{s a t}-T_{s}\right) x}\right]^{\frac{1}{4}}
$$

O coeficiente médio ao logo de toda a placa é determinado a partir de sua definição, substituindo a relação por $h_{x}$ e integrando-se de 0 a $L$, conforme a seguir:

$$
h_{m}=\frac{1}{L} \int_{0}^{L} h_{x} d x=\frac{4}{3} h_{x=L}=0,943\left[\frac{g \rho_{l}\left(\rho_{l}-\rho_{v}\right) k_{l}^{3} h_{l g}}{\mu_{l}\left(T_{s a t}-T_{s}\right) x}\right]^{1 / 4}
$$




\subsubsection{Análise teórica da condensação na presença de gases não condensáveis segundo a teoria de Colburn e Hougen}

Uma das abordagens mais difundidas e frequentemente tomada como referência por diversos estudos teórico-numéricos para a avaliação de processos de condensação na presença de GNC se baseia na aplicação da analogia de calor e massa derivada da teoria de Colburn e Hougen (1934). Neste trabalho, os autores propuseram que a condensação é controlada pela difusão do vapor de água através da camada de GNC sendo que a taxa de transferência de massa é análoga à taxa de transferência de calor. $\mathrm{O}$ modelo se baseia no balanço de energia na região interfacial liquido-gás onde a quantidade calor transferida a partir da mistura gasosa através da camada limite vaporgás é equiparada à quantidade de calor transferida através do filme de líquido condensado. Desta forma, a taxa de transferência de calor é dada pela soma da quantidade de calor sensível, transferida a partir da mistura de gases em direção ao fluido de resfriamento, e a entalpia proveniente da condensação do vapor de água. A temperatura da interface varia ao longo do tubo devido ao efeito da camada de GNC adjunta à mesma, sendo determinada iterativamente ao longo do comprimento do condensador.

O fluxo da mistura de vapor de água e GNC é ilustrado na Fig. 2.21, em que a mistura ingressa a temperatura uniforme e em regime turbulento de escoamento. A temperatura da superfície de troca de calor é determinada pela temperatura do fluido de resfriamento, o qual escoa no interior do tubo.

A fração mássica de vapor diminui nas proximidades da interface, enquanto a fração de GNC aumenta. A resistência térmica da mistura de vapor e gases não condensáveis em relação ao fluido de resfriamento consiste nas resistências térmicas relativas às transferencias de calor sensível e de condensação, $R_{g} \mathrm{e} R_{c d}$, respectivamente. As demais são as resistências térmicas referentes ao filme líquido, a parede do tubo e ao fluido de resfriamento; $R_{f}, R_{w}$ e $R_{c}$, respectivamente, sendo que a soma de todas elas fornece a resistência térmica total existente entre a mistura gasosa e o fluido de resfriamento. 


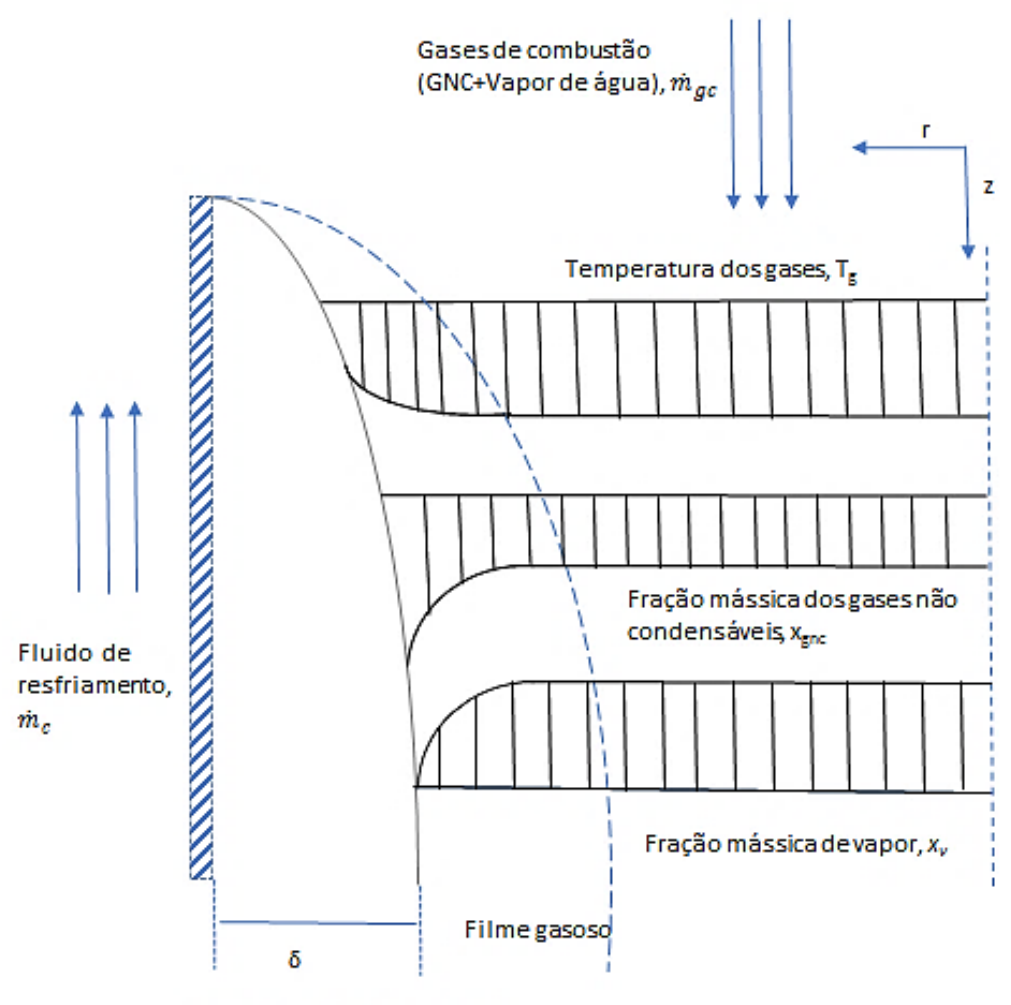

Filme líquido (condensado)

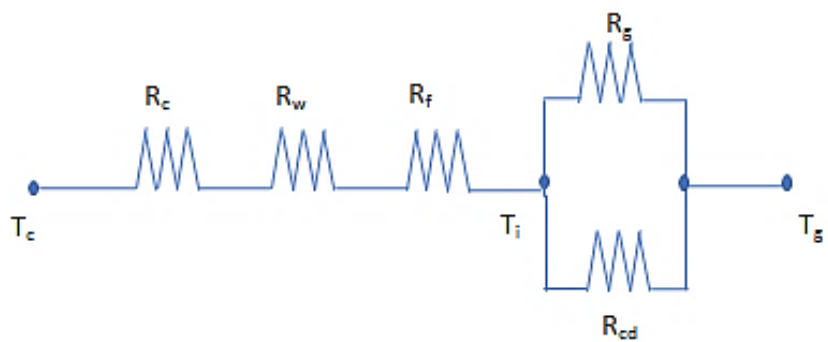

Figura 2.21 - Perfis de concentração e temperatura na condensação de vapor na na presença de não condensáveis. Fonte: Elaboração própria. 


\subsection{Revisão da Literatura}

Nas seções seguintes serão apresentados e discutidos estudos referentes à questão da captação e consumo de água em UTEs; recuperação de água presente em produtos de combustão por meio de condensação e sistemas de separação por membrana; e condensação na presença de gases não condensáveis.

\subsubsection{Captação e consumo de água em UTEs}

Yang e Dziegielewski (2007) realizaram um estudo estatístico no qual compararam a captação e o consumo de água em dez diferentes configurações de sistemas de resfriamento utilizados em centrais termelétricas norte americanas. Os valores médios de captação indicaram que as dez distintas configurações podem ser classificadas em três grandes grupos: sistemas de resfriamento de passagem única (once-through), sistemas de resfriamento de recirculação com reservatório (lagos, lagoas, rios, etc.) e sistemas de recirculação com torres de resfriamento. Os resultados obtidos confirmaram que a captação de água nos sistemas de resfriamento de passagem única é muito superior ao encontrado em sistemas com recirculação. O valor médio de captação nos sistemas once-through é superior a $0,15 \mathrm{~m}^{3} / \mathrm{kWh}$, enquanto sistemas de recirculação associados a reservatórios captam em média aproximadamente $0,10 \mathrm{~m}^{3} / \mathrm{kWh}$ e sistemas de recirculação com torres de resfriamento em média $0,005 \mathrm{~m}^{3} / \mathrm{kWh}$.

Carney et al. (2008) apresentam em seu trabalho dados estimados de consumo de água de cinco diferentes tecnologias de centrais termelétricas equipadas com torres de resfriamento evaporativas, incluindo as plantas equipadas com sistemas de captura de carbono por meio de monoethanolamina (MEA). Os autores enfatizam que o termo "consumo" corresponde à quantidade de água que deve ser reposta levando-se em conta a água perdida por meio da evaporação que ocorre na torre de resfriamento e uma parcela relativamente pequena que é perdida em operações unitárias ao logo do processo de geração. Os dados estimados são apresentados nas Tabelas 2.3 e 2.4.

O National Energy Technology Laboratory-NETL (2008) estimou que a implementação de sistemas de captura de $\mathrm{CO}_{2}$ em UTEs norte-americanas até 2030 pode elevar a taxa de captura de água doce em até 2 a $3 \%$ e o consumo em 
aproximadamente 52 a 55\%. O estudo assume que todas as plantas movidas a carvão mineral dos EUA serão readaptadas com sistemas de retenção de $\mathrm{CO}_{2}$ até 2030.

Tabela 2.3 - Consumo de água na geração termelétrica com utilização de torre de resfriamento úmida. Adaptado de Carney et al. (2008).

\begin{tabular}{cc} 
Tipo da planta & Consumo de água $\left(\mathbf{m}^{\mathbf{3}} / \mathbf{M W h}\right)$ \\
\hline Nuclear & 2,73 \\
Carvão pulverizado $\left(\right.$ Subcrítica $\left.^{4}\right)$ & 1,97 \\
Carvão pulverizado $\left(\right.$ Supercritica $\left.^{5}\right)$ & 1,70 \\
Ciclo combinado com sistema de gaseificação integrado & 1,17 \\
Ciclo combinado a gás natural & 0,72 \\
\hline
\end{tabular}

Tabela 2.4 - Consumo de água na geração termelétrica com utilização de torre de esfriamento úmida e sistema de absorção de $\mathrm{CO}_{2}$. Fonte: Adaptado de Carney et al. (2008).

\section{Tipo da planta}

\section{Consumo de água em plantas} equipadas com sistema de captura de $\mathrm{CO}_{2}\left(\mathrm{~m}^{3} / \mathrm{MWh}\right)$

\begin{tabular}{cc}
\hline Carvão pulverizado (Subcrítica) & 3,75 \\
Carvão pulverizado (Supercrítica) & 3,18 \\
Ciclo combinado com sistema de gaseificação integrado & 1,70 \\
Ciclo combinado a gás natural & 1,29 \\
\hline
\end{tabular}

Bistline \& Rai (2010) afirmam, com base no trabalho de Klara et al. (2007), que o aumento do consumo de água em centrais termelétricas a carvão nos EUA, após a implementação de sistemas de captura de $\mathrm{CO}_{2}$ por meio de MEA, é da ordem de $97 \%$ $\left(5,04 \mathrm{~m}^{3} / \mathrm{MWh}\right)$ em ciclos subcríticos e de $94 \%\left(4,32 \mathrm{~m}^{3} / \mathrm{MWh}\right)$ em ciclos supercríticos.

De acordo com Chandel et al. (2011), no ano de 2010, 89\% do total de energia elétrica gerada nos EUA, o que corresponde a 3,97 bilhões de MWh, empregaram sistemas de resfriamento, sendo que $47 \%$ deste valor foram originadas por sistemas que utilizavam torres de resfriamento, $44 \%$ por sistemas abertos de circulação de água e o restante por outros diferentes tipos de sistemas, tais como condensadores a ar. As centrais movidas a carvão se mostraram dominantes no que se refere à utilização de água doce em suas operações, contabilizando $61 \%$ do total de captação e $66 \%$ do total de consumo. A geração nuclear se encontra na segunda posição com $25 \%$ do total de

\footnotetext{
${ }^{4}$ Usinas subcríticas operam com pressões no evaporador abaixo da pressão crítica da água (22,09 MPa).

${ }^{5}$ Usinas supercríticas, ao contrário das subcríticas, operam com pressões no evaporador acima da pressão crítica da água.
} 
captação e $22 \%$ do total de consumo. Nesse trabalho os autores sumarizaram valores médios, disponibilizados no período entre 1996 a 2005 pelo EIA (United States Energy Information), de consumo e de captação de água em UTEs de diferentes tecnologias de geração equipadas com torres de resfriamento úmidas. Os valores são apresentados na Tabela 2.5 abaixo.

Tabela 2.5 - Valores médios de captação e consumo de água em UTEs com torres de resfriamento evaporativas. Fonte: Adaptado de Chandel, Pratson e Jackson (2011).

\begin{tabular}{cccc}
\hline Combustível & $\begin{array}{c}\text { Tipo de máquina } \\
\text { térmica }\end{array}$ & Captação $\left(\mathbf{m}^{\mathbf{3} / \mathbf{M W h})}\right.$ & Consumo $\left(\mathbf{m}^{\mathbf{3}} \mathbf{M W h}\right)$ \\
\hline Carvão mineral & Turbina a vapor & 2,78 & 2,14 \\
Nuclear & Turbina a vapor & 5,40 & 2,39 \\
Gás Natural & Ciclo combinado & 1,56 & 1,16 \\
Óleo/Gás & Turbina a vapor & 4,66 & 2,99 \\
\hline
\end{tabular}

Gerdes \& Nichols (2009) apud Merschmann et al. (2013) afirmam que no Brasil não existem estudos que avaliem os impactos dos processos de captura de carbono no consumo de água em centrais termelétricas, seja em plantas em fase de projeto ou em instalações já existentes e operacionais. Informações detalhadas acerca das plantas em planejamento ou em construção não são facilmente encontradas, e a forte dependência do país da geração hidrelétrica reduz a percepção de urgência em se lidar com as emissões de $\mathrm{CO}_{2}$ associadas a este tipo de produção de energia. Neste mesmo trabalho os autores avaliaram a utilização da água em doze centrais termelétricas brasileiras movidas a carvão mineral, frente às atuais demandas ambientais associadas a retenção de carbono. Os autores concluíram que para quase todas a plantas avaliadas, a implementação de instalações para captação de carbono baseadas em sistemas de absorção com amina duplicaria o volume de água consumida, o que causaria impactos negativos especialmente nas regiões das plantas de Pecém 1 e 2, Presidente Médice A e B, Candiota 3 e Seival. As localidades onde se encontram as termelétricas supracitadas estão em estado crítico de escassez de água. Nas considerações finais desse trabalho, os autores afirmam que alternativas menos convencionais para $\mathrm{o}$ aumento da disponibilidade de água incluem o tratamento e reutilização de parcelas de água de processo e residuais. A recuperação da água contida nos gases de combustão, com a 
finalidade de suprir os processos de resfriamento, é também uma opção para reduzir a quantidade de água doce consumida.

Scanlon et al. (2013) avaliaram o impacto do tipo de sistema de resfriamento no consumo de água em plantas termelétricas de tecnologia de geração similar instaladas no estado o Texas/USA. A Fig. 2.22 sumariza os resultados obtidos, os quais demonstraram que ciclos simples movidos a gás natural consumiam 55\% a mais de água quando utilizavam torres de resfriamento úmidas do que quando utilizavam sistemas de resfriamento once-through. Similarmente, ciclos combinados, também movidos a gás natural com torres de resfriamento úmidas, consumiam 92\% em relação aos sistemas once-through.

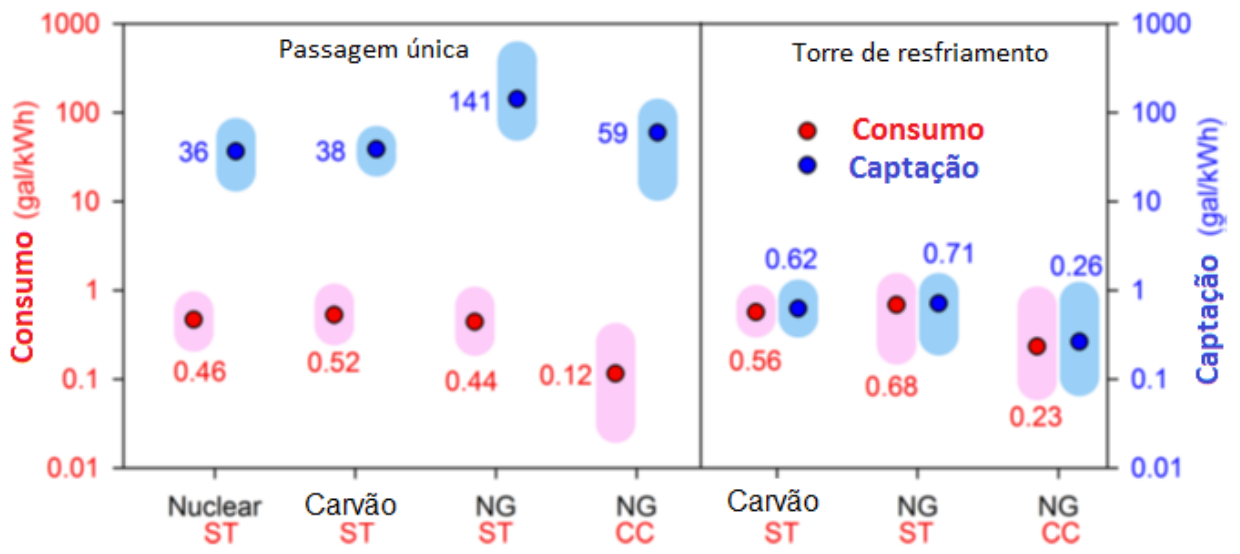

Figura 2.22 - Captação e consumo de água para diferentes tipos de centrais termelétricas de acordo com o tipo de combustível, geração e sistema de resfriamento. Fonte: Adaptado de Scanlon et al. (2013).

\subsubsection{Recuperação de água a partir dos GC em UTEs}

Um dos estudos experimentais mais relevantes e completos acerca do tema é o desenvolvido por Levy et al. (2011). Neste trabalho os autores avaliaram experimentalmente o processo de condensação e o desenvolvimento da tecnologia de troca de calor para recuperação de água presente nos GC em plantas termelétricas movidas a carvão mineral. $\mathrm{O}$ aparato experimental consistia de um duto retangular no interior do qual haviam trocadores de calor arranjados em série, no interior dos quais escoava água fria e os gases de combustão escoavam em contra-corrente na região externa destes tubos. O aparato foi instrumentado com medidores para aquisição das vazões de água de resfriamento e de gases de combustão, bem como com sensores para 
medição da temperatura destas correntes e das paredes dos tubos. Ao longo dos testes, foram coletadas amostras de condensado e avaliadas as concentrações presentes de ácido sulfúrico, ácido clorídrico, ácido nítrico e mercúrio. O esquema do aparato experimental extraído deste trabalho é apresentado na Fig. 2.23.

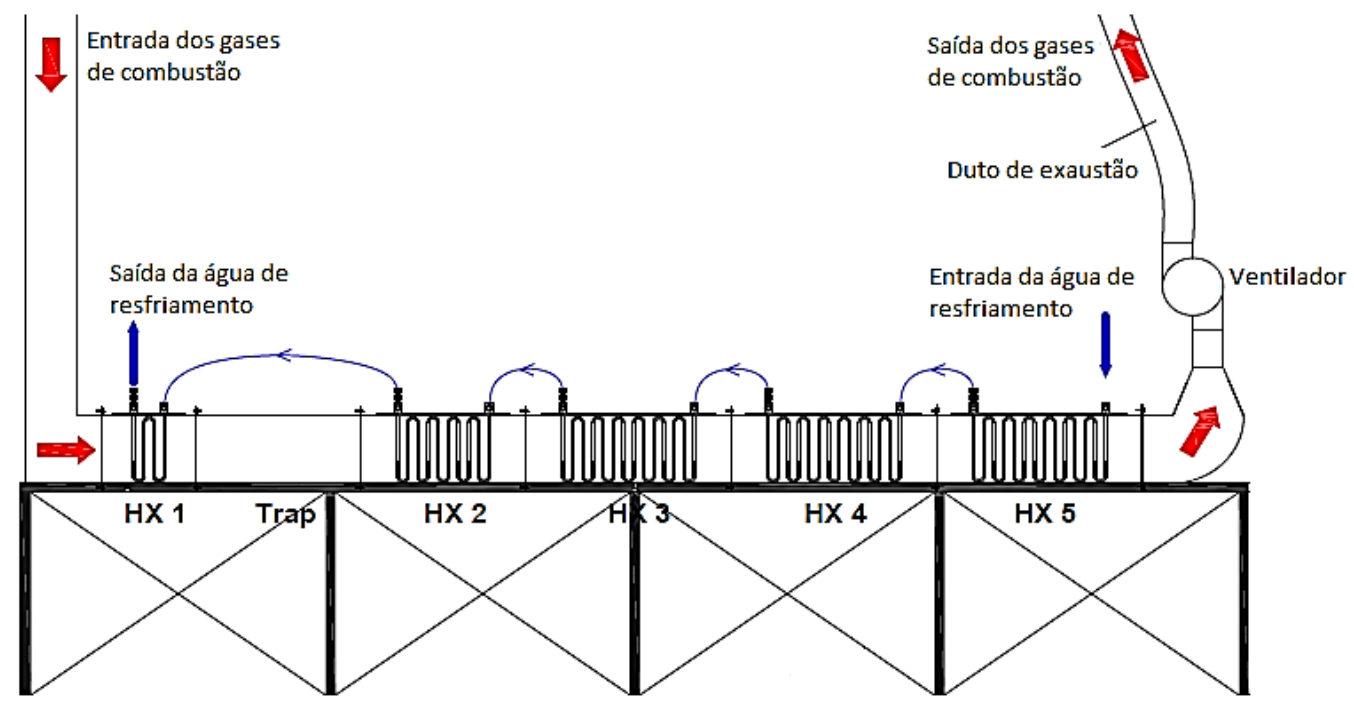

Figura 2.23 - Aparato experimental para condensação de gases de combustão. Fonte: Adaptado de Levy et al. (2011).

Os resultados apresentados pelo referido trabalho demonstraram forte dependência da quantidade total de calor transferida e da eficiência na captura de vapor de água com a vazão da água de resfriamento. A temperatura de entrada da água de resfriamento também teve forte impacto na eficiência da condensação do vapor de água. Para uma razão de 2,0 entre a vazão da água de resfriamento e a vazão dos gases de combustão foi observado que a eficiência aumentou de $44 \%$ para $71 \%$ quando a temperatura da água de resfriamento foi reduzida de $38^{\circ} \mathrm{C}$ para $24^{\circ} \mathrm{C}$. O experimento tratou de monitorar as concentrações de ácido sulfúrico que variaram entre 50 e 1800 $\mathrm{mg} / \mathrm{L}$, as concentrações de ácido clorídrico que variaram entre 0 e $100 \mathrm{mg} / \mathrm{L}$ e as concentrações de ácido nítrico entre 0 e $15 \mathrm{mg} / \mathrm{L}$. A porcentagem de mercúrio presente na fase vapor decresceu cerca de $60 \%$ desde a entrada até a saída do trocador de calor com a porcentagem de captura se elevando em função da redução da temperatura de saída dos gases de combustão. 
A quantidade de vapor de água presente nos gases de exaustão possui acentuada dependência do tipo de combustível empregado. Tomando-se como referência uma planta termelétrica abastecida por carvão pulverizado e operando com a geração de $600 \mathrm{MW}$, a quantidade de água produzida pode variar entre $103 \mathrm{~m}^{3} / \mathrm{h}$ e $295 \mathrm{~m}^{3} / \mathrm{h}$. Por outro lado, as taxas típicas de evaporação de água na torre de resfriamento, considerando a capacidade de geração desta planta, variam em torno de $953 \mathrm{~m}^{3} / \mathrm{h}$. Desta forma, caso esta planta fosse capaz de capturar toda a água existente nos gases de combustão e utilizá-la como reposição na torre de resfriamento, a mesma seria capaz de suprir de $10 \%$ a $33 \%$ da quantidade requerida (Levy et al., 2011).

São encontrados inúmeros estudos que abordam a separação água/GC por meio do emprego de sistemas de separação por membranas seletivas. Sijbesma et al. (2008) investigaram experimentalmente o potencial de duas tecnologias de membrana de desidratação diferentes, a PEBAX® 1074 e a SPEEK (sulfonated poly ether ether ketone). Neste estudo, os módulos de membrana foram expostos de forma direta a uma corrente artificial de gases de combustão, composta por $11,2 \%$ de água e o restante por $\mathrm{CO}_{2}$ e $\mathrm{N}_{2}$, sendo alcançadas taxas de remoção contínua de $0,6-1 \mathrm{~kg} / \mathrm{m}^{2}$.h ao longo de 150 horas de teste a $50^{\circ} \mathrm{C}$. Também foram executados ensaios em condições reais de operação em uma central termelétrica a carvão, em que se obteve, ao longo de um período $5300 \mathrm{~h}$, taxas de remoção de vapor de $0,2-0,46 \mathrm{~kg} / \mathrm{m}^{2} . \mathrm{h}$. Embora o fluxo decrescesse ao longo do tempo, devido deposição de particulados na superfície da membrana, o desempenho foi considerado adequado, contudo a água produzida não apresentava qualidade suficiente para ser reaproveitada diretamente no ciclo a vapor, mas poderia ser aproveitada, como água desmineralizada em outro setor da planta, como por exemplo, a torre de resfriamento. De acordo com os autores, a parcial remoção de vapor de água dos gases de exaustão advindos da turbina a gás, anteriormente à sua emissão para a atmosfera, resultaria em significativa economia de energia e melhoraria a eficiência global da planta. Existem diversas técnicas disponíveis para realização deste tipo de separação. Em geral, podem-se utilizar condensadores, sistemas dessecantes ou membranas poliméricas semipermeáveis. Os condensadores possuem a desvantagem de a água condensada ser relativamente suja e corrosiva, enquanto que sistemas dessecantes necessitam de constante regeneração do elemento dessecante, o que implicaria em elevação dos custos energéticos e geração de água de baixa qualidade. 
Metz et al. (2005) sumarizaram os valores de seletividade e permeabilidade, encontrados na literatura, para o transporte de vapor de água e nitrogênio através de membranas poliméricas, sendo verificado que os valores são dependentes do material utilizado na confecção da membrana. A partir da Fig. 2.24, construída pelos autores, observa-se que os materiais de interesse para o processo de desidratação do gás de exaustão se localizam na porção superior direita (área sombreada). A PEBAX® 1074 combina elevada permeabilidade do vapor de água $\left(1,6.10^{5}\right.$ Barrer $\left.^{6}\right)$ com moderada seletividade $\left(2.10^{5} \mathrm{H}_{2} \mathrm{O} / \mathrm{N}_{2}\right)$ e é comercialmente disponível, já a SPEEK apresenta valores bastante grandes, tanto de permeabilidade $\left(7.10^{4}\right.$ Barrer $)$ quanto de seletividade $\left(7.10^{7} \mathrm{H}_{2} \mathrm{O} / \mathrm{N}_{2}\right)$. Tecnologias que se utilizam de membranas semipermeáveis são eficientes do ponto de vista energético, uma vez que não há necessidade de mudança de fase para que ocorra o processo de separação, e confiáveis do ponto de vista operacional, já que não possuem partes móveis. O processo de separação permite a remoção seletiva do vapor de água presente na corrente de exaustão, produzindo água com elevado grau de pureza sem adição ou retirada de calor ao processo.

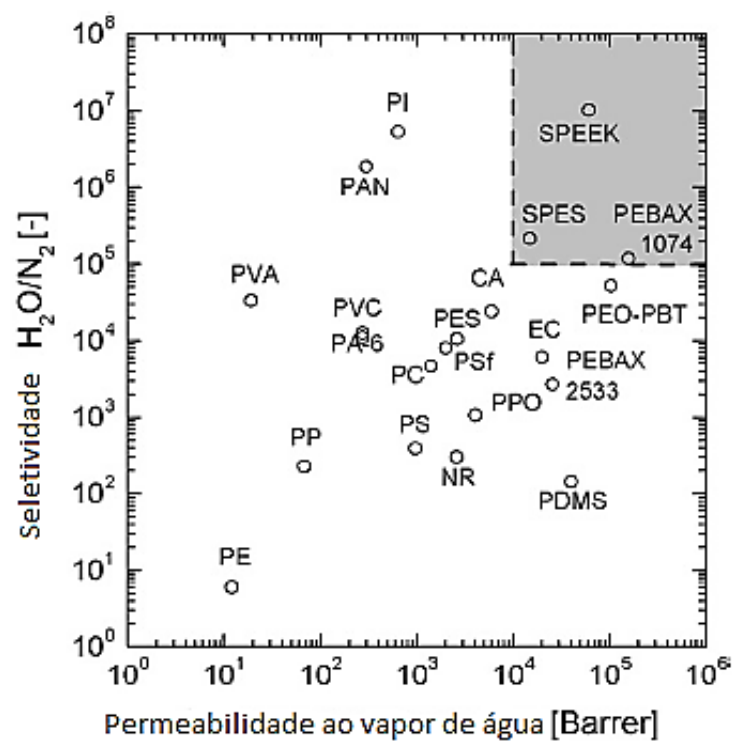

Figura 2.24 - Permeabilidade do vapor de água vs. seletividade $\mathrm{H}_{2} \mathrm{O} / \mathrm{N}_{2}$ de várias membranas poliméricas a $30^{\circ} \mathrm{C}$. Fonte: Adaptado de Metz et al. (2005).

Wang (2012) afirma que ainda não existem tecnologias aplicáveis em nível industrial, para recuperação tanto de calor residual como de água, posto que a

\footnotetext{
${ }^{6}$ Unidade específica de permeabilidade de gases em membranas poliméricas $\left[10^{-10} \frac{\mathrm{cm} s t p . c m}{\mathrm{~cm}^{2} . s . c m H g}\right]$.
} 
condensação dos componentes existentes nos gases de combustão, por meio da simples remoção de calor em um trocador de calor, possui limitações tais como a necessidade de elevadas áreas superficiais e a ocorrência de corrosão do equipamento decorrente da condensação de ácidos (caso de gases provenientes da queima de carvão mineral). Sendo assim, para que a água recuperada possa ser utilizada em outras partes do processo, há a necessidade de tratamento adicional no sentido de reduzir a quantidade de contaminantes presentes.

Brunetti et al. (2013) avaliaram experimentalmente um equipamento denominado por eles próprios de condensador de membranas para a recuperação de água descartada em gases industriais. O equipamento era constituído por membranas microporosas hidrofóbicas através das quais fluíam os gases. A água se condensava na superfície e era coletada, enquanto os demais componentes eram admitidos pela membrana seletiva. Cerca de $30 \%$ do vapor de água era recuperado quando a diferença de temperatura entre a membrana e a corrente dos gases era de $8^{\circ} \mathrm{C}$ e mais de $60 \%$ quando a diferença estabelecida era de $15^{\circ} \mathrm{C}$. Os autores demonstraram que a relação entre a vazão dos gases e a área da membrana é um fator fundamental no projeto da unidade.

\subsubsection{Condensação na presença de gases não condensáveis}

Em 1929, Donald Othmer foi o primeiro a estudar experimentalmente a condensação de vapor de água na presença de GNC. Em sua pesquisa, foi instalado um tubo de cobre, com água de resfriamento escoando em sem seu interior, dentro de uma pequena caldeira. Os resultados indicaram que à medida que as frações volumétricas de ar no interior da caldeira eram incrementadas desde 0 até $0,5 \%$, o coeficiente de transferência de calor superficial decrescia aproximadamente 50\%. Posteriormente, diversos pesquisadores avaliaram experimentalmente o processo de condensação de vapor de água na presença de diferentes tipos de gases, tais como nitrogênio, argônio, neônio e hidrogênio em superfícies horizantais ou verticais sob convecção forçada ou natural. Os resultados de todos estes estudos demonstram que qualquer quantidade de GNC, por menor que seja, causa considerável resistência ao processo de condensação (Huang et al., 2015). 
As análises teórico-numéricas dos processos de transferência de calor e massa no decorrer da condensação na presença de GNC têm sido usualmente tratadas por meio de duas abordagens distintas, quais sejam: análise de camada limite e analogias de transfererência de calor e massa (Martin-Vandepenas et al., 2005). Na primeira forma a região de transferência de calor e massa é analisada conforme as aproximações de camada limite, com emprego das equações diferenciais de conservação, cujas soluções são obtidas por meio de diferentes métodos, tais como similaridade, integral e numérico.

A segunda abordagem se baseia na obtenção dos coeficientes convectivos de transferência por meio de analogias de calor e de massa. Esta segunda metodologia, também conhecida como teoria de filme, possui maior facilidade de implementação, contudo, de acordo com Stephan (2006), quando o efeito de sucção é proeminente e desconsiderado no equacionamento, estima-se um fluxo de massa inferior ao real. $\mathrm{O}$ efeito de sucção ocasiona encolhimento da camada limite do gás decorrente da convecção transversal provocada pela absorção do vapor no líquido, o que por sua vez acentua os gradientes de pressão e de temperatura na região.

Rose (1968) desenvolveu um trabalho analítico baseado nas equações de conservação e de difusão de massa. O modelo considera o processo de condensação em uma placa vertical com escoamento por meio da gravidade de uma mistura de vapor e ar. Foi obtida uma solução aproximada, calculando-se o perfil de velocidades e de concentrações ao longo da camada de difusão. O autor realizou a comparação de sua solução aproximada com a solução exata obtida por Minkowycz e Sparrow (1966) com base no coeficiente de transferência de calor na condensação.

Lee e Rose (1984) obtiveram resultados repetitivos e precisos de coeficientes de transferência de calor para a condensação em regime de filme de vapor puro e mistura e vapor e gases não condensáveis escoando descendentemente ao redor de um único tubo horizontal. O principal objetivo deste estudo experimental foi validar os resultados do trabalho teórico de Rose (1980). Os parâmetros avaliados foram os seguintes: pressão (4 - $124 \mathrm{kPa})$, velocidade de entrada da fase gasosa $(0,3-26 \mathrm{~m} / \mathrm{s})$, fração mássica de gás $(0,02-32 \%)$.

Wang et al. (1988) aperfeiçoaram o modelo de Colburn e Hougen incorporando os efeitos da tensão de cisalhamento na interface líquido-vapor, com o objetivo de prever a influência de GNC nos coeficientes de transferência de calor no interior de um 
tubo vertical em escoamento turbulento de uma mistura de vapor de água e ar. Foi observado que os efeitos dos GNC eram mais pronunciados em dutos do que em locais não confinados, como por exemplo placas planas. A redução dos coeficientes de transferência de calor se acentuavam a baixas pressões, e conforme as velocidades de entrada da mistura gasosa decresciam os efeitos se tornavam cada vez mais pronunciados. Os resultados obtidos foram comparados com dados experimentais de Borishansky et al. (1977) observando-se boa concordância entre os mesmos.

O trabalho de Chan et al. (1990), apresenta os resultados de uma uma série de experimentos que complementaram e utilizaram o mesmo aparato experimental de Lim et al. (1984), incluindo os efeitos dos GNC na condensação de vapor de água. Foram realizados sessenta experimentos no total, os quais alternaram as frações mássicas de ar e as vazões de água e de ar. O aparato se trata de um condensador horizontal com entradas individuais de ar, vapor e água para resfriamento, Fig. 2.25.

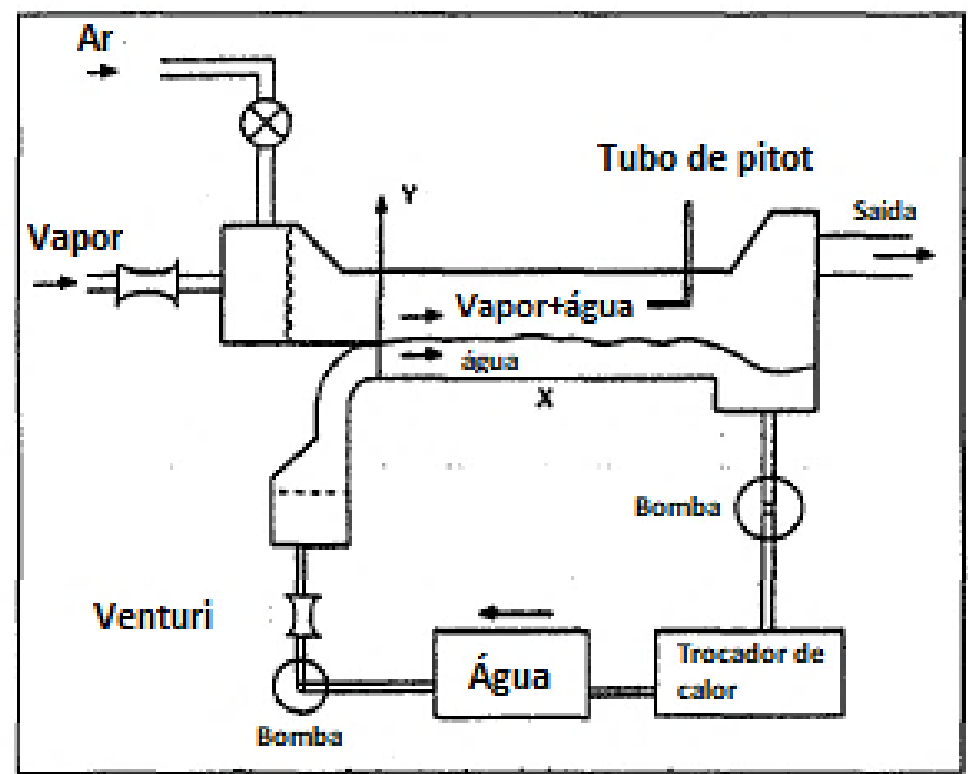

Figura 2.25 - Ilustração do aparato experimental utilizado por Chan et al. (1990). Fonte: Adaptado de Chan et al. (1990). 
$\mathrm{Na}$ Tabela 2.6 estão sumarizadas as condições experimentais adotadas no referido estudo.

Tabela 2.6 - Condições experimentais estabelecidas no trabalho de Chan et al. (1990). Adaptado de Chan et al., (1990).

\begin{tabular}{ccccccccc}
\hline Vazão de água (kg/s) & 1,0 & 1,36 & 0,7 & 1,0 & 1,36 & 0,7 & 1,0 & 1,0 \\
\hline Vazão de vapor (kg/s) & 0,065 & 0,065 & 0,09 & 0,09 & 0,09 & 0,13 & 0,13 & 0,16 \\
\hline & 0,02 & 0,02 & 0,02 & 0,02 & 0,02 & 0,02 & 0,02 & 0,02 \\
& 0,15 & 0,15 & 0,15 & 0,15 & 0,15 & 0,13 & 0,15 & 0,14 \\
Fração mássica de ar na & 0,55 & 0,58 & 0,55 & 0,57 & 0,55 & 0,36 & 0,55 & 0,57 \\
entrada (\%) & 1,5 & 1,4 & 1,5 & 1,4 & 1,5 & 1,6 & 1,5 & 1,36 \\
& 3,3 & 3,4 & 3,0 & 3,3 & 3,3 & - & - & - \\
\hline
\end{tabular}

Foi observado que, para as mesmas vazões de água e de vapor, a taxa de condensação decrescia conforme a vazão mássica de ar era elevada. Desta forma, a camada de ar acumulada na interface na porção final do condensador propiciava significante redução nas taxas de condensação. Tal efeito se mostrou mais pronunciado nas maiores frações mássicas de ar. A Fig. 2.26, extraída do trabalho em questão, demonstra a diminuição dos coeficientes locais de transferência de calor, estes proporcionais, sobretudo, ao decréscimo das taxas de condensação de vapor.

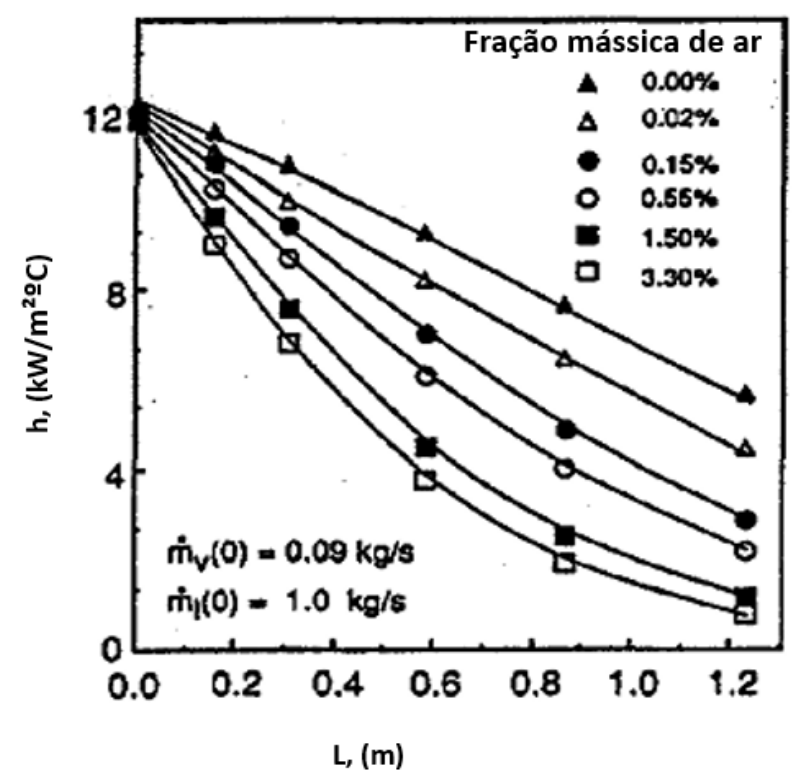

Figura 2.26 - Resultados dos coeficientes locais de transferência de calor em função das frações mássicas de ar de Chan et al. (1990). Fonte: Adaptado de Chan et al. (1990). 
Siddique et al. (1994) desenvolveram um modelo analítico para avaliar os efeitos de ar, hélio ou hidrogênio nos coeficientes de transferência de calor na condensação de vapor de água no interior de tubos. O modelo, de maneira geral, também seguiu a metodologia proposta por Colburn e Hougen, porém avaliou dois aspectos adicionais. $\mathrm{O}$ primeiro se trata do fato de que a maioria da transferência de calor que ocorre ao longo da condensação ocorre nos primeiros centímetros do condensador, onde o escoamento da fase gasosa não se encontra plenamente desenvolvido, ao contrário da hipótese originalmente estabelecida. Desta forma, a hipótese de escoamento plenamente desenvolvido guiaria a estimativas de menores coeficientes de transferência de calor em relação à realidade, o que viria a superdimensionar a área necessária para condensação. Em segundo lugar, ondulação e rugosidade do filme contribuem por aumentar os coeficientes de transferência de calor e de massa na fase gasosa. Os resultados obtidos por meio do modelo foram comparados com resultados experimentais de Siddique et al. (1993), tendo sido obtida boa concordância entre os mesmos, conforme pode ser observado nos gráficos da Fig. 2.27.
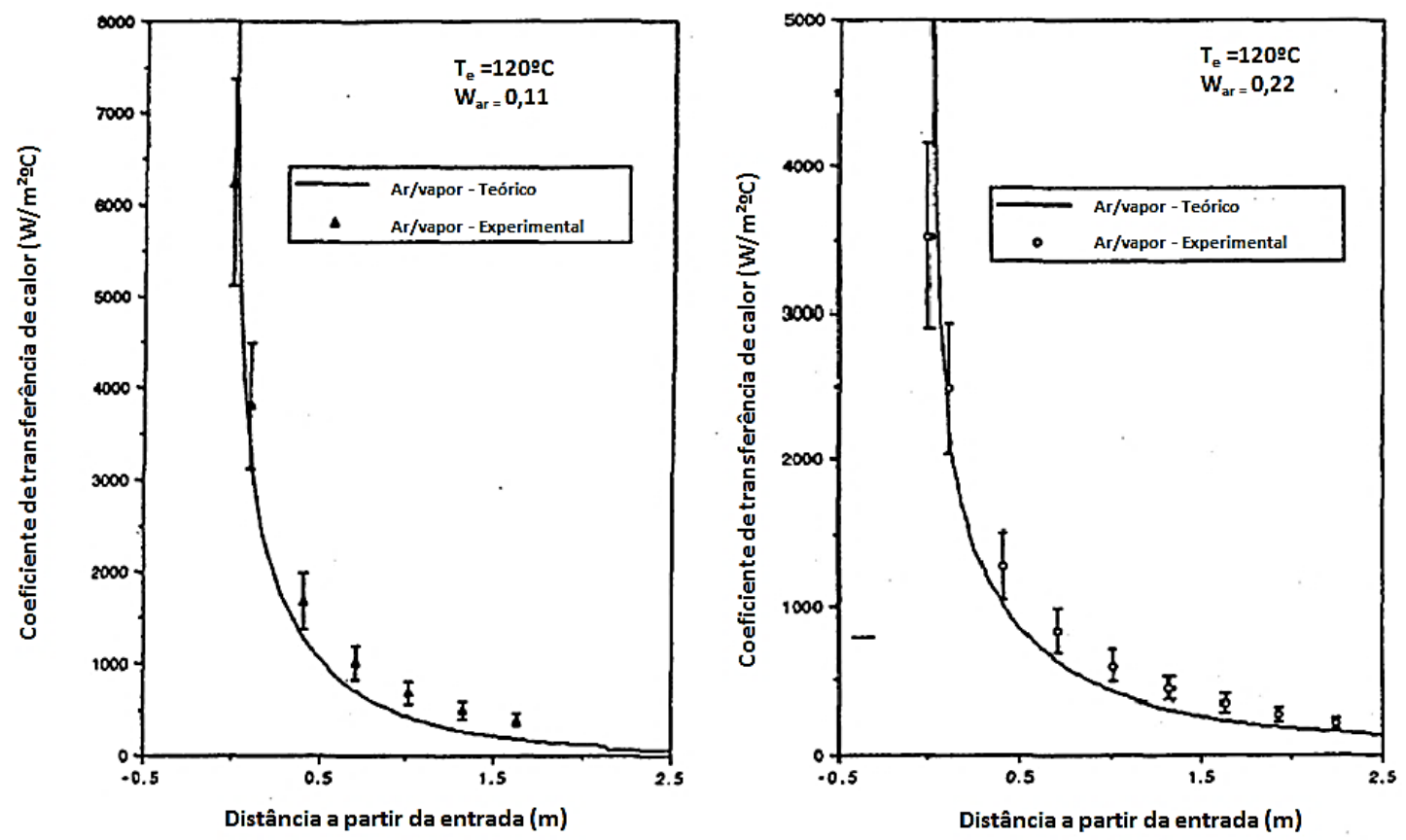

Figura 2.27 - Comparação entre os resultados numéricos e experimentais de Siddique et al. (1993) e Siddique et al. (1994), para frações mássicas de ar iguais a 0,11 e 0,22. Adaptado de Siddique et al. (1994).

Park et al. (1996) estudaram o efeito de ondulações na superfície do líquido condensado sobre a transferência de calor na presença de não condensáveis. Através dos 
testes realizados num duto retangular vertical, para uma dada concentração e velocidade de entrada da mistura, foi observado que o coeficiente de transferência de calor crescia com o aumento do número de Reynolds do líquido condensado, para o caso em que a resistência térmica dominante se localizava do lado do gás. Isso ocorre devido ao movimento dinâmico da superfície ondulada, que ajuda a dispersar a camada limite de gás que se sobrepõe ao condensado.

Jia et al (2001) conduziram estudos experimentais e numéricos com o intuito de avaliar o comportamento do coeficiente de transferência de calor na condensação de vapor de água na presença de grandes quantidades de ar, simulando os gases de combustão produzidos a partir da queima de gás natural. A mistura de gases escoava e o vapor de água condensava no interior um tubo vertical de $0,475 \mathrm{~m}$, com números de Reynolds que variavam de 2300 a 5000 . A região externa deste tubo era mantida em temperatura constante por meio do fluxo de água de resfriamento, que escoava no interior do revestimento que o envolvia. Os valores dos coeficientes de transferência de calor estimados a partir do modelo teórico se mostraram consistentes com os resultados experimentais. Cabe observar que o comprimento do condensador utilizado neste estudo era bastante pequeno se comparado aos comprimentos adotados em outros trabalhos. Adicionalmente, observou-se que os efeitos de sucção na entrada do tubo e de rugosidade interfacial não foram considerados no modelo numérico.

Maheshwari et al. (2004) obtiveram resultados numéricos, referentes ao processo de condensação de vapor de água na presença de uma fração mássica de ar de $27,8 \%$, pressão de $0,398 \mathrm{Mpa}$, vazão mássica de vapor igual a $0,0298 \mathrm{~kg} / \mathrm{s}$ e número de Reynolds de 85898, levando em consideração os efeitos de sucção e da rugosidade do filme líquido. Os autores simularam dois modelos distintos (McAdam e Blangetti). Os coeficientes de transferência de calor $h_{f}$ (filme líquido), $h_{\text {cond }}$ (condensação) e $h_{g}$ (fase gasosa), observados na Fig. 2.28 extraída do referido estudo, denotam o comportamento característico da condensação na presença de GNC, onde os maiores coeficientes de transferência de calor se concentram na região de origem do processo. A queda abrupta de $h_{c d}$, observada nos dois modelos simulados, está associada à ocorrência da maior parte da condensação logo nos primeiros metros do condensador. Os autores afirmam que os comportamentos evidenciados decorrem da natureza do processo de condensação na presença de GNC e da proeminência dos efeitos de sucção, que se concentram no início da condensação e elevam os coeficientes de transferência. Os resultados 
provenientes deste estudo, de forma semelhante aos demais, também indicaram que os coeficientes de transferência de calor e massa diminuíam drasticamente ao longo do condensador, porém os mesmos se elevavam proporcionalmente ao número de Reynolds da mistura.

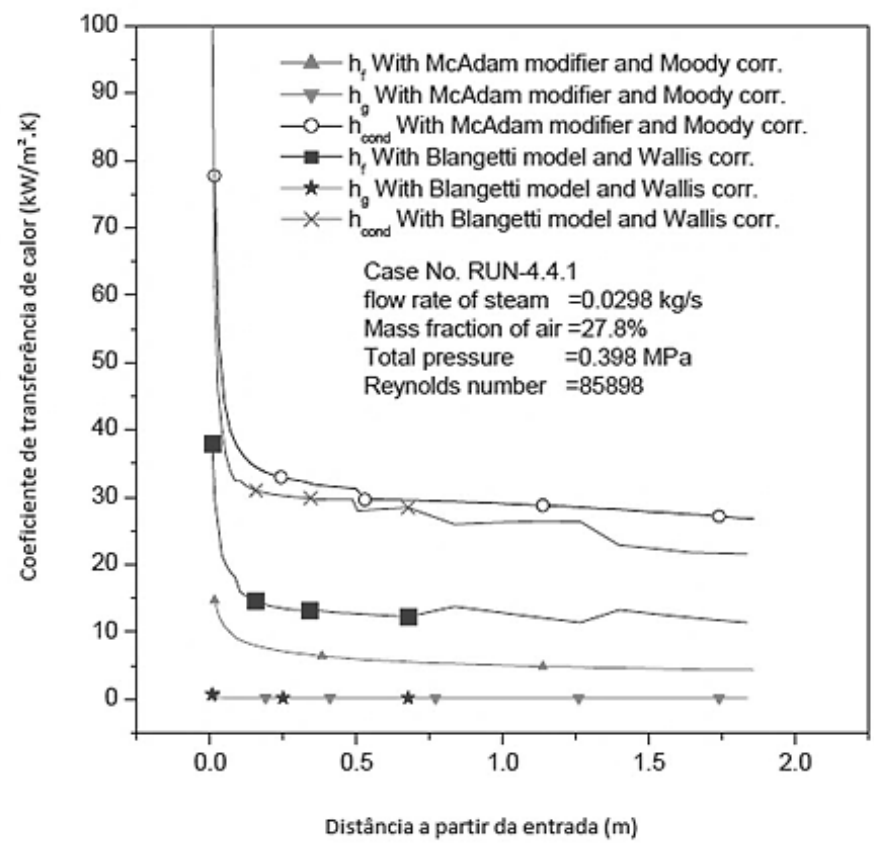

Figura 2.28 - Resultados de $h_{c d}, h_{f}$ e $h_{g}$ obtidos por Maheshwari et al. (2004). Fonte: Adaptado de Maheshwari et al. (2004).

A partir de uma abordagem numérica implícita totalmente acoplada, Siow et al. (2004) obtiveram resultados numéricos para o caso de condensação de película laminar a partir de misturas de vapor e ar em um canal de placas paralelas verticais. Foram estimados os números Nusselt e os coeficientes de transferência locais e médios, espessura da película de condensado e gradiente de pressão a partir de resultados numéricos para misturas de vapor e ar em amplos intervalos de quatro parâmetros independentes do sistema, tais como concentração de gás não condensável, número de Reynolds em fase gasosa, gradiente de pressão e a diferença entre as temperaturas da entrada e da parede.

Zhu et al. (2007) investigaram experimentalmente a condensação de misturas com altas concentrações de gases não condensáveis no interior de tubos. Os ensaios foram realizados para composições de mistura entre 34 e $81 \%$ de fração mássica de gases não condensáveis e para diferentes valores de velocidade variando de 1,08 a 
$10,8 \mathrm{~m} / \mathrm{s}$, com números de Reynolds entre 500 e 5000 . Concluiu-se que, para uma mesma concentração de GNC, com o incremento no número de Reynolds da mistura, a camada limite do gás que se sobrepõe a do líquido condensado é dispersada gradativamente e os coeficientes de transferência de calor aumentam até um comportamento estável, onde a camada limite do gás já não mais exerce influência no processo.

Dharma Rao et. al (2008) abordaram teoricamente o problema da condensação de vapor de água a partir de ar úmido em escoamento turbulento no interior de condutos verticais. Foram obtidos os números de Nusselt locais e médios, número de Reynolds do condensado, temperatura da interface líquido-ar e queda de pressão em face a diferentes parâmetros de entrada, tais como umidade relativa, temperatura, número de Reynolds da fase gasosa e pressão total do sistema. A umidade relativa da mistura na entrada do condensador variava de $50 \%$ a $100 \%$, o número de Reynolds era inferior a 2000 e as pressões eram situadas entre 0,5 e 2 bar. Os resultados indicaram que os coeficientes de transferência de calor e as taxas de condensação decresciam consideravelmente de acordo com a proporcção de GNC na mistura. Em contrapartida, os mesmos coeficientes e taxas de condensação aumentavam conforme maior era a pressão do sistema.

Lee e Kim (2008), realizaram um estudo experimental e analítico no qual investigaram o efeito de gases não condensáveis (nitrogênio em concentrações variando de 0 a 40\%) na condensação de vapor de água em um tubo de $13 \mathrm{~mm}$ de diâmetro e $2,8 \mathrm{~m}$ de comprimento. Os resultados demonstraram que a influência do nitrogênio nos coeficientes de transferência de calor é reduzida em tubos pequenos em virtude do estresse interfacial que ocorre nesses casos. A partir dos resultados deste estudo os autores obtiveram um adimensional de estresse interfacial.

Ambrosini et al. (2008) utilizaram o software de CFD FLUENT® para a simulação numérica do processo de condensação de uma mistura de ar e vapor de água em uma parede vertical isotérmica localizada no interior de um conduto quadrado. Os autores chegaram à conclusão de que o modelo apresentou boa aproximação com as correlações experimentais existentes, contudo identificou-se maiores erros em relação às taxas de condensação na região de entrada do conduto. 
Su et al. (2013) investigaram experimentalmente o processo de condensação em filme na presença de GNC sob a superfície externa de um tubo vertical. Os principais parâmetros avaliados foram o sub-resfriamento da parede, a pressão total do sistema e a fração mássica de não condensável (Hélio). Os resultados mostraram que os coeficientes de transferência na fase gasosa aumentavam proporcionalmente ao aumento da pressão, quando a fração de GNC era mantida constante.

Fu et. al (2016), desenvolveram um modelo CFD no simulador ANSYS Fluent para processos de condensação de vapor de água em tubos verticais em regime turbulento de escoamento na presença de ar e de hélio cujas porcentagens mássicas eram de $30 \%$ e $90 \%$ para ambos. Este estudo também levou em consideração os efeitos de sucção característicos deste tipo de processo. A partir da Fig. 2.29, retirada do referido estudo, pode-se constatar que ocorre redução muito mais acentuada e com o alcance de valores mais baixos, das curvas relativas ao ar do que nas curvas referentes ao hélio. Tal fato demonstra que existe maior resistência imposta pelo ar aos processos de transferência de calor e de massa. A influência da porcentagem dos componentes não condensáveis é também evidente nos resultados obtidos por Fu et. al (2016), uma vez que quando a porcentagens vapor são iguais a 30\%, as taxas de condensação de vapor iniciais são superiores a $0,15 \mathrm{~kg} / \mathrm{m}^{2}$ na presença de hélio, e de aproximadamente $0,045 \mathrm{~kg} / \mathrm{m}^{2}$ na presença de ar. Já quando as porcentagens de vapor são iguais a $90 \%$, observam-se taxas de condensação muito superiores - aproximadamente $1,6 \mathrm{~kg} / \mathrm{m}^{2}$ na presença de hélio e 0,4 na presença de ar. 

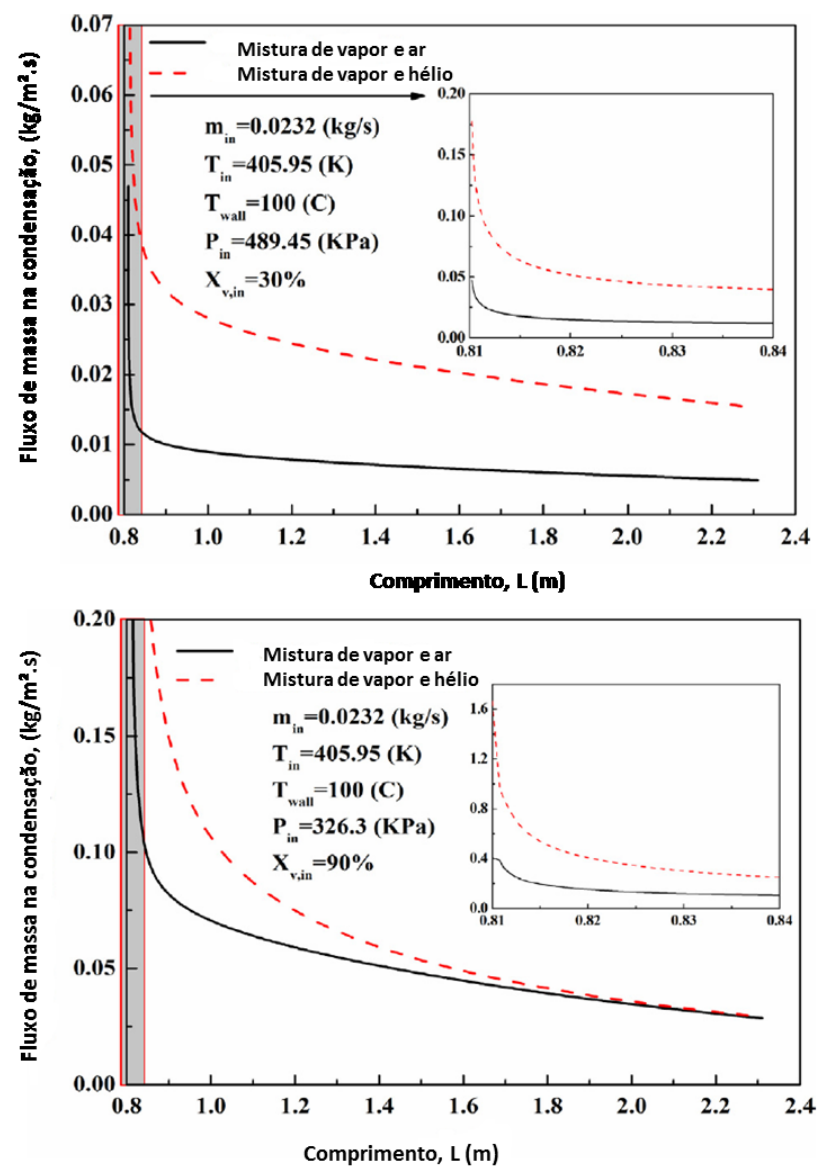

Figura 2.29 - Resultados de fluxo de condensação de Fu et al. (2016). Fonte: Adaptado de Fu et al. (2016).

Parte dos resultados deste trabalho também são apresentados também podem ser observados na Fig. 2.30, na qual se observa a relação estabelecida entre a fração mássica de vapor e os respectivos coeficientes de transferência de calor, os quais se reduzem acentuadamente com o aumento das frações de GNC.

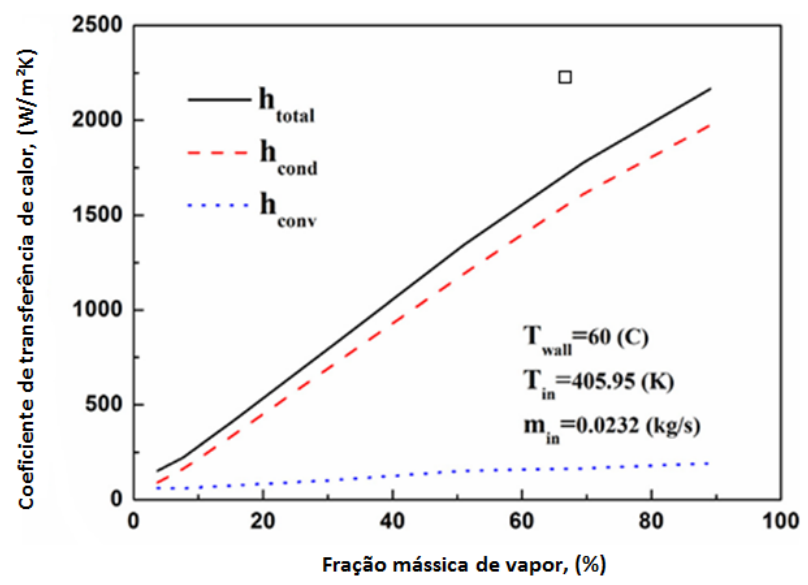

Figura 2.30 - Coeficientes locais de transferência de calor em função das frações mássicas de ar. Fonte: Fu et al. (2016). 


\section{Estimativa do potencial de produção de água em determinadas centrais termelétricas brasileiras}

\subsection{Método}

As estimativas das quantidades de água presente nos $\mathrm{GC}$, assim como dos demais componentes, são realizadas com base nas relações estequiométricas das reações elementares de combustão do gás natural e do carvão mineral. São consideradas as seguintes especificidades:

- Composição do combustível empregado;

- Tipo de ciclo de potência: combinado ou simples;

- Condições ambientais do local de operação (Umidade relativa e pressão atmosférica);

- Coeficientes de excesso de ar típicos de acordo com o tipo do ciclo de potência adotado.

A quantidade de água estimada é relacionada com a quantidade de energia produzida pela planta termelétrica por meio de seu consumo específico de combustível (CEC), cuja obtenção se dá a partir de parâmetros operacionais de cada tipo de UTE abordada. Da mesma forma que o consumo de água é usualmente expresso na forma de um fator de consumo $\left(\mathrm{m}^{3} / \mathrm{MWh}\right)$, a quantidade de água presente nos gases de combustão das UTEs também será expressa na forma de um "fator de produção" na mesma unidade.

De posse das quantidades de cada um dos componentes e da pressão total do sistema é possível estabelecer a pressão parcial do vapor de água na mistura gasosa e, assim, por fim, determinar sua temperatura de saturação na mistura.

O equacionamento e as hipóteses pertinentes para seu desenvolvimento são apresentados nas seções subsequentes. 


\subsubsection{Coeficiente de excesso de ar}

O cálculo da quantidade de água produzida pelo processo de combustão, assim como dos demais produtos, demanda a estimativa da quantidades mínima (teórica) e da quantidade real de ar envolvidas no processo. Conforme já bem consolidado tanto pela teoria como pela prática industrial, o meio mais simples de se atingir a combustão completa de determinado combustível se dá por meio do fornecimento de ar em excesso ao processo.

O coeficiente de excesso de ar pode ser definido pelas razões teórica e real entre ar e combustível, descritas, respectivamente por $f_{r}$ e $f_{t}$, conforme Eq. 3.1.

$$
\gamma=\frac{f_{r}}{f_{t}}
$$

O excesso de ar empregado é uma variável dependente das características do combustível e dos parâmetros construtivos e operacionais de equipamentos envolvidos no processo, especificamente o queimador, a fornalha, a câmara de combustão e a turbina a gás. Segundo Khartchenko e Kharchenko (2014) e Mazurenko et al. (2013) plantas que trabalham a partir da queima de carvão pulverizado, óleo combustível e gás para alimentação de caldeiras a vapor, adotam valores de $\gamma$ situados entre 1,03 e 1,1. Em fornalhas movidas a carvão bruto $\gamma$ se situa entre 1,3 e 1,6. Em câmaras de combustão de turbinas a gás, $\gamma$ atinge valores superiores a 2.

O número de mols de oxigênio necessários para a combustão completa de determinado número de mols de combustível é obtido por meio das relações estequiométricas da reação de combustão. Deste modo, os volumes teóricos mínimos de ar necessários para ocorrência da reação completa de gás natural e de carvão, são dados pelas Eqs. 3.2 e 3.3, respectivamente, tomando-se como referência as densidades dos componentes a $0^{\circ} \mathrm{C}$ e $101,32 \mathrm{kPa}$.

$$
V_{a, t}^{g n}=4,76\left[0,5\left(y_{H_{2}}+y_{C O}\right)+2 y_{C_{4}}+\sum\left(n+\frac{m}{4}\right) y_{C n H m}-y_{O_{2}}\right]
$$




$$
V_{a, t}^{c m}=8,89 x_{C}+26,47 x_{H}+3,33\left(x_{S}-x_{O}\right)
$$

Onde $y$ representa as frações volumétricas dos elementos constituintes do gás natural, e $x$ as frações mássicas dos componentes que compõem o carvão mineral.

\subsubsection{Quantificação dos produtos de combustão}

A estimativa da quantidade dos produtos de combustão considera a seguintes hipóteses descritas abaixo:

- Que a reação de combustão sempre ocorra na presença de excesso de ar $(\gamma>1)$ ou na condição estequiométrica $(\gamma=1)$;

- $\mathrm{O}$ ar de combustão seja composto exclusivamente por $\mathrm{O}_{2}(21 \%$ em volume) e $\mathrm{N}_{2}(79 \%$ em volume).

- Que o gás natural seja isento de enxofre e de umidade e que sua combustão produza exclusivamente $\mathrm{H}_{2} \mathrm{O}, \mathrm{N}_{2}, \mathrm{CO}_{2}$ e $\mathrm{O}_{2}$;

- As composições do carvão mineral utilizadas possuem relevantes quantidades de enxofre, portanto, considera-se que sua combustão produza $\mathrm{SO}_{2}$, além de $\mathrm{H}_{2} \mathrm{O}, \mathrm{N}_{2}, \mathrm{CO}_{2}$ e $\mathrm{O}_{2}$.

As massas molares dos componentes envolvidos em ambos os processos de combustão, bem como suas respectivas densidade na condição de referência adotada $\left(0^{\circ} \mathrm{C}\right.$ e $\left.101,32 \mathrm{kPa}\right)$, são apresentadas na Tabela 3.1 a seguir: 
Tabela 3.1 - Massa molecular e densidade $\left(0^{\circ} \mathrm{C}\right.$ e $\left.101,32 \mathrm{kPa}\right)$ dos componentes envolvidos nos processos de combustão de gás natural e carvão mineral. Fonte: Smith et al. (2000).

\begin{tabular}{ccc}
\hline Substância & $\begin{array}{c}\text { Massa molecular, MM } \\
(\mathbf{k g} / \mathbf{k g m o l})\end{array}$ & Densidade, $\boldsymbol{\rho}\left(\mathbf{k g} / \mathbf{m}^{\mathbf{3}}\right)$ \\
\hline Ar & 28,96 & 1,293 \\
Carbono & 12,01 & - \\
Hidrogênio & 2,016 & 0,090 \\
Nitrogênio & 28,16 & 1,257 \\
Oxigênio & 32,00 & 1,429 \\
Enxofre & 32,06 & - \\
Dióxido de carbono & 44,01 & 1,977 \\
Dióxido de enxofre & 64,06 & 2,931 \\
Vapor de água & 18,016 & 0,804 \\
Água líquida & 18,016 & 999,83 \\
\hline
\end{tabular}

Assim sendo, as quantidades dos constituintes presentes nos produtos de combustão podem ser calculadas a partir das relações estequiométricas apresentadas a seguir na Eqs (3.4) a (3.11):

- Vapor de água:

$$
\begin{gathered}
V_{v}^{g n}=y_{H_{2}}+2 y_{C_{H_{4}}}+0,5 m y_{C_{n} H_{m}}+1,6 \omega \gamma V_{a, t}{ }^{g n} \\
V_{v}^{c m}=11,1 x_{H}+1,24 M+1,24 \omega \gamma V_{a, t}{ }^{c m}
\end{gathered}
$$

- Nitrogênio:

$$
\begin{gathered}
V_{N_{2}}^{g n}=y_{N_{2}}+0,79 \gamma V_{a, t}^{g n} \\
V_{N_{2}}^{c m}=0,5 x_{N_{2}}+0,79 \gamma V_{a, t}^{c m}
\end{gathered}
$$


- Dióxido de carbono:

$$
\begin{gathered}
V_{\mathrm{CO}_{2}}^{g n}=y_{\mathrm{CO}_{2}}+y_{C O}+y_{\mathrm{CH}_{4}}+\sum n y_{C_{n} \mathrm{H}_{m}} \\
V_{C O_{2}}^{c m}=1,867 x_{C}
\end{gathered}
$$

- Oxigênio:

$$
V_{O_{2}}^{g n}=V_{O_{2}}^{c m}=0,21(\gamma-1) V_{a, t}
$$

- Dióxido de enxofre:

$$
V_{S O_{2}}^{c m}=0,84 x_{S}
$$

Nas equações (3.4) a (3.11), y e $x$ representam as frações volumétricas e mássicas dos elementos que constituem, respectivamente, o gás natural e o carvão mineral empregados em cada uma das unidades termelétricas selecionadas neste estudo. O termo " $M$ ", presente na Eq. 3.5, se refere à umidade presente no carvão mineral. As respectivas composições dos combustíveis são apresentadas nas Tabelas A1 e A2 disponibilizadas no Apêndice A.

Além da água produzida pela combustão propriamente dita, o equacionamento também leva em conta a parcela de vapor de água existente no ar atmosférico admitido no processo, sendo que esta é contabilizada por meio da umidade absoluta do ar $(\omega)$. A obtenção de $\omega$ é feita a partir das condições ambientais encontradas nas localidades da centrais termelétricas avaliadas. As Tabelas A3 e A4 localizadas no Apêndice A disponibilizam valores médios de pressão, temperatura e umidade relativa calculados a partir de dados brutos obtidos no site do INMET (2016). 


\subsubsection{Umidade absoluta do ar de combustão}

A umidade absoluta é determinada com base no exposto por Simões-Moreira (1999), que apresenta a definição de umidade absoluta como sendo a razão entre as massas de vapor de água e de ar seco presentes no ar:

$$
\omega=\frac{m_{v}}{m_{a}}
$$

Uma importante simplificação pode ser feita considerando-se a mistura de dois gases perfeitos por meio da lei de mistura de Dalton. Então, obtêm-se as Eqs. 3.13 e 3.14 .

$$
\begin{gathered}
m_{a}=\frac{P_{a} V}{R_{a} T} \\
m_{v}=\frac{P_{v} V}{R_{v} T}
\end{gathered}
$$

Onde $V$ é o volume da mistura, $T$ é a temperatura, $R_{a}$ e $R_{v}$ são as constantes particulares dos gases e $P_{a}$ e $P_{v}$ são suas pressões parciais na mistura. Deste modo, substituindo $m_{a}$ e $m_{v}$ na Eq. 3.15, encontra-se que:

$$
\omega=\frac{R_{a}}{R_{v}} \cdot \frac{P_{v}}{P_{a}}
$$

Porém, sabendo-se que as constantes particulares dos gases se relacionam com a chamada constante universal dos gases perfeitos, $\mathcal{R}$, por meio de: 


$$
R=\frac{\mathcal{R}}{M M}
$$

Sendo $M M$ a massa molecular do gás e $\mathcal{R}=8,314 \mathrm{~kJ} / \mathrm{kgmol} . \mathrm{K}$. Portanto, utilizando-se os valores das massa molares da água e do ar seco que constam na Tabela 3.1 , tem-se que:

$$
\omega=0,62198 \frac{P_{v}}{P_{a}}
$$

Uma vez que a pressão total da mistura, $P$, é dada pela soma das pressões parciais de seus componentes, $P_{a}$ e $P_{v}$, a Eq. 3.17 é melhor representada pela Eq. 3.18.

$$
\omega=0,62198 \frac{P_{v}}{P-P_{v}}
$$

O valor da pressão parcial do vapor da água, $P_{v}$, na mistura pode ser determinado por meio da umidade relativa, conforme descrito na seção seguinte.

\subsubsection{Umidade relativa do ar de combustão}

Segundo Simões-Moreira (1999) a umidade relativa é definida como a razão entre a fração molar do vapor de água presente na mistura, $N_{v}$, e a fração molar que o vapor de água teria se a mistura estivesse saturada, $N_{\text {sat }}$, à mesma temperatura e pressão total, ou seja:

$$
\phi=\frac{N_{v}}{N_{s a t}}
$$

Considerando a equação dos gases perfeitos, já apresentada, e a definição das frações molares do vapor de água: 


$$
\begin{gathered}
N_{v}=\frac{n_{v}}{n} \\
N_{\text {sat }}=\frac{n_{\text {sat }}}{n}
\end{gathered}
$$

Assim, tem-se que:

$$
\phi=\frac{P_{v}}{P_{\text {sat }}}
$$

A simplificação demonstra que a umidade relativa é dada pela razão entre a pressão parcial do vapor de água na mistura e a pressão parcial que o vapor exerceria se a mistura estivesse saturada à mesma temperatura e pressão total. Obviamente a umidade relativa varia entre 0 e 1 e, por isso, é usual o fornecimento destes valores em termos percentuais. Deste modo, quando $\phi=0 \%$ significa que o ar é seco e ausente de qualquer umidade, e quando $\phi=100 \%$ o ar é úmido e saturado.

A pressão de saturação, $P_{\text {sat }}$, pode ser obtida por meio de tabelas de vapor saturado ou por correlações disponibilizadas pela literatura, tal qual a Eq. 3.23 apresentada por Rao et al. (2008).

$$
P_{\text {sat }}=\exp \left(18,79-0,0075 T-\frac{5965,6}{T}\right)
$$

Sendo $T$ em Kelvin e $P_{\text {sat }}$ em bar.

\subsubsection{Frações volumétricas e temperatura de saturação}

Os volumes totais dos gases provenientes da combustão do gás natural e do carvão mineral são dados pelas Eqs. 3.24 e 3.25, respectivamente. 


$$
\begin{gathered}
V_{t o t, g n}=V_{v, g n}+V_{N_{2}, g n}+V_{C_{2}, g n}+V_{O_{2}, g n} \\
V_{t o t, c m}=V_{v, c m}+V_{N_{2}, \mathrm{~cm}}+V_{\mathrm{CO}_{2}, \mathrm{~cm}}+V_{\mathrm{SO}_{2}, \mathrm{~cm}}
\end{gathered}
$$

Considerando todos os gases presentes na mistura gases ideais, a pressão parcial do vapor pode ser definida como a relação entre seu volume e o volume total dos gases multiplicada pela pressão total do sistema $\left(P_{o}\right)$, conforme expresso pela Eq. 3.26.

$$
P_{v}=\frac{V_{v}}{V_{t o t}} P_{o}
$$

Assim, é possível, por meio da teoria apresentada, determinar qual a temperatura de saturação do vapor de água, levando-se em consideração sua pressão parcial na mistura gasosa. A temperatura de saturação pode ser determinada pela resolução da Eq. 3.23 em função da pressão de saturação $P_{\text {sat }}$.

\subsubsection{Consumo de combustível e fator de produção de água}

O desempenho de UTEs, sejam elas compostas por ciclos Rankine, Brayton ou por ciclo Combinado, pode ser descrito em termos dos seguintes parâmetros operacionais:

- Potência líquida, $P_{n e t}$;

- Potência elétrica, $P_{e l}$;

- Eficiência térmica, $\eta_{t h}$;

- Eficiência líquida, $\eta_{n e t}$;

- Eficiência elétrica, $\eta_{e l \text {; }}$

- Taxas de adição e rejeição de calor, $\dot{Q}_{a d}$ e $\dot{Q}_{r e j}$;

- Consumo de combustível, $\dot{m}_{c m}$ ou $\dot{V}_{g n}$;

- Consumo específico de combustível, CEC. 
A potência líquida, $P_{n e t}$, de uma UTE pode ser obtida através da taxa de adição de calor ao sistema e de sua eficiência líquida, conforme Eq. 3.27.

$$
P_{\text {net }}=\dot{Q}_{a d} \eta_{n e t}
$$

Determina-se a taxa de calor adicionada correspondente pela quantidade de calor produzida pelo processo de combustão e pela eficiência do mesmo, Eq. 3.28.

$$
\dot{Q}_{a d}=\dot{Q}_{c b} \eta_{c b}
$$

A energia liberada pela combustão é calculada através da vazão (volumétrica ou mássica) de combustível e do poder calorífico inferior do mesmo $(P C I)$, conforme Eqs. 3.29 e 3.30, relativas à combustão do carvão mineral e do gás natural, respectivamente.

$\mathrm{O} P C I$ é definido como a quantidade de calor entregue à vizinhança quando uma unidade de combustível, em condições de referência, é queimada completamente em regime permanente e a totalidade da água produzida pela combustão encontra no estado vapor (Lora e Do Nascimento, 2004). De acordo com Dos Santos et al. (2017) o valor do poder calorífico é determinado de modo experimental e quando a água formada durante o processo de combustão se encontra no estado líquido o mesmo é chamado de poder calorífico superior $(P C S)$, isso porque a parcela da entalpia de vaporização da água é contabilizada como disponível. No entanto, quando a parcela referente à entalpia de vaporização da água é subtraída do $P C S$, o valor do poder calorífico determinado é denominado poder calorífico inferior $(P C I)$. Observa-se que a diferença entre o $P C S$ e o $P C I$ é igual à entalpia de vaporização da água formada na combustão do hidrogênio presente no combustível e da sua umidade.

$$
\begin{gathered}
\dot{Q}_{c b}=\dot{m}_{c m} P C I_{c m} \\
\dot{Q}_{c b}=\dot{V}_{g n} P C I_{g n}
\end{gathered}
$$

A partir daí, pode-se determinar a potência elétrica da planta, Eq. 3.31. 


$$
P_{e l}=P_{n e t} \eta_{g}
$$

onde $\eta_{g}$ é a eficiência da conversão de trabalho de eixo em energia elétrica no gerador. O eixo da turbina a vapor ou a gás é acoplado ao eixo do gerador elétrico, fornecendo em seus terminais de saída a potência elétrica, $P_{e l}$. De forma geral, as perdas que ocorrem no gerador elétrico podem dividir-se em perdas nas bobinas de cobre do estator e do rotor e na magnetização do núcleo. Para geradores com arrefecimento a ar as eficiências típicas se situam ao redor 0,986 e para os arrefecidos por hidrogênio em torno de 0,990 (Mazurenko et al., 2013).

O consumo específico de combustível é definido como sendo vazão de combustível (volumétrica ou mássica) necessária para a produção de uma unidade de energia elétrica. Desta forma, o CEC pode ser obtido pela Eqs. 3.32 e 3.33 .

$$
\begin{aligned}
& C E C_{c m}=\frac{3600 \dot{m}_{c m}}{P_{e l}} \\
& C E C_{g n}=\frac{3600 \dot{V}_{g n}}{P_{e l}}
\end{aligned}
$$

As vazões de combustível são definidas indiretamente a partir das potências fiscalizadas de cada uma das unidades termelétricas compreendidas neste trabalho, conforme informações obtidas no BIG (2016). As eficiências líquidas admitidas para realização dos cálculos baseiam-se em valores típicos encontrados na literatura e sumarizados na Tabela 3.2. Evidentemente, os valores de eficiência admitidos podem não corresponder aos valores que de fato ocorrem em cada uma das UTEs avaliadas. Porém, esta informação não é disponibilizada, tampouco informada pelos operadores das UTEs. Desta forma, faz-se necessário recorrer a valores típicos correspondentes a cada tipo de ciclo, fornecidos pela literatura. 
Tabela 3.2 - Eficiências típicas dos três tipos genéricos de UTEs avaliadas. Fontes: Khartchenko e Kharchenko (2014), Mazurenko et al.(2013) e Lora e Do Nascimento (2004).

\begin{tabular}{cccc}
\hline Tipo da planta & $\begin{array}{c}\text { Khartchenko e } \\
\text { Kharchenko (2014) }\end{array}$ & $\begin{array}{c}\text { Mazurenko } \text { et al. } \\
\mathbf{( 2 0 1 3 )}\end{array}$ & $\begin{array}{c}\text { Lora e Do Nascimento } \\
\mathbf{( 2 0 0 4 )}\end{array}$ \\
\hline $\begin{array}{c}\text { Ciclos vapor a carvão } \\
\text { mineral } \\
\text { Ciclos simples a gás } \\
\text { natural }\end{array}$ & $42-45 \%$ & Máximo de $45 \%$ & $42-44,5 \%$ \\
$\begin{array}{c}\text { Ciclos combinados a gás } \\
\text { natural }\end{array}$ & $39-42 \%$ & $36-37 \%$ & $37,5-38,7 \%$ \\
\hline
\end{tabular}

Portanto, o consumo de combustível $\left(\dot{V}_{g n}, \dot{m}_{c m}\right)$ pode ser calculado pela Eq. 3.34.

$$
\dot{V}_{g n}=\dot{m}_{c m}=\frac{P_{e l}}{P C I \eta_{n e t} \eta_{g}}
$$

A partir da vazão de combustível pode-se estimar a vazão de água líquida contida nos gases de combustão, conforme Eqs. 3.35 e 3.36, para UTEs a gás natural e carvão mineral, respectivamente.

$$
\begin{gathered}
\dot{V}_{l, g n}=\dot{V}_{g n} V_{v, g n}\left(\frac{\rho_{v}}{\rho_{l}}\right) \\
\dot{V}_{l, c m}=\dot{m}_{c m} V_{v, c m}\left(\frac{\rho_{v}}{\rho_{l}}\right)
\end{gathered}
$$

Por meio do $C E C$ e do $V_{v}$, determina-se o fator de produção de vapor de água ( $\mathrm{m}^{3}$ vapor/MWh), conforme Eq. 3.37.

$$
V_{v}^{\prime}=V_{v} C E C
$$

Então, ao considerar as densidades do vapor e do líquido nas condições de referência adotadas, pode-se determinar o fator de produção de água no estado líquido, $V_{l}^{\prime}\left(\mathrm{m}^{3}\right.$ água/MWh), por meio da Eq. 3.38. Este parâmetro se torna relevante do ponto de 
vista comparativo, uma vez que a literatura, em geral, expressa as taxas de consumo e captação de água nas UTEs em termos do fator de consumo também em $\mathrm{m}^{3} / \mathrm{MWh}$ :

$$
V_{l}^{\prime}=V_{v}^{\prime}\left(\frac{\rho_{v}}{\rho_{l}}\right)
$$

Já o fator de produção em base mássica pode ser facilmente determinado multiplicando-se $V_{l}^{\prime}$ pela densidade da água no estado líquido. Ou seja:

$$
m_{l}^{\prime}=V_{l}^{\prime} \rho_{l}
$$

\subsection{Resultados e discussões parciais}

As estimativas propostas foram realizadas a partir do consumo de combustível e com base na potência fiscalizada, com referência a dados do BIG da Aneel (2016), de cada uma das UTEs selecionadas e conforme os equacionamentos realizados na seção precedente. Os resultados são expressos em função do coeficiente de excesso de ar $(\gamma)$ típico do ciclo de potência correspondente.

As UTEs selecionadas totalizam 14 plantas movidas a carvão mineral compostas por ciclos simples a vapor e 22 plantas movidas a gás natural, sendo 14 delas compostas por ciclos combinados e 8 por ciclos simples. Apesar das unidades movidas a gás natural compostas por ciclos simples não possuírem torres de resfriamento e, consequentemente, não apresentarem os mesmas taxas de consumo de água que plantas compostas por ciclos a vapor, entende-se ser relevante realizar as estimativas de produção de água também destas plantas.

As UTEs selecionadas são as seguintes:

- Carvão Mineral - Ciclos a vapor: Jorge Lacerda I, II, III e IV, Presidente Médice A e B, Candiota III, Porto de Itaqui, Pecém I e II, Porto do Açu, Seival, CTSul e Jacuí.

- Gás natural - Ciclos simples e combinados: Governador Leonel Brizola (Termorio), Santa Cruz, Mário Lago (Macaé Merchant), Norte Fluminense, 
Termopernambuco, Araucária, Fernando Gasparian (Nova Piratininga), Barbosa Lima Sobrinho (Eletrobolt), Camaçari, Termofortaleza, Jesus Soares Pereira (Termoaçu), Luiz Carlos Prestes, Aureliano Chaves (Ibiritermo), Termoceará, Euzébio Rocha ( CCBS), Willian Arjona, Celso Furtado (Termobahia), Rômulo Almeida (Fafen), Juiz de Fora, Sepé Tiarajú, AES Uruguaiana e Mário Covas (Termocuiabá).

\subsubsection{Consumo de combustível $\left(\dot{m}_{c m} e \dot{V}_{g n}\right)$, consumo específico de combustível $(C E C)$ e vazão de água nos GC $\left(\dot{V}_{l}\right)$}

Nas Tabelas 3.3 e 3.4 são apresentados o consumo de combustível $\left(\dot{m}_{c m} e \dot{V}_{g n}\right)$, consumo específico de combustível $(C E C)$ e as vazões de água (estado líquido, $\dot{V}_{l}$ ) produzidas em função coeficiente de excesso de ar empregado $(\gamma)$ e da potência fiscalizada de cada uma das UTEs selecionadas.

Para as UTEs a carvão mineral os cálculos foram efetuados com valores de $\gamma$ que variaram de 1,0 (condição estequiométrica) a 2,0. Pode-se observar que, uma vez abastecidas com o mesmo tipo de carvão mineral, as UTEs apresentam o mesmo valor de $C E C$, já que que admitiu-se um único valor de eficiência líquida para todas as plantas alimentadas por carvão mineral, no caso $\eta_{n e t}=43 \%$.

A UTE Porto do Açu, muito por conta de possuir a maior capacidade fiscalizada (2013MW), é unidade que apresenta o maior consumo absoluto de carvão, $\dot{m}_{c m}=177,37 \mathrm{~kg} / \mathrm{s}$, e os maiores vazões de água produzida $\left(\dot{V}_{l}\right)$, as quais variam de $0,1168 \mathrm{~m}^{3} / \mathrm{s}$, quando $\gamma=1$, e $0,1425 \mathrm{~m}^{3} / \mathrm{s}$, quando $\gamma=2,0$. No entanto, esta unidade juntamente com Porto de Itaqui, Pecém I e Pecém II, exibe o menor consumo específico de combustível, o que se deve ao maior valor de $P C I$ do carvão mineral que abastece estas quatro plantas $(26,40 \mathrm{~kJ} / \mathrm{kg})$.

Por outro lado, as UTEs Jorge Lacerda I e II, cujas potências fiscalizadas são as menores dentre as avaliadas, foram as unidades que apresentaram os menores consumos de carvão $\left(\dot{m}_{c m}=28,60 \mathrm{~kg} / \mathrm{s}\right)$ e os menores valores de $\dot{V}_{l}, 0,0135 \mathrm{~m}^{3} / \mathrm{s}$ e $0,0155 \mathrm{~m}^{3} / \mathrm{s}$, para $\gamma$ igual a 1 e 2 , respectivamente.

Quanto às UTEs movidas a gás natural, os cálculos foram realizados para valores de $\gamma$ que variaram de 2 a 4, não levando-se em conta a condição estequiométrica de combustão. Adotou-se $\eta_{n e t}=40 \%$ para as UTEs de ciclo simples e $\eta_{n e t}=60 \%$ para 
as UTEs de ciclo combinado. Observa-se por meio da Tabela 3.4, que as unidades compostas por ciclos simples apresentam valores $C E C$ muito superiores se comparados aos valores encontrados para a plantas compostas por ciclos combinados, o que se deve à diferença entre as eficiências adotadas para cada tipo de ciclo e principalmente pela capacidade de ciclos combinados aproveitarem os gases de exaustão a elevadas temperaturas da turbina a gás para alimentação do ciclo Rankine, elevando a potência gerada a partir da mesma quantidade consumida de gás natural. Isso se forem desconsideradas eventuais queimas suplementares na caldeira de recuperação.

Verifica-se que a UTE Mário Lago, uma unidade constituída por ciclos simples com vinte turbinas a gás, apesar de não possuir a maior capacidade dentre as plantas avaliadas $(880 \mathrm{MW})$, é a que possui o maior $C E C\left(0,2320 \mathrm{~m}^{3} / \mathrm{kWh}\right)$, o maior consumo absoluto de gás natural $\left(56,70 \mathrm{~m}^{3} / \mathrm{s}\right)$ e as maiores vazões de água nos gases de combustão, com valores situados entre $0,1103 \mathrm{~m}^{3} / \mathrm{s}$ para $\gamma=2,0$, e $0,1291 \mathrm{~m}^{3} / \mathrm{s}$ para $\gamma=4,0$.

Dentre as unidades compostas por ciclos simples movidas a gás natural, a UTE Juiz de Fora de 88MW - planta de menor capacidade avaliada - possui os menores resultados de consumo e consumo específico de combustível, $5,67 \mathrm{~m}^{3} / \mathrm{s}$ e $0,2320 \mathrm{~m}^{3} / \mathrm{kWh}$. As vazões de água encontradas para esta planta variam entre $0,0113 \mathrm{~m}^{3} / \mathrm{s}$ e $0,0131 \mathrm{~m}^{3} / \mathrm{s}$. 
Tabela 3.3 - Consumo e consumo específico de carvão mineral e vazões de água produzida pelas UTEs movidas a carvão mineral.

\begin{tabular}{|c|c|c|c|c|c|c|c|c|c|}
\hline \multirow[b]{2}{*}{ UTE } & \multirow[b]{2}{*}{$C E C_{c m}(\mathrm{~kg} / \mathrm{kWh})$} & \multirow{2}{*}{$\begin{array}{c}\text { Potência } \\
\text { fiscalizada } \\
\text { (MW) }\end{array}$} & \multirow[b]{2}{*}{$\begin{array}{l}\dot{m}_{c m} \\
(\mathrm{~kg} / \mathrm{s})\end{array}$} & \multicolumn{6}{|c|}{$\dot{V}_{l}\left(\mathrm{~m}^{3} / \mathrm{s}\right)$} \\
\hline & & & & $\gamma=1,0$ & $\gamma=1,1$ & $\gamma=1,2$ & $\gamma=1,4$ & $\gamma=1,8$ & $\gamma=\mathbf{2 , 0}$ \\
\hline Jorge Lacerda I e II & 0,444 & 232 & 28,60 & 0,0135 & 0,0137 & 0,0139 & 0,0143 & 0,0151 & 0,0155 \\
\hline Jorge Lacerda III & 0,444 & 262 & 32,29 & 0,0152 & 0,0155 & 0,0157 & 0,0162 & 0,0171 & 0,0176 \\
\hline Jorge Lacerda IV & 0,444 & 363 & 44,74 & 0,0211 & 0,0214 & 0,0217 & 0,0224 & 0,0237 & 0,0243 \\
\hline Presidente Médici A e B & 0,605 & 446 & 74,90 & 0,0258 & 0,0261 & 0,0264 & 0,0270 & 0,0282 & 0,0288 \\
\hline Candiota III & 0,605 & 350 & 58,78 & 0,0202 & 0,0205 & 0,0207 & 0,0212 & 0,0221 & 0,0226 \\
\hline Porto de Itaqui & 0,317 & 360 & 31,72 & 0,0209 & 0,0213 & 0,0218 & 0,0227 & 0,0246 & 0,0255 \\
\hline Pecém I & 0,317 & 720 & 63,44 & 0,0418 & 0,0427 & 0,0436 & 0,0455 & 0,0491 & 0,0510 \\
\hline Pecém II & 0,317 & 365 & 32,16 & 0,0212 & 0,0216 & 0,0221 & 0,0230 & 0,0249 & 0,0258 \\
\hline Porto do Açu & 0,317 & 2013 & 177,37 & 0,1168 & 0,1194 & 0,1219 & 0,1271 & 0,1373 & 0,1425 \\
\hline Seival & 0,605 & 540 & 90,69 & 0,0293 & 0,0296 & 0,0300 & 0,0307 & 0,0320 & 0,0327 \\
\hline CTSUL & 0,571 & 650 & 103,07 & 0,0385 & 0,0389 & 0,0393 & 0,0402 & 0,0419 & 0,0428 \\
\hline Jacuí & 0,618 & 350 & 60,05 & 0,0170 & 0,0173 & 0,0175 & 0,0181 & 0,0191 & 0,0196 \\
\hline
\end{tabular}


Tabela 3.4 - Consumo e consumo específico de gás natural e vazões de água produzida pelas UTEs movidas a gás natural.

\begin{tabular}{|c|c|c|c|c|c|c|c|c|c|c|}
\hline \multirow[b]{2}{*}{ UTE } & \multirow{2}{*}{$\begin{array}{l}\text { Tipo de } \\
\text { Ciclo }\end{array}$} & \multirow{2}{*}{$\begin{array}{c}C E C_{g n} \\
\left(\mathrm{~m}^{3} / \mathbf{k W h}\right)\end{array}$} & \multirow{2}{*}{$\begin{array}{c}\mathbf{N}^{\mathbf{o}} \text { Turbinas a } \\
\text { Gás }\end{array}$} & \multirow{2}{*}{$\begin{array}{c}\text { Potência } \\
\text { Nominal } \\
\text { (MW) }\end{array}$} & \multirow{2}{*}{$\begin{array}{c}\text { Potência } \\
\text { fiscalizada } \\
\text { (MW) }\end{array}$} & \multirow{2}{*}{$\begin{array}{c}\dot{V}_{g n} \\
\left(\mathbf{m}^{3} / \mathbf{s}\right)\end{array}$} & \multicolumn{4}{|c|}{$\dot{V}_{l}\left(\mathrm{~m}^{3} / \mathrm{s}\right)$} \\
\hline & & & & & & & $\gamma=\mathbf{2 . 0}$ & $\gamma=2,7$ & $\gamma=3,4$ & $\gamma=4$ \\
\hline $\begin{array}{c}\text { Governador Leonel } \\
\text { Brizola }\end{array}$ & Combinado & 0,0927 & 6 & 105,7 & 1058 & 27,24 & 0,0531 & 0,0564 & 0,0596 & 0,0624 \\
\hline Santa Cruz & Combinado & 0,0513 & 2 & 166 & 1000 & 14,26 & 0,0277 & 0,0294 & 0,0311 & 0,0325 \\
\hline Mário Lago & Simples & 0,2320 & 20 & 44 & 880 & 56,70 & 0,1103 & 0,1169 & 0,1235 & 0,1291 \\
\hline Norte Fluminense & Combinado & 0,0909 & 3 & 170 & 868 & 21,91 & 0,0426 & 0,0452 & 0,0477 & 0,0499 \\
\hline TermoPernambuco & Combinado & 0,1035 & 2 & 160 & 533 & 15,33 & 0,0349 & 0,0376 & 0,0402 & 0,0425 \\
\hline Araucária & Combinado & 0,1022 & 2 & 160 & 484 & 13,75 & 0,0266 & 0,0278 & 0,0290 & 0,0300 \\
\hline Fernando Gasparian & Combinado & 0,1276 & 4 & 105,7 & 560 & 19,85 & 0,0387 & 0,0406 & 0,0425 & 0,0442 \\
\hline $\begin{array}{l}\text { Barbosa Lima } \\
\text { Sobrinho }\end{array}$ & Simples & 0,2320 & 8 & 47,5 & 380 & 24,48 & 0,0481 & 0,0511 & 0,0541 & 0,0566 \\
\hline Camaçari & Simples & 0,2320 & 5 & 70 & 350 & 22,55 & 0,0462 & 0,0495 & 0,0527 & 0,0554 \\
\hline Termofortaleza & Combinado & 0,1149 & 2 & 115 & 346 & 11,05 & 0,0227 & 0,0243 & 0,0259 & 0,0272 \\
\hline Jesus Soares Pereira & Simples & 0,2320 & 1 & 171 & 171 & 11,02 & 0,0226 & 0,0242 & 0,0258 & 0,0272 \\
\hline Luiz Carlos Prestes & Combinado & 0,1042 & 4 & 65 & 386 & 11,17 & 0,0228 & 0,0242 & 0,0256 & 0,0268 \\
\hline Aureliano Chaves & Combinado & 0,1170 & 1 & 171 & 226 & 7,35 & 0,0144 & 0,0151 & 0,0158 & 0,0165 \\
\hline Termoceará & Simples & 0,2594 & 8 & 30 & 240 & 17,29 & 0,0355 & 0,0380 & 0,0405 & 0,0426 \\
\hline Euzébio Rocha & Combinado & 0,1021 & 1 & 165 & 249,9 & 7,09 & 0,0145 & 0,0154 & 0,0163 & 0,0171 \\
\hline William Arjona & Simples & 0,2320 & 5 & 40 & 200 & 12,89 & 0,0261 & 0,0276 & 0,0291 & 0,0305 \\
\hline Celso Furtado & Combinado & 0,0653 & 1 & 190 & 450 & 8,16 & 0,0167 & 0,0179 & 0,0191 & 0,0201 \\
\hline Rômulo Almeda & Combinado & 0,0942 & 3 & 28 & 137,9 & 3,61 & 0,0074 & 0,0079 & 0,0084 & 0,0089 \\
\hline Juiz de Fora & Simples & 0,2320 & 2 & 44 & 88 & 5,67 & 0,0113 & 0,0119 & 0,0125 & 0,0131 \\
\hline Sepé Tiaraju & Combinado & 0,1500 & 1 & 161 & 249 & 10,37 & 0,0206 & 0,0217 & 0,0228 & 0,0238 \\
\hline AES Uruguaiana & Combinado & 0,0758 & 2 & 170 & 693,9 & 14,60 & 0,0291 & 0,0307 & 0,0323 & 0,0336 \\
\hline Mario Covas & Combinado & 0,0966 & 2 & 150 & 480 & 12,89 & 0,0267 & 0,0285 & 0,0302 & 0,0317 \\
\hline
\end{tabular}


As UTEs de ciclo combinado, em virtude de possuírem valores maiores de eficiência, apresentam menores valores de consumo específico de combustível em relação à centrais de ciclos simples. As UTEs Governador Leonel Brizola e Santa Cruz são as unidades de maior potência fiscalizada, ambas compostas por ciclos combinados, de $1058 \mathrm{MW}$ e $1000 \mathrm{MW}$ de potência, cujos valores de $\dot{V}_{l}$ variam de $0,0531 \mathrm{~m}^{3} / \mathrm{s}$ a $0,0624 \mathrm{~m}^{3} / \mathrm{s}$ e de $0,0277 \mathrm{~m}^{3} / \mathrm{s}$ a $0,0325 \mathrm{~m}^{3} / \mathrm{s}$, para Governador Leonel Brizola e Santa Cruz, respectivamente.

Nota-se que, embora as UTEs Governador Leonel Brizola e Santa Cruz sejam plantas que possuem potências semelhantes, os resultados de $\dot{V}_{l}, C E C_{g n}$ e $\dot{V}_{g n}$ são bastante distintos. Tal diferença se justifica por conta do número de turbinas a gás que compõem cada uma das unidades. Segundo informações da Turbine Inlet Cooling Association (TICA, 2016), a UTE Governador Leonel Brizola possui, em seu ciclo Brayton, seis turbinas a gás modelo GT11-N2 da Alstom, cuja capacidade nominal é 105,7MW e a UTE Santa Cruz duas turbinas a gás modelo SW 501-FD da Siemens de capacidade nominal de $166 \mathrm{MW}$. Desta forma, como feito em todo o equacionamento das demais UTEs de ciclo combinado, admite-se que na UTE Governador Leonel Brizola o ciclo Brayton é responsável pela geração de aproximadamente $634 \mathrm{MW}$ e o ciclo Rankine pelo restante da potência fiscalizada, ou seja 424MW. Da mesma forma, na UTE Santa Cruz 332MW são originados pelo ciclo Brayton e 668MW pelo Rankine. Portanto, como os cálculos são efetuados considerando apenas o consumo de combustível correspondente a geração nas turbinas a gás e não contabilizam eventuais queimas suplementares nas caldeiras de recuperação para geração de vapor no ciclo Rankine, verifica-se que os números relativos ao consumo de combustível e, consequentemente, de produção de água, são maiores na unidade de maior potência associada ao ciclo Brayton, no caso a UTE Governador Leonel Brizola.

Em suma, constata-se que a vazão de água produzida pela combustão em UTEs, além de estar associada às características do combustível empregado, ao coefciente de excesso de ar adotado e às condições ambientais do local de operação, depende principalmente da potência gerada pela planta, que por sua vez determina seu consumo de combustível. Além disso, no caso de ciclos combinados, a distribuição de potência entre os ciclos Rankine e Brayton, afeta diretamente a quantidade de vapor de água produzida e contida nos GC. 


\subsubsection{Fator de produção de produção de água $\left(V_{l}^{\prime}\right)$}

A seguir, na Fig. 3.1 são apresentados os resultados do fator de produção de água de cada uma das UTEs a carvão mineral avaliadas, em função do coeficiente de excesso de ar, $\gamma$, que no caso varia de 1 a 2.

Os resultados se situam entre, aproximadamente, $0,180 \mathrm{~m}^{3} / \mathrm{MWh}$ e $0,210 \mathrm{~m}^{3} / \mathrm{MWh}$, quando $\gamma=1$, e entre $0,200 \mathrm{~m}^{3} / \mathrm{MWh}$ e $0,260 \mathrm{~m}^{3} / \mathrm{MWh}$, quando $\gamma=2$. A UTE Jacuí é a unidade que apresenta os menores valores, os quais se situam entre 0,175 $\mathrm{m}^{3} / \mathrm{MWh}$ e 0,202 $\mathrm{m}^{3} / \mathrm{MWh}$. Em contrapartida, as UTEs Porto de Itaqui $\left(0,209 \mathrm{~m}^{3} / \mathrm{MWh}\right.$ a $\left.0,255 \mathrm{~m}^{3} / \mathrm{MWh}\right)$ e Pecém I e II $\left(0,210 \mathrm{~m}^{3} / \mathrm{MWh}\right.$ a $\left.0,256 \mathrm{~m}^{3} / \mathrm{MWh}\right)$ são plantas que possuem o maior fator de produção de água.

A UTE CTSul apesar de também possuir valores de $V_{l}^{\prime}$ próximos de $0,210 \mathrm{~m}^{3} / \mathrm{MWh}$ quando $\gamma=1$, não demonstra o mesmo crescimento a com o aumento de $\gamma$, apresentando valores de $V_{l}^{\prime}$ em torno de $0,230 \mathrm{~m}^{3} / \mathrm{MWh}$ quando $\gamma=4$.

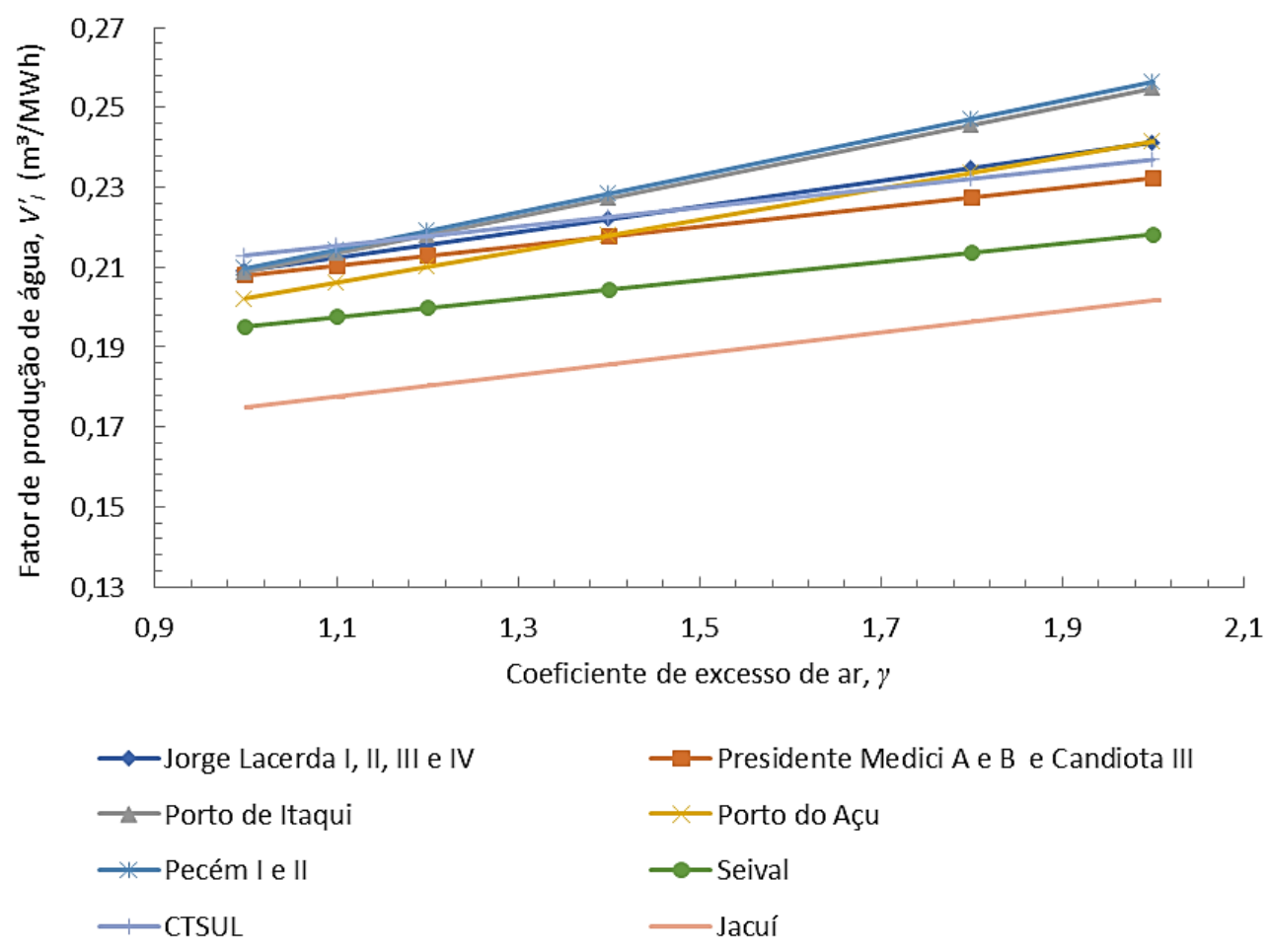

Figura 3.1 - Fator de produção de água, $V_{l}{ }_{l}$, das UTEs movidas a carvão mineral avaliadas. 
Na Fig. 3.2 são apresentados os gráficos referentes ao fator de produção das UTEs movidas a gás natural, cujos coeficientes $\gamma$ variam de 2 a 4 .

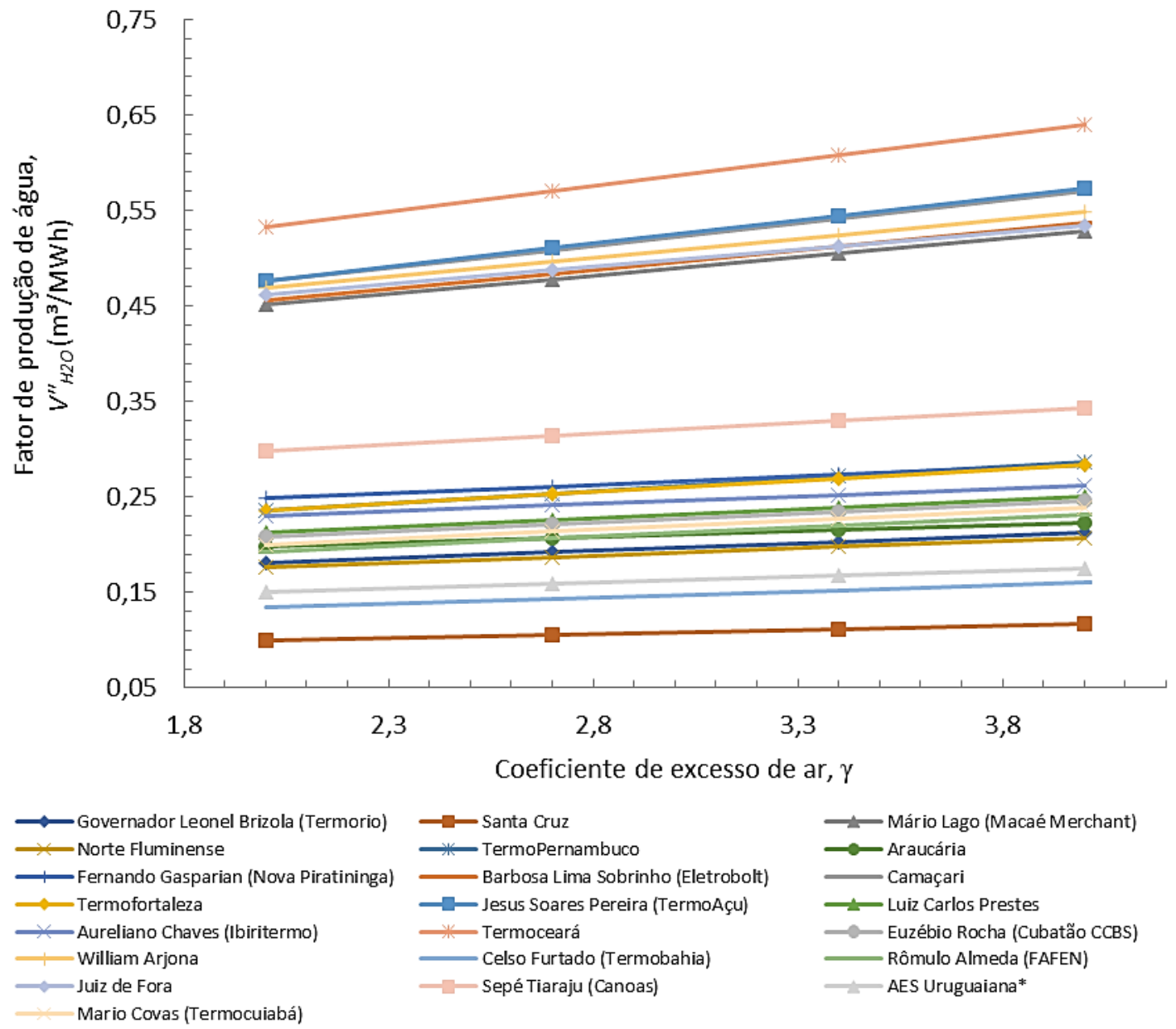

Figura 3.2 - Fator de produção de água, $V_{l}$, das UTEs movidas a gás natural avaliadas.

Os gráficos evidenciam maior amplitude entre os resultados das plantas movidas a gás natural em relação aos resultados das plantas a carvão, visto que, quando $\gamma=2$, os valores se situam entre, aproximadamente, $0,100 \mathrm{~m}^{3} / \mathrm{MWh}$ e $0,550 \mathrm{~m}^{3} / \mathrm{MWh}$ e quando $\gamma=4$, se situam entre $0,125 \mathrm{~m}^{3} / \mathrm{MWh}$ e $0,650 \mathrm{~m}^{3} / \mathrm{MWh}$. Isso se deve à maior diferença do valor de $C E C_{g n}$ que ocorre entre as UTEs de ciclo simples (valores em torno de $0,23 \mathrm{~m}^{3}$ de gás natural por kWh gerado) e de ciclo combinado (valores se situam abaixo de $0,12 \mathrm{~m}^{3}$ de gás natural por $\mathrm{kWh}$ gerado). Assim, as curvas relativas às plantas de ciclo simples se localizam na porção superior do gráfico, com valores compreendidos entre 
aproximadamente $0,450 \mathrm{~m}^{3} / \mathrm{MWh}$ e $0,525 \mathrm{~m}^{3} / \mathrm{MWh}$, para $\gamma=2$, e entre $0,525 \mathrm{~m}^{3} / \mathrm{MWh}$ e $0,650 \mathrm{~m}^{3} / \mathrm{MWh}$, para $\gamma=4$.

A Termoceará, unidade de ciclo simples, se destaca por apresentar o maior fator de produção de água dentre todas as unidades envolvidas no estudo, com valores compreendidos entre $0,532 \mathrm{~m}^{3} / \mathrm{MWh}$ e $0,639 \mathrm{~m}^{3} / \mathrm{MWh}$. Já dentre as unidades de ciclo combinado, Sepé Tiarajú possui os melhores resultados, os quais variam de $0,297 \mathrm{~m}^{3} / \mathrm{MWh}$ a $0,343 \mathrm{~m}^{3} / \mathrm{MWh}$.

Em contrapartida, a UTE Santa Cruz (ciclo combinado) possui os valores mais baixos dentre todas as unidades movidas a gás natural avaliadas, com resultados situados entre $0,099 \mathrm{~m}^{3} / \mathrm{MWh}$ e $0,116 \mathrm{~m}^{3} / \mathrm{MWh}$.

\subsubsection{Gases não condensáveis (GNC) e temperatura de saturação do vapor $\left(T_{\text {sat }}\right)$}

$\mathrm{Na}$ segunda etapa do trabalho, objetiva-se a abordagem do processo de recuperação de água por meio de um processo de condensação. Desse modo, foi realizada a quantificação dos demais componentes presentes nos gases de combustão, no caso $\mathrm{CO}_{2}, \mathrm{~N}_{2}, \mathrm{O}_{2}$ e $\mathrm{SO}_{2}$. A presença deste último componente foi considerada apenas nos GC de UTEs movidas a carvão mineral, cujas quantidades de enxofre (S) são relevantes na composição do combustível.

A partir da determinação das porcentagens volumétricas destes gases na mistura, pode-se também determinar as pressões parciais do vapor de água e consequentemente as correspondentes temperaturas de saturação. Novamente, os resultados são expressos em função de $\gamma$.

No Apêndice B são disponibilizados gráficos de barras representativos dos valores percentuais de cada um dos componentes que compõem os GC de cada uma das UTEs para os coeficientes $\gamma$ correspondentes. Na Fig. 3.3, a seguir, são plotadas as porcentagens volumétricas totais de GNC referentes às UTEs movidas a carvão mineral. 

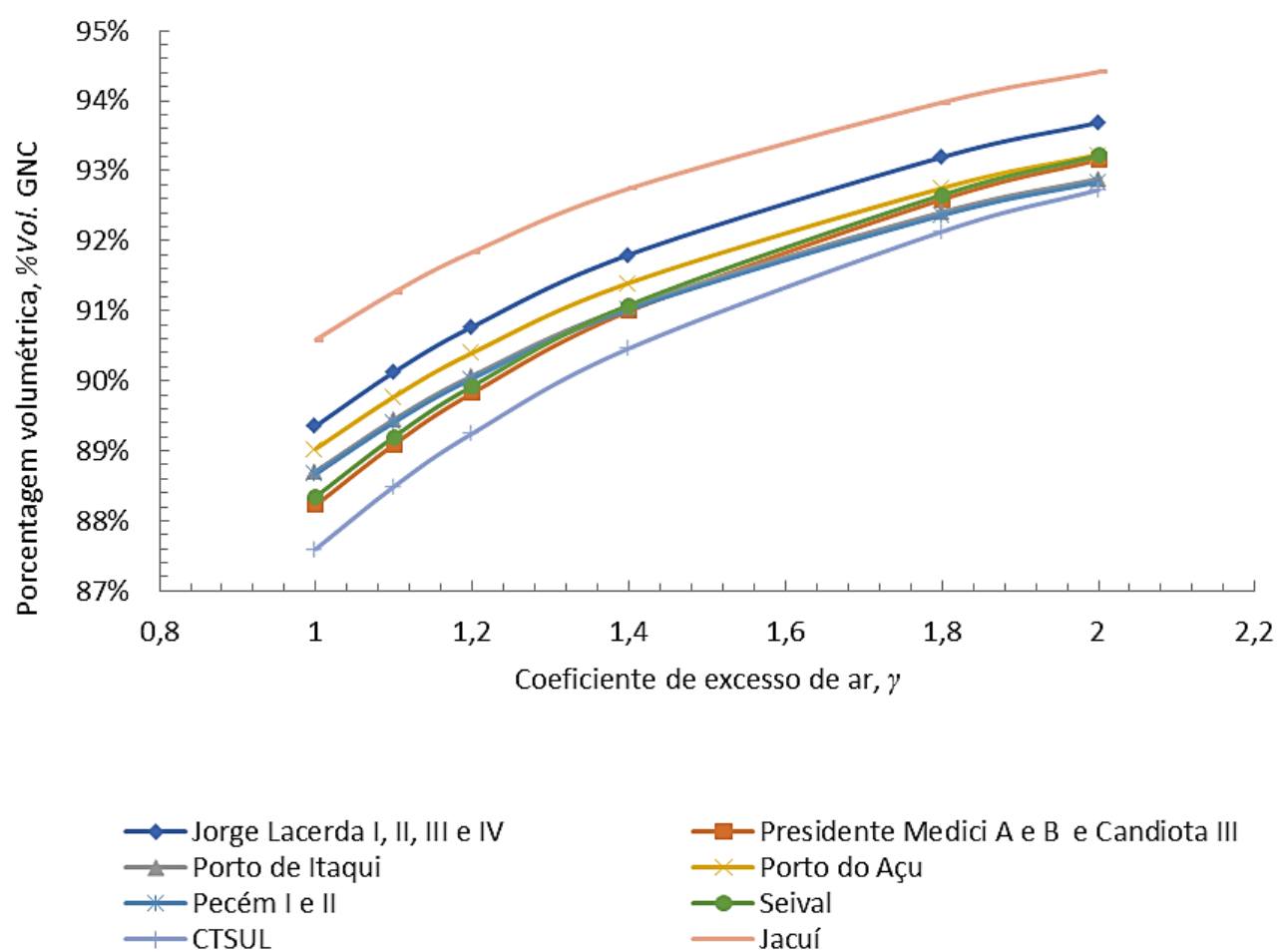

Figura 3.3 - Porcentagem volumétrica de GNC das UTEs movidas a carvão mineral avaliadas.

Observa-se que as porcentagens de GNC, que já são substanciais na condição estequiométrica, crescem com o aumento de $\gamma$, uma vez que o processo de combustão passa a conter maiores quantidades de $\mathrm{N}_{2}$ e $\mathrm{O}_{2}$ (parcela de gases não consumida) que compõem o ar atmosférico. Em contrapartida, apesar da umidade associada ao ar de combustão aumentar com o acréscimo de $\gamma$, a porcentagem volumétrica de vapor de água nos gases de combustão decresce. Assim, apesar da umidade presente no ar de combustão ser contabilizada, ela é pequena se comparada à parcela de água produzida pela combustão e, portanto, não exerce influência efetiva na proporção dos produtos de combustão. Além disso, a fração de água se torna menor em relação à fração de GNC, estes produzidos em maior proporção conforme maior é o excesso de ar.

Nota-se que a UTE Jacuí possui as maiores porcentagens de GNC, as quais variam em torno de $90,5 \%$ quando $\gamma=1$, e $94,5 \%$ quando $\gamma=2$. Em contrapartida, a UTE CTSUL apresenta as menores quantidades, com valores compreendidos entre $87,5 \% \mathrm{e}$ $92,73 \%$. As demais termelétricas apresentam porcentagens de GNC que se situam entre os valores de Jacuí e CTSUL, algo em torno de $88,5 \%$ e $89,5 \%$ para $\gamma=1$, e $92,0 \%$ e $93,5 \%$ para $\gamma=2$. 
A temperatura de saturação do vapor de água $\left(T_{\text {sat }}\right)$, de acordo o equacionamento previamente apresentado na seção 3.1.5, depende, sobretudo, de sua pressão parcial na mistura. Assim, percebe-se por meio da Fig. 3.4, que ocorre diminuição das temperaturas de saturação proporcionalmente ao acréscimo de ar na combustão; ou seja, tal redução se dá a partir do aumento das frações de GNC e consequente diminuição da porcentagem de vapor de água na mistura.

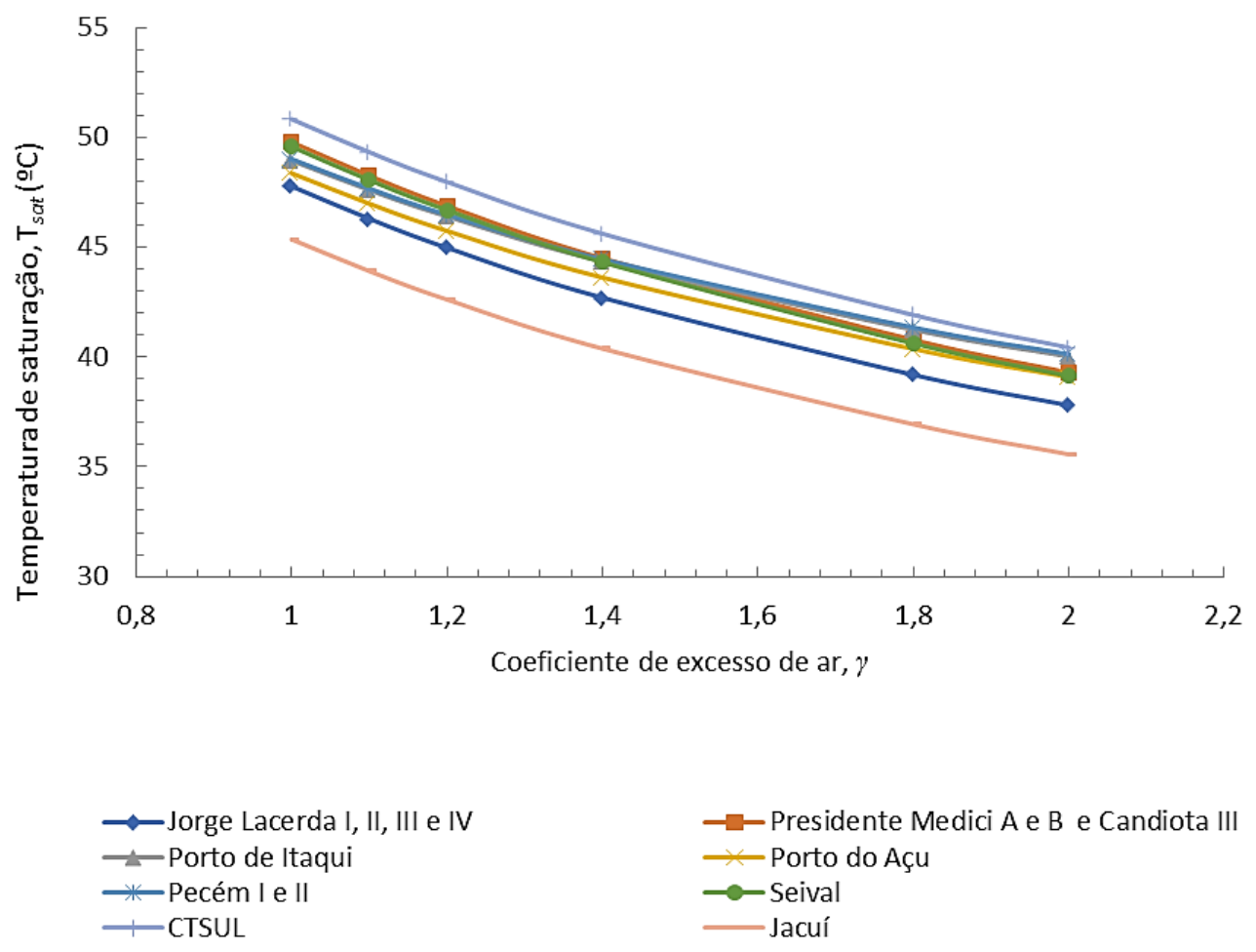

Figura 3.4 - Temperatura de saturação do vapor de água, $T_{\text {sat }}$, das UTEs movidas a carvão mineral avaliadas.

Deste modo, pode-se constatar que o comportamento das curvas da Fig. 3.4 é justamente o oposto do evidenciado pelas curvas da Fig.3.3. A UTE Jacuí que apresenta as maiores porcentagens de GNC possui as menores temperaturas de saturação, as quais variam de $45,36^{\circ} \mathrm{C}$ a $35,57^{\circ} \mathrm{C}$. A UTE CTSUL, cujas procentagens de GNC são as mais baixas, possui as maiores temperaturas de saturação.

Da mesma forma, são expostos na Fig. 3.5 as curvas relativas às porcentagens de GNC das UTEs movidas a gás natural e na Fig 3.6 suas respectivas temperaturas de saturação. 

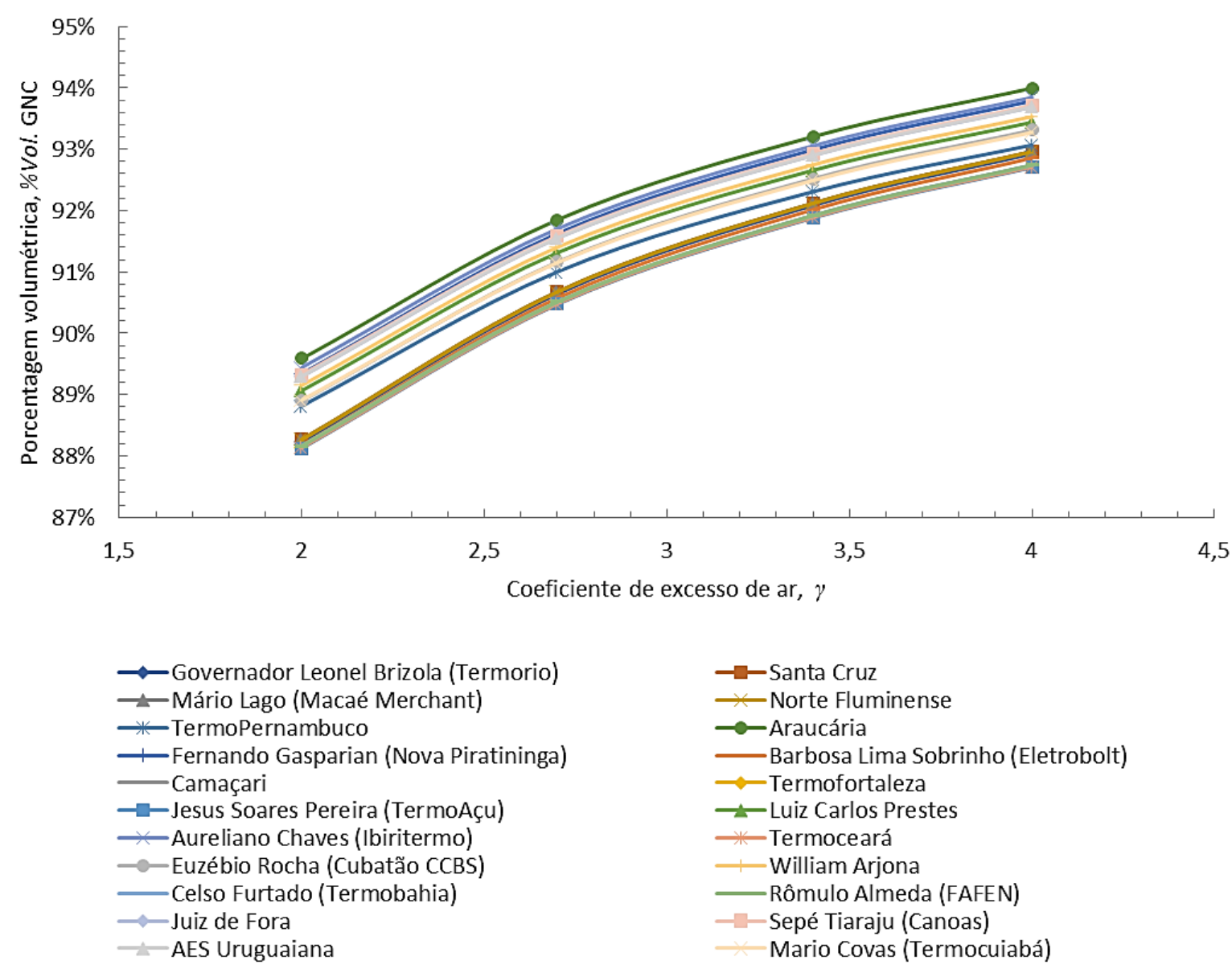

Figura 3.5 - Porcentagem volumétrica de GNC das UTEs movidas a gás natural avaliadas.

Embora as turbinas a gás operem com maiores coeficientes de excesso de ar do que as fornalhas de ciclos a vapor, verifica-se que seus produtos de combustão possuem porcentagens de GNC ligeiramente menores em relação às unidades movidas a gás natural, cujos resultados variam em torno de $88 \%$ a $89,5 \%$ para $\gamma=2$, e de $92,5 \%$ a $94 \%$ quando $\gamma=4$.

Igualmente ao que ocorre nas UTEs a carvão, unidades que produzem maiores volumes de GNC possuem as menores temperaturas de saturação de vapor, como é o caso de Araucária e Aureliano Chaves. Em contrapartida, observa-se um número grande de unidades que apresentam frações de GNC semelhantes (valores em torno de $88 \%$ a 93\%) e que consequentemente possuem temperaturas de saturação semelhantes (aproximadamente de $50^{\circ} \mathrm{C}$ a $40^{\circ} \mathrm{C}$ ), no caso as as UTEs Governador Leonel Brizola, Santa Cruz, Mário Lago, Norte Fluminense, Barbosa Lima Sobrinho, Camaçari, Termofortaleza, Jesus Soares Pereira, Celso Furtado e Rômulo Almeida. 


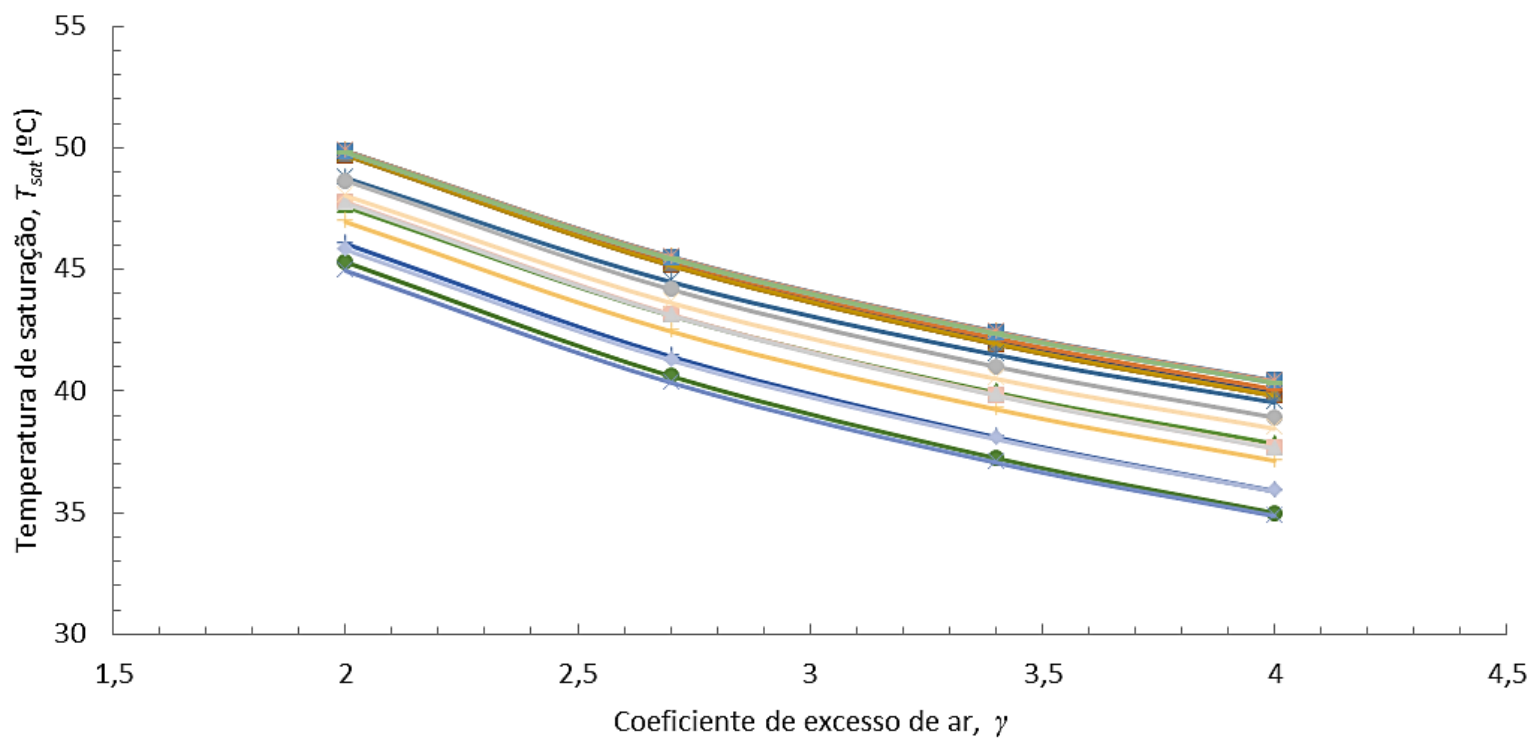

-Governador Leonel Brizola (Termorio)
- Mário Lago (Macaé Merchant)
- TermoPernambuco
- Jesuascari Soares Pereira (TermoAçu)
- Eureliano Chaves (Ibiritermo)
- Euzébio Rocha (Cubatão CCBS)
- Juiz de Furtado (Termobahia)
- AES Uruguaiana

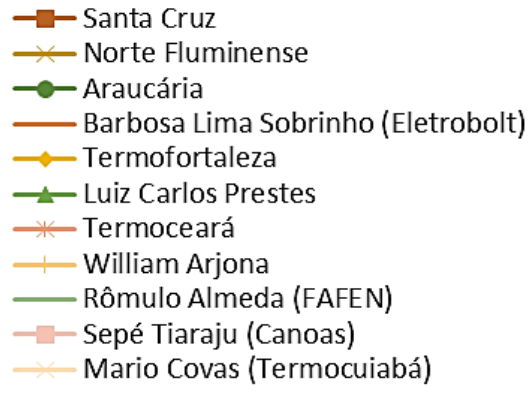

Figura 3.6 - Temperatura de saturação do vapor de água, $T_{\text {sat }}$, das UTEs movidas a gás natural avaliadas. 


\subsection{Conclusões Parciais}

Nas seções 3.2.1 e 3.2.2 foram realizadas as estimativas de produção de água e dos demais gases de combustão de trinta e seis UTEs brasileiras de capacidade de geração superior a $50 \mathrm{MW}$. Adicionalmente, na seção 3.2.3, com base nas porcentagens dos GNC, estimou-se as temperaturas de saturação do vapor de água na mistura gasosa em função dos coeficientes de excesso de ar adotados. Os resultados obtidos possibilitaram a obtenção de um panorama geral acerca do tema e confirmaram, conforme preconizado pela literatura, que os volumes de água produzidos são relevantes frente à quantidades consumidas, sugerindo a priori que existe potencial para se mitigar o intensivo gasto deste recurso que ocorre na geração termelétrica. Sobretudo em plantas que se utilizam de ciclos a vapor devido ao maior consumo na operação de resfriamento da água do condensador.

Observou-se que a quantidade de água presente nos GC depende predominantemente do tipo de ciclo de potência e da composição do combustível empregado, havendo variações entre as UTEs avaliadas. Constatou-se que o aumento de $\gamma$, apesar de elevar a quantidade vapor de água presente nos gases de combustão, promove também a elevação da porcentagem volumétrica de GNC em maior intensidade, o que consequentemente reduz a proporção de vapor de água na mistura, ocasionando, desta forma, redução da sua pressão parcial e de sua temperatura de saturação.

A avaliação das UTEs movidas a carvão mineral forneceu volumes de água que se encontravam entre aproximadamente, $0,180 \mathrm{~m}^{3} / \mathrm{MWh}$ e $0,210 \mathrm{~m}^{3} / \mathrm{MWh}$, quando $\gamma=1$ e entre $0,200 \mathrm{~m}^{3} / \mathrm{MWh}$ e $0,260 \mathrm{~m}^{3} / \mathrm{MWh}$, quando $\gamma=2$. A literatura consultada disponibiliza fatores de consumo de água que se situam entre $1,70 \mathrm{~m}^{3} / \mathrm{MWh}$ e $2,14 \mathrm{~m}^{3} / \mathrm{MWh}$, se consideradas plantas a carvão pulverizado com torre de resfriamento úmida sem sistema de captura e de $\mathrm{CO}_{2}$. Em unidades mais avançadas tecnologicamente, que contam com sistemas de captura de $\mathrm{CO}_{2}$, o fator de consumo é de $3,10 \mathrm{~m}^{3} / \mathrm{MWh}$.

Portanto, tomando-se como referência os valores médios dos fatores de consumo de água encontrados na literatura consultada, e admitindo-se que o resfriamento nas unidades avaliadas se dá por meio de torres úmidas, depreende-se que os volumes de água produzidos pelas UTEs movidas a carvão mineral avaliadas, nas condições pré- 
estabelecidas, representam cerca de $9,4 \%$ a $11 \%$ do volume de água consumida quando $\gamma=1$, e de $10,4 \%$ a $13,6 \%$ quando $\gamma=2$. No caso destas plantas serem integradas a sistemas de captação de $\mathrm{CO}_{2}$, os volumes de água se situam entre aproxidamente $5,5 \%$ e $6,8 \%$ do volume consumido, quando $\gamma=1$, e entre $6,5 \%$ e $8,4 \%$, quando $\gamma=2$.

Para UTEs movidas a gás natural de ciclo combinado equipadas com torres de resfriamento úmidas, as referências consultadas disponibilizam fatores de consumo de água que variam de $0,72 \mathrm{~m}^{3} / \mathrm{MWh}$ (sem sistemas de gaseificação e de captura de $\mathrm{CO}_{2}$ ) a $1,70 \mathrm{~m}^{3} / \mathrm{MWh}$ (com sistemas de gaseificação e de captura de $\mathrm{CO}_{2}$ ). Deste modo, considerando-se o primeiro caso, estas UTEs produzem de $13,9 \%$ a $42 \%$ do volume de água consumido quando $\gamma=2$, e de $16,2 \%$ a $48,6 \%$ quando $\gamma=4$. Para o segundo caso, os valores se localizam entre aproximadamente 5,9\% e $17,6 \%$ do volume consumido quando $\gamma=2$, e entre $6,9 \%$ e $20,6 \%$ quando $\gamma=4$.

Portanto, de acordo com exposto, pode-se concluir que a quantidade de água presente nos gases de combustão de plantas termelétricas é relevante e, se recuperada e devidamente condicionada, pode auxiliar na reposição das perdas que ocorrem especialmente por conta dos sistemas de resfriamento, de modo a possibilitar a redução dos volumes captados a partir das fontes hídricas. 


\section{Recuperação da água presente nos gases de combustão}

O capítulo anterior tratou fundamentalmente da estimativa da parcela de água e dos demais gases presentes nos produtos de combustão de determinadas UTEs brasileiras.

Já o presente capítulo tem a finalidade de abordar a recuperação do vapor de água contido nestes gases de combustão. Apesar de existirem estudos e tecnologias que tratam da separação de água por meio de membranas semipermeáveis seletivas, conforme apresentado na revisão da literatura presente na seção 2.2.2 do capítulo 2, o processo que será estudado e avaliado nesta etapa é a condensação sobre uma superfície resfriada.

\subsection{Idealização do condensador de superfície}

A idealização do condensador, conforme ilustrado na Fig. 4.1, consiste em dois tubos verticais concêntricos. No interior do tubo de menor diâmetro escoa a mistura de vapor de água e GNC no sentido descendente, sendo que a condensação ocorre na parede interna desse tubo.

$\mathrm{Na}$ região externa anular formada pelos dois tubos, escoam no sentido ascendente e por meio de convecção natural, uma mistura de ar atmosférico e de GNC, este remanescente do processo de condensação coletado na base do condensador. Considera-se que o mecanismo de convecção natural seja promovido pela diferença temperatura (e consequente diferenças de densidade) entre a superfície externa do tubo interno, $T_{s e}$, a qual se eleva desde a base até o topo do condensador, e a temperatura longe dessa superfície, $T_{\infty}$.

A seção de saída do fluido de resfriamento é aberta para atmosfera, com os GC remanescentes do processo sendo lançados para a mesma.

Cabe salientar que o objetivo deste trabalho não é realizar o detalhamento do equipamento frente seus aspectos construtivos, mas sim avaliar os processos de transferência de calor que ocorrem no lado do resfriamento, e de transferência calor e de massa que ocorem no lado da condensação, com objetivo de se definir os 
correspondentes coeficientes de transferência e, deste modo, com base nas temperaturas estabelecidas ao longo do condensador, calcular a quantidade de água presente nos GC que pode ser recuperada sob determinadas condições de condensação.

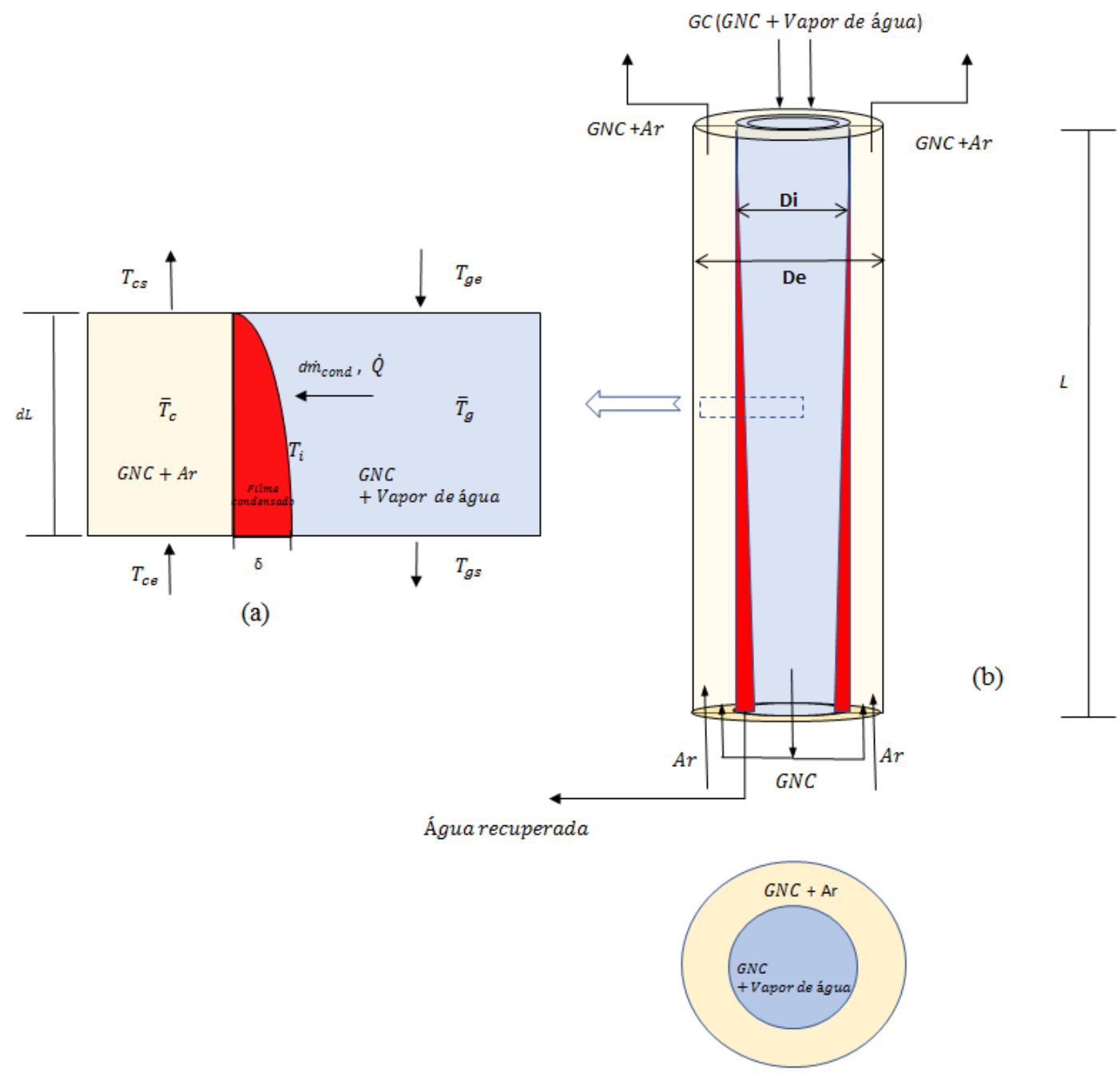

Figura 4.1 - Condensador idealizado neste trabalho. Fonte: Elaboração prórpria

Assume-se que a partir do ponto de início da condensação, ocorra a formação de um filme líquido uniforme que passa a recobrir toda a superfície interna do tubo. A espessura do filme cresce à medida que a água que migra da fase gasosa se condensa na superfície, cuja temperatura, a partir de determinado comprimento, se torna menor que a temperatura de saturação do vapor na mistura $\left(T_{s a t}\right)$. 
O processo de condensação ocorre mediante a transferência de calor sensível, devido à diferença de temperatura estabelecida entre o fluido de resfriamento (GNC/ar) e os produtos de combustão (GC/vapor de água), e de transferência de entalpia de condensação, proveniente da mudança da fase vapor para a fase líquida.

O volume de controle tomado como referência para derivação das equações de governo, referentes aos processos de transferência de calor e de massa, é definido como sendo uma região fixa do espaço que contém os gases de combustão, o filme de condensado e o fluido de resfriamento, conforme descrito na Fig. 4.1. Nas seções posteriores são apresentadas as equações constituintes do modelo, assim como as hipóteses adotadas para seu desenvolvimento.

As temperaturas que se estabelecem nos diferentes pontos radiais do condensador são ilustradas na Fig. 4.2 abaixo. São elas: $T_{g}$ (gases de combustão), $T_{i}$ (interface líquido-vapor), $T_{s i}$ (superfície interna), $T_{s e}$ (superfície externa), $T_{f}$ (filme líquido), $T_{c}$ (fluido de resfriamento), $T_{\infty}$ (temperatura distante da superfície de resfriamento) e $T_{a}$ (ambiente).

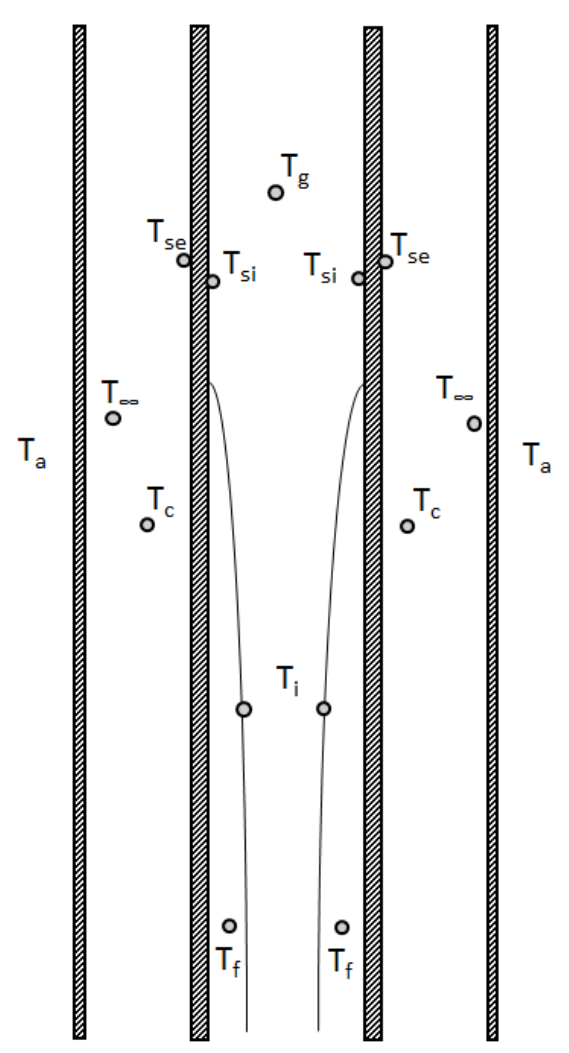




\subsection{Modelagem do processo de condensação}

O modelo desenvolvido baseia-se no tradicional equacionamento de Colburn e Hougen (1934), introduzido na seção 2.1.15, acrescido de modificações que levam em conta os efeitos de sucção e de rugosidade do filme de condensado.

As equações que constituem o modelo numérico se dividem em três grupos distintos, descritos a seguir:

1) Balanços de massa e energia: destinados à obtenção das taxas de transferência de calor e massa e das temperaturas dos GC, do filme condensado, da superfície e do fluido de resfriamento ao longo do condensador;

2) Correlações empíricas e analogias de calor e massa: destinadas à obtenção dos coeficientes de transferência de calor e massa nos GC, no filme de condensado e no fluido de resfriamento;

3) Propriedades termofísicas: equações e correlações derivadas de dados de tabelas com a finalidade de se fornecer condutividade térmica, densidade, viscosidade, difusividade e calor específico dos três fluidos envolvidos nos pocesso, sendo eles: Fluido de resfriamento (GNC/ar), Filme líquido (água) e GC (GNC/vapor)

O desenvolvimento apóia-se nas seguintes hipóteses:

- No lado dos GC, escoamento em regime permanente e simétrico axialmente;

- Todo o vapor que migra da fase gasosa em direção à interface se condensa na superfície do tubo;

- A redução de massa nos $\mathrm{GC}$, decorrente da condensação de parte do vapor de água, é desprezada, uma vez que a fração mássica dos GNC é amplamente superior à fração mássica de vapor de água;

- $\delta<<D_{i}$, o que implica em desconsiderar a curvatura do tubo;

- Assume-se que o coeficiente de difusividade mássica do vapor de água nos gases de combustão é aproximadamente igual ao coeficiente de difusividade do vapor no ar ; 
- Os GNC e o vapor de água estão localmente bem misturados, em equilíbrio termodinâmico e são tratados como gases ideais;

- Na interface entre os GC e a película líquida, considera-se que o vapor de água é saturado;

- Tensão de cisalhamento entre a fase gasosa e a interface, bem como arraste de condensado, são desprezados.

Quando a temperatura da parede do tubo interno atinge um valor inferior à temperatura de saturação do vapor de água, levando-se em conta a presença de GNC, o processo de condensação passa a ocorrer na superfície como resultado da transferência convectiva do vapor de água ao longo da camada dos gases de combustão em direção a interface liquido-vapor.

Com fundamento na hipótese de que toda a parcela de vapor que migra a partir da fase gasosa em direção à interface se condensa, a taxa de condensação do vapor de água pode ser determinada em função de dois parâmetros distintos: coeficiente de transferência de massa nos GC, $k_{g}$, e diferença entre as frações mássicas de vapor de água no seio da mistura de gases e na interface líquido/gás.

Na convecção de massa, a camada limite de concentração é definida de maneira análoga à camada limite térmica, sendo definidos novos números adimensionais equivalentes aos números de Nusselt e Prandtl, no caso os números de Sherwood e de Schmidt. A taxa convectiva de calor é expressa pela Lei de resfriamento de Newton a seguir:

$$
\dot{Q}_{\text {conv }}=h A\left(T_{s}-T_{\infty}\right)
$$

Onde $h$ é o coeficiente convectivo de transferência de calor, $A$ é a area da superfície e $\left(T_{S}-T_{\infty}\right)$ é a diferença de temperatura através da camada limite térmica.

Analogamente, a taxa de de convecção de massa pode ser expressa pela Eq. 4.2

$$
\dot{m}_{\text {conv }}=k A\left(C_{s}-C_{\infty}\right)
$$


Sendo que $k$ é o coeficiente de transferência de massa por convecção e $\left(C_{s}-C_{\infty}\right)$ é a diferença de concentração existente. Segundo Burmeister (1993), a analogia entre convecção de calor e massa é válida somente para casos onde a vazão de transferência estabalecida é inferior a 10\% em relação a vazão total da mistura gasosa.

Admitindo-se que toda água que migra através da camada gasosa em direção a interface se condensa, a taxa de condensação pode ser determinada colocando-se a Eq. 4.2 na forma diferencial e substituindo-se as concentrações pelas frações mássicas na interface e no seio da mistura gasosa. Assim:

$$
\frac{d \dot{m}_{c d}}{d A}=k_{g}\left(x_{v, b}-x_{v, i}\right)
$$

O coeficiente convectivo de transferência de massa, $k_{g}$, pode ser determinado por meio da analogia de transferência de calor e massa, onde o coeficiente de tranferência de calor em convecção, $h_{g}$, pode ser obtido a partir da correlação de Nusselt .

Baseado na teoria apresentada por Colburn and Hougen (1934), pode-se impor que, em qualquer seção do condensador, a transferência de calor a partir da mistura gasosa em direção a interface é dada pela soma dos calores sensível, proveniente das diferenças de temperatura estabelecidas, e da entalpia de condensação resultante da mudança de fase, conforme expresso pela Eq. 4.4.

$$
d \dot{q}=h_{g}\left(T_{g}-T_{i}\right)+k_{g} h^{*}{ }_{l g}\left(x_{v, b}-x_{v, i}\right)=U^{\prime}\left(T_{i}-T_{c}\right)
$$

Os termos $h_{g}$ e $k_{g}$ são os coeficientes de transferência de calor e de massa da mistura gasosa na temperatura $T_{g}$, e $h^{*}{ }_{l g}$ é a entalpia específica de condensação do vapor. Na segunda parcela da igualdade, $U^{\prime}$ representa o coeficiente global de tranferência de calor entre a interface, na temperatura $T_{i}$, e o fluido de resfriamento, na temperatura $T_{c}$

Uma vez que os gases de combustão ingressam no condensador a uma temperatura bastante superior à temperatura de condensação do vapor de água, a parcela 
referente ao superaquecimento deve ser considerada na avaliação de $h_{f g}$, conforme proposto pela Eq. 4.5 apresentada por Nag (2011).

$$
h^{*}{ }_{l g}=h_{l g}+0,68 C_{p l}\left(T_{s a t}-T_{s i}\right)+C_{p g}\left(T_{g}-T_{s a t}\right)
$$

onde $C_{p l}$ é o calor específico da água no filme líquido avaliado na temperatura $T_{f}$, dada pela média entre $T_{i}$ e $T_{s i}$, conforme Eq. 4.6, e $C_{p g}$ é o calor específico da mistura de gases e vapor avaliado na temperatura $T_{g}$.

$$
T_{f}=\frac{\left(T_{i}+T_{s}\right)}{2}
$$

Com a admissão de condição de saturação na interface, a fração molar de vapor neste ponto pode ser obtida por meio da relação entre a pressão de saturação local e a pressão total do sistema, de acordo com a Eq. 4.7. Sendo $P_{s a t, i}$ a pressão de saturação do vapor de água na interface, e $P_{o}$ a pressão total.

$$
x_{i}=\frac{P_{s a t, i}}{P_{o}}
$$

A Eq. 4.8 pode ser reescrita em termos dos coeficientes globais de transferência de calor considerando-se as diferentes seções, compreendidas entre a mistura gasosa e o fluido de resfriamento. Assim, o balanço de energia pode ser reescrito como:

$$
d \dot{Q}=U\left(T_{g}-T_{c}\right) d A=U^{\prime}\left(T_{i}-T_{c}\right) d A
$$

Sendo assim, os coeficientes globais de transferência de calor $U^{\prime}$ e $U$, podem ser expressos como a soma dos recíprocos de cada uma das resistências térmicas existentes 
entre a mistura gasosa e o fluido de refriamento e entre a interface e o fluido de resfriamento, conforme Eqs. 4.9 e 4.10.

$$
\begin{gathered}
U^{\prime}=\left(\frac{1}{h_{f}}+R_{w}+\frac{1}{h_{c}}\right)^{-1} \\
U=\left(\frac{1}{h_{g}+h_{c d}}+\frac{1}{h_{f}}+R_{w}+\frac{1}{h_{c}}\right)^{-1}
\end{gathered}
$$

Sendo que $h_{f}$ é o coeficiente convectivo de transferência de calor do filme líquido, $h_{c}$ o coeficiente convectivo de transferência de calor do fluido de resfriamento e $R_{w}$ é a resistência térmica da parede do tubo, definida pela Eq. 4.11.

$$
R_{w}=\frac{\ln \left(\frac{D_{e}}{D_{i}}\right)}{2 \pi \lambda_{w}}
$$

Onde, $D_{e}$ é o diâmetro externo do tubo, $D_{i}$ seu diâmetro interno e $\lambda_{w}$ a condutividade térmica do material. Foi admitido que o tubo é constituído de aço inox 316, cujo coeficiente de condutividade térmica é fornecido no Apêndice C.

A taxa de transferência do calor de condensação, representada pelo segundo termo da Eq. 4.4, pode ser reescrita em termos do coefciente de transferência de calor de condensação, $h_{c d}$, e da taxa de condensação local propriamente dita, $d \dot{m}_{c d}$. Deste modo, têm-se que:

$$
h_{c d}\left(T_{g}-T_{i}\right) d A=d \dot{m}_{c d} h^{*}{ }_{l g}
$$




\subsubsection{Transferência de calor e massa nos GC (GNC/vapor de água)}

A taxa de transferência de calor sensível nos GC pode ser obtida por meio balanço de energia que contabiliza a variação de entalpia sofrida pelo gás ao longo do volume de controle definido, conforme Eq. 4.13.

$$
d \dot{Q}_{g}=h_{g}\left(T_{g}-T_{i}\right) d A=\dot{m}_{g} C_{p g} d T
$$

Para escoamento turbulento plenamente desenvolvido, tanto hidrodinamicante quanto termicamente, o número de Nusselt local pode ser calculado a partir da Eq. 4.14, conhecida com equação de Gileninski (1976) apud Çengel (2009). Esta correlação é válida para $0,5<\operatorname{Pr}<2000$ e $3000<\operatorname{Re}<5.10^{6}$.

$$
N u_{g}=\frac{h_{g} D_{i}}{\lambda_{g}}=\frac{\left(\frac{f_{g}}{8}\right)\left(R e_{g}-1000\right) P r_{g}}{1+12,7\left(\frac{f_{g}}{8}\right)^{\frac{1}{2}}\left(P r_{g}^{\frac{2}{3}}-1\right)}
$$

O fator de atrito, $f_{g}$, considerando que ambas as superfícies da região anular sejam lisas, é determinado pela Eq. 4.15.

$$
f_{g}=\left(0,790 \ln R e_{g}-1,64\right)^{-2}
$$

onde $\lambda_{g}$ é coeficiente de condutividade térmica dos gases de combustão e $D_{i}$ o diâmetro diâmetro interno do tubo.

Os números de Reynolds e de Prandtl da mistura gasosa são definidos como: 


$$
\begin{gathered}
R e_{g}=\frac{\rho_{g} v_{g} D_{i}}{\mu_{g}} \\
\operatorname{Pr}_{g}=\frac{\mu_{g} C_{p g}}{k_{g}}
\end{gathered}
$$

Aplicando-se a analogia de transferência de massa através da substituição do números de Nusselt e Prandtl pelos números de Sherwood e Schimidt, respectivamente, obtém-se o coeficiente convectivo de transferência de massa no gás, $k_{g}$, conforme Eq. 4.18, válida para $0,6<S c_{g}<3000$.

$$
S h_{g}=\frac{k_{g} D_{i}}{\rho_{g} D i f_{v, a r}}=0,023 R e_{g}^{0,8} S c_{g}{ }^{0,4}
$$

sendo que $\rho_{g}$ é a densidade da mistura dos gases de combustão e $D i f_{v, a r}$ é o coeficiente de difusão do vapor de água no ar.

\subsubsection{Transferência de calor no filme de condensado}

Corradini (1984) afirma que a resistência térmica do filme líquido é pequena quando comparada à resistência térmica total na presença de gases não condensáveis. Segundo Goldbrunner (2003) apud Jeong (2010) essa resistência representa cerca de 1 a $3 \%$ da resistência térmica total. Contudo, apesar dessa resistência ser pequena, e ainda

que grande parte dos estudos acerca do tema a desprezem, no presente trabalho optoupor considerá-la no equacionamento.

Em condições de escoamento turbulento o filme líquido se torna ondulado em sua superfície o que pode elevar as taxas de transferência de calor e consequentemente de massa (Park et al. 1996). A espessura do filme pode ser determinada a partir da reconhecida teoria de Nusselt, conforme Eq. 4.19. 


$$
\delta=\left[\frac{3 v_{l} \Gamma}{\left(\rho_{l}-\rho_{g}\right) g}\right]^{1 / 3}
$$

sendo $\Gamma$ definido pela Eq. 4.20.

$$
\Gamma=\frac{\dot{m}_{c d}}{\pi D_{i}}
$$

Onde $\Gamma$ é a vazão de condensado por unidade de comprimento da seção circular (kg/m.s) e $D i$ é o diâmetro interno do tubo.

Segundo Cengel 2009, o número de Reynolds do filme líquido ao redor da superfície do duto cilindrico é definido pela Eq. 4.21.

$$
R e_{f}=\frac{4 \Gamma}{\mu_{l}}
$$

De acordo com Hewitt et al. (1993), a transição entre regime laminar e turbulento ocorre tipicamente quando o número de Reynolds do filme $\left(R e_{f}\right)$ se situa entre 1600 e 1800. Admitindo-se que $\rho_{g}<<\rho_{f}$, pode-se utilizar a correlação proposta por Labuntsov (1957) para determinação do coeficiente convectivo de transferência de calor na película de condensado em escoamento turbulento em placas planas.

$$
h_{f}=\left[\frac{R e_{f} \lambda_{f}}{8750+58 \operatorname{Pr}_{f}^{-1}\left(\operatorname{Re}_{f}^{0,75}-253\right)}\left(\frac{g}{v_{f}^{2}}\right)^{\frac{1}{3}}\right]^{0,820}
$$

Então, a taxa de transferência de calor no filme líquido pode ser determinada a partir da diferença de temperatura entre sua superfície e a superfície do tubo e também por meio da variação de temperatura ao longo do filme, juntamente com sua vazão mássica e calor específico, conforme Eq. 4.23. 


$$
d \dot{Q}_{f}=h_{f}\left(T_{i}-T_{s i}\right) d A=\dot{m}_{f} C_{p f} d T_{f}
$$

\subsubsection{Transferência de calor no fluido de resfriamento}

No modelo proposto, o fluido de resfriamento é composto pela mistura de GNC e ar atmosférico, este escoando ascendentemente na região anular dos dois tubos por meio de convecção natural. Deste modo, considera-se que suas propriedades termofísicas sejam dadas por médias ponderadas em função das vazões admitidas e das temperaturas observadas ao longo do comprimento do condensador, uma vez que as propriedades dos GNC e do ar são, isoladamente, calculadas conforme o exposto no Apêndice C.

De acordo com Hollman (1999), considerando que a placa vertical da Fig. 4.3 se encontre aquecida, ocorre a formação de uma camada limite de convecção natural. $O$ perfil de velocidade nesta camada limite é bastante diferente do perfil de velocidade em uma camada limide de convecção forçada. $\mathrm{Na}$ parede a velocidade é zero devido à condição de aderência aumentando até um certo valor máximo e posteriormente diminuindo até zero na extremidade da camada limite. O desenvolvimento inicial da camada limite é laminar, no entanto em determinada distância do bordo inicial da placa, dependendo das propriedades do fluido e das diferenças de temperatura estabelecidas, ocorre a formação de correntes turbulentas se iniciando a transição de camada limite laminar para turbulenta. 


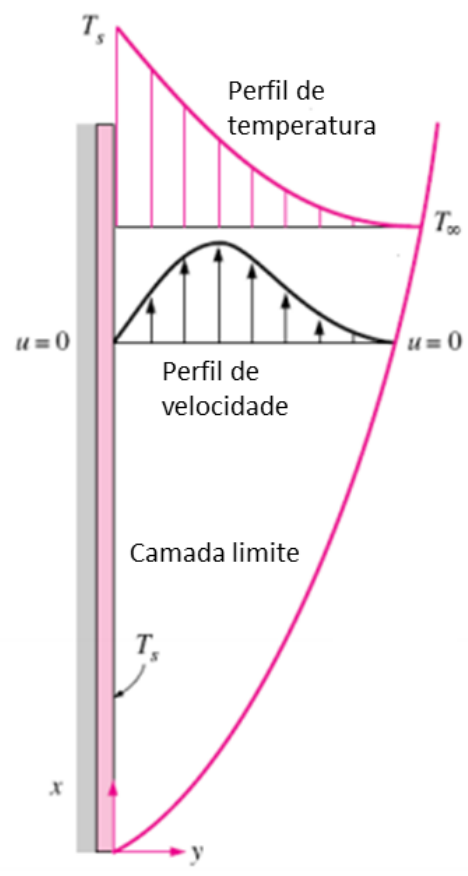

Figura 4.3 - Camada limite na convecção natural ao longo de uma placa vertical. Fonte: Adaptado de Holman (2010).

O mecanismo pelo qual se dá a convecção natural está associado às variações de densidade que ocorrem em função das diferenças de temperatura $T_{s}$ e $T_{\infty}$, com a gravidade como força motriz (Hewitt et al., 1993). A condição do fluido suficientemente longe da superfície quente é indicada pelo subscrito $\infty$.

No caso da convecção natural, o coeficiente convectivo de transferência de calor é definido a partir de correlações que levam em conta o número de Grashof, Gr, definido na Eq. 4.24 a seguir:

$$
G r_{c}=\frac{g \beta\left(T_{s}-T_{\infty}\right) z^{3}}{v_{c}}
$$

Onde:

$\beta$ : coeficiente de expansão volumétrica, igual a $1 / T(\mathrm{~K})$ para um gás perfeito;

$T_{s}$ : temperatura da superfície aquecida, $\left({ }^{\circ} \mathrm{C}\right)$;

$T_{\infty}$ : temperatura do fluido distante da superfície $\left({ }^{\circ} \mathrm{C}\right)$;

$z$ : comprimento característico da geometria, (m);

$v_{c}$ : viscosidade cinemática do fluido $(\mu / \rho),\left(\mathrm{m}^{2} / \mathrm{s}\right)$. 
Este adimensional representa a relação entre as forças de empuxo e as forças viscosas na convecção natural, desempenhando papel semelhante ao do número de Reynolds na convecção forçada. Deste modo, as equações de quantidade de movimento e energia podem ser escritas como função dos números de Grashof e de Prandtl :

$$
N u=f(G r, P r)
$$

As relações empíricas para determinação dos coeficientes de transferência de calor por convecção natural podem ser relacionados da seguinte forma:

$$
\overline{N u}=C(G r P r)^{m}=C R a^{m}
$$

Sendo que $R a$ é conhecido como número de Rayleight ( $R a$ ), dado pelo produto dos números de Grashoff e de Prandtl. A magnitude de Ra é um bom indicador para se avaliar se a camada limite na convecção natural é laminar ou turbulenta, de acordo com os critérios establecidos na Tabela 4.1 encontrada em Çengel (2009).

Tabela 4.1 - Coeficientes C e m para obtenção do número de Nusselt em convecção natural ao longo de placas e cilindros verticais. Holman (2010).

\begin{tabular}{cccc}
\hline Ra & C & m & Regime de escoamento \\
\hline $10^{4}$ a $10^{9}$ & 0,59 & $1 / 4$ & Laminar \\
$10^{9}$ a $10^{13}$ & 0,10 & $1 / 3$ & Turbulento \\
\hline
\end{tabular}

De acordo com Çengel (2009), a superfície externa de um cilindro vertical aquecido pode ser tratada como uma placa vertical quando seu diâmetro é suficientemente grande de modo que os efeitos de curvatura sejam insignificantes. Esta condição é satisfeita se a relação presente na Eq. 4.26 é atendida:

$$
D \geq \frac{35 L}{G r_{L}^{\frac{1}{4}}}
$$


Segundo Burmeister (1993), a delimitação entre a ocorrência de convecção puramente natural, convecção puramente forçada e combinação entre natural e forçada é definida em termos do grupo adimensional $G r / R e^{2}$. Quando o valor observado de $G r / R^{2}$ é da ordem de 1, os dois mecanismos convectivos são relevantes e ambos efeitos devem ser combinados. Caso $G r / \operatorname{Re}^{2}$ seja muito maior que 1, a convecção natural é dominante e a convecção forçada pode ser negligenciada. Em contrapartida, se $G r / R e^{2}$ é muito menor que 1 a convecção a convecção forçada é dominante e a natural é negligenciada.

Em Siegel (1958) apud Burmeister (1993) encontra-se uma correlação geral para obtenção dos coeficientes locais de transferência de calor sob regime de convecção natural e camada limite turbulenta $\left(2.10^{9} \leq R a \leq 10^{15}\right)$ com $\operatorname{Pr} \approx 1$, ao longo de uma placa plana vertical ou de um cilindro vertical.

$$
N u_{c}=\frac{0,080 P r_{c}{ }^{1 / 3} G r_{c}{ }^{2 / 7}}{\left(1+0,444 P r_{c}{ }^{2 / 3}\right)^{2 / 7}}
$$

Hewitt et al., (1993) estabelece que a ligação entre a densidade do fluido, $\rho_{c}$, e sua temperatura é dada por:

$$
\rho_{s}=\frac{\rho_{\infty}}{1+\beta\left(T_{s}-T_{\infty}\right)}
$$

Portanto, determinando-se a densidade do fluido nas adjacências da superfície pode-se, por consequência, avaliar se as condições de escoamento e temperaturas estabelecidas propiciam a ocorrência do processo por meio de convecção natural. A temperatura longe da superfície de resfriamento $\left(T_{\infty}\right)$ é considerada como sendo a média entre a temperatura ambiente $\left(T_{a}\right)$ e a temperatura do fluido de resfriamento $\left(T_{c}\right)$. Desta forma, a taxa de transferência de calor sensível para o fluido de resfriamento pode ser obtida a partir do balanço de energia conforme Eq. 4.29.

$$
d \dot{Q}_{c}=h_{c}\left(T_{s e}-T_{\infty}\right) d A=\dot{m}_{c} C_{p c} d T_{c}
$$




\subsubsection{Efeito de sucção}

Segundo Kays e Moffat (1975), na região onde se situa o início da condensação, ocorre o chamado efeito de sucção, ocasionado pelos elevados gradientes de temperatura e de concentração nas proximidades da interface líquido-vapor. Deste modo, a espessura da camada limite se reduz e as taxas de transferência de calor e de massa se intensificam localmente. De acordo com Caruso e DiMaio (2014) a absorção de vapor pelo filme líquido induz um fluxo convectivo adicional em direção à interface, o que causa encolhimento dos perfis de velocidade e de temperatura na camada limite, bem como da concentração das espécies envolvidas. Tal fenômeno contribui para elevação dos coeficientes de transferência na região. Maheshwari et al (2004) afirmam que a condensação induz a um estreitamento da camada limite gasosa e isso é o chamado efeito de sucção, o que significa que na interface a componente normal da velocidade em relação à parede do tubo não é zero, e portanto, as correlações utilizadas para se estimar os coeficientes de transferência de calor e de massa devem levar tal aspecto em consideração.

Uma das maneiras de se contabilizar este efeito foi utilizada por Saraireh (2012), que introduziu o chamado parâmetro de Spalding $\left(b_{h}\right)$ na relação entre os números de Nusselt e de Sherwood com e sem o efeito de sucção, conforme descrito pelas Eqs. 4.30 e 4.31. O subscrtito “ $o$ ”, se refere aos números adimensionais na ausência do efeito de sucção.

$$
\begin{gathered}
N u_{g}=N u_{g o} \frac{b_{h}}{\exp \left(b_{h}\right)-1} \\
b_{h}=\frac{\dot{m}_{c d}}{\rho_{g} v_{g} S t_{g o}}
\end{gathered}
$$

O número de Stanton, $S t_{o}$, é obtido pela Eq. 4.32.

$$
S t_{g o}=\frac{N u_{g o}}{\operatorname{Re} \operatorname{Pr}}
$$


A relação entre o número de Sherwood na presença do efeito de sucção é dada pela Eq. 4.33 .

$$
S h_{g}=S h_{g o} \frac{b_{m}}{\exp \left(b_{m}\right)-1}
$$

Analogamente, $b_{m}$ é obtido por:

$$
b_{m}=\frac{\dot{m}_{c d}}{\rho_{g} v_{g} S t_{g o, m}}
$$

Onde:

$$
S t_{g o, m}=\frac{S h_{o}}{\operatorname{Re} S c}
$$

Deste modo, torna-se possível "corrigir" os números de Nusselt e de Sherwood de modo que os mesmos incorporem a influência dos efeitos de sucção citados.

\subsubsection{Efeito da rugosidade do filme}

De acordo com Chantana e Kummar (2013), conforme o processo condensação ocorre ao longo da superfície, o regime de escoamento do filme líquido pode se modificar de laminar para turbulento em decorrência da incorporação de água líquida que migra a partir da fase gasosa. Consequentemente, o filme se torna rugoso e ondulado o que contribui para a intensificação dos coeficientes de transferência de calor e, por consequência, dos coeficientes de transferência de massa no lado de escoamento dos GC.

A influência da rugosidade do filme pode ser incorporada no equacionamento por meio da correlação sugerida por Norris (1970), apresentada a seguir, onde o subscrito " $f_{s}$ " é indicativo do número de Nusselt do filme liso e " $f_{r}$ " do do número de Nusselt do filme rugoso. 


$$
N u_{g, f r}=N u_{g, f s}\left(\frac{f_{r}}{f_{s}}\right)^{m}
$$

Aplicando-se a analogia de calor e massa, o número de Sherwood é expresso pela Eq. 4.37.

$$
S h_{g, f r}=S h_{g, f s}\left(\frac{f_{r}}{f_{s}}\right)^{n}
$$

Os subscritos $r$ e $s$ se referem aos fatores de atrito considerando filme rugoso e liso, respectivamente. Os expoentes $m$ e $n$ são determinados pelas Eqs. 4.38 e 4.39

$$
\begin{aligned}
& m=0,68 P r_{f}^{0,215} \\
& n=0,68 S c_{f}^{0,215}
\end{aligned}
$$

Os fatores de atrito para filme liso e rugoso podem ser determinados por meios das Eqs. 4.40 e 4.41, respectivamente.

$$
\begin{gathered}
f_{s}=0,0791 R e^{-0,25} \\
f_{r}=f_{s}\left(1+\frac{300 \delta}{D}\right)
\end{gathered}
$$




\subsubsection{Rendimento do processo de condensação}

O rendimento do processo de condensação pode ser expresso como a relação entre a vazão mássica de condensado (parcela total de água recuperada, $\dot{m}_{c d}$ ) e a vazão mássica de vapor de água presente nos GC que ingressa no condensador $\left(\dot{m}_{v, e}\right)$, ou seja:

$$
\eta_{c d}=\left(\frac{\dot{m}_{c d}}{\dot{m}_{v, e}}\right) \cdot 100
$$

A vazão mássica de condensado pode ser calculada integrando-se, de 0 até $L$ (comprimento do condensador) a Eq. 4.42, conforme abaixo:

$$
\dot{m}_{c d}=\int_{0}^{L} k_{g}\left(x_{v, b}-x_{v, i}\right) \pi D_{i} d L
$$

Neste caso, a integração se torna o mesmo que somar as vazões mássicas locais $\left(d \dot{m}_{c d}\right)$ em cada um dos $N$ elementos diferenciais $d L$ discretizados ao longo do comprimento $L$. 


\subsection{Resultados e discussões parciais}

O comprimento do condensador foi dividido em elementos diferenciais denominados $d A$. As equações diferenciais representativas de conservação de energia e de massa, correspondentes a cada um dos volumes de controle, foram colocadas na forma de diferenças finitas regressivas. O método de "diferenças finitas regressivas" e o conjunto de equações discretizadas ao longo da área se encontram no Apêndice D. Os parâmetros conhecidos eram a temperatura dos GC $\left(T_{g}\right)$, vazão de $\mathrm{GC}\left(\dot{m}_{g}\right)$, vazão mássica do fluido de resfriamento $\left(\dot{m}_{c}\right)$ e porcentagem volumétrica de vapor de água nos GC (\%Vol. v). A temperatura da interface líquido-vapor $\left(T_{i}\right)$ foi inicialmente arbitrada e tomada como um dos critérios de convergência para determinação do fim do processo iterativo.

O sistema de equações obtido foi implementado na forma matricial e solucionado por meio da obtenção de sua matriz inversa empregando-se iterações sucessivas programadas no módulo $V B A$ da planilha eletrônica Excel $^{\circledR} 2016$ da Microsoft. O fluxograma referente à rotina de cálculo empregada pode ser encontrada no Apêndice E.

Tomou-se como referência para realização das simulações, os parâmetros dos gases de combustão da UTE Aureliano Chaves (Ibiritermo) operando com coeficiente de excesso de ar igual a 4. Nesta condição de operação, a UTE produz uma vazão de gases de combustão $\left(\dot{m}_{g c}\right)$ igual a $244 \mathrm{~kg} / \mathrm{s}$, cuja porcentagem volumétrica de vapor $\left(\%\right.$ Vol. v) é igual a $6,16 \%$ correspondente a uma vazão mássica de água $\left(\dot{m}_{l}\right)$ igual a $16 \mathrm{~kg} / \mathrm{s}$.

Como descrito anteriormente na seção 4.1, o modelo proposto considera que o resfriamento ocorra aproveitando-se a parcela de GNC remanescente da condensação. Contudo, simulações preliminares indicaram que esta vazão remanescente, por si só, não era suficiente para que fosse atingida a temperatura de saturação necessária para que o processo de condensação ocorresse. Portanto, as simulações foram realizadas empregando-se uma vazão adicional de $50 \mathrm{~kg} / \mathrm{s}$ de ar atmosférico, tomando-se como condição restritiva a imposição de que as temperaturas de saída na base do condensador fossem inferiores à $T_{\text {sat }}$ local. Cabe dizer que não são abordados os aspectos associados aos meios de promoção de escoamento desta corrente adicional de ar. 
A utilização de GNC e ar como fluido de resfriamento pode não ser a alternativa mais interessante do ponto de vista de eficiência quando se analisa os processos de transferência de calor que ocorrem ao longo do condensador. Contudo, a não utilização da água como fluido de resfriamento vai ao encontro da questão essencial vinculada a este trabalho, que é a necessidade de se reduzir o consumo de água e/ou viabilizar formas e tecnologias para sua recuperação e reaproveitamento. Portanto, optou-se por realizar a modelagem e as simulações não considerando água como fluido de resfriamento.

As simulações são divididas em três conjuntos distintos:

$1^{\circ}$ Avaliação da influência da temperatura de entrada do fluido de resfriamento (GNC/ar), $T_{c e}$;

$2^{\circ}$ Avaliação da influência da pressão do sistema, $P_{o}$, e;

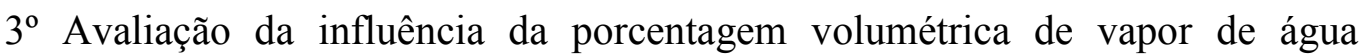
presente nos produtos de combustão, \%Vol. v.

Na Tabela 4.2 são apresentadas as condições estabelecidas nos três conjuntos de simulações. Admitiu-se que a temperatura de entrada dos $\mathrm{GC}$ fosse $100^{\circ} \mathrm{C}$.

Tabela 4.2 - Condições de simulação estabelecidas

\begin{tabular}{cccc}
\hline & $\mathbf{1}^{\mathbf{0}}$ & $\mathbf{2}^{\mathbf{0}}$ & $\mathbf{3}^{\mathbf{0}}$ \\
\hline$T_{\text {ce }}\left({ }^{\circ} \mathrm{C}\right)$ & 25,30 e $35^{\circ} \mathrm{C}$ & 25 & 25 \\
$P_{o}(\mathrm{kPa})$ & 101,32 & 101,32 a 120 & 101,32 \\
$\%$ Vol.v & 6,16 & 6,16 & 6,16 a 90 \\
\hline
\end{tabular}

As dimensões admitidas para execução das simulações são disponibilizadas na Tabela 4.3 abaixo.

Tabela 4.3 - Dimensões do condensador

Comprimento, $L$

Diâmetro do tubo externo, $D_{e}$

Diâmetro do tubo interno, $D_{i}$

Área interna, $A_{t i}$

Área externa, $A_{t e}$
$70 \mathrm{~m}$

$20 \mathrm{~m}$

$14 \mathrm{~m}$

$3078,76 \mathrm{~m}^{2}$

$3079,87 \mathrm{~m}^{2}$ 


\subsubsection{Temperatura de entrada do fluido de resfriamento (GNC/ar), $T_{c e}$}

O primeiro conjunto de simulações diz respeito à variação da temperatura do fluido de resfriamento, $T_{c e}$. Os valores avaliados foram 25,30 e $35^{\circ} \mathrm{C}$.

Na Fig. 4.4 são apresentados os perfis das temperaturas da superfície interna do tubo $\left(T_{s i}\right)$, temperatura do fluido de resfriamento $\left(T_{c}\right)$, gases de combustão $\left(T_{g}\right)$ e temperatura de saturação do vapor no $\mathrm{GC}\left(T_{\text {sat }}\right)$ ao longo do comprimento adimensionalizado $^{7}(z / L)$ do condensador.

Vê-se que as temperaturas decrescem ao longo de $z / L$ e praticamente convergem ao final do condensador. Isso ocorre em virtude das dimensões e das vazões de fluido de resfriamento empregadas proporcionarem área e capacidade de transferência de calor suficientemente grandes para que a temperatura de saída dos GC se aproximem da temperatura de entrada da corrente de resfriamento. Além disso, como o fluido de resfriamento é a mistura de GNC remanescente e ar, a temperatuta de saída dos GC está condicionada à temperatura de entrada do fluido de resfriamento $\left(T_{c e}\right)$.

Pelo fato dos GC, nas condições simuladas, ingressarem no condensador a uma temperatura muito superior à temperatura de saturação do vapor de água, não ocorre condensação na região inicial do tubo, havendo nela apenas transferência de calor sensível entre as correntes até o alcance da $T_{\text {sat }}$ necessária para início do processo, que no caso é igual a $37,9^{\circ} \mathrm{C}$ (correspondente a $\%$ Vol.v igual a 6,16\%). A intersecção da curva da temperatura de saturação, $T_{s a t}$, com a curva de $T_{s i}$, determina a região de ínicio da condensação. Observa-se que quanto mais baixa é $T_{c e}$, menor é a área exigida para alcance da temperatura de saturação na superfície de resfriamento. Para $T_{c e}=25^{\circ} \mathrm{C}$ são necessários $513,12 \mathrm{~m}^{2}$, para $T_{c e}=30^{\circ} \mathrm{C}$ são necessários $718,38 \mathrm{~m}^{2}$ e quando $T_{c e}=35^{\circ} \mathrm{C}$ necessita-se de $1026,30 \mathrm{~m}^{2}$. A partir do momento em que a superfície interna do tubo atinge a temperatura de saturação, parte da água contida nos GC se condensa formando uma película líquida que recobre a superfície. A partir daí, conforme ocorre o fluxo de massa em direção ao filme líquido, a fração mássica de água presente nos GC passa a decrescer ocasionando igual redução de sua pressão parcial na mistura gasosa, deste modo passa a ocorrer também a redução de $T_{\text {sat }}$ observada nos gráficos da Fig. 4.4.

\footnotetext{
${ }^{7} \mathrm{O}$ topo do condensador (entrada dos GC) corresponde a $\mathrm{z}=0$ e sua base (saída de GNC e entrada do fluido de resfriamento $\mathrm{GNC} / \mathrm{ar}$ ) corresponde a $z=L$ (no caso $70 \mathrm{~m}$ ).
} 

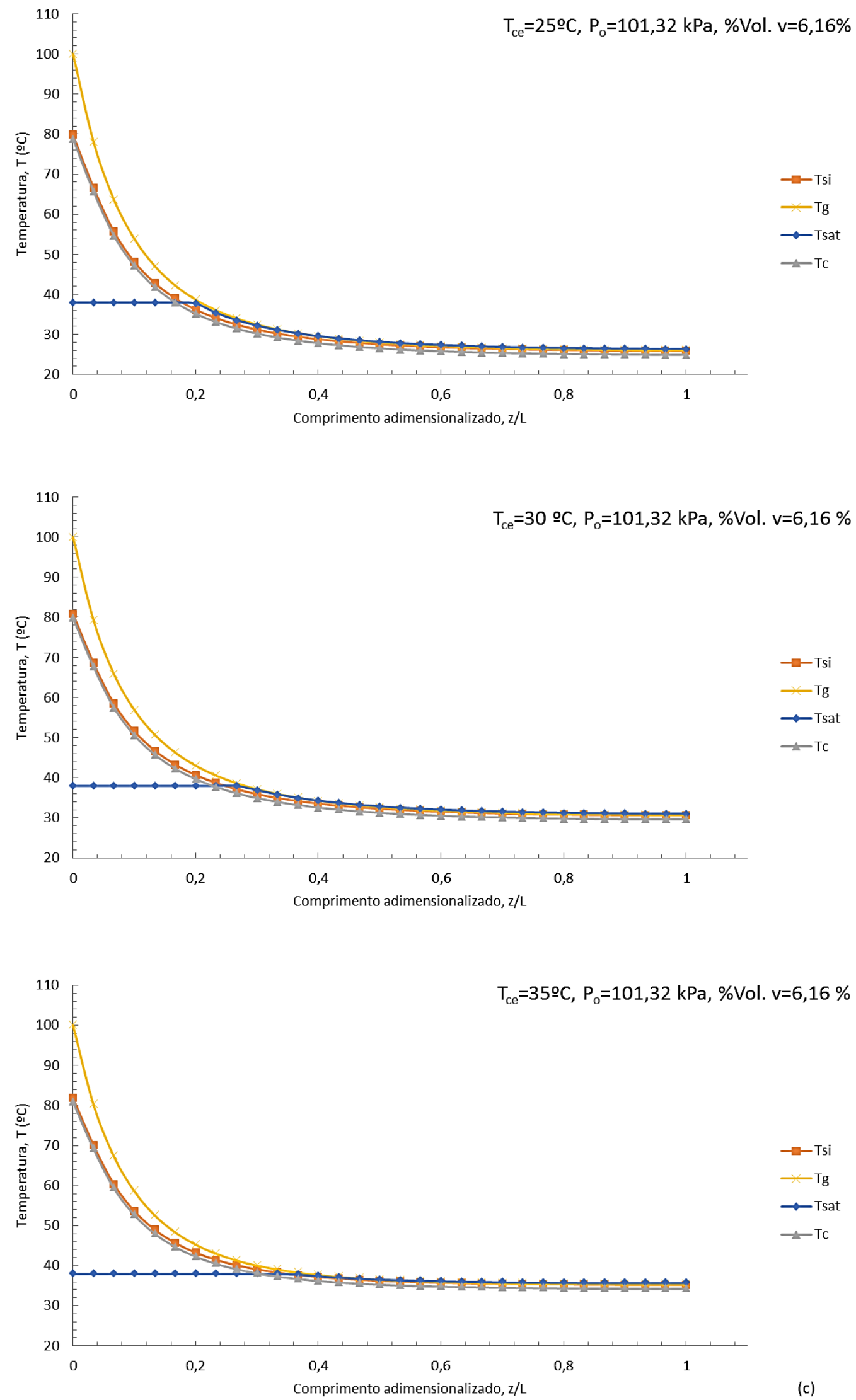

Figura 4.4 - Perfis de temperatura, $T_{s i}, T_{g}, T_{s a t}$ e $T_{c}$ para $T_{c e}=25,30$ e $35^{\circ} \mathrm{C}, P_{o}=101,32 \mathrm{kPa}$ e $\%$ Vol. $v=6,16 \%$ 
A condição para tratamento do tubo cilíndrico como sendo uma placa plana, estabelecida na seção 4.2.3 por meio da Eq. 4.26, é satisfeita desde que o diâmetro do tubo seja superior ou igual $0,49 \mathrm{~m}$. Ou seja, a abordagem realizada considerando a convecção natural ao longo de uma placa vertical placa é viável, uma vez que o diâmetro empregado $\left(D_{i}=14 \mathrm{~m}\right)$ é superior à $0,49 \mathrm{~m}$.

Na Fig. 4.5 são apresentados quatro gráficos relativos aos valores encontrados de números de Grashof, (a); número de Rayleigh, (b); número de Nusselt, (c) e coeficientes convectivos de transferência de calor do fluido de resfriamento, (d), para cada uma das $T_{c e}$ avaliadas. Vale citar que em virtude da amplitude dos valores de $G r_{c}$ e $R a_{c}$ ser muito grande, seus valores são apresentados na escala logarítimica. Observa-se que todos os referidos parâmetros decrescem ao longo de $L$, comportamento este que está diretamente associado ao perfil de temperatura evidenciado anteriormente na Fig. 4.4.

Os números de $G r_{c}$ e $R a_{c}$ indicam que o escoamento se encontra em regime turbulento ao longo da maior parte do condensador, uma vez que os mesmos partem de valores da ordem de $10^{15} \mathrm{em} \mathrm{z}=0$, onde as temperaturas são mais elevadas, e decrescem até atingirem valores da ordem de $10^{5}$ na base do condensador, região de temperaturas substancialmente menores.

Apesar de existir uma parte do condensador onde os números de Rayleigh se encontram abaixo de $2.10^{9}$, e portanto o escoamento se encontra em regime laminar, leva-se em conta o fato de que essa região se trata de uma porção muito pequena (menos de $4 \%$ do comprimento total) e que se localiza justamente onde o processo apresenta taxas de condensação extremamente baixas (como será evidenciado mais adiante). Deste modo, o escoamento dos gases de resfriamento foi tratado como sendo exclusivamente turbulento ao longo de todo o comprimento do equipamento.

Os números de Nusselt e os coeficientes convectivos de transferência de calor locais, apresentados nos gráficos (c) e (d), demonstram tendências semelhantes ao que ocorre com $G r_{c}$ e $R a_{c}$. Observa-se que nas três temperaturas simuladas os valores de origem de $N u_{c}$ e $h_{c}$ são praticamente iguais e se situam em torno de 2500 e $25 \mathrm{~W} / \mathrm{m}^{2} . \mathrm{K}$, respectivamente, com ambos tendendo a zero em $z=L$. Entretanto, percebe-se que fora das extremidades, os valores de $N u_{c}$ e de $h_{c}$ são maiores conforme maior é a $T_{c e}$. Isso se justifica à medida que os números de Grashof e, consequentemente os demais adimensionais envolvidos, estão diretamente associados às diferenças de temperatura 
que ocorrem ao longo condensador no lado do resfriamento, $\left(T_{s e}-T_{\infty}\right)$, conforme pode ser constado nas Figs. 4.6 e 4.7.

Os números de Rayleigh não sofrem variações perceptíveis em relação aos valores de $G r_{c}$ uma vez que os números de Prandtl se situam muito próximos da unidade ao longo de todo o condensador nos três casos simulados, conforme pode ser verificado nos gráficos (a) e (b) da Fig. 4.5.
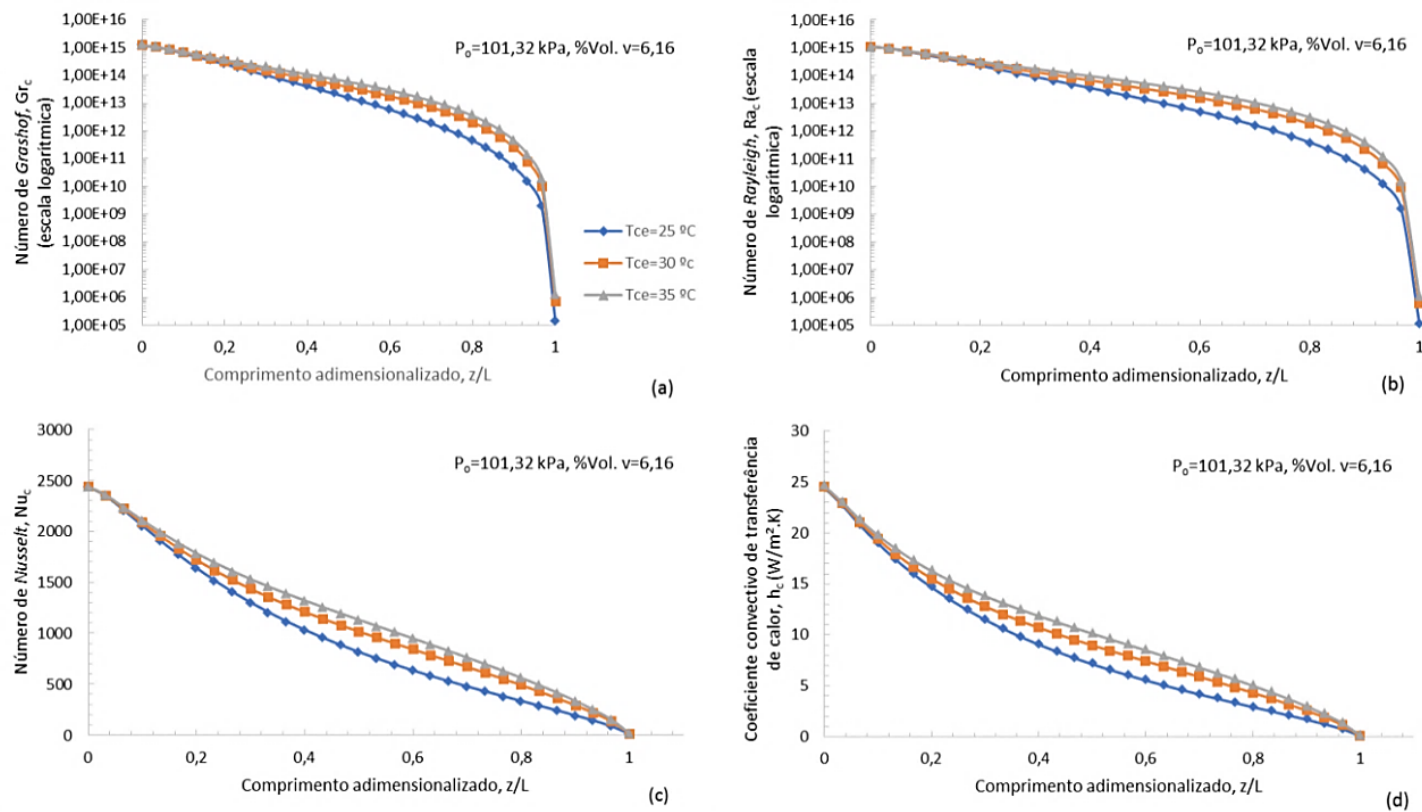

Figura 4.5 - Números adimensionais e coeficientes convectivos de transferência de calor do fluido de resfriamento, $P_{o}=101,32 \mathrm{kPa}, \%$ Vol. $v=6,16, T_{c e}=25,30$ e $35^{\circ} \mathrm{C}$

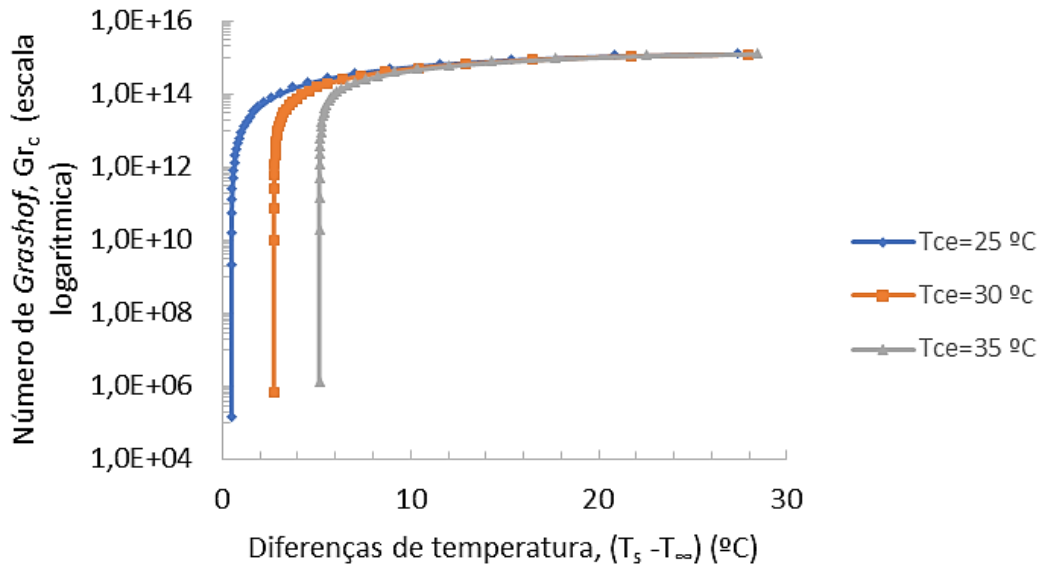

Figura 4.6 - Número de Grashof do fluido de resfriamento em função das diferenças de temperatura $\left(\mathrm{T}_{\mathrm{s}}-\mathrm{T}_{\infty}\right)$, $P_{o}=101,32 \mathrm{kPa}, \%$ Vol. $v=6,16, T_{c e}=25,30$ e $35^{\circ} \mathrm{C}$ 


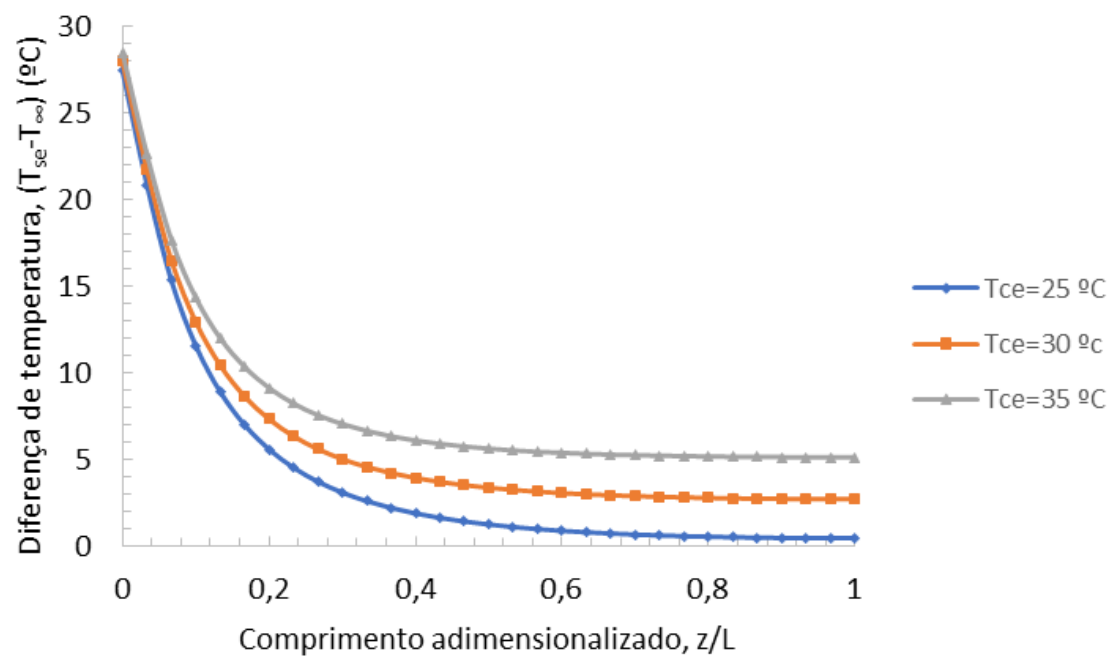

Figura 4.7 - Diferenças de temperatura $\left(T_{s e}-T_{\infty}\right)$ no lado do fluido de resfriamento, $P_{o}=101,32 \mathrm{kPa}, \%$ Vol. v $=6,16$, $T_{c e}=25,30$ e $35^{\circ} \mathrm{C}$

Devido à necessidade de introdução de uma vazão adicional de ar associdada aos GNC remanescentes para o alcance da vazão de resfriamento necessária, de modo que fossem atingidas temperaturas inferiores às de saturação nos $\mathrm{GC}$, torna-se pertinente e necessário avaliar a ocorrência do regime de convecção forçada ou combinada e quais seriam suas influências no processo. Deste modo, na Fig. 4.8 são expostas as razões $G r_{c} / R e^{2}{ }_{c}$ encontradas para cada uma das $T_{c e}$ avaliadas. Ressaltando-se que $R e_{c}$ é calculado levando-se em conta a associação das vazões de GNC e de ar utilizando-se as propriedades médias da mistura.

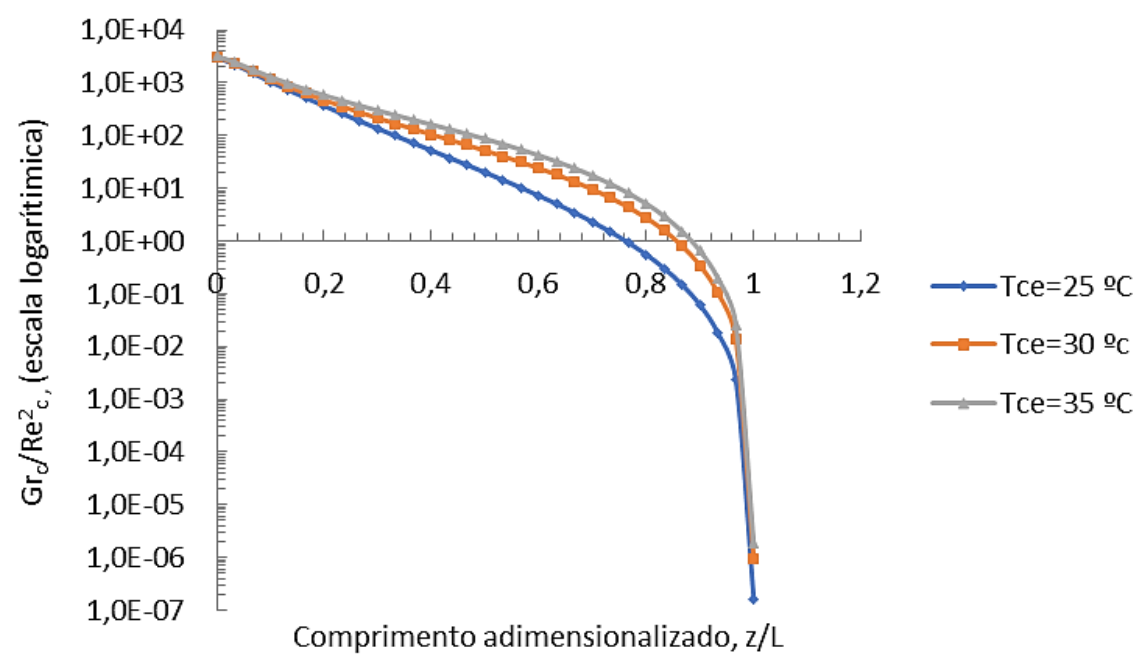

Figura 4.8 - Parâmetro adimensional $G r_{c} / R e^{2}$ ao longo de $L, P_{o}=101,32 \mathrm{kPa}, \%$ Vol. v=6,16, $T_{c e}=25,30$ e $35^{\circ} \mathrm{C}$ 
Deste modo, com base na Fig. 4.8, pode-se afirmar que nas três $T_{c e}$ simuladas a transferência de calor ocorre predominantemente sob o regime de convecção natural, uma vez que os valores de $G r_{c} / R e^{2}{ }_{c}$ avaliados ao longo do condensador são muito superiores a 1 na maior parte do equipamento. Contudo, verifica-se que quanto menor é a $T_{c e}$, a região do condensador que se encontra sob efeito de convecção forçada ou combinada (valores de $G r_{c} / R e^{2}{ }_{c}$ iguais a 1 e menores que 1), se torna maior, apesar de pequena em relação ao restante do equipamento. É também possível confirmar tal comportamento por meio dos resultados presentes na Tabela 4.4.

Com base nos dados da Tabela 4.4 pode-se calcular as áreas sob ocorrência de convecção força/combinada. Para $T_{c e}=25^{\circ} \mathrm{C}$ ocorre convecção forçada/combinada em aproximadamente $23 \%$ do condenador, para $T_{c e}=30^{\circ} \mathrm{C}$ em $13 \%$ e para $T_{c e}=35^{\circ} \mathrm{C}$ em $10 \%$.

Tabela 4.4 - Valores de $\mathrm{Gr}_{\mathrm{c}} / \mathrm{Re}_{\mathrm{c}}{ }^{2}$ na região de transição da convecção natural e combinada/forçada

\begin{tabular}{cccc}
\hline $\boldsymbol{z} / \boldsymbol{L}$ & $\boldsymbol{G} \boldsymbol{r}_{\boldsymbol{c}} / \boldsymbol{R e}_{\boldsymbol{c}}{ }^{2}\left(\mathbf{T}_{\mathbf{c e}}=\mathbf{2 5} \mathbf{C}\right)$ & $\boldsymbol{G r}_{\boldsymbol{c}} / \boldsymbol{R e}_{\boldsymbol{c}}{ }^{2}\left(\mathbf{T}_{\mathrm{ce}}=\mathbf{3 0} \mathbf{C}\right)$ & $\boldsymbol{G r}_{\boldsymbol{c}} / \boldsymbol{R e}_{\boldsymbol{c}}{ }^{2}\left(\mathbf{T}_{\mathrm{ce}}=\mathbf{3 5} \mathbf{C}\right)$ \\
\hline 0,70 & 2,346 & 9,566 & 17,418 \\
0,73 & 1,524 & 6,630 & 12,182 \\
$\mathbf{0 , 7 7}$ & $\mathbf{0 , 9 5 2}$ & 4,396 & 8,139 \\
0,80 & 0,563 & 2,748 & 5,120 \\
0,83 & 0,309 & 1,583 & 2,966 \\
$\mathbf{0 , 8 7}$ & 0,152 & $\mathbf{0 , 8 1 0}$ & 1,524 \\
$\mathbf{0 , 9 0}$ & 0,062 & 0,343 & $\mathbf{0 , 6 4 9}$ \\
0,93 & 0,018 & 0,104 & 0,196 \\
0,97 & 0,002 & 0,014 & 0,026 \\
1,00 & 0,000 & 0,000 & 0,000 \\
\hline
\end{tabular}

Os valores em negrito indicam a região em que o parâmetro adimensional $G r_{c} / R e_{c}^{2}$ passa a ser menor que 1 e, portanto, onde de acordo com a literatura, ocorre transição do mecanismo de transmissão de calor de convecção natural para forçada ou combinada. É importante frisar que pelo fato de não haver uma delimitação exata de onde os valores de $G r_{c} / \operatorname{Re}_{c}{ }^{2}$ se tornam iguais a 1 e onde os mesmos passam a ser menores que 1 , não é possível se delimitar com precisão as regiões de ocorrência da combinação entre convecção natural e forçada.

Embora tenha sido demonstrado que o processo também ocorra por meio de convecção forçada e combinada em uma pequena região da base do condensador, levou-se em conta apenas a ocorrência de convecção natural para estimativa dos 
coeficientes de transferência de calor do fluido de resfriamento. Isso porque a região citada é proporcionalmente pequena frente ao restante do equipamento. Complementarmente, em razão das características do processo, observa-se que nesta região os coeficientes de transferência de calor e de massa do gás de combustão são demasiadamente pequenos e correspondem a ínfimas taxas de condensação, aspecto que será discutido adiante.

A ocorrência da convecção natural está associada à diferença de densidade que se estabelece progressivamente entre os gases de resfriamento nas imediações da superfície e longe dela, uma vez que o tubo interno apresenta temperaturas que aumentam a partir base do condensador $(z=L)$ em direção ao seu topo $(z=0)$. Esta condição de temperatura crescente em direção ao topo é responsável por estabelecer diferenças de densidade ao longo de todo o comprimento do condensador, gerando assim o movimento ascendente da mistura de GNC/ar, responsável pelo resfriamento. Nos gráficos (a), (b) e (c) da Fig. 4.9 são apresentadas as curvas das densidades estabelecidas para cada das $T_{c e}$ avaliadas, obtidas a partir da Eq. 4.28.

Verifica-se que a menor $T_{c e}, 25^{\circ} \mathrm{C}$, promove temperaturas menores na superfície de troca de calor, o que por sua vez acarreta densidades maiores do fluido de resfriamento, as quais variam de $1,1583 \mathrm{~kg} / \mathrm{m}^{3}$, na base do condensador $(z=L)$, até $0,9874 \mathrm{~kg} / \mathrm{m}^{3}$ no topo. Em contrapartida, as temperaturas superiores a $25^{\circ} \mathrm{C}$ promovem temperaturas mais elevadas na superfície, ocasionando densidades mais baixas que variam de $1,1412 \mathrm{~kg} / \mathrm{m}^{3}$ a $0,9847 \mathrm{~kg} / \mathrm{m}^{3}$, para $T_{c e}=30^{\circ} \mathrm{C}$, e de $1,1136 \mathrm{~kg} / \mathrm{m}^{3}$ a $0,9820 \mathrm{~kg} / \mathrm{m}^{3}$, para $T_{c e}=35^{\circ} \mathrm{C}$. 
$\mathrm{T}_{\mathrm{ce}}=25 \stackrel{\circ}{ } \mathrm{C}, \mathrm{P}_{\mathrm{o}}=101,32 \mathrm{kPa}, \%$ Vol. v=6,16

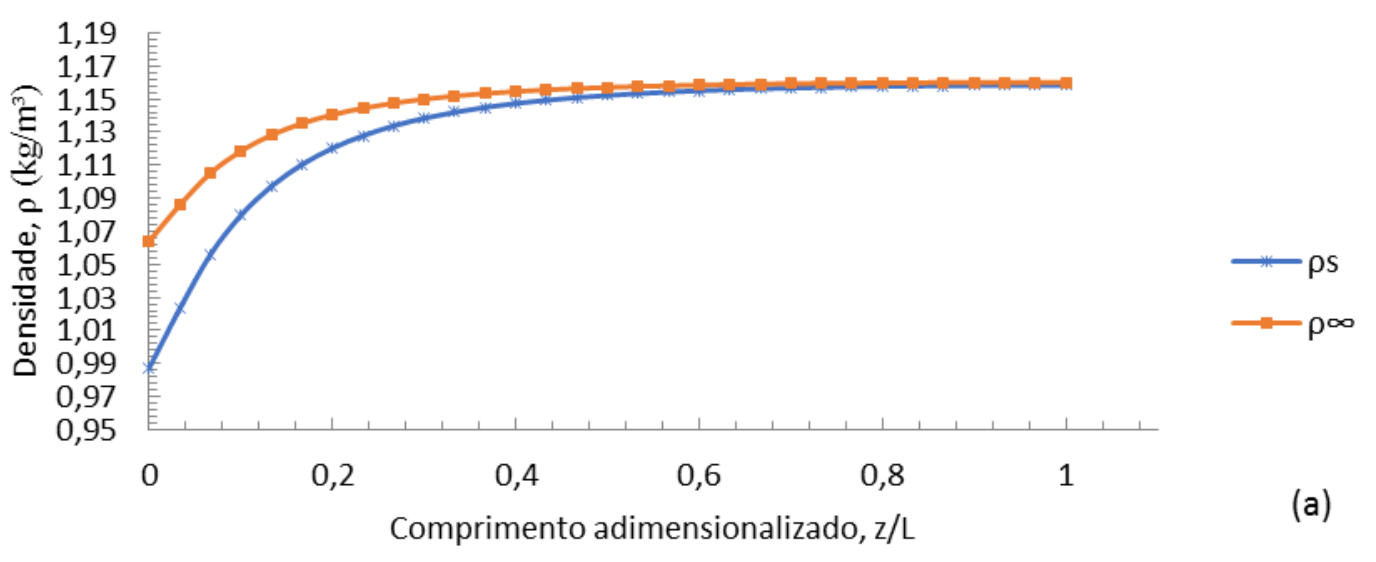

$\mathrm{T}_{\mathrm{ce}}=30 \stackrel{\circ}{\mathrm{C}}, \mathrm{P}_{\mathrm{o}}=101,32 \mathrm{kPa}, \% \mathrm{Vol} . \mathrm{v}=6,16$

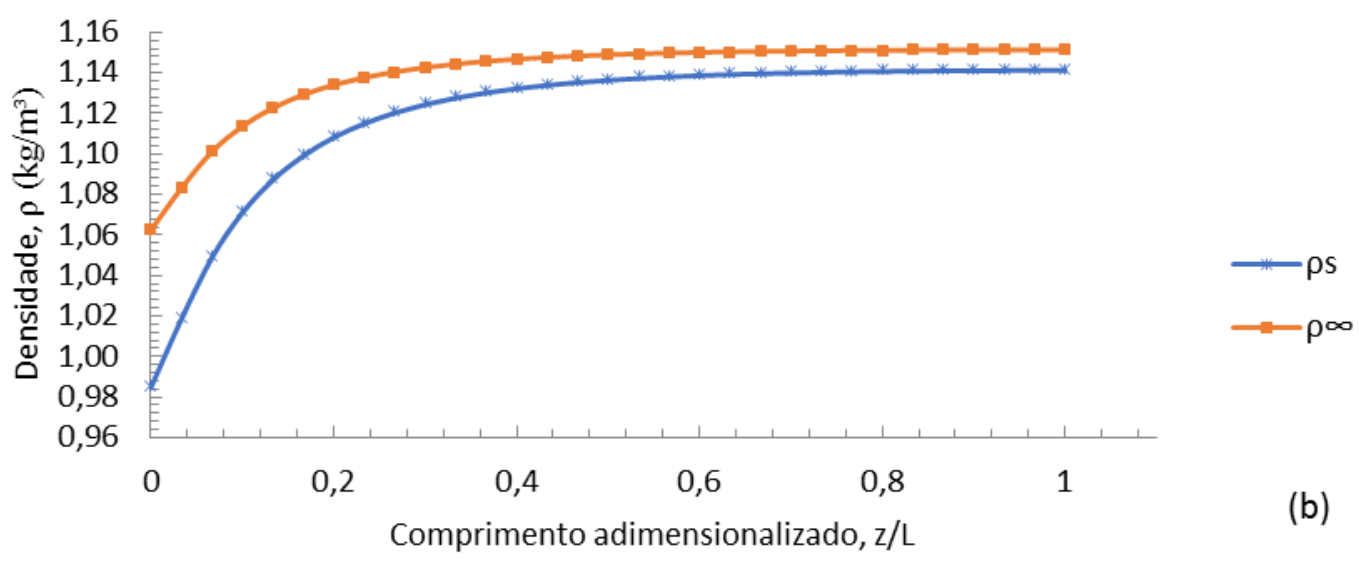

$\mathrm{T}_{\mathrm{ce}}=35 \stackrel{\circ}{\circ} \mathrm{C}, \mathrm{P}_{\mathrm{o}}=101,32 \mathrm{kPa}, \% \mathrm{Vol} . \mathrm{v}=6,16$

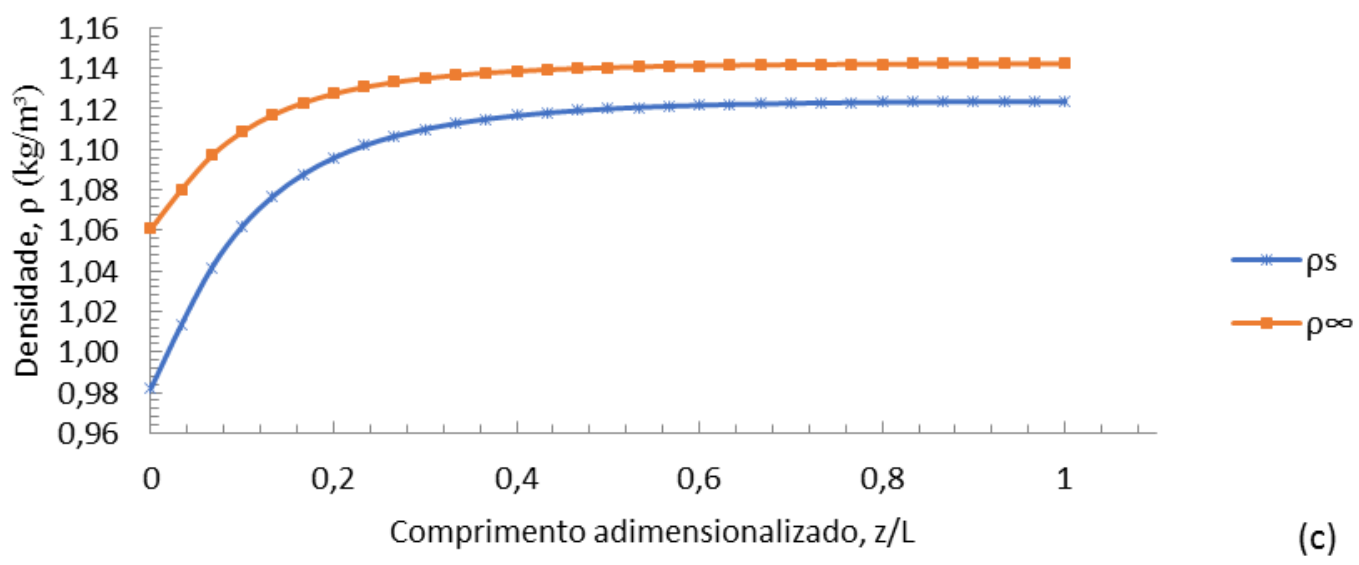

Figura 4.9 - Densidades do fluido de resfriamento na superfície e ao longe. (a) $T_{c e}=25^{\circ} \mathrm{C}$, (b) $T_{c e}=30^{\circ} \mathrm{C}$, (c) $T_{c e}=$ $35^{\circ} \mathrm{C}, P_{o}=101,32 \mathrm{kPa}$ e $\%$ Vol. $v=6,16$

Até o momento foram tratados apenas aspectos relacionados à transferência de calor no fluido de resfriamento e ao mecanismo de convecção natural empregado para tal. Não obstante, o processo de condensação, conforme discutido no desenvolvimento 
do modelo, também depende dos coeficientes de transferência de calor dos GC $\left(h_{g}\right)$ do filme líquido $\left(h_{f}\right)$ e do coeficiente de condensação propriamente dito $\left(h_{c d}\right)$. A partir destes coeficientes, aliados ao coeficiente convectivo do fluido de resfriamento $\left(h_{c}\right)$ e à resistência térmica da parede do tubo $\left(R_{w}\right)$, pôde ser calculado o coeficiente global de transferência de calor $(U)$.

Nas Figs. $4.10,4.11$ e 4.12 podem ser verificados os comportamentos de $h_{c d}, h_{f l}$ e $h_{g}$ para $T_{c e}=25,30$ e $35^{\circ} \mathrm{C}$ com $P_{o}=101,32 \mathrm{kPa}$. Considera-se que os referidos coeficientes sejam relevantes a partir do momento que a temperatura da superfície atinge a temperatura de saturação do vapor e a condensação passa a acontecer, o que ocorre a partir de $z / L$ igual a $0,20,0,27$ e 0,33 , subsequentemente.

Os coeficientes de condensação $\left(h_{c d}\right)$ apresentam forte redução nos primeiros metros do equipamento após início do processo, com valores partindo de aproximadamente $5500 \mathrm{~W} / \mathrm{m}^{2} . \mathrm{K}$, que decrescem acentuadamente nos comprimentos subsequentes, tendendo a valores notoriamente pequenos em $z / L=1$, onde as taxas de condensação são extremamente baixas.

Da mesma forma, os coeficientes $h_{g}$, apesar de possuírem valores inicialmente muito menores se comparados à $h_{c d}$, também demonstram redução acentuada ao longo de $L$, atingindo valores bastante baixos ao final do condensador, estando estes associados à elevação da fração de GNC nos GC, no caso de $h_{g}$, e ao decréscimo das taxas de condensação, no caso de $h_{c d}$. Não foram encontradas diferenças substanciais entre coeficientes observados em relação às $T_{c e}$ simuladas. Nos três casos, os valores de $h_{g}$ variam de, aproximadamente, $900 \mathrm{~W} / \mathrm{m}^{2} . \mathrm{K}$ até $20 \mathrm{~W} / \mathrm{m}^{2} . \mathrm{K}$.

À medida que a água passa da fase vapor para a fase líquida, o filme líquido tem sua espessura incrementada, o que por sua vez eleva sua resistência térmica e diminui seu coeficiente de transferência de calor. Deste modo, $\underline{h}_{f}$ também tem seus valores degradados ao longo comprimento, com valores iniciais em torno de $1500 \mathrm{~W} / \mathrm{m}^{2}$.K que decrescem até, aproximadamente, $850 \mathrm{~W} / \mathrm{m}^{2} . \mathrm{K}$.

De modo geral, constata-se por meio dos três gráficos, que os maiores coeficientes de transferência de calor se concentram na região do trocador de calor localizada logo após o início do processo, independentemente da temperatura de entrada do fluido de resfriamento. 

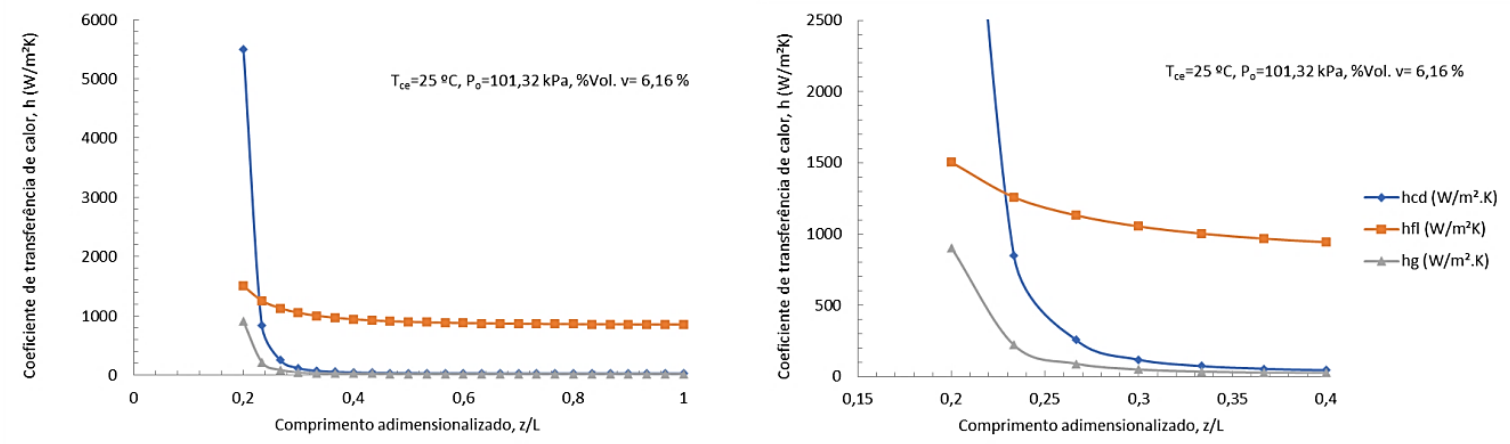

Figura 4.10 - Coeficientes de transferência de calor de condensação $\left(h_{c d}\right)$, do filme líquido $\left(h_{f l}\right)$ e dos gases de combustão $\left(h_{g}\right), T_{c e}=25^{\circ} \mathrm{C}, P_{o}=101,32 \mathrm{kPa}$ e $\%$ Vol. $v=6,16$
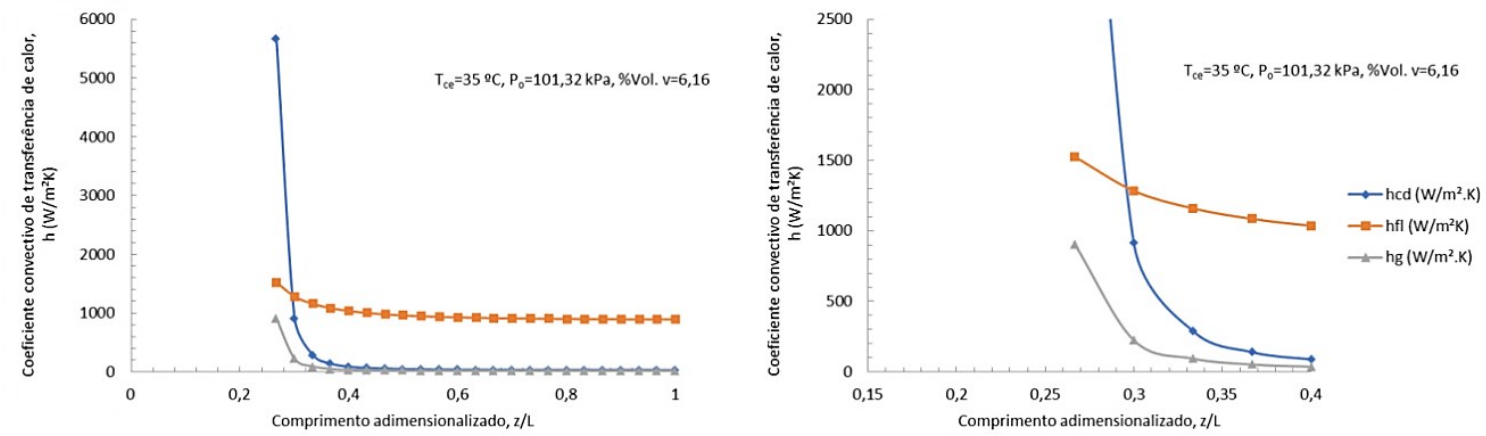

Figura 4.11 - Coeficientes de transferência de calor de condensação $\left(h_{c d}\right)$, do filme líquido $\left(h_{f l}\right)$ e dos gases de combustão $\left(h_{g}\right), T_{c e}=30^{\circ} \mathrm{C}, P_{o}=101,32 \mathrm{kPa}, \%$ Vol. $v=6,16$
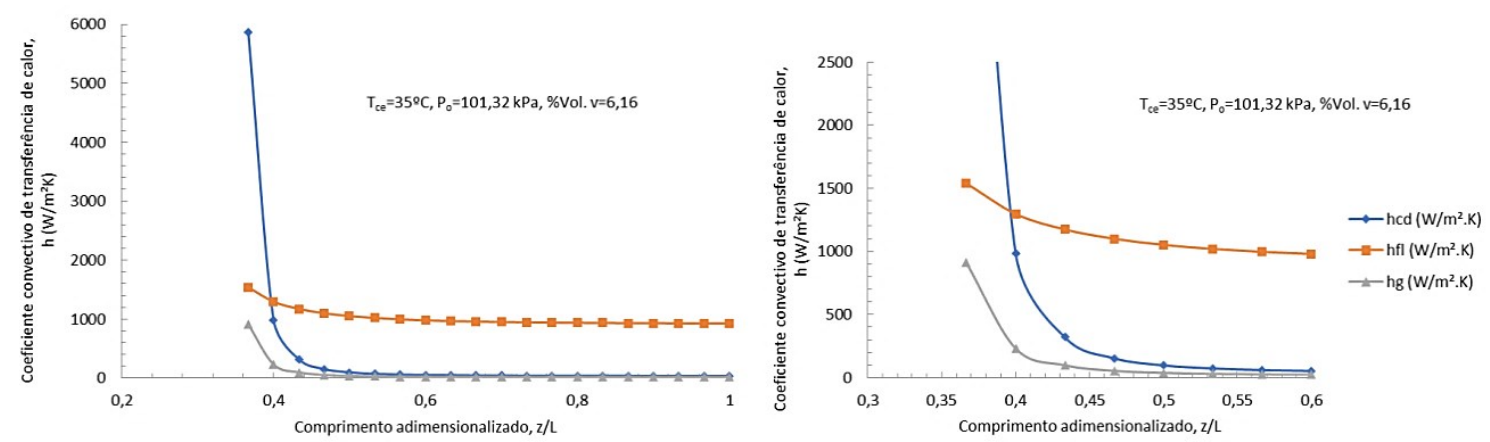

Figura 4.12 - Coeficientes de transferência de calor de condensação $\left(h_{c d}\right)$, do filme líquido $\left(h_{f l}\right)$ e dos gases de combustão $\left(h_{g}\right), T_{c e}=35^{\circ} \mathrm{C}, P_{o}=101,32 \mathrm{kPa}, \%$ Vol. $v=6,16$

Na Fig. 4.13 são apresentados os coeficientes globais de transferência de calor, $U$. Os resultados, notoriamente baixos, são resultantes da elevada resistência térmica encontrada no fluido de resfriamento, a qual é decorrente dos baixos coeficientes de transferência de calor ao longo de todo o condensador $\left(24 \mathrm{~W} / \mathrm{m}^{2} . \mathrm{K}\right.$ no topo até valores próximos de zero na base). Apesar de baixos, estes resultados são compatíveis com valores típicos preconizados pela literatura envolvendo processos de convecção natural 
com gases ao longo de placas planas verticais. Incropera et al. (2011), por exemplo, cita valores de 2 a $25 \mathrm{~W} / \mathrm{m}^{2} . \mathrm{K}$; Lienhard IV e Lienhard V (2001) reportam um valor médio de $4,33 \mathrm{~W} / \mathrm{m}^{2} . \mathrm{K}$ para uma parede de $0,3 \mathrm{~m}$ exposta ao ar e diferença de temperatura igual a $30^{\circ} \mathrm{C}$; Hewitt et al. (1993) indicam valores entre 5 e $25 \mathrm{~W} / \mathrm{m}^{2} . \mathrm{K}$.

Deste modo, os valores de $U$ são limitados, na maior parte do equipamento, e notoriamente semelhantes aos valores encontrados para $h_{c}$, os quais foram previamente apresentados no gráfico $(\mathrm{d})$ da Fig. 4.5.

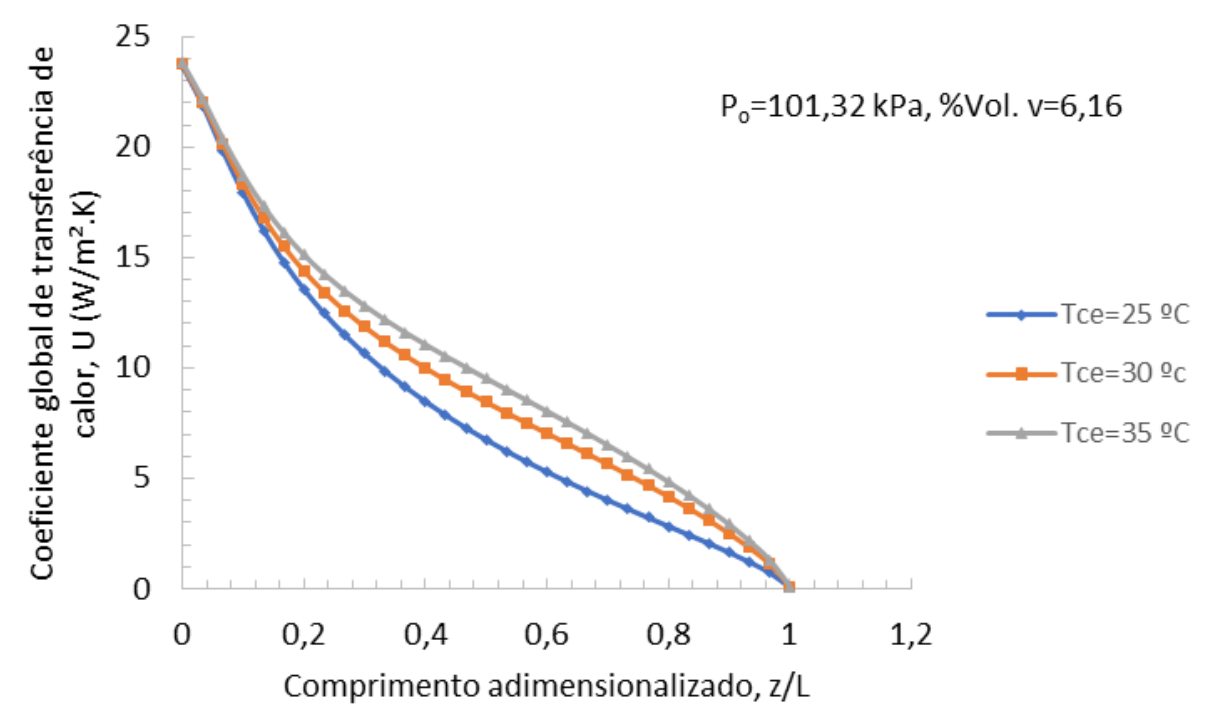

Figura 4.13 - Coeficientes globais de transferência de calor, $U, P_{o}=101,32 \mathrm{kPa}, \%$ Vol $v=6,16, T_{c e}=25,30$ e $35^{\circ} \mathrm{C}$.

No lado dos GC, além da transferência de calor sensível, decorrente das diferenças de temperatura estabelecidas, e da transferência da entalpia de condensação resultante da mudança de fase do vapor de água, o processo de condensação é, neste caso específico de presença de outros gases além do vapor de água, também dependente do transporte do vapor através da camada de GNC que se estabelece, em um primeiro momento, enquanto não ocorre condensação, na região adjacente à superfície, e posteriormente, após o começo da condensação, na região adjacente ao filme líquido.

O processo de migração do vapor é condicionado ao coeficiente convectivo de transferência de massa, $k_{g}$, e à diferença de fração mássica estabelecida entre o seio do fluido e a interface com o filme de condensado $\left(x_{v, b}-x_{v, i}\right)$. 
Estimados os coeficientes de transferência de massa, em princípio, não se constata influência relevante da $T_{c e}$, uma vez que as curvas apresentam valores praticamente iguais, porém deslocados em $z / L$ por conta dos diferentes pontos de início da condensação, conforme pode ser observado na Fig. 4.14.

De modo semelhante ao que ocorre com os coeficientes de transferência de calor, verifica-se acentuada redução dos valores nos primeiros metros logo após o início da condensação. Ressaltam-se valores iniciais ligeiramente superiores conforme maior é a $T_{c e}$. Nos três casos os valores iniciais se situam em torno de $0,13 \mathrm{~kg} / \mathrm{m}^{2} . \mathrm{s}$ e decaem para valores da ordem de $5.10^{-3} \mathrm{~kg} / \mathrm{m}^{2} . \mathrm{s}$ no final do condensador.

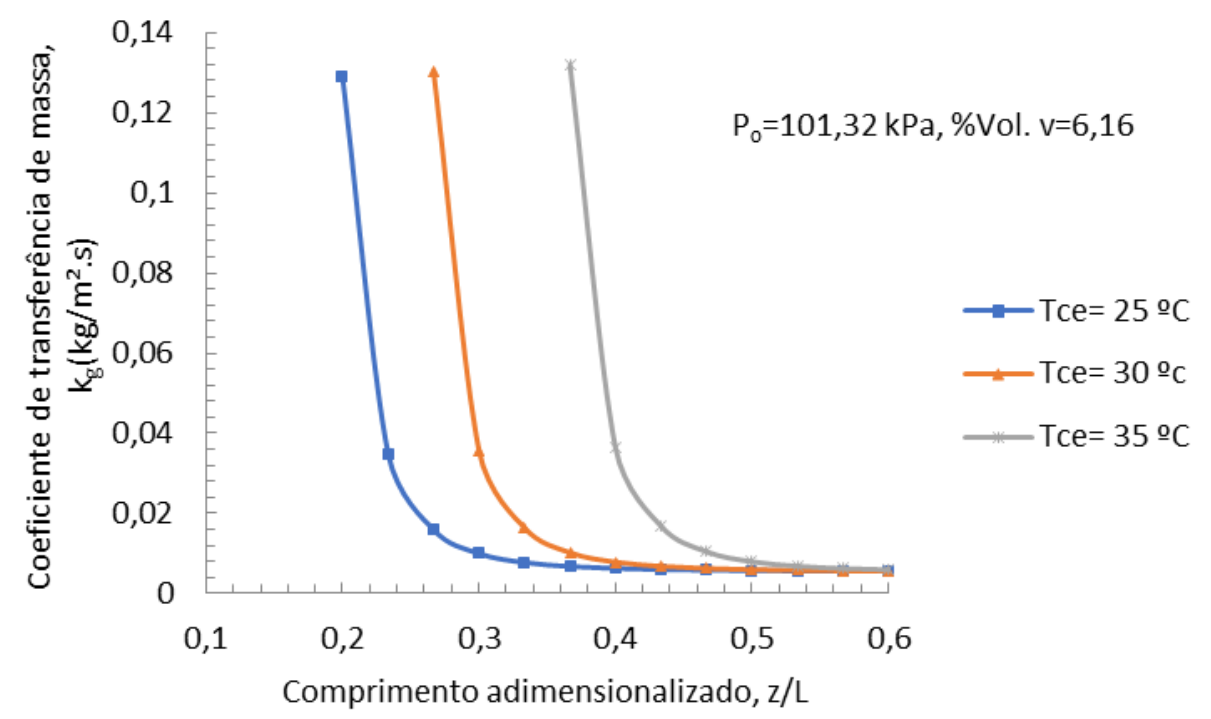

Figura 4.14 - Coeficientes de transferência de massa nos GC, $k_{g}, P_{o}=101,32 \mathrm{kPa}, \% \mathrm{Vol} v=6,16, T_{c e}=25,30 \mathrm{e} 35^{\circ} \mathrm{C}$.

A seguir, a Fig. 4.15 (a) e (b) mostra os valores das diferenças de fração mássica de vapor $\left(x_{v, b}-x_{v, i}\right)$ que se estabelecem ao longo do condensador, bem como estes mesmos resultados em função das respectivas diferenças de temperatura, $\left(T_{g}-T_{i}\right)$, observadas no decorrer do processo. Tomando-se como referência o ponto de início da condensação particular de cada uma das $T_{c e}$ avaliadas, nota-se a ocorrência de valores ligeiramente maiores de $\left(x_{v, b}-x_{v, i}\right)$ conforme menor é a $T_{c e}$, fato justificado pela existência de maiores gradientes de temperatura entre o seio da mistura gasosa e a interface na região correspondente ao início da condensação. 
Como já evidenciado pelos perfis de temperatura expostos na Fig. 4.4, as temperaturas dos $\mathrm{GC}$ e da interface decrescem ao longo do condensador, fazendo com que a pressão de saturação do vapor, nesta mesma interface, também decresça. Deste modo, sendo a pressão do sistema constante e a fração de vapor definida como a relação entre sua pressão parcial e a pressão total do sistema, observa-se igual redução de seus valores ao longo de $L$. Assim, conforme menor é a $T_{c e}$, menores são as temperaturas observadas na interface e, por consequência, mais baixas se tornam as pressões parciais e as frações mássicas correspondentes.
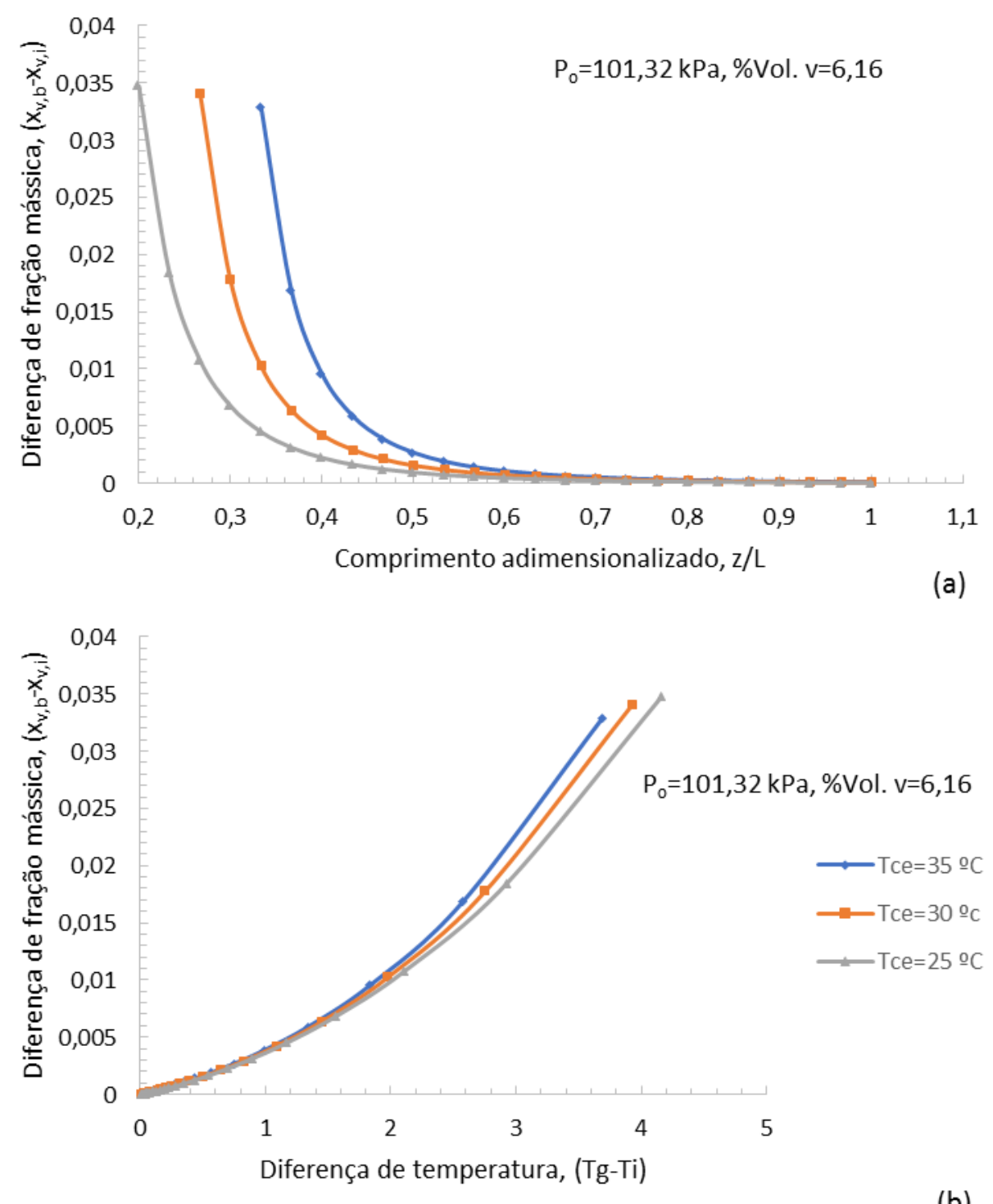

Figura 4.15 - Diferença de fração mássica entre o GC e a interface $\left(x_{v, b}-x_{v, i}\right)$. (a) ao longo de $L$. (b) em função de $\left(T_{g}-T_{i}\right), P_{o}=101,32 \mathrm{kPa}, \%$ Vol $v=6,16, T_{c e}=25,30$ e $35^{\circ} \mathrm{C}$. 
Avaliados os coeficientes de transferência de calor $\left(h_{c}\right.$ e $\left.h_{g}\right)$ e de massa $\left(k_{g}\right)$, assim como foram também calculadas as diferenças de concentração e de temperatura que se estabelecem ao longo do condensador, pôde-se, para cada uma das condições de simulação, se obter a vazão mássica de água recuperada, a taxa de transferência de calor e o rendimento do processo de condensação correspondentes às condições simuladas. Os resultados encontrados são apresentados na Tabela 4.5, a seguir.

Tabela 4.5 - Resultados obtidos para avaliação da variação da temperatura de entrada do fluido de resfriamento, $T_{c e}$. $P_{o}=101,32 \mathrm{kPa}$ e $\%$ Vol. $v=6,16 \%$.

\begin{tabular}{cccc}
\hline & $\boldsymbol{T}_{c e}=\mathbf{2 5}^{\mathbf{0}} \mathbf{C}$ & $\boldsymbol{T}_{c e}=\mathbf{3 0}^{\mathbf{0}} \mathbf{C}$ & $\boldsymbol{T}_{c e}=\mathbf{3 5}^{\mathbf{0}} \mathbf{C}$ \\
\hline$\dot{\boldsymbol{m}}_{\boldsymbol{c d}}(\mathbf{k g} / \mathbf{s})$ & 3,01 & 2,99 & 2,95 \\
$\boldsymbol{\eta}_{c d}(\mathbf{\%})$ & 18,83 & 18,67 & 18,43 \\
$\dot{\boldsymbol{Q}}(\mathbf{M W})$ & 7,05 & 6,90 & 6,87 \\
\hline
\end{tabular}

A partir dos resultados da Tabela 4.5, pode-se depreender que o desempenho do processo se mostrou pouco dependente das temperaturas de entrada do fluido de resfriamento. O fato dos coeficientes de transferência de calor e de massa serem superiores nas maiores $T_{c e}$ não é representativo, já que a maior influência, em se tratando da presente análise, reside na ocorrência de diferenças de concentração mais elevadas, resultantes das maiores diferenças de temperatura entre o seio da mistura de gases e a interface com o filme, correspondentes às menores $T_{c \text { e }}$.

Em se tratando de convecção natural, observam-se coeficientes superiores para as maiores $T_{c e}$, uma vez que o número de Grashof é, em essência, diretamente proporcional e dependente das diferenças de temperatura que se constituem ao longo do comprimento do condensador. Portanto, as maiores diferenças de temperatura encontradas para maiores $T_{c e}$ possibilitam o alcance de coeficientes de transferência de calor ligeiramente maiores. Entretanto, a temperatura de entrada do fluido de resfriamento é limitada pela temperatura mínima para que a convecção natural ocorra e, do mesmo modo, pela temperatura máxima para que sejam atingidas temperaturas inferiores às temperaturas de saturação no lado dos GC.

Os resultados demonstram que o fato do processo se iniciar mais tardiamente, quando são empregadas $T_{c e}$ mais elevadas é irrelevante, já que a área superficial de troca de calor empregada nas simulações é suficientemente grande para que a 
condensação ocorra por completo e para que as temperaturas do fluido de resfriamento e dos gases de combustão se igualem na área restante do condensador. Ou seja, pode-se dizer que a área empregada está superdimensionada para quaisquer que sejam as condições de operação simuladas.

Analisando-se os números da Tabela 4.5 de forma quantitativa, pode-se afirmar que as taxas de condensação e seus respectivos rendimentos de recuperação, nas três condições de simulação avaliadas, são notoriamente baixos.

\subsubsection{Pressão de operação, $P_{o}$}

Além da pressão atmosférica $(101,32 \mathrm{kPa})$ empregada nas simulações anteriores, foram avaliadas outras três pressões de operação: 105, 110 e $120 \mathrm{kPa}$. Como mencionado nas hipóteses de desenvolvimento do modelo, considera-se que a pressão se mantenha constante ao longo de todo o condensador.

A Fig. 4.16 (a) e (b) disponibiliza o comportamento dos coeficientes convectivos de transferência de calor e de massa no lado dos GC ao longo do condensador em cada uma das pressões avaliadas. 


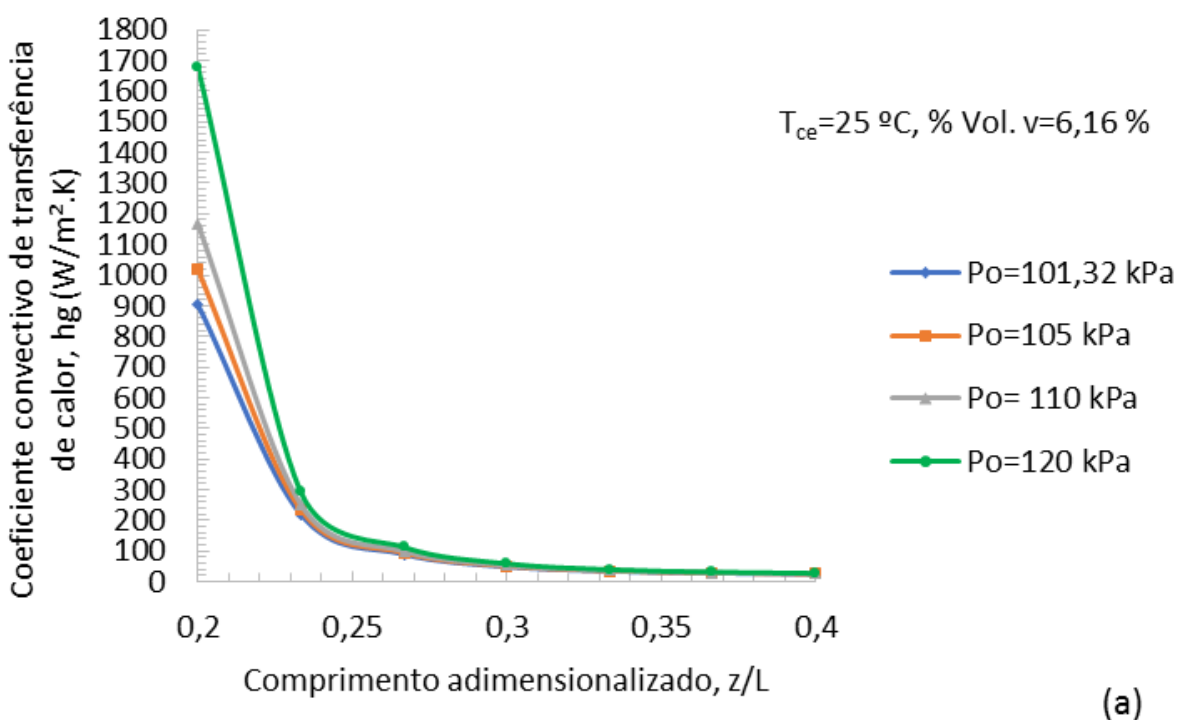

(a)

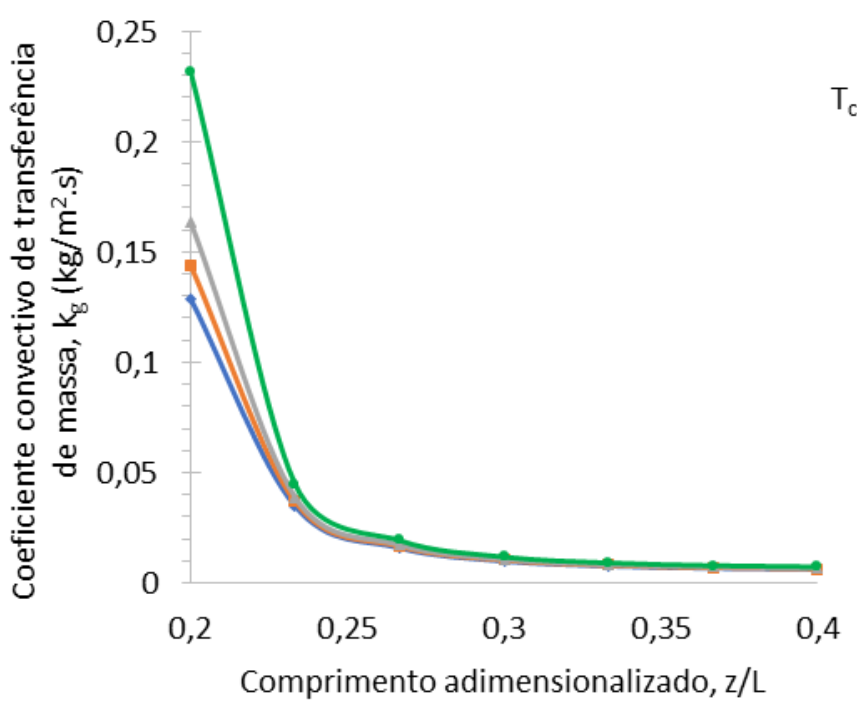

$\mathrm{T}_{\text {ce }}=25 \stackrel{\circ}{\circ}, \%$ Vol. v=6,16\%

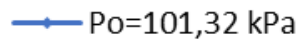

$-\mathrm{Po}=105 \mathrm{kPa}$

$-\mathrm{Po}=110 \mathrm{kPa}$

$\longrightarrow \mathrm{Po}=120 \mathrm{kPa}$

Figura 4.16 - Influência da pressão nos coeficientes de transferência de calor e de massa. (a) coeficiente convectivo de transferência de calor, (b) coeficiente convectivo de transferência de massa. $T_{c e}=25^{\circ} \mathrm{C}, \%$ Vol. $v=6,16$ e $P_{o}=$ $101,32,105,110$ e $120 \mathrm{kPa}$.

Verifica-se que o aumento da pressão influencia positivamente ambos os coeficientes, ocasionando acréscimos expressivos em seus valores, sobretudo no início da condensação. Como mencionado previamente, quando a pressão do sistema é $101,32 \mathrm{kPa}$, os valores de $h_{g}$ e $k_{g}$ se situam ao redor de $900 \mathrm{~W} / \mathrm{m}^{2} . \mathrm{K}$ e $0,13 \mathrm{~kg} / \mathrm{m}^{2} . \mathrm{s}$, respectivamente. Já quando a pressão é elevada a $105 \mathrm{kPa}$, os coeficientes iniciais observados se encontram em torno de $1000 \mathrm{~W} / \mathrm{m}^{2} . \mathrm{K}$ e $0,15 \mathrm{~kg} / \mathrm{m}^{2}$.s e quando $P_{o}$ é igual a $110 \mathrm{kPa}$, os valores iniciais de $h_{g}$ e $k_{g}$ saltam para aproximadamente $1150 \mathrm{~W} / \mathrm{m}^{2}$ e $0,16 \mathrm{~kg} / \mathrm{m}^{2} . \mathrm{s}$. Na condição de $P_{o}=120 \mathrm{kPa}$ notam-se coeficientes iniciais bem mais elevados, em torno de $1700 \mathrm{~W} / \mathrm{m}^{2} . \mathrm{K}$ e $0,23 \mathrm{~kg} / \mathrm{m}^{2} . \mathrm{s}$. 
Decorridos os primeiros metros do condensador, constata-se que em aproximadamente $z / L=0,35$, os valores correspondentes às quatro curvas se tornam bastante reduzidos e praticamente se igualam - ao redor de $20,5 \mathrm{~W} / \mathrm{m}^{2} . \mathrm{K} \mathrm{e} 0,03 \mathrm{~kg} / \mathrm{m}^{2} . \mathrm{s}-$ seguindo a mesma tendência até o final do condensador. A proximidade dos valores, a partir de $z / L=0,35$, sugere que apesar da influência da pressão continuar existindo, ela já não é mais significativa no restante do condensador.

Adicionalmente, pode-se verificar a influência da pressão nos coeficientes de transferência de massa por meio da análise dos coeficientes de difusividade $\left(\right.$ Dif $\left._{v, a r}\right)$, Fig. 4.17, e dos correspondentes números de $S c h m i d t\left(S c_{g}\right)$, Fig. 4.18.

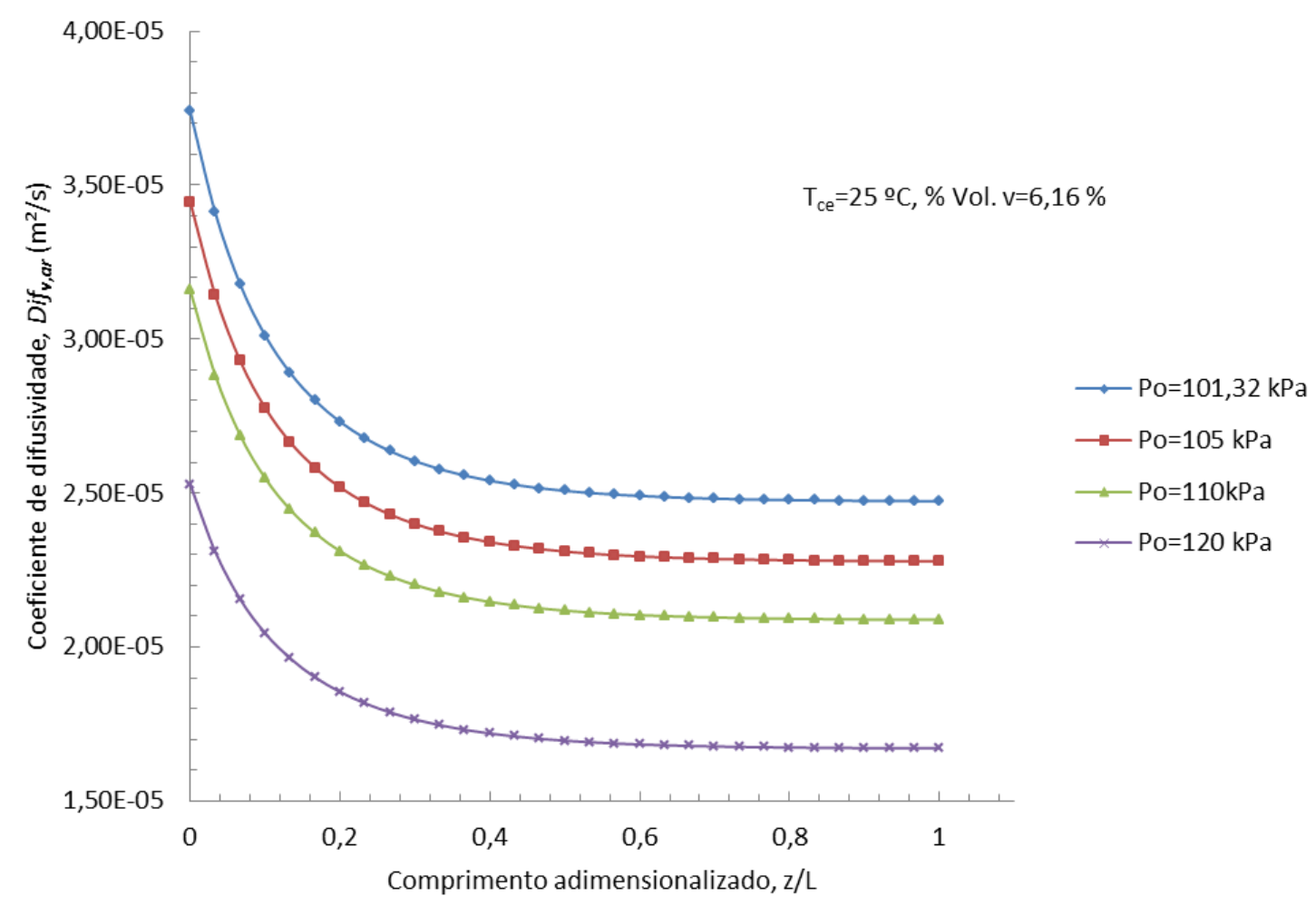

Figura 4.17 - Coefcientes de difusividade do vapor ao longo do condensador, $T_{c e}=25^{\circ} \mathrm{C}, \%$ Vol. $v=6,16, P_{o}=101,32$, 105,110 e $120 \mathrm{kPa}$.

O coeficiente de difusividade é inversamente proporcional à pressão e diretamente proporcional à temperatura do fluido, conforme pode ser observado tanto pelos resultados da Fig. 4.17 como pela Eq. 4.44. 


$$
D i f_{v, a r}=\frac{1,87 \times 10^{-10} T^{2,072}}{P_{o}}
$$

Apesar das menores pressões propiciarem maiores coeficientes de difusividade, estes valores resultam em maiores valores de $S c_{g}$, conforme pode ser constatado por meio dos resultados expostos na Fig. 4.18. O número de Schmidt é definido como a razão de difusividade de momento e difusividade de massa nas camadas limite hidrodinâmica e de concentração $\left(v / D i f_{v, a r}\right)$. Deste modo, têm-se maiores valores de $S c_{g}$ correspondentes às maiores pressões.

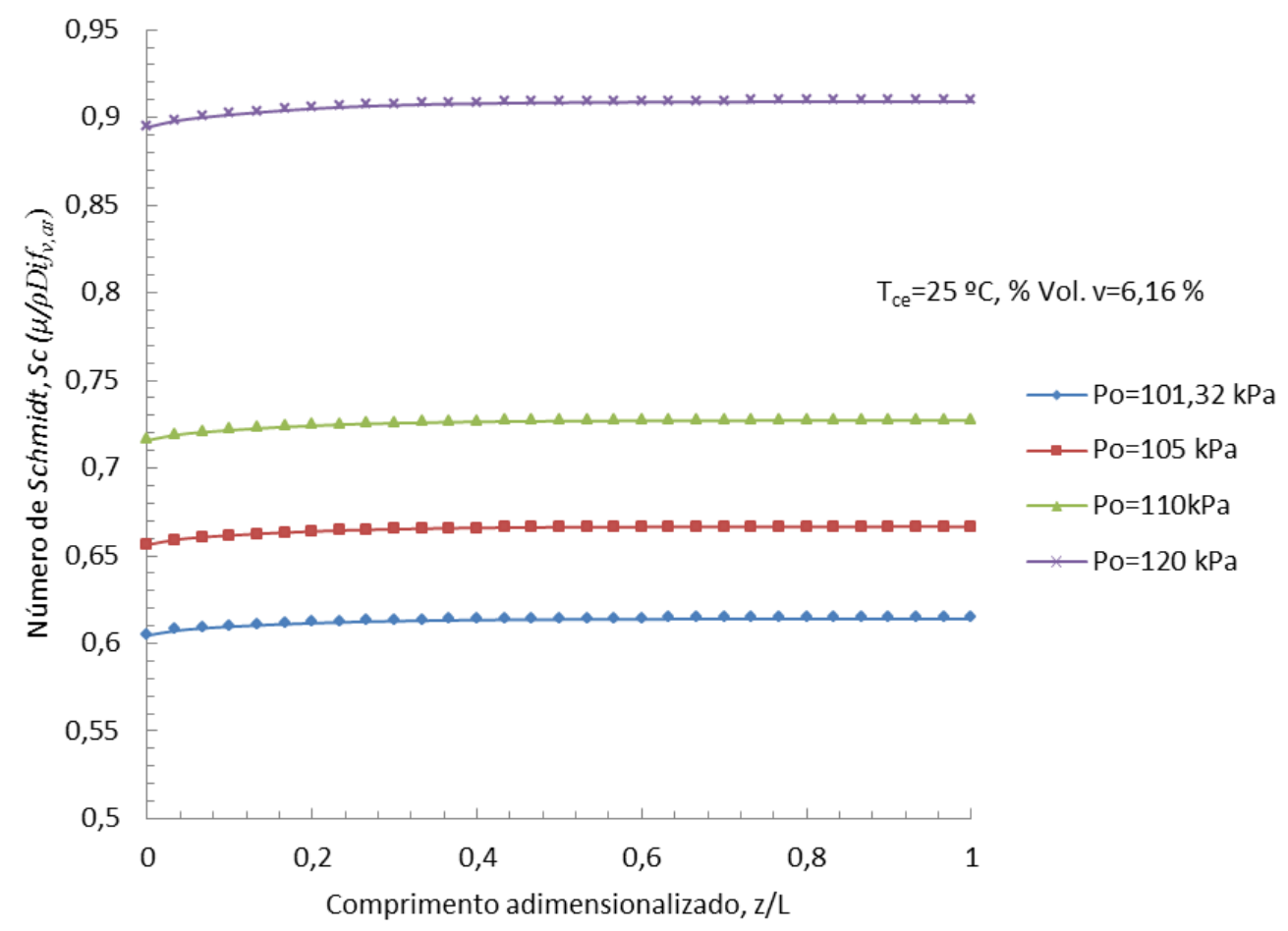

Figura 4.18 - Números de Schmidt ao longo do condensador, $T_{c e}=25^{\circ} \mathrm{C}, \%$ Vol. $v=6,16, P_{o}=101,32,105,110 \mathrm{e}$ $120 \mathrm{kPa}$.

No entanto, a influência do número de Schmidt nos coeficientes convectivos de transferência de massa se sobrepõe à influência do coeficiente de difusividade na Eq. 4.18, reapresentada abaixo. Em resumo, as maiores pressões proporcionam maiores números de Schmidt, que por suas vezes resultam em números de Sherwood mais elevados. 


$$
S h_{g}=\frac{k_{g} D_{i}}{\rho_{g} D i f_{v, a r}}=0,023 R e_{g}{ }^{0,8} S c_{g}{ }^{0,4}
$$

É importante salientar que o modelo incorpora ao seu equacionamento os efeitos de sucção. De modo a avaliar a influência desses efeitos, são apresentadas na Fig. 4.19 (a), (b), (c) e (d) as relações encontradas entre os números de Nusselt na presença $\left(N u_{g}\right)$ e na ausência $\left(N u_{g o}\right)$ do referido efeito, assim como as mesmas relações entre os respectivos números de $S h e r w o o d\left(S h_{g}\right.$ e $\left.S h_{g o}\right)$ para as quatro pressões avaliadas.
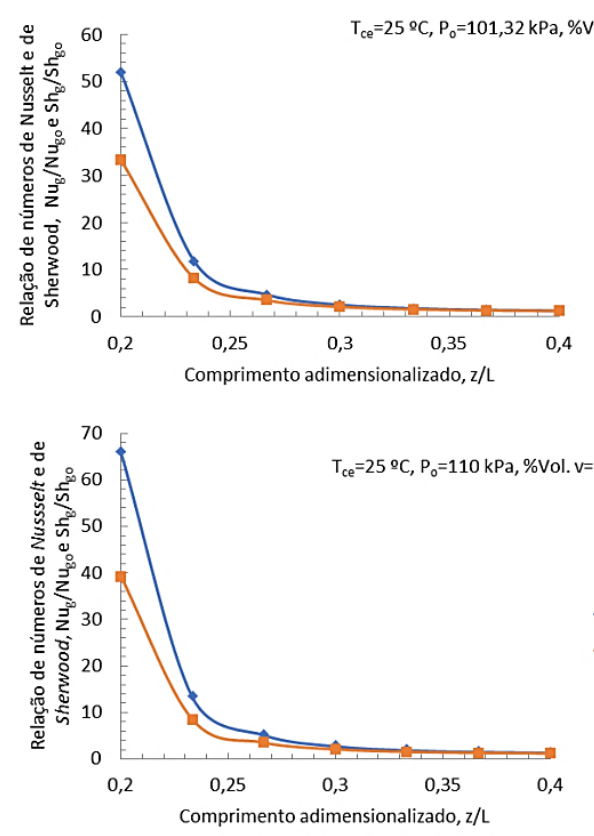

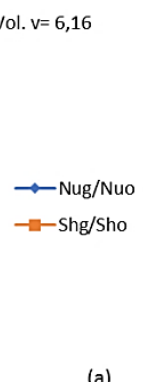

(a)
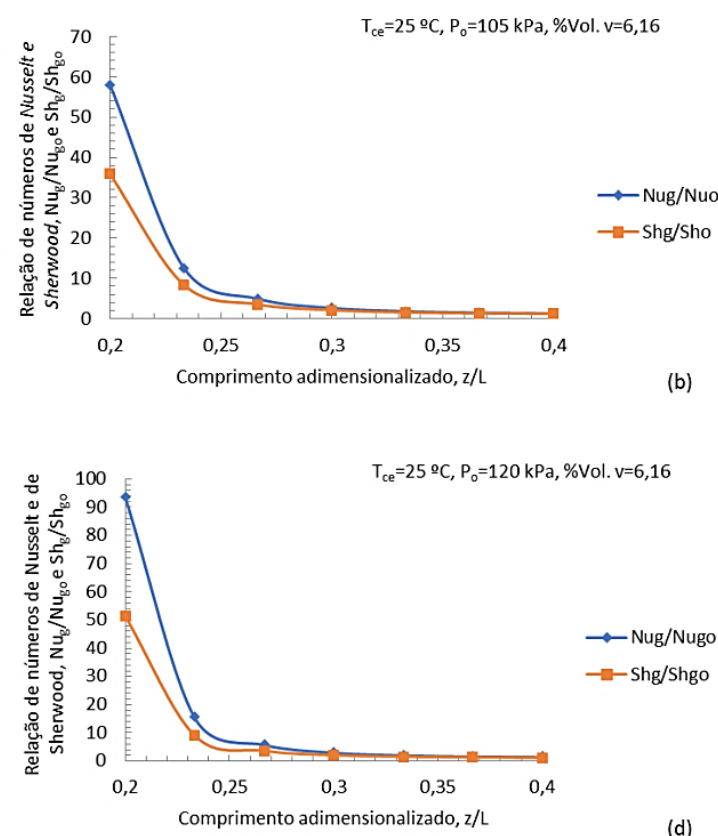

Figura 4.19 - Relações entre números de Nusselt e de Sherwood com e sem efeito de sucção, $T_{c e}=25^{\circ} \mathrm{C}, \% \mathrm{Vol}$. v= 6,16, (a) $P_{o}=101,32 \mathrm{kPa}$; (b) $P_{o}=105 \mathrm{kPa}$; (c) $P_{o}=110 \mathrm{kPa}$; (c) $P_{o}=120 \mathrm{kPa}$

De fato, pode-se constatar que os comportamentos das curvas demonstrados nos quatro gráficos da Fig. 4.19 corrobora com a tendência dos resultados de $h_{g}$ e $k_{g}$ que foram apresentados anteriormente na Fig. 4.16. As relações $N u_{g} / N u_{g_{o}}$ e $S h_{g} / S h_{g o}$ são notadamente elevadas na origem da condensação e decrescem acentuadamente ao longo de $L$, praticamente se estabilizando a partir $z / L=0,3$. A tendência observada confirma a ocorrência dos efeitos de sucção nos primeiros metros do condensador. Do mesmo modo, pode-se afirmar que a redução dos valores, tanto de $N u_{g} / N u_{g o}$ como de $S h_{g} / S h_{g o}$, denota a atenuação dos referidos efeitos e sua ausência a partir do ponto no qual as relações se tornam aproximadamente iguais à unidade. 
Outro aspecto importante a ser observado é que a influência da pressão nos coeficientes de transferência de calor e massa deriva também de seu impacto no efeito de sucção, já que as relações estabelecidas para $N u_{g} / N u_{g o}$, sobretudo no início do condensador, aumentam de aproximadamente 50, quando $P_{o}=101,32 \mathrm{kPa}$, para 90 , quando $P_{o}=120 \mathrm{kPa}$. Seguindo a mesma tendência, os resultados de $S h_{g} / S h_{g o}$ aumentam de aproximadamente 30 , quando $P_{o}=101,32 \mathrm{kPa}$, para 90 , quando $P_{o}=120 \mathrm{kPa}$. Tais valores sugerem haver maior influência do efeito de sucção no processo quando este ocorre sob pressões mais elevadas.

Em geral, a literatura acerca do assunto estabelece que a não incorporação do efeito de sucção nos modelos preditivos de coeficientes de transferência de calor e massa, em processos de condensação na presença de GNC, faz com que os valores estimados dos coeficientes sejam inferiores aos reais. Chantana e Kumar (2013), por exemplo, demonstram por meio de resultados numéricos validados experimentalmente, que elevados números de Reynolds - tanto do próprio filme líquido como da mistura de gases - intensificam a ondulação do filme na interface o tornando rugoso. Além disso, o efeito de sucção, decorrente da condensação do vapor, aumenta os coeficientes de transferência de calor e de massa, mesmo em processos cujas taxas não são tão elevadas.

Nesta seção foi avaliada a influência que a pressão exerce no processo de condensação estudado. Do mesmo modo realizado na avaliação da influência de $T_{c e}$, foram também obtidas as vazões mássicas de água recuperada $\left(\dot{m}_{c d}\right)$ e a taxa de transferência de calor $(\dot{Q})$ para cada uma das situações de simulação. Os resultados consolidados são apresentados na Tabela 4.6, onde fica evidenciado que operações a pressões mais elevadas aumentam as vazões de condensado, assim como a quantidade de calor absorvida pelo fluido de resfriamento. 
Tabela 4.6 - Resultados obtidos para avaliação da variação da pressão do sistema, $P_{o} . T_{c e}=25^{\circ} \mathrm{C}, \% \mathrm{Vol}$. v $=6,16 \%$.

\begin{tabular}{ccccc}
\hline & $\boldsymbol{P}_{\boldsymbol{o}}=\mathbf{1 0 1 , 3 2} \mathbf{~ k P a}$ & $\boldsymbol{P}_{\boldsymbol{o}}=\mathbf{1 0 5} \mathbf{~ k P a}$ & $\boldsymbol{P}_{\boldsymbol{o}}=\mathbf{1 1 0} \mathbf{~ k P a}$ & $\boldsymbol{P}_{\boldsymbol{o}}=\mathbf{1 2 0} \mathbf{~ k P a}$ \\
\hline$\dot{\boldsymbol{m}}_{\boldsymbol{c d}}(\mathbf{k g} / \mathbf{s})$ & 3,01 & 3,52 & 4,15 & 6,48 \\
$\boldsymbol{\eta}_{\boldsymbol{c} d}(\boldsymbol{\%})$ & 18,83 & 21,98 & 25,95 & 40,49 \\
$\dot{\boldsymbol{Q}}(\mathbf{M W})$ & 7,05 & 8,23 & 9,71 & 15,15
\end{tabular}

Apesar de maiores pressões de operação proporcionarem maiores taxas de condensação, as quais mais que duplicam entre $101,32 \mathrm{kPa}$ e $120 \mathrm{kPa}(3,01 \mathrm{~kg} / \mathrm{s} \mathrm{e}$ $6,48 \mathrm{~kg} / \mathrm{s}$ ), os resultados expostos na Tabela 4.6, da mesma forma como observado na avaliação da $T_{c e}$, em geral são baixos, principalmente se consideradas as necessidades de reposição hídrica da UTE em questão e visto que nenhum dos rendimentos observados atinge ao menos 50\%, sendo o máximo valor observado de $40,49 \%$ correspondente a maior pressão simulada $(120 \mathrm{kPa})$.

\subsubsection{Porcentagem volumétrica de vapor de água no GC, \%Vol. v}

Nesta seção é realizada a avaliação da influência exercida pela porcentagem de vapor de água presente nos gases de combustão, \% Vol. v. Esta análise pode também ser entendida como a avaliação da influência dos GNC no processo, já que menores frações de vapor representam maiores frações de GNC e vice-versa. Além do valor de 6,16\%, utilizado nas simulações anteriores, foram avaliadas as porcentagens volumétricas 10 , 15, 20, 70 e 90\%. Apesar dos GC provenientes das unidades termelétricas avaliadas o Capítulo 3 não apresentarem composições com presença de alta porcentagem de vapor de água (nenhuma das UTEs apresentou \%Vol. $v$ acima de 13\%, conforme pode ser observado nos gráficos do Apêndice B), como em alguns dos casos aqui simulados, entende-se que seja relevante, e também válido do ponto de vista comparativo, a avaliação dos coeficientes de transferência e do rendimento da condensação em condições de maiores frações de água.

Nos gráficos (a) e (b) da Fig. 4.20 são apresentados os comportamentos dos coeficientes $h_{g}$ e $k_{g}$, ao longo do condensador sob a influência de \%Vol. $v$. O comportamento característico, já constatado nas análises precedentes, é novamente observado, onde os maiores valores dos coeficientes ocorrem no início no processo, e se deterioram ao longo de $L$, tendendo a valores bastante reduzidos ao final do processo. 
Conforme esperado, constata-se que a elevação das porcentagens de vapor nos GC, propicia elevação dos coeficientes $h_{g}$ e $k_{g}$. Estes resultados confirmam a influência negativa dos GNC, posto que quanto maior é a porcentagem de vapor de água na mistura de gases, maiores são os coeficientes observados.

Apesar da influência da \%Vol. $v$ em $h_{g}$ ser notável, com valores iniciais variando entre $900 \mathrm{~W} / \mathrm{m}^{2} . \mathrm{K}$, quando $\%$ Vol. $v=6,16$, e $1120 \mathrm{~W} / \mathrm{m}^{2} . \mathrm{K}$, quando $\%$ Vol. $v=90 \%$, observam-se diferenças substanciais entre os valores de $k_{g}$, sendo que os mesmos praticamente duplicam entre $\%$ Vol. $v=6,16$ e $\%$ Vol. $v=90 \%$, indo de $0,13 \mathrm{~kg} / \mathrm{m}^{2} . \mathrm{s}$ a $0,25 \mathrm{~kg} / \mathrm{m}^{2} . \mathrm{s}$, para as respectivas frações volumétricas.
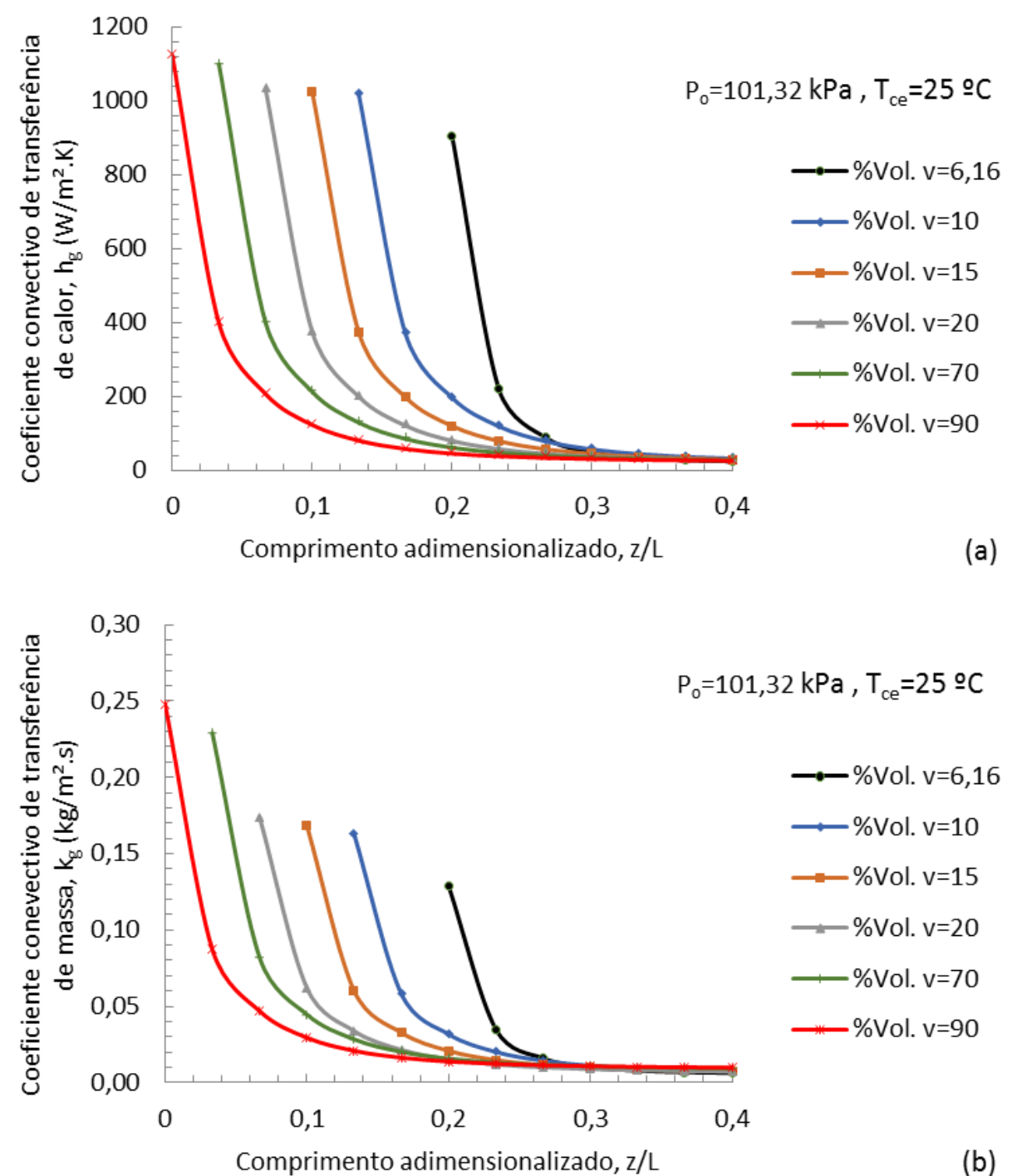

- — \% Vol. v=6,16

$\longrightarrow \%$ Vol. $v=10$

$\longrightarrow$ \%Vol. v=15

$\simeq \%$ Vol. v $=20$

- $\%$ Vol. v $=70$

— \% Vol. v=90

(a)

primento adimensionalizado, $\mathrm{z} /$

Figura 4.20 - Coeficientes convectivos de transferência de calor e de massa $\left(h_{g}\right.$ e $\left.k_{g}\right), P_{o}=101,32 \mathrm{kPa}, T_{c e}=25^{\circ} \mathrm{C}$, $\%$ Vol. $v=6,16 ; 10 ; 15 ; 20 ; 70$ e 90 . 
A fração mássica de vapor além de alterar sensivelmente os coeficientes de transferência, também modifica as temperaturas de saturação $\left(T_{\text {sat }}\right)$. Esse aspecto foi demonstrado e discutido na primeira fase deste trabalho por meio da verificação de $T_{\text {sat }}$ em cada uma da UTEs em função do coeficiente de excesso de ar de combustão $(\gamma)$. Quanto mais elevada é a porcentagem de vapor na mistura, maior sua pressão parcial e, por consequência, maior sua temperatura de saturação inicial. Deste modo, verifica-se que a condensação se inicia mais cedo nas situações de maiores \%Vol. $v$. As temperaturas de saturação iniciais são disponibilizadas na Tabela 4.7, localizada no final desta seção.

No entanto, os maiores coeficientes de transferência iniciais observados nos casos de maior \%Vol. $v$ promovem, ao mesmo tempo, maiores fluxos de calor e de massa, fazendo com que as frações de vapor nos GC também decresçam rapidamente à medida que a água migra em maior quantidade na direção do filme líquido. Portanto, iniciada condensação nos casos de elevadas \% Vol. v, a tendência é de que a fração de GNC aumente rapidamente e seu acúmulo nas adjacências do filme líquido faça com que os coeficientes de transferência de calor e de massa se degradem na mesma intensidade. Paralelamente, a diferença de concentração decresce acentuadamente na mesma proporção em que vapor de água migra através do filme gasoso em direção ao filme líquido, ou seja, a força motriz responsável pela transferência de massa também se torna reduzida.

Fica evidente que o processo de condensação aqui estudado, apesar de estar acoplado à transferência de calor no lado do resfriamento, é majoritariamente limitado e resultante das taxas de transmissão de calor e de massa através da camada de GNC que se estabelece nas adjacências do filme. Os resultados sugerem que embora as temperaturas alcançadas na superfície e na interface estejam abaixo das correspondentes temperaturas de saturação do vapor, a condensação passa a não ocorrer a taxas suficientes para que maior quantidade de água presente nos GC seja condensada e, por fim, recuperada.

Em face aos baixos coeficientes locais e às reduzidas diferenças de concentração que se estabelecem, as moléculas de vapor se tornam incapazes de vencer a resistência imposta pela camada de GNC e assim se condensar na superfície de resfriamento. Os resultados presentes nos gráficos (a) e (b) da Fig. 4.20, assim como alguns dos resultados expostos e discutidos nas seções anteriores, reforçam tal característica. 
Embora em todas as condições simuladas a área superficial do condensador possa ser considerada superdimensionada e que esta promova a redução de $T_{g}$ na saída ao mesmo valor de $T_{c}$ na entrada, verifica-se que as baixas taxas de transferência de calor e de massa no lado dos gases de combustão inviabilizam a obtenção de maiores taxas locais de condensação $\left(d \dot{m}_{c d}\right)$, as quais tendem a zero ao final do condensador, conforme pode ser verificado na Fig. 4.21.

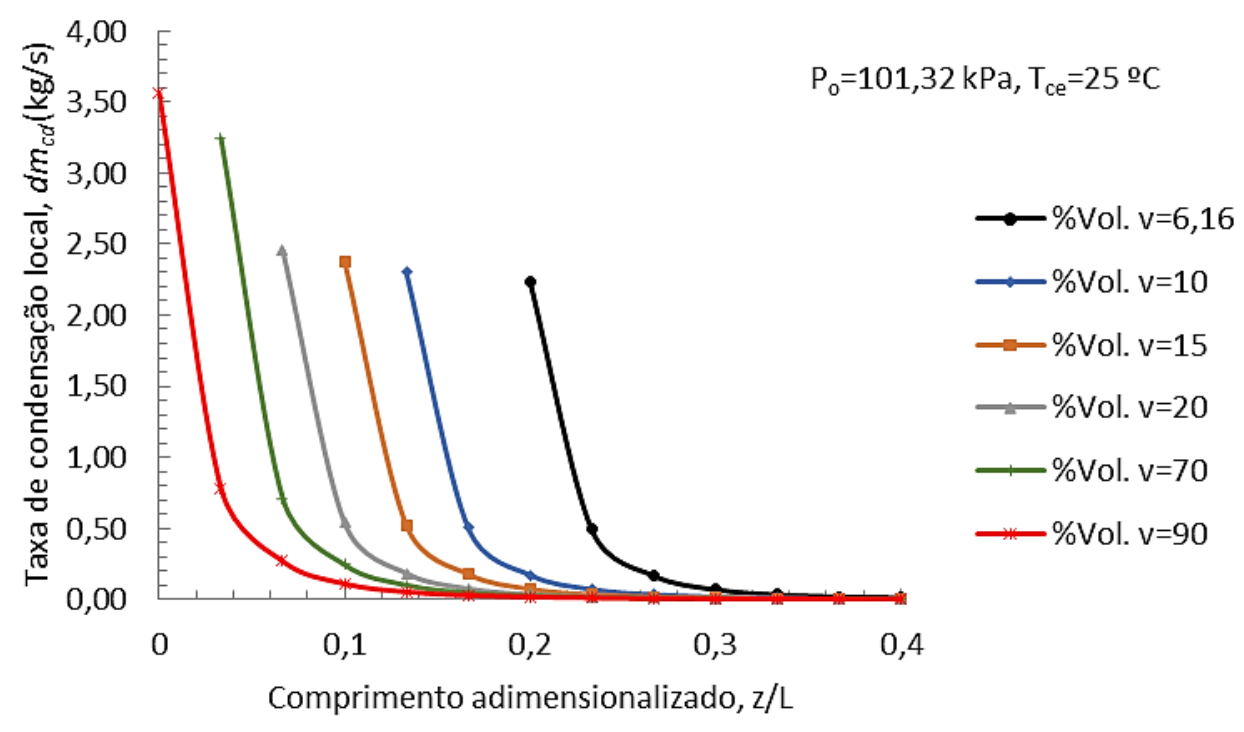

Figura 4.21 - Taxas de condensação locais $\left(d \dot{m}_{c d}\right), P_{o}=101,32 \mathrm{kPa}, T_{c e}=25^{\circ} \mathrm{C}, \%$ Vol. $v=6,16 ; 10 ; 15 ; 20 ; 70$ e 90 .

É interessante observar que a condensação na presença de GNC revela características típicas que podem ser observadas tanto na literatura, como no presente trabalho, tais como coeficientes elevados inicialmente que se deterioram rapidamente e tendem a zero ao final do condensador, havendo influência significativa da porcentagem de GNC presente na mistura. Esta condição determina que a maior parte da condensação ocorra, do mesmo modo, em regiões restritas e próximas da localidade de início do processo.

De modo a realizar uma análise comparativa, cabe aqui resgatar o estudo experimental de Chan et al. (1990) previamente discutido na revisão da literatura. Neste trabalho as porcentagens em massa de ar empregadas no experimento - $0 \%$ a $3,30 \%-$ eram baixas se comparadas às frações de GNC encontradas nos produtos de combustão de UTEs - 96\% no caso da UTE Aureliano Chaves (Ibiritermo). No entanto, conforme a Fig. 2.26 presente na seção 2.3.3 demonstra, bastam pequenas frações de GNC para 
que o processo seja nitidamente prejudicado por conta da deterioração dos coeficientes de transferência de calor (e consequentemente dos coeficientes de transferência de massa).

A influência da \% Vol. $v$ nos coeficientes locais de transferência de calor e massa e nas taxas locais de condensação, evidenciada nas Figs. 4.20 e 4.21 se reflete nos resultados presentes na Tabela 4.7. Pode-se observar que mesmo os GC contendo \%Vol. $v$ elevada, igual a 90\% por exemplo, a vazão mássica de condensado ainda pode ser considerada baixa, $4,88 \mathrm{~kg} / \mathrm{s}$, o que corresponde a um rendimento de recuperação de $30,48 \%$, e uma taxa de transferência de calor de 11,32MW.

Tabela 4.7 - Resultados obtidos para avaliação das porcentagens de vapor nos GC, \%Vol. v, $P_{o}=101,32 \mathrm{kPa}$ e $T_{c e}=$ $25^{\circ} \mathrm{C}$.

\begin{tabular}{|c|c|c|c|c|c|}
\hline & $\%$ Vol. $v=10$ & $\%$ Vol. $v=15$ & $\%$ Vol. $v=20$ & $\%$ Vol. $v=70$ & $\%$ Vol. $v=90$ \\
\hline$\dot{m}_{c d}(\mathrm{~kg} / \mathrm{s})$ & 3,15 & 3,25 & 3,36 & 4,34 & 4,88 \\
\hline$\eta_{c d}(\%)$ & 19,66 & 20,32 & 21,00 & 27,15 & 30,48 \\
\hline$\dot{Q}$ (MW) & 7,05 & 7,36 & 7,6 & 10,06 & 11,32 \\
\hline$T_{\text {sat }}\left({ }^{\circ} \mathrm{C}\right)$ & 46,40 & 53,58 & 58,64 & 78,72 & 82,03 \\
\hline
\end{tabular}




\subsection{Conclusões Parciais}

Nesta parte do trabalho foi desenvolvido o modelo de um condensador duplotubo vertical, no qual gases de combustão de características conhecidas escoam em sentido descendente no interior do tubo central, enquanto o fluido de resfriamento, composto por uma mistura de GNC e ar, flui no sentido ascendente por meio de convecção natural na região anular formada pelos dois tubos. A partir dos resultados obtidos é possível chegar a conclusões, as quais são explicitadas pontualmente a seguir, de acordo com a influência avaliada:

\section{$\underline{\text { Influência da temperatura do fluido de resfriamento, } T_{c e}:}$}

1) De acordo com os resultados apresentados, o escoamento do fluido de resfriamento por meio de convecção natural ocorre desde que as temperaturas de entrada se situem entre $25^{\circ} \mathrm{C}$ e $35^{\circ} \mathrm{C}$, isso se empregada uma vazão adicional de ar igual a $50 \mathrm{~kg} / \mathrm{s}$;

2) O emprego da parcela de GNC remanescente da condensação e ar como fluido de resfriamento leva a necessidade de um condensador de elevada área superficial de transferência de calor;

3) Os coeficientes $h_{c}$ encontrados são coerentes com valores preconizados pela literatura para convecção natural de gases (valores iniciais de $24 \mathrm{~W} / \mathrm{m}^{2} . \mathrm{K}$ no topo que se deterioram atingindo valor próximos de zero na base do condensador);

4) Apesar de maiores $T_{c e}$ promoverem maiores coeficientes de transferência de calor no fluido de resfriamento $\left(h_{c}\right)$ na maior parte de condensador, as menores $T_{c e}$ possibilitam o alcance de maiores diferenças de temperatura no lado dos GC, o que resulta em maiores diferenças de fração mássica entre o seio da mistura e a interface;

5) Os coeficientes convectivos de transferência de calor $\left(h_{g}\right)$ e os coeficientes convectivos de transferência de massa $\left(k_{g}\right)$ não sofrem interferência significativa de $T_{c e}$. No entanto, conforme menor é a $T_{c e}$, menor é o comprimento necessário para o alcance da temperatura de saturação do vapor, $T_{\text {sat }}$.

6) A maior taxa de condensação $\left(\dot{m}_{c d}\right)$ observada foi de $3,01 \mathrm{~kg} / \mathrm{s}$, o que corresponde a um rendimento de $18,83 \%$ com uma taxa de transferência de calor igual a 7,05MW. 


\section{Influência da pressão do sistema, $\boldsymbol{P}_{\underline{o}}$ :}

1) $O$ aumento de pressão de operação favorece a elevação dos coeficientes convectivos de transferência de calor e de massa $\left(h_{g}\right.$ e $\left.k_{g}\right)$ na região de início da condensação. Quando $P_{o}=101,32 \mathrm{kPa}, h_{g}$ e $k_{g}$ são iguais a aproximadamente $900 \mathrm{~W} / \mathrm{m}^{2} \cdot \mathrm{K}$ e $0,13 \mathrm{~kg} / \mathrm{m}^{2} . \mathrm{s}$, já quando $P_{o}=120 \mathrm{kPa}, h_{g}$ e $k_{g}$ aumentam para aproximadamente $1700 \mathrm{~W} / \mathrm{m}^{2} . \mathrm{K}$ e $0,23 \mathrm{~kg} / \mathrm{m}^{2} . \mathrm{s}$.

2) Com base nos resultados das relações $N u_{g} / N u_{g o}$ e $S h_{g} / S h_{g o}$ observados, pode-se afirmar que os efeitos de sucção se mostram mais influentes nas maiores pressões de operação;

3) A maior pressão simulada, $P_{o}=120 \mathrm{kPa}$, corresponde à maior taxa de condensação, igual $6,48 \mathrm{~kg} / \mathrm{s}$, com rendimento de $40,40 \%$ e uma taxa de transferência de calor de $15,15 \mathrm{MW}$.

\section{Influência da porcentagem de vapor de água, \%Vol. v}

1) Apesar da porcentagem de vapor na mistura alterar significantemente os coeficientes $h_{g}$, observou-se maior influência nos coeficientes $k_{g}$, cujos valores praticamente duplicaram no início da condensação, indo de $0,13 \mathrm{~kg} / \mathrm{m}^{2} . \mathrm{s}$ a $0,25 \mathrm{~kg} / \mathrm{m}^{2} . \mathrm{s}$, para $\%$ Vol. $v$ iguais a 6,16 e 90 , respectivamente. Além, disso a $\%$ Vol $v$. modifica sensivelmente as temperaturas de saturação do vapor, o que determina a região do condensador onde se inicia o processo.

2) Os resultados comprovam que quanto maior fração de GNC na mistura, maior se torna a resistência à transferência de calor e de massa através da camada que se estabelece nas adjacências do filme líquido.

3) As baixas frações de vapor de água resultam na redução da temperatura de condensação do vapor, o que demanda maiores áreas de troca de calor, aspecto demonstrado na seção 4.3.1. Além disso, conforme verificado por meio da consulta à literatura e da análise dos resultados obtidos neste trabalho, os GNC representam limitações severas ao rendimento do processo resultando em baixas taxas de condensação.

4) Observou-se um comportamento característico do processo de condensação modelado em todas as condições estabelecidas. Todas as curvas de $h_{g}$ e $k_{g}$, e consequentemente das taxas locais de condensação $\left(\dot{m}_{c d, l}\right)$, demonstraram decréscimo 
acentuado nos primeiros comprimentos do condensador, os quais posteriormente se estabilizam em valores bastante baixos.

5) Como esperado, a maior taxa de condensação obtida, $4,88 \mathrm{~kg} / \mathrm{s}$, corresponde à $\% \mathrm{Vol}$. $\nu=90 \%$, com rendimento de recuperação de $30,48 \%$ e taxa de transferência de calor de 11,32MW.

6) Constata-se que mesmo pequenas frações de GNC (10\%), se comparadas com as que ocorrem de fato nos GC de UTEs, afetam drasticamente o processo de condensação. Fato que vai ao encontro ao que já é bem consolidado pela literatura.

7) Apesar das taxas de transferência de calor no resfriamento também serem baixas, fator que influencia expressivamente o coeficiente global de transferência de calor $(U)$, o processo se mostra especialmente limitado pela resistência imposta à transferência de massa existente nos GC, esta decorrente do acúmulo de GNC nas adjacências do filme;

8) Embora a área de condensação esteja superdimensionada, as taxas de condensação são claramente baixas impossibilitando o alcance de melhores rendimentos de condensação, estes condicionados justamente ao que foi explicitado no item anterior. 


\section{Considerações finais e trabalhos futuros}

A respeito da primeira parte do trabalho, as estimativas, tanto de quantidade de água como dos demais gases presentes nos produtos de combustão, foram realizadas levando-se em conta as eficiências de geração típicas de cada tipo de ciclo de potência e as composições de combustível disponíveis na literatura e pelas concessionárias distribuidoras locais. Ficou evidenciado, por meio dos resultados expostos nas Tabelas 3.3 e 3.4 e nos gráficos das Figs. 3.1 e 3.2, bem como pelos volumes de consumo advindos da literatura, que a recuperação de água gerada pela combustão, por si só, não é capaz de suprir o completamente o volume de reposição demandado. Porém, pode, de forma subsidiária a outras alternativas, contribuir para utilização racional deste recurso e mitigar as perdas que ocorrem.

Embora as estimativas realizadas na primeira etapa tenham evidenciado que os processos de combustão em UTEs produzem quantidades relevantes de água, principalmente se os volumes produzidos forem comparados aos volumes consumidos, observou-se que as frações mássicas de água contidas na mistura gasosa são pequenas frente às frações de GNC e variam de acordo com o tipo de combustível e com o coeficiente de excesso de ar empregado $(\gamma)$. Adicionalmente, constatou-se a dependência e acentuada redução das temperaturas de saturação do vapor de água $\left(T_{\text {sat }}\right)$ em função do coeficiente $\gamma$.

Considera-se importante que trabalhos futuros efetuem análises complementares, específicas e, principalemente, individualizadas, que abordem os seguintes aspectos de forma minuciosa:

- o tipo de resfriamento adotado e consequentemente o consumo de água efetivo da unidade;

- consumo de combustível associado ao tipo de ciclo e à sua eficiência de geração;

- coeficiente de excesso de ar de fato adotado pela unidade;

- utilização ou não de queima suplementar na caldeira de recuperação;

- existência ou não de sistemas auxiliares (captura de $\mathrm{CO}_{2}$, gaseificação, etc..) que possam impactar no consumo de água e na eficiência da unidade; 
- caracterização experimental dos gases de combustão após as etapas de tratamento de efluentes gasosos de modo a confirmar os volumes de vapor de água e $\mathrm{GNC}$;

- qualidade da água recuperada, pois dependendo da presença de enxofre no combustível haverá a formação de $\mathrm{SO}_{2}$ e $\mathrm{SO}_{3}$, com posterior formação de $\mathrm{H}_{2} \mathrm{SO}_{4}$ (ácido sulfúrico);

- expansão da análise às UTEs movidas à biomassa, levando-se em consideração os diferentes combustíveis possíveis, os quais podem ser classificados como vegetais lenhosos (madeiras), vegetais não lenhosos (sacarídeos, celulósicos, amiláceos e aquáticos), resíduos orgânicos (agrícolas, industriais, urbanos) e biofluidos (óleos vegetais);

- captação conjunta de $\mathrm{CO}_{2}$ e água.

Acerca da segunda parte do trabalho, considera-se que os resultados relativos às taxas de condensação e ao rendimento do processo de recuperação são baixos se consideradas condições reais dos gases de combustão de uma unidade termelétrica (segundo as porcentagens de vapor presentes nos GC obtidas na primeira etapa do trabalho).

Existem ressalvas a serem realizadas, sendo uma delas relativa à validação experimental do modelo numérico. Acredita-se que o desenvolvimento de um aparato experimental, que possibilite a realização de ensaios em condições semelhantes de ocorrência de convecção natural e/ou em convecção forçada e de elevadas frações de GNC, seja de grande contribuição para a continuidade do desenvolvimento do aspecto tecnológico relativo ao tema. Estudos experimentais que se utilizem de técnicas de visualização e que objetivem a caracterização e a compreensão dos fenômenos associados às limitações impostas pela camada de GNC podem ser úteis na busca de soluções que reduzam sua influência no processo de condensação.

Ademais, do ponto de vista da abordagem teórico-numérica, é possível incrementar este modelo, de modo a se estudar a influência e a possível melhora de desempenho, utilizando-se superfícies modificadas para intensificação dos processos de transferência de calor e de massa no lado dos gases de combustão.

Este trabalho não se ateve à qualidade da água obtida ao final da condensação, porém considera-se que esse aspecto deva ser abordado em futuros estudos, a fim de se 
avaliar quais processos secundários podem ser empregados para condicionamento da água recuperada.

Por fim, entende-se que o tema, aqui apresentado em duas partes (estimativas e recuperação), é desafiador e deve continuar sendo explorado sob abordagens distintas, que gerem resultados complementares e contribuam com a presente urgência de se desenvolver novas tecnologias no que concerne ao reaproveitamento de água em UTEs. O tema não se encontra esgotado e há ainda pontos importantes que podem e devem ser investigados sob diferentes pontos de vista. 


\section{Referências bibliográficas}

Ambrosini, W., M. Bucci, N Forgione, F. Oriolo, e Paci. "Comparison and analysis of the condensation benchmark results." The 3rd European review meeting on severe accident research, September de 2008: 2.

ANP. 11 de 2016. www.anp.gov.br/wwwanp/.

Arroyo, Eveline Maria Vasquez. "Proposta metodológica para avaliação da vulnerabilidade da geração termelétrica a carvão mineral no Brasil às mudanças climáticas." Rio de Janeiro, Outubro de 2012. 193.

ASHRAE. Handbook of Fundamentals, Atlanta. - American Society of Heating, 2007.

Badr, L, e J Bigger. "Review of water use in U. S thermoelectric power plants." Journal of Energy Engineering, 2012: 1.

Banco de Informações de Geração da Aneel (BIG). 2016. http://www2.aneel.gov.br/aplicacoes/capacidadebrasil/GeracaoTipoFase.asp.

Bistline, J, e V Rai. "The role of carbon capture technologies in greenhouse gas emissions-reduction models: a parametric study for the U.S power sector." Energy Policy 38 (2010): 1177-1191.

Boyce, Meherwan P. Gas Turbine Engineering Handbook. Second . Houston: Gulf Professional Publishing, 2002.

Branco, Fabiano Pagliosa. "Análise termoeconômica de uma usina termelétrica a gás natural operando em ciclo aberto e em ciclo combinado. Dissertação de mestrado." Ilha Solteira -SP, 2005, 179.

Brunetti, Adele, Sergio Santoro, Francesca Macedonio, Alberto Figoli, Enrico Drioli, e Giuseppe Barbieri. "Waste Gaseous Streams: From Environmental Issue to Source of Water by Using Membrane Condensers." Clean Soil Air Water (WILEY-VCH Verlag GmbH \& Co. KGaA, Weinheim), 2013: 1145-1153.

Burmeister, L C. Convective heat transfer. New York: John Wiley \& Sons, INC., 1993.

Carbó, Hector Mario. Aços Inoxidáveis: aplicações e especificações. Arcelor Mittal. Janeiro de 2008.

Carey, V P. Liquid-vapor phase-change phenomena. EUA: Taylos \& Francis, 1992.

Carney, Barbara, Tomas Feeley, e Thomas Mcnemar. "Department of Energy, National Energy Technology Laboratory, Power Plant-Water R\&D Program." U.S. Department of Energy/National Energy Technology Laboratory, 2005.

Caruso, Gianfranco, e Damiano Vitale Di Maio. "Heat and mass transfer analogy applied to condensation in the presence of noncondensable gases inside inclined tubes." International Journal of Heat and Mass Transfer 68 (2014): 401-414.

Cegas. 11 de 2016. www.cegas.com.br. 
Çengel, Yunus A. Transferência de Calor e Massa. Terceira Edição. São Paulo: McGraw Hill, 2009.

Chan, T S, e M C Yuen. "The Effect of Air on Condensation of Stratified Horizontal Cocurrent Steam/Water Flow.” Journal of Heat Transfer 112 (1990): 1092.

Chandel, Munish K, Lincoln F Pratson, e Robert B Jackson. "The potential impacts of climate-change policy on fresh water use in thermoelectric power generation." Energy Policy, 2011: 6234-6242.

Colburn, A P, e O A Hougen. "Design of Cooler Condensers for Mixtures of Vapors with Noncondensing Gases." Industrial and Egineering Chemistry 26 (1934): 11781182.

Comgas. 11 de 2016. www.comgas.com.br/.

Copergas. 11 de 2016. www.copergas.com.br.

Corradini, M L. "Turbulent condensation on a cold wall in the presence of a noncondensable gas." Nuclear Technology 64 (1984): 86-90.

Dharma Rao, V, V Murali Krishna, K V Sharma, e P V.J Mohana Rao. "Convective condensation of vapor in the presence of a non-condensable gas of high concentration in laminar flow in a vertical pipe." International Journal of Heat and Mass Transfer (Elsevier) 51 (2008): 6090-6101.

Dos Santos, Fabiane Binsfeld Ferreira. "Dissolução do calcário no processo de dessulfurização de gases de combustão.” Florianópolis, 2007. 149.

Dos Santos, Marilin Mariano, Patricia Helena Lara dos Santos Matai, e Laiete Soto Messias. "Combustão e combustíveis." Em Energias renováveis, geração distribuída e eficiência energética, por José Roberto Simões-Moreira, 67-69. Rio de Janeiro: LTCGEN, 2017.

DREW Produtos Químicos. Princípios de Tratamento de Água Industrial. Tradução: Thomas J. Buchard. São Paulo, 1979.

EPE. "Energia Termelétrica: Gas Natural, Biomassa, Carvão, Nuclear." Empresa de Pesquisa Energética, Rio de Janeiro, 2016, 417.

EPRI - Electric Power Research Institute. "Water \& Sustainability (Volume 3): U.S." Technical Report, Palo Alto, California, USA, 2002.

Feeley III, Thomas J, et al. "Water: A critical resource in the thermoelectric power industry." Energy, 2008: 1-11.

Gallo, W L. R. "A comparison between the hat cycle and other gas turbine based cycle; Eficiency, specific power anda water consumption." Energy Conversion and Management, 1997: 1595-1604.

Gas Natural Fenosa. 11 de 2016. www.gasnaturalfenosa.com.br/br.

General Electric. 11 de 2017. https://www.gepower.com/gas/gas-turbines/lm6000. 
General Electric. "General Electric." Heavy duty gas turbines. 2012. https://powergen.gepower.com/products/heavy-duty-gas-turbines.html.

Gerdes, K, e C Nichols. "Water requirements for existing and emerging thermoelectric." DOE/NETL-402/080108, Pittsburg, 2009.

Glassman, I. Combustion. New York: Academic Press, 1977.

Gleick, P H. Water in Crisis: A Guide to the World's Fresh Water Resources. New York: Oxford University Press, 1993.

Goldbrunner, M. "Lokale Phänomene bei der Kondensation von Dampf in Anwesenheit eines nightkondensierbaren Gases." Dissertação de mestrado, Universität Munchen, 2003.

Gupta, Manoj Kumar. Power Plant Engineering. Delhi: PHI Learning, 2012.

Hewitt, G F, G L Shires, e T R Bott. Process Heat Transfer. CRC Pressa Inc., s.d.

Holman, J P. Heat Transfer. 10th Ed. México, DF: McGraw HilI Book Company, Inc., 2010 .

Horlock, J H. Combined power plants: Including ciclo gas turbines (CCGT) plants. New York: Pregamon press, 1992.

Huang, Jian, Junxia Zhang, e Li Wang. "Review of vapor condensation heat and mass transfer in the presence." Applied Thermal Engineering (Elsevier) 89 (2015): 469-484.

Incropera, Frank P, David P Dewitt, Theodore L Bergman, e Adrienne S Lavine. Fundamentals of heat and mass transfer. John Wiley Sons, 2011.

Instituto Nacional de Meterorologia. 11 de novembro de 2016. http://www.inmet.gov.br/portal/index.php?r=estacoes/estacoesAutomaticas.

Jeong, Kwangkook, Michael J Kessen, Harun Bilirgen, e Edward K Levy. "Analytical modeling of water condensation in condensing heat exchanger." International Journal of Heat and Mass Transfer 53 (2010): 2361-2368.

Jia, L, X F Peng, Y J Yan, D Sun, e X P Li. "Effects of water vapor condensation on the convection heat transfer of wet flue gas in a vertical tube." International Journal of Heat and Mass Transfer 44 (2001): 4257-4265.

Kays, W M, e R J Moffat. "The Behavior of Transpired Turbulent Boundary Layers." Studies in Convection, 1975.

Khartchenko, Nikolai V, e Vadym M Kharchenko. Advanced Energy Systems. Boca Raton, FL: CRC Press, 2014.

Klara, Julianne M. "Cost and Performance Baseline for Fossil Energy Plants." Technical Report, National Energy Technology Laboratory, 2007, 516.

Lee, K Y, e M H Kim. "Effect of an interfacial shear stress on steam condensation." International Journal of Heat and Mass Transfer 51 (2008): 5333-5343. 
Lee, W C, e J W Rose. "Forced Convection Film Condensation on a Horizontal Tube with and without Non-condensing Gases." International Journal of Heat and Mass Transfer 27 (1984): 519.

Levy, E, H Bilirgen, C Samuelson, K Jeong, M Kessen, e C Whitcomb. "Separation of water and acid vapors from boiler flue gas in a condensing heat exchanger." Proceedings of the 33rd International Technical Conference on Coal Utilization and Fuel Systems, 2008.

Levy, Edward, Harun Bilirgen, e John DuPont. "Recovery of water from boiler flue gas using condensing heat exchangers." Final Technical Report, Energy Research Center, Lehigh University, 2011, 155.

Lienhard IV, John H, e John H Lienhard V. A heat transfer textbook. Third Edition. Houston, 2001.

Lora, Electo Eduardo da Silva, e Marco Antônio Rosa Do Nascimento. Geração Termelétrica: Planejamento, Projeto e Operação. Vol. 1. Rio de Janeiro: Interciência, 2004.

Macedonio, Francesca, Adele Brunetti, Giuseppe Barbieri, e Enrico Drioli. "Membrane Condenser as a New Technology for Water Recovery from." Ind. Eng. Chem. Res, 2012: 1160-1167.

Macedonio, Francesca, Maurizio Cersosimo, Adele Brunetti, e Giuseppe Barbieri. "Water recovery from humidified waste gas streams: Qualitycontrol using membrane condenser technology." Chemical EngineeringandProcessing., 2014: 196-203.

Maheshwari, N K, D Saha, R K Sinha, e M Aritomi. "Investigation on condensation in presence of a noncondensable." Nuclear Engineering and Design 227 (2004): 219-238.

Martin-Vandepenas, J M, M A Jiminez, F Martin-Fuertes, e J A Fernandez. "Comparison of film condensation models in presence of non-condensable in a CFD code." Heat Mass Transfer 41 (2005): 961-976.

Mazurenko, Anton Stanislavovich, Zulcy De Souza, e Eduardo Da Silva Lora. Máquinas Térmicas de Fluxo. Rio de Janeiro: Interciência, 2013.

MEDEIROS, Alexandre Mollica. "Bases metodológicas para incorporação da variável ambiental no planejamento da expansão termelétrica no Brasil." Rio de Janeiro, RJ, Março de 2003.

Merschmann, Paulo R de C, Eveline Vasquez, Alexandre S Szklo, e Roberto Schaeffer. "Modeling water use demands for thermoelectric power plants with CCS in." International Journal of Greenhouse Gas Control, 16 de January de 2013: 87-101.

Metz, S J, W J.C Van de Ven, M H.V Mulder, e M Wessling. "Mixed gas water vapor/N2 transport in poly(ethylene oxide) poly(butylene terephthalate) block copolymers." Journal of Membrane Science 266 (2005): 51-61.

Minkowycz, W J, e E M Sparrow. "Condensation heat transfer in the presence of noncondensables, interfacial resistance, superheating, variable properties, and diffusion.” International Journal of Heat Mass Transfer 9 (1966): 1125-1144. 
Moran, Michael J, e Howard N Shapiro. Fundamentals of Engineering Thermodynamics. Chichester: John Wiley \& Sons Ltd, 2006.

N.V. Nederlandse Gasunie. Physical Properties of Natural Gases. 1980.

Nag, P K. Heat and mass transfer. New York: McGraw-Hill, 2011.

Nusselt, W. (1916). Die Oberflaohen-Kondensation des Wasserdampfes. VDI Zeitung, 1996: 60, 541-546 e 569-575.

NETL. "Water Requirements for Existing and Emerging Thermoelectric Plant Technologies." 2008.

Neves, Flávio Barroso. "Otimização do funcionamento da torre de resfriamento." Relatório Técnico, Instituto de Pesquisas Tecnológicas do Estado de São Paulo, São Paulo, 2013, 147.

Norris, R H. "Some Simple Approximate Heat Transfer Correlations for Turbulent Flow in Ducts with Rough Surfaces." Augmentation of Convective Heat and Mass Transfer, ASME, 1970.

NUNES, Márcio. "Utilização dos métodos de Merkel e de Poppe na modelagem do." Dissertação de mestrado, Instituto de Pesquisas Tecnológicas do Estado de São Paulo, São Paulo, 2014, 109.

Pan, L, P Liu, e L Ma. "A supply chain based assesment of water issues in the coal industry in China." Energy Policy, 48: 93-102.

Park, S K, M H Kim, e K J Yoo. "Condensation of pure steam and steam-air mixture with surface waves of condensate film on a vertical wall." International Journal of Multiphase Flow 22 (1996): 893-908.

Rao, V D, V M Krishna, K V Sharma, e P V. J. M Rao. "Convective condensation of vapor in the presence of a non-condensable gas of high concentration in laminar flow in a vertical pipe." International Journal of Heat Mass Transfer, 2008: 6090-6101.

Rochelle, G T. “Amine scrubbing for CO2 capture.” Science, 2009: 1652-1654.

Rodrigues, A. N.C, e A. B.V. Daltro. "Simulação do procedimento de partida de uma turbina a gás operando em ciclo simples." Trabalho de Graduação, Rio de Janeiro, 2013, 76.

Rose, J W. "Condensation of a vapor in the presence of a noncondensable." International Journal of Heat Mass Transfer 12 (1968): 233-237.

Rostrup-Nielsen, J, e L J Christiansen. "Concepts in Syngas Manufacture." Catalytic Science Series (Imperial College Press) 10 (2011).

Ruggiero, Márcia A. Gomes, e Vera Lúcia Rocha Lopes. Cálculo Numérico - Aspectos Teóricos e Computacionais. Segunda Edição. Pearson, 1988.

Rutberg, Michael J. "Modeling Water Use at Thermoelectric Power Plants." Dissertação de mestrado, Massachusetts Institute of Technology, Massachusetts, 2003, 77. 
Scanlon, Bridget R., Robert C. Reedy, Ian Duncan, William F. Mullican, e Michael Young. "Controls on Water Use for Thermoelectric Generation: Case Study." Environmental Science and Technology, 12 de Agosto de 2013: 8.

Siddique, M, M W Golay, e M Kazimi. "Local Heat Transfer Coefficients for Forced Convection Condensation of Steam in a Vertical Tube in the Presence of a Noncondensible Gas." Nuclear Technology 102 (1993): 386.

Siddique, M, M W Golay, e M S Kazimi. "Theoretical Modelling of Forced Condensation of Steam in a Vertical Tube in the Presence of a Non-condensible gas." Nuclear Technologia 106 (1994).

Sijbesma, Hylke, Kitty Nymeijer, Van Rob Marwijk, Rob Heijboer, Jens Potreck, e Matthias Wessling. "Flue gas dehydration using polymer membranes." Journal of Membrane Science (Elsevier), 2008: 263-276.

Simões Moreira, José Roberto. Fundamentos e Aplicações da Psicrometria. São Paulo: RPA Editorial Ltda, 1999.

Simões-Moreira, José Roberto, e Marcos de Mattos Pimenta. "Máquinas e processos de transformação de energia térmica." Em Energias renováveis, geração distribuída e eficiência energética, por José Roberto Simões-Moreira, 33-63. Rio de Janeiro: LTCGEN, 2017.

Siow, E C, S J Ormiston, e H M Soliman. "A two-phase model for laminar film condensation from steam-air mixtures in vertical parallel-plate channels." Heat and Mass Transfer 40 (2004): 365-375.

Smith, J M, H C Van Ness, e M M Abbot. Introdução à Termodinâmica da Engenharia Química. $5^{\circ}$ Edição. Rio de Janeiro: LTC, 200.

Stephan, K. Heat Transfer in Condensation and Boiling. New York: Springer-Verlag, 1992.

Tolmasquim, M T. Geração de energia elétrica no Brasil. Rio de Janeiro: Interciência, 2005.

United Nations International Year of Water Cooperation. http://www.un.org/en/events/worldwateryear/. 2015. (acesso em 20/10/2015).

Van Wylen, Gordon, Richard Sonnttag, e Claus Borgnakke. Fundamentos da Termodinâmica Clássica. 4a. São Paulo: Edgard Blucher LTDA, 1994.

Wang, C Y, e C Tu. "Effects of Non-condensable Gas on Laminar Film Condensation in a Vertical Tube." International Journal of Heat Mass Transfer 31 (1988): 2339.

Wang, Yungang, Qinxin Zhao, Qulan Zhou, Zijin Kang, e Wenquan Tao. "Experimental and numerical studies on actual flue gas condensation." International Journal of Heat and Mass Transfer (Elsevier), 2013: 10-20.

Yang, Xiaoying, e Benedykt Dziegielewski. "Water use by thermoelectric power plants in the united states." Journal of the american water resourses association, February de 2007: 7. 
Zhelev, Toshko K. "Water conservation through energy management." Journal of Cleaner Production, 2005: 1395-1404.

Zhu, A M, S C Wang, J X Sun, L X Xie, e Z Wang. "Wang, Effects of high fractional noncondensable gas on condensation in the dewvaporation desalination process." Desalination 214 (2007): 128-137. 


\section{APÊNDICE A - Composições de Gás Natural e Carvão Mineral e Condições Ambientais Locais}

Nas Tabelas A1 e A2 são apresentadas as composições do gás natural e do carvão mineral, respectivamente, empregados em cada uma das UTEs avaliadas neste estudo.

Tabela A1 - Composição do gás natural utilizados nas centrais termelétrica brasileira (frações volumétricas). Fontes: Gas Natural Fenosa (2016), Cegas ( 2016), Copergas (2016), ANP (2016), Comgas (2016).

$\begin{array}{llllllll}\text { UTE } & \mathrm{CH}_{4} & \mathrm{C}_{2} \mathrm{H}_{6} & \mathrm{C}_{3} \mathrm{H}_{8} & \mathrm{C}_{\mathrm{x}} \mathrm{H}_{\mathrm{y}} & \mathrm{N}_{2} & \mathrm{CO}_{2} & \begin{array}{c}\mathrm{PCI}^{8} \\ \left(\mathrm{MJ} / \mathrm{m}^{3}\right)\end{array}\end{array}$

Governador Leonel Brizola

(Termorio),

Santa Cruz.

Mário Lago (Macaé Merchant),

$\begin{array}{lllllll}0,9903 & 0,0060 & 0,0000 & 0,0002 & 0,0035 & 0,000 & 38,80\end{array}$

Norte Fluminense,

Barbosa Lima Sobrinho (Eletrobolt)

\begin{tabular}{|c|c|c|c|c|c|c|c|}
\hline Termo Pernambuco & 0,8746 & 0,0570 & 0,0415 & 0,0259 & 0,0010 & 0,000 & 34,80 \\
\hline $\begin{array}{c}\text { Araucária, Luiz Carlos Prestes, } \\
\text { Aureliano Chaves (Ibiritermo), } \\
\text { William Arjona, Juiz de Fora, Sepé } \\
\text { Tiaraju (Canoas), AES } \\
\text { Uruguaiana*, Mario Covas } \\
\text { (Termocuiabá) }\end{array}$ & 0,8850 & 0,0620 & 0,0220 & 0,0080 & 0,0050 & 0,018 & 38,80 \\
\hline $\begin{array}{c}\text { Fernando Gasparian (Nova } \\
\text { Piratininga), Euzébio Rocha } \\
\text { (Cubatão CCBS) }\end{array}$ & 0,8987 & 0,0566 & 0,0157 & 0,0090 & 0,0063 & 0,018 & 38,80 \\
\hline $\begin{array}{c}\text { Termofortaleza, Jesus Soares } \\
\text { Pereira (TermoAçu),Termoceará }\end{array}$ & 0,9698 & 0,0252 & 0,0038 & 0,0010 & 0,0001 & 0,000 & 34,70 \\
\hline $\begin{array}{c}\text { Camaçari, Celso Furtado } \\
\text { (Termobahia), Rômulo Almeida } \\
\text { (Fafen) }\end{array}$ & 0,9683 & 0,0280 & 0,0029 & 0,0007 & 0,0001 & 0,000 & 38,80 \\
\hline
\end{tabular}

\footnotetext{
${ }^{8}$ Valores nas condições de referência adotadas, 0 ㅇ e 101,32 kPa (normal m³ $\mathrm{Nm}^{3}$ ).
} 
Tabela A2 - Composição dos diferentes tipos de carvão utilizados nas centrais termelétricas brasileiras (frações mássicas em base úmida). Fontes: CTSUL (2005) apud Mercschmann (2013), Gomes et al. (2003), IBAMA (2009).

\begin{tabular}{ccccccccc}
\hline UTE & $\begin{array}{c}\text { Teor de } \\
\text { Umidade }\end{array}$ & Cinzas & $\mathbf{C}$ & $\mathbf{H}$ & $\mathbf{N}$ & $\mathbf{O}$ & $\mathbf{S}$ & $\begin{array}{c}\text { PCI } \\
\mathbf{( k J / k g})\end{array}$ \\
\hline $\begin{array}{c}\text { Jorge Lacerda I, II, } \\
\text { III e IV }\end{array}$ & 0,0850 & 0,3924 & 0,4623 & 0,0351 & 0,0072 & 0,0001 & 0,0178 & 18,87 \\
$\begin{array}{c}\text { Presidente Medici A } \\
\text { e B e Candiota III }\end{array}$ & 0,1031 & 0,4753 & 0,3125 & 0,0224 & 0,0045 & 0,0352 & 0,0117 & 13,85 \\
$\begin{array}{c}\text { Porto de Itaqui; } \\
\text { Pecém I e II e Porto } \\
\text { do Açu }\end{array}$ & 0,1200 & 0,0800 & 0,6424 & 0,0440 & 0,0123 & 0,0938 & 0,0070 & 26,40 \\
Seival & 0,0967 & 0,5000 & 0,2930 & 0,0210 & 0,0190 & 0,0330 & 0,0190 & 13,85 \\
CTSUL & 0,1379 & 0,4250 & 0,3250 & 0,0216 & 0,0600 & 0,0672 & 0,0172 & 14,67 \\
Jacuí & 0,0637 & 0,4860 & 0,3436 & 0,0197 & 0,0037 & 0,0393 & 0,0047 & 13,56 \\
\hline
\end{tabular}


As Tabelas A3 e A4 contém as condições ambientais (Temperatura média, Umidade relativa média, Pressão atmosférica média e Umidade absoluta) nas localidades onde se encontram as UTEs abordadas neste trabalho.

Tabela A3 - Condições ambientais nos locais das termelétricas a gás natural avaliadas. Fonte: INMET (2017), http://www.inmet.gov.br/portal/

\begin{tabular}{|c|c|c|c|c|}
\hline UTE & $\begin{array}{c}\text { Temperatura } \\
\text { Média }\left({ }^{\circ} \mathrm{C}\right)\end{array}$ & $\begin{array}{c}\text { Umidade } \\
\text { Relativa } \\
\text { Média, } \phi(\%) \\
\end{array}$ & $\begin{array}{c}\text { Pressão } \\
\text { atmosférica } \\
\text { média }(\mathrm{kPa})\end{array}$ & $\begin{array}{c}\text { Umidade absoluta, } \\
\omega(\mathrm{kg} \text { vapor } \\
\text { água/kg ar seco) }\end{array}$ \\
\hline $\begin{array}{l}\text { Governador Leonel } \\
\text { Brizola (Termorio) }\end{array}$ & 22,27 & 81,24 & 101,35 & 0,0137 \\
\hline Santa Cruz & 23,96 & 72,09 & 101,31 & 0,0134 \\
\hline $\begin{array}{c}\text { Mário Lago (Macaé } \\
\text { Merchant) }\end{array}$ & 23,96 & 72,09 & 101,31 & 0,0134 \\
\hline Norte Fluminense & 23,96 & 72,09 & 101,31 & 0,0134 \\
\hline TermoPernambuco & 25,92 & 76,57 & 101,35 & 0,0161 \\
\hline Araucária & 17,69 & 71,02 & 91,32 & 0,0089 \\
\hline $\begin{array}{l}\text { Fernando Gasparian } \\
\text { (Nova Piratininga) }\end{array}$ & 20,04 & 68,57 & 92,76 & 0,0100 \\
\hline $\begin{array}{l}\text { Barbosa Lima Sobrinho } \\
\text { (Eletrobolt) }\end{array}$ & 23,61 & 77,59 & 101,23 & 0,0142 \\
\hline Camaçari & 26,10 & 74,45 & 100,97 & 0,0158 \\
\hline Termofortaleza & 27,92 & 67,51 & 100,98 & 0,0160 \\
\hline $\begin{array}{l}\text { Jesus Soares Pereira } \\
\text { (TermoAçu) }\end{array}$ & 27,91 & 67,89 & 100,96 & 0,0161 \\
\hline Luiz Carlos Prestes & 24,51 & 66,42 & 97,6970 & 0,0128 \\
\hline $\begin{array}{l}\text { Aureliano Chaves } \\
\text { (Ibiritermo) }\end{array}$ & 20,29 & 67,39 & 88,46 & 0,0100 \\
\hline Termoceará & 27,92 & 67,51 & 100,98 & 0,0160 \\
\hline $\begin{array}{l}\text { Euzébio Rocha } \\
\text { (Cubatão CCBS) }\end{array}$ & 21,02 & 85,52 & 101,57 & 0,0133 \\
\hline William Arjona & 23,44 & 67,37 & 95,38 & 0,0122 \\
\hline $\begin{array}{l}\text { Celso Furtado } \\
\text { (Termobahia) }\end{array}$ & 26,10 & 74,45 & 100,97 & 0,0158 \\
\hline $\begin{array}{l}\text { Rômulo Almeida } \\
\text { (FAFEN) }\end{array}$ & 26,10 & 74,45 & 100,97 & 0,0158 \\
\hline Juiz de Fora & 19,24 & 79,54 & 91,23 & 0,0111 \\
\hline Sepé Tiaraju (Canoas) & 19,02 & 79,08 & 101,06 & 0,0109 \\
\hline AES Uruguaiana & 21,24 & 70,19 & 100,51 & 0,0111 \\
\hline $\begin{array}{l}\text { Mário Covas } \\
\text { (Termocuiabá) }\end{array}$ & 26,19 & 65,44 & 98,55 & 0,0139 \\
\hline
\end{tabular}


Tabela A4 - Condições ambientais nos locais das UTEs movidas a gás natural. Fonte: INMET (2016)

\begin{tabular}{ccccc}
\hline UTE & $\begin{array}{c}\text { Temperatura } \\
\text { Média }\left({ }^{\circ} \mathbf{C}\right)\end{array}$ & $\begin{array}{c}\text { Umidade } \\
\text { Relativa Média, } \\
\boldsymbol{\phi}(\mathbf{\%})\end{array}$ & $\begin{array}{c}\text { Pressão } \\
\text { atmosférica } \\
\text { média }(\mathbf{k P a})\end{array}$ & $\begin{array}{c}\text { Umidade absoluta - } \\
\boldsymbol{\omega}(\mathbf{k g} \text { vapor água } / \mathbf{k g} \\
\mathbf{a r ~ s e c o}^{*}\end{array}$ \\
\hline $\begin{array}{c}\text { Jorge Lacerda I, II, III e } \\
\text { IV }\end{array}$ & 19,0 & 80,0 & 101,60 & 0,0138 \\
$\begin{array}{c}\text { Presidente Medici A e B, } \\
\text { Candiota III e Seival }\end{array}$ & 18,6 & 71,1 & 101,70 & 0,0134 \\
Porto de Itaqui & 26,4 & 78,4 & 101,00 & 0,0218 \\
Pecém I e II & 27,2 & 76,1 & 100,98 & 0,0229 \\
Porto do Açu & 23,5 & 80,0 & 101,30 & 0,0143 \\
CTSUL & 19,6 & 69,3 & 101,20 & 0,0183 \\
Jacuí & 19,3 & 69,4 & 101,10 & 0,0140 \\
\hline
\end{tabular}

*Valores calculados 


\section{APÊNDICE B - Porcentagem volumétrica dos componentes dos gases de combustão}

São disponibilizadas nos gráficos B1 a B6 as frações volumétricas de cada componente presente nos gases de combustão das UTEs movidas a carvão mineral. Já nos gráficos B7 a B10 são apresentadas as frações dos gases de combustão referentes às UTEs a gás natural. 


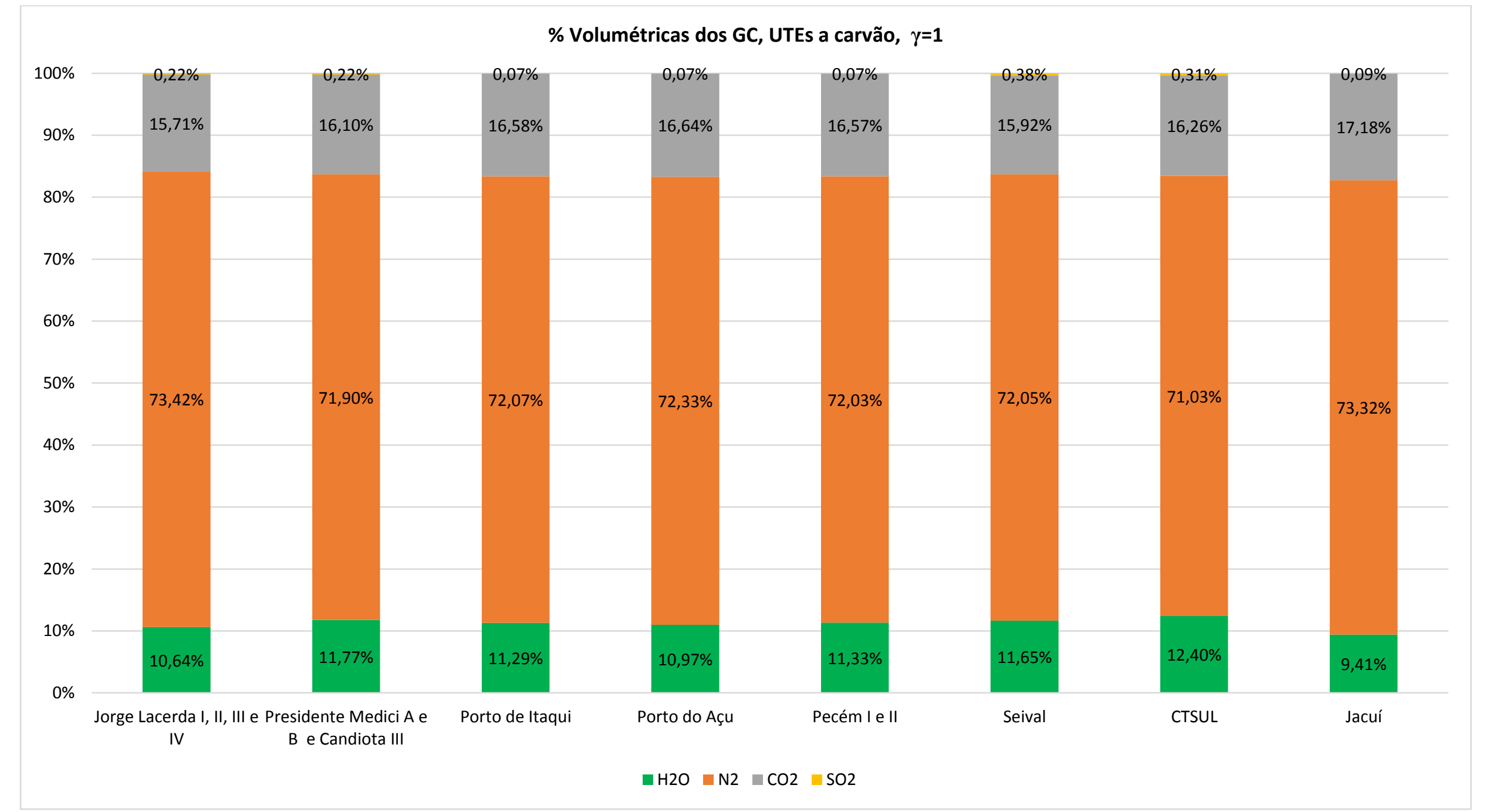

Figura B1 - Porcentagens volumétricas dos GC, UTEs a carvão mineral, $\gamma=1$ 


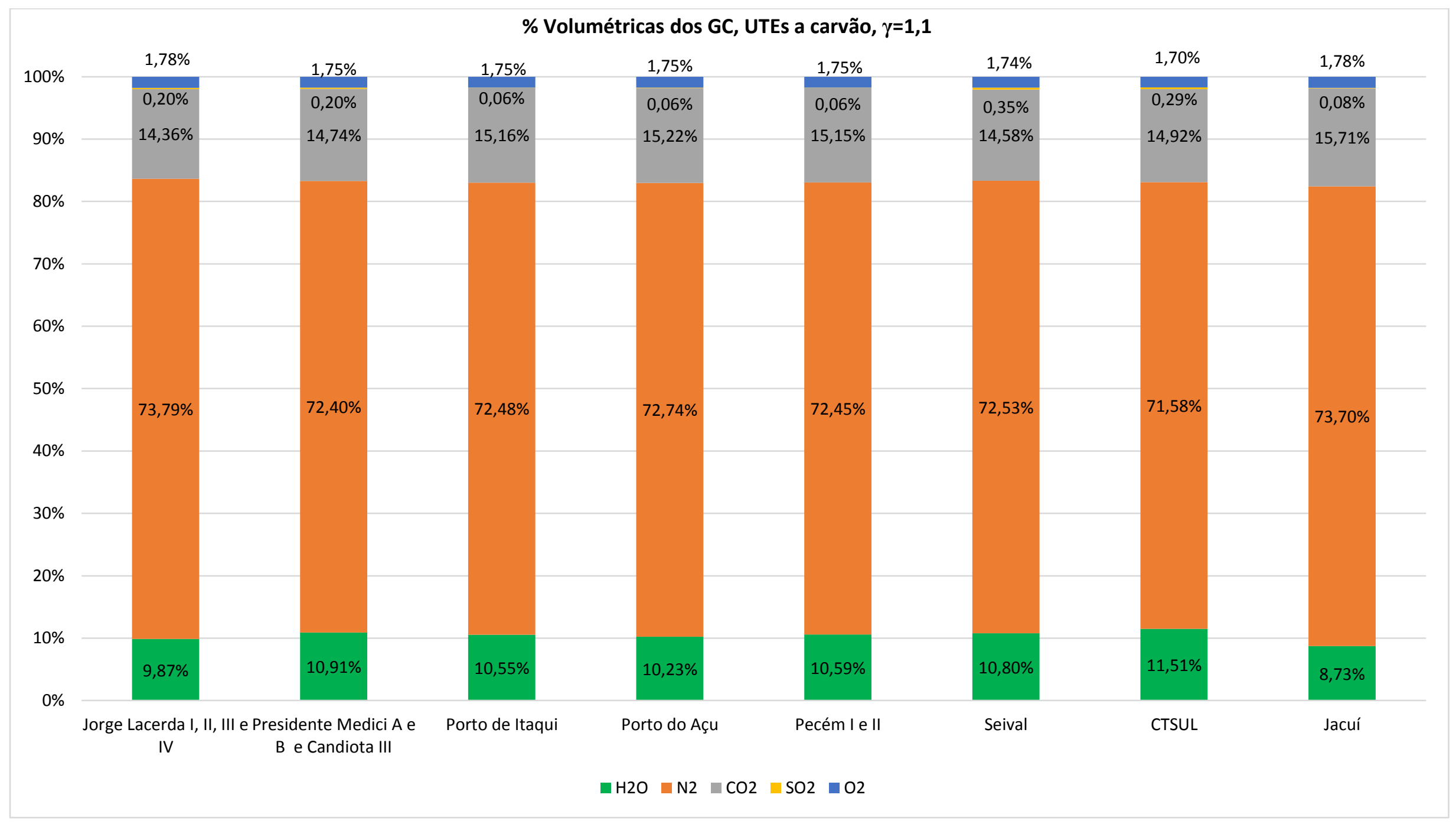

Figura B2 - Porcentagens volumétricas dos GC, UTEs a carvão mineral, $\gamma=1,1$ 
\% Volumétricas dos GC, UTEs a carvão, $\gamma=1,2$

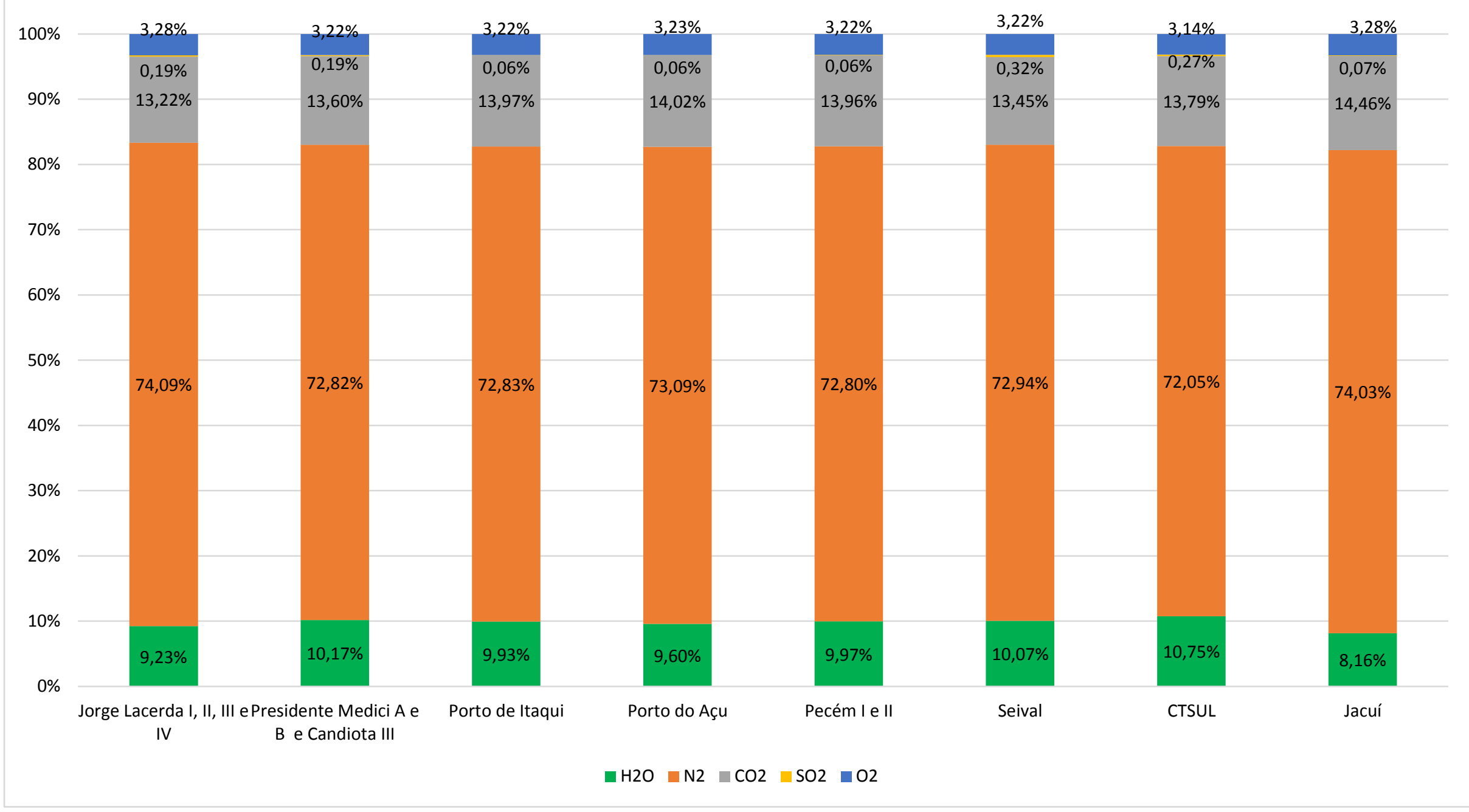

Figura B3 - Porcentagens volumétricas dos GC, UTEs a carvão mineral, $\gamma=1,2$ 


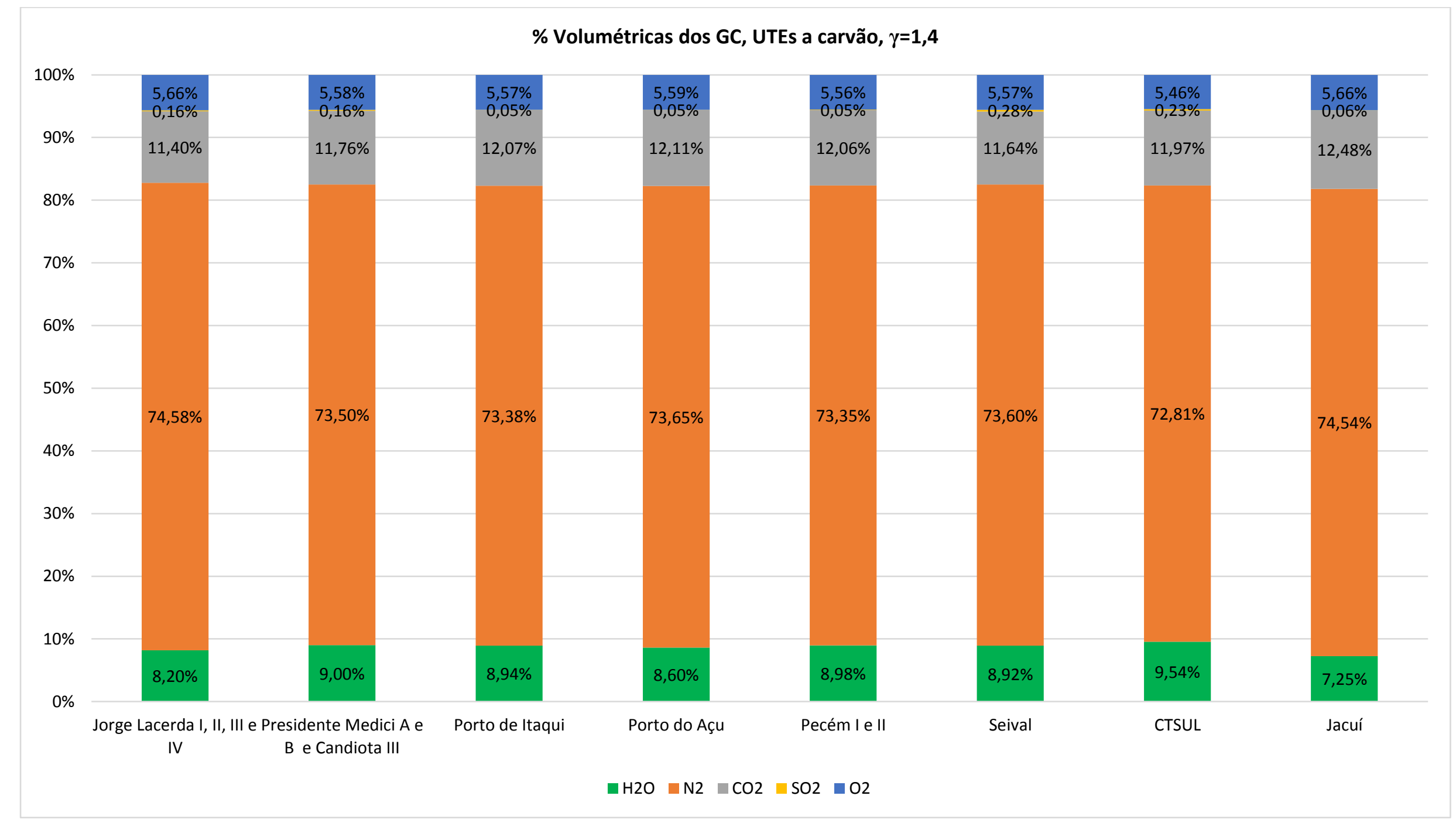

Figura B4 - Porcentagens volumétricas dos GC, UTEs a carvão mineral, $\gamma=1,4$ 
\% Volumétricas dos GC, UTEs a carvão, $\gamma=1,8$

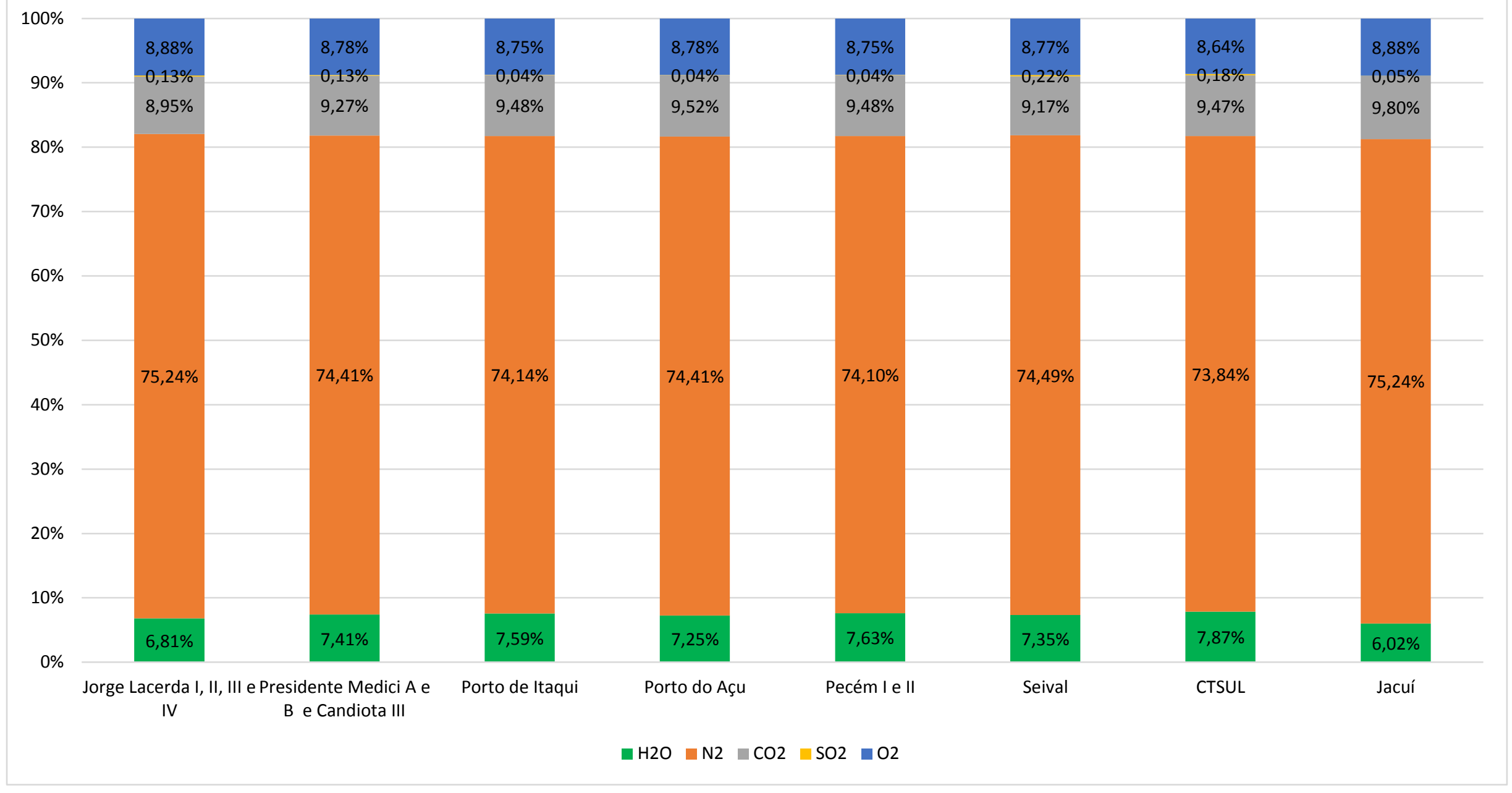

Figura B5 - Porcentagens volumétricas dos GC, UTEs a carvão mineral, $\gamma=1,8$ 


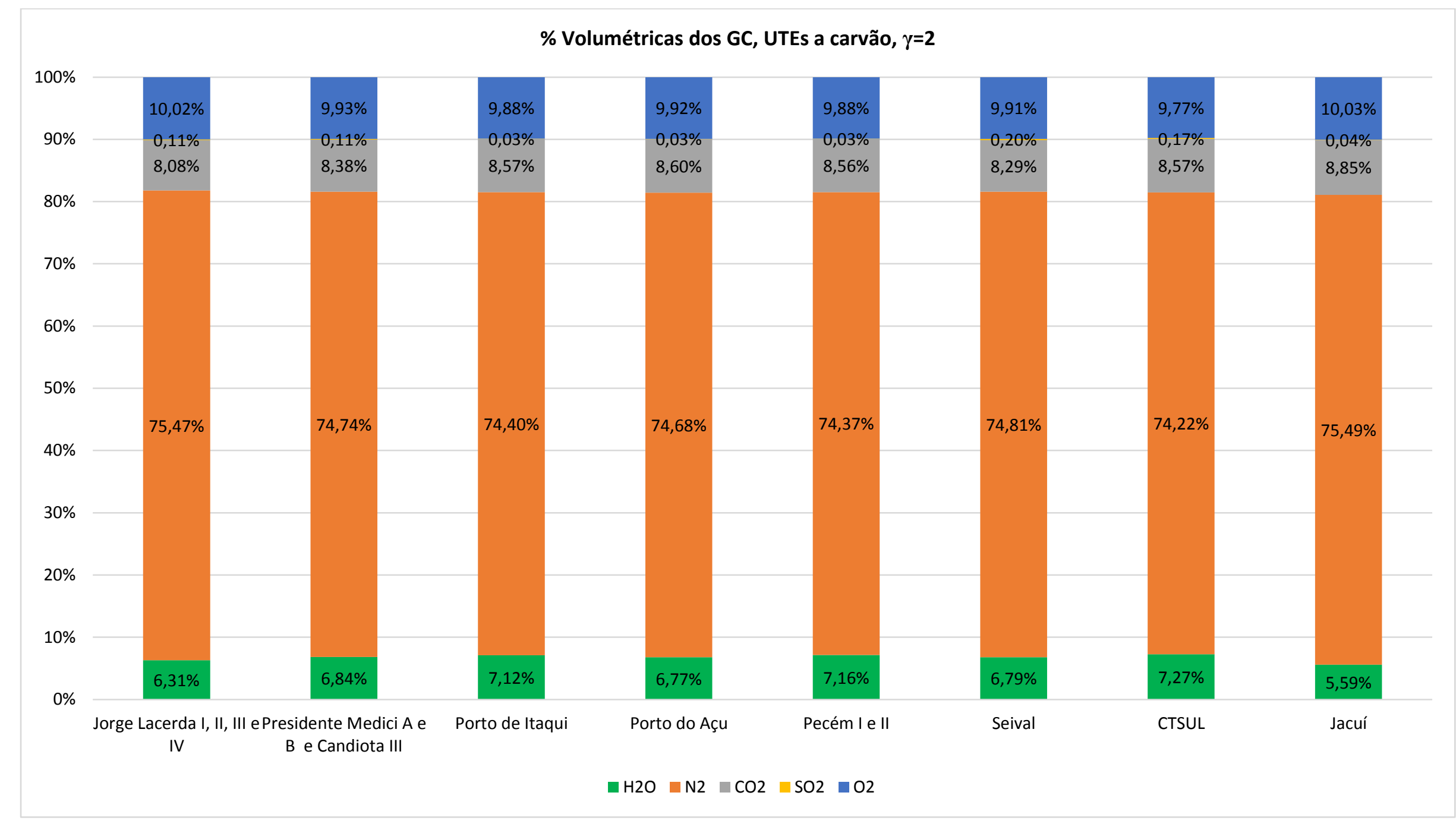

Figura B6 - Porcentagens volumétricas dos GC, UTEs a carvão mineral, $\gamma=2$ 


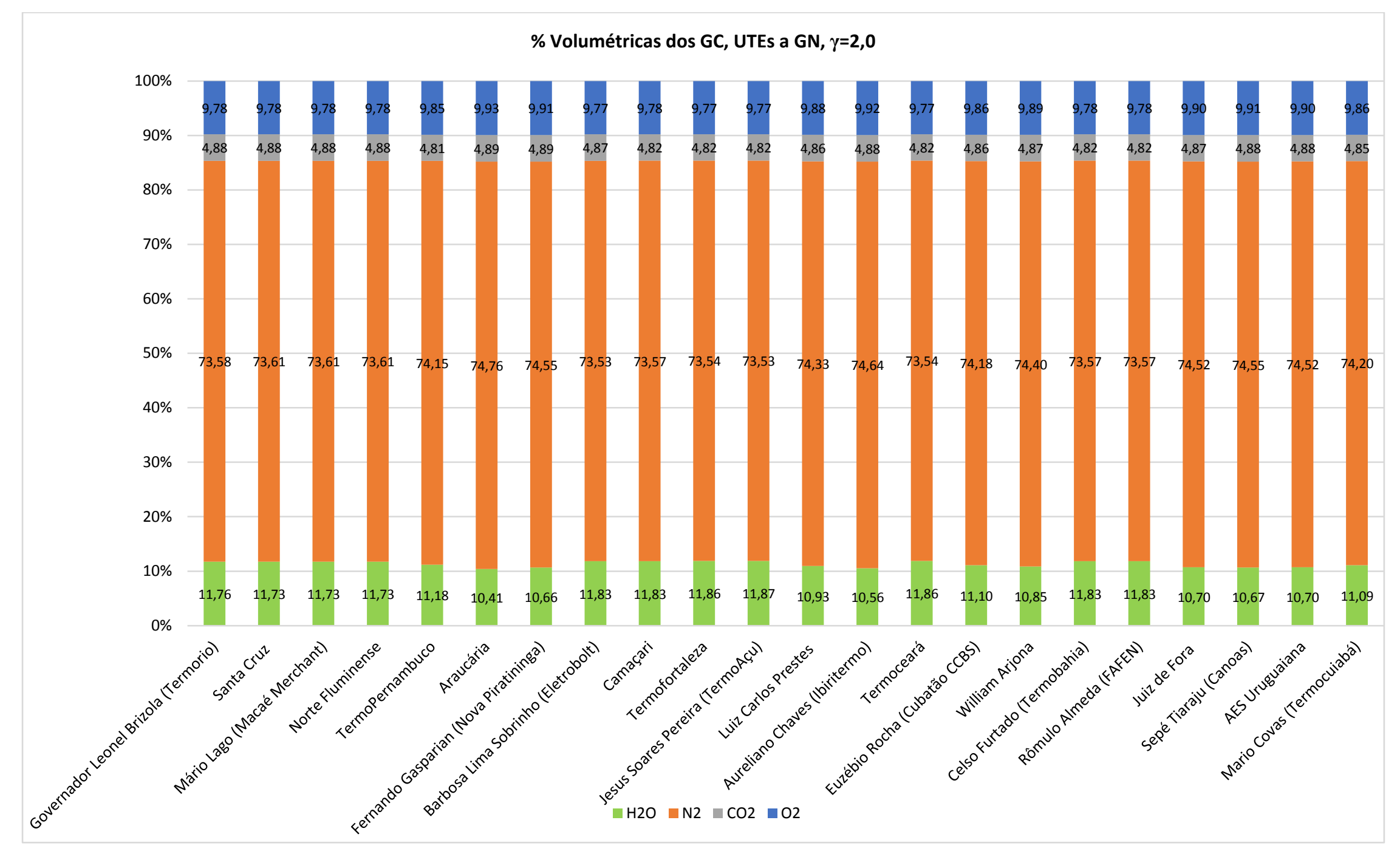

Figura B7 - Porcentagens volumétricas dos GC, UTEs a gás natural, $\gamma=2,0$ 


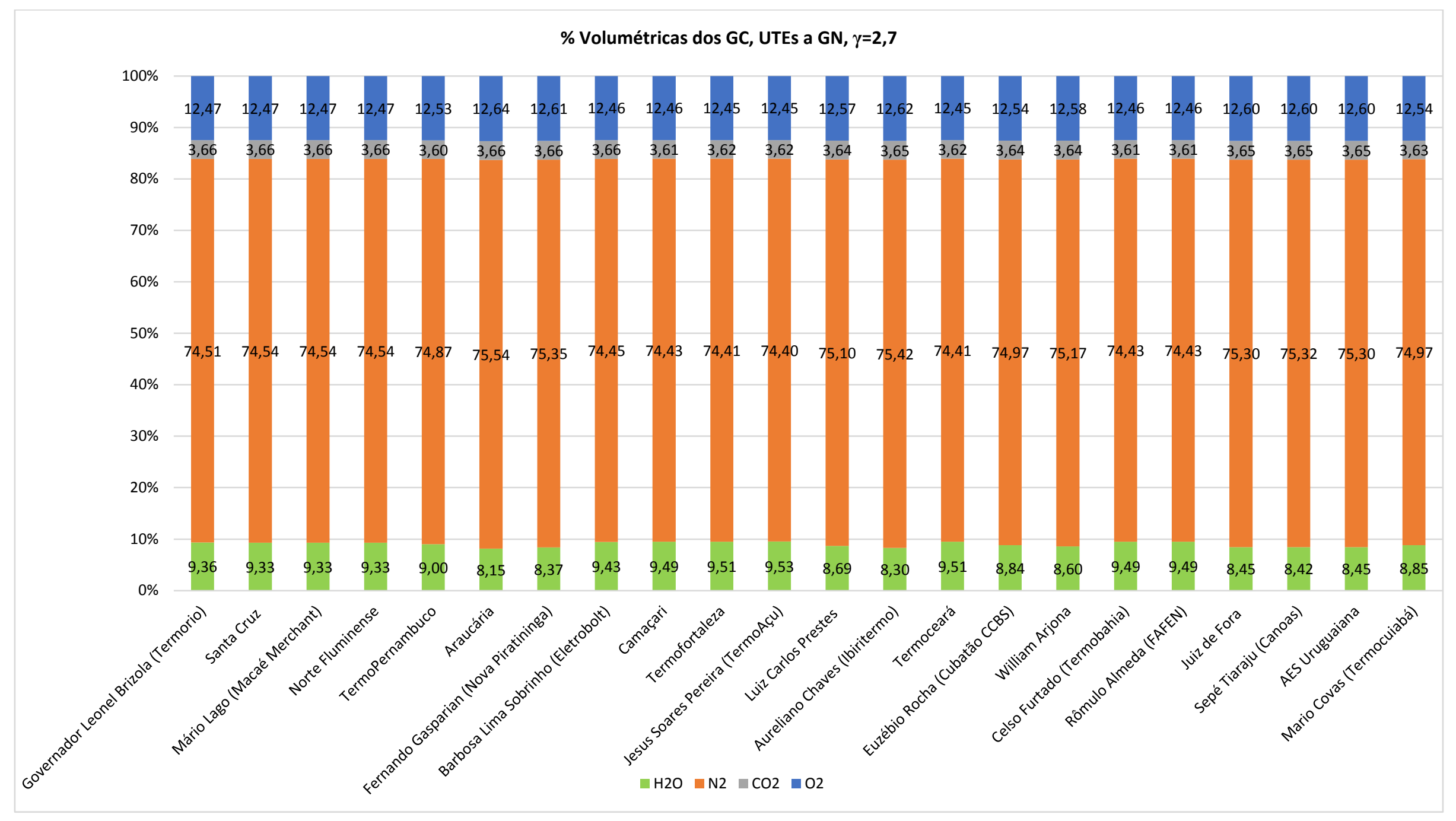

Figura B8 - Porcentagens volumétricas dos GC, UTEs a gás natural, $\gamma=2,7$ 


\section{$\%$ Volumétricas dos GC, UTEs a GN, $\gamma=3,4$}

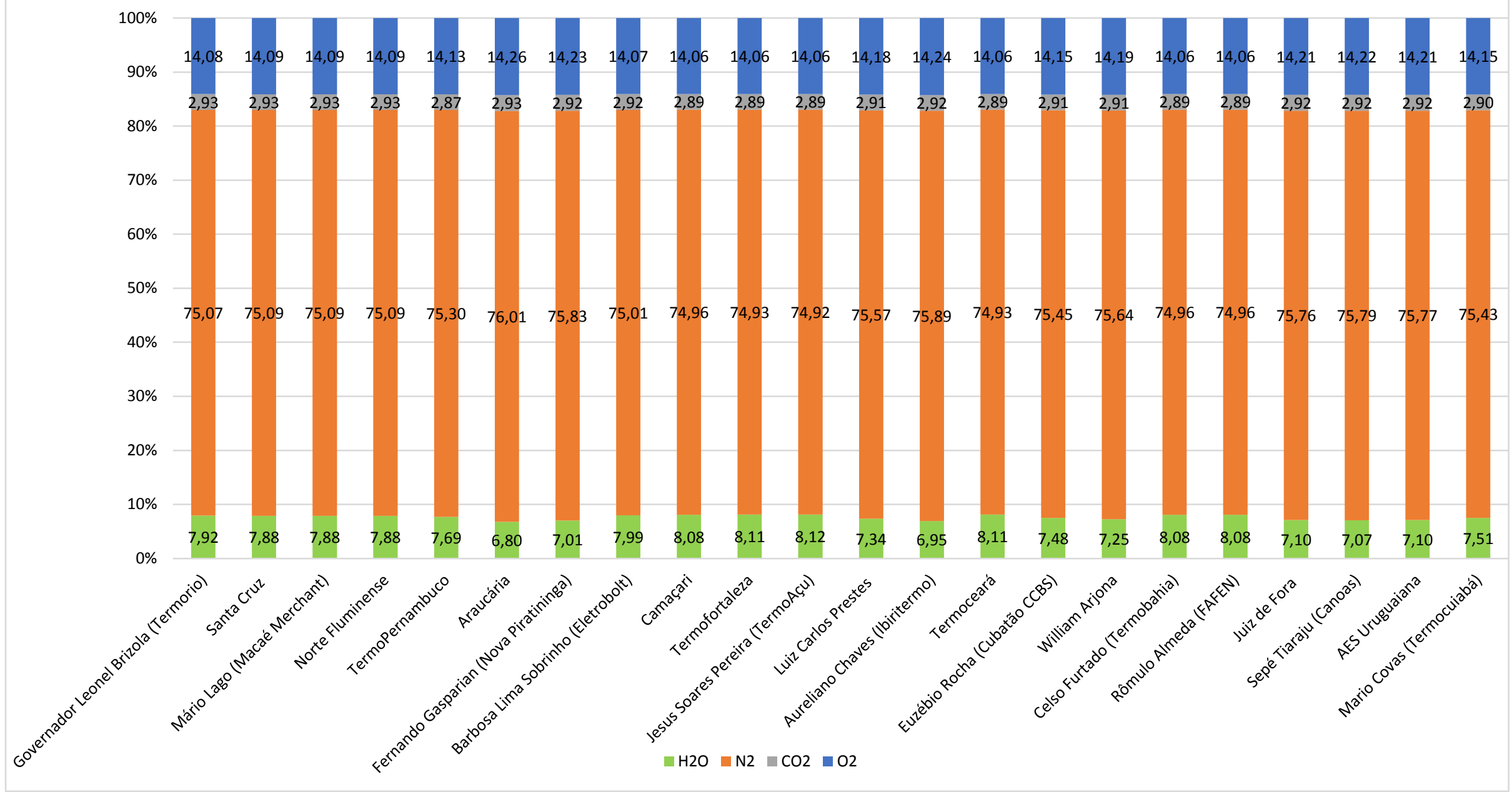

Figura B9 - Porcentagens volumétricas dos GC, UTEs a gás natural, $\gamma=3,4$ 
\% Volumétricas dos GC das UTES a gás natural , $\gamma=4,0$

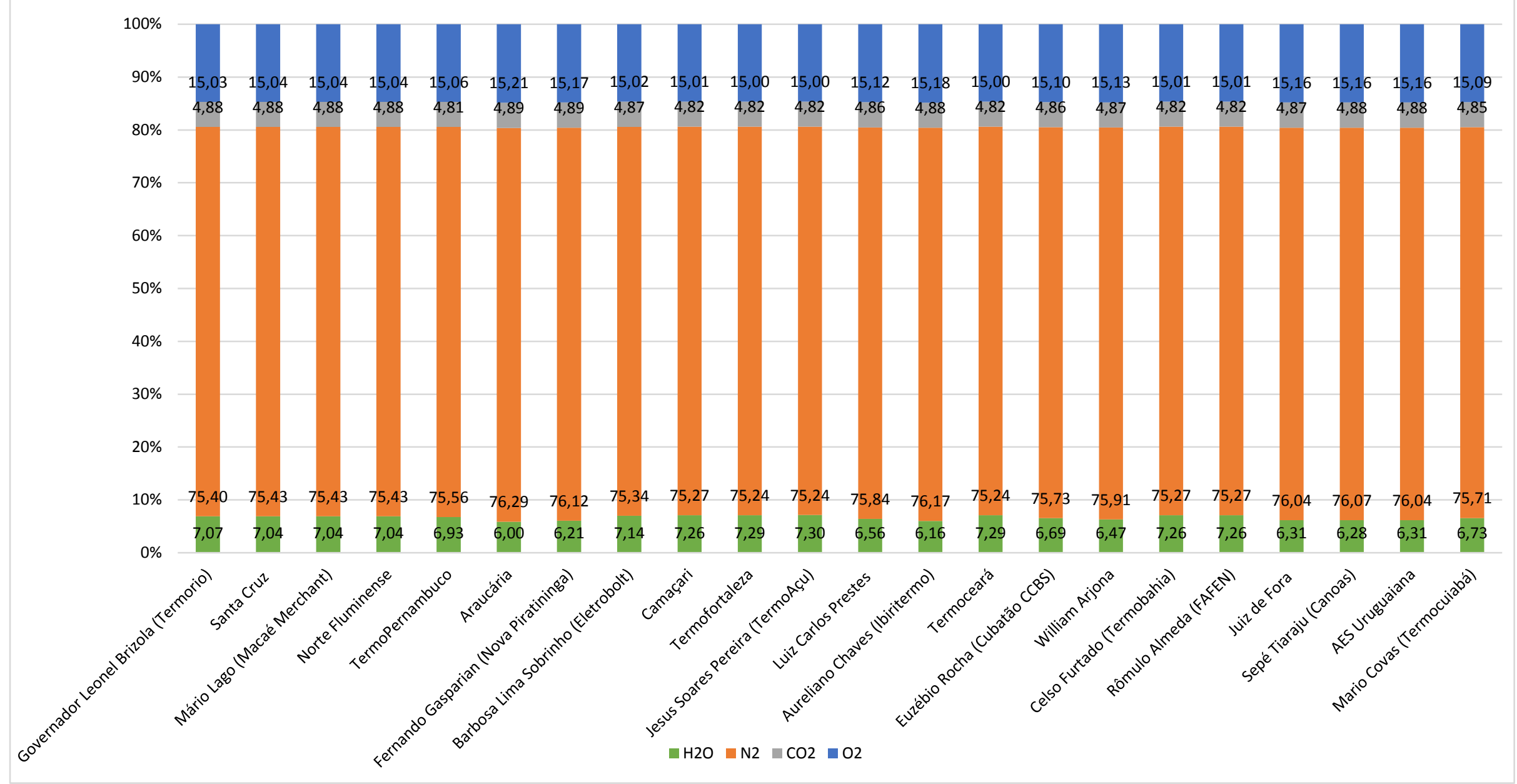

Figura B10 - Porcentagens volumétricas dos GC, UTEs a gás natural, $\gamma=4,0$ 


\section{APÊNDICE C - Propriedades termofísicas dos fluidos e do material do condensador}

\section{Gases de combustão}

As propriedades do gás de combustão foram calculadas a partir de correlações encontradas em "Physical properties of natural gases", N.V Nederlandse Gasunie, 1988, com base nos valores individuais de cada um dos componentes disponibilizados na Tabela $\mathrm{C} 1$.

Tabela C1. Propriedades dos componentes dos gases de combustão em condições de referência

\begin{tabular}{cccccc}
\hline Espécie & $\boldsymbol{\mu}_{\mathbf{o}}$ (Pa.s) & $\mathbf{C s}$ & $\begin{array}{c}\mathbf{C} \mathbf{p}_{\mathbf{i}}(\mathbf{k J} / \mathbf{k g ~ K}) \\
\mathbf{0 - 2 0 0} \mathbf{o}^{\mathbf{C}} \mathbf{C}\end{array}$ & $\begin{array}{c}\boldsymbol{\rho}_{\mathbf{i}} \\
\left(\mathbf{k g} / \mathbf{m}^{\mathbf{3}}\right)\end{array}$ & $\begin{array}{c}\boldsymbol{\lambda}_{\mathbf{i}}(\mathbf{W} / \mathbf{m ~ K}) \\
\mathbf{0}-\mathbf{2 0 0}^{\mathbf{0}} \mathbf{C}\end{array}$ \\
\hline $\mathrm{CO}_{2}$ & 0,0000138 & 266 & 1,809 & 1,977 & 0,0223 \\
$\mathrm{~N}_{2}$ & 0,00001663 & 112 & 1,306 & 1,25 & 0,0311 \\
$\mathrm{H}_{2} \mathrm{O}$ & 0,00000866 & 673 & 1,520 & 0,833 & 0,0248 \\
$\mathrm{O}_{2}$ & 0,00001919 & 131 & 1,336 & 1,429 & 0,0315 \\
\hline
\end{tabular}

- Condutividade térmica

$$
\lambda=\left[1+\frac{\left(\frac{x_{p}}{100}\right)-\left(\frac{x_{p}}{100}\right)^{2}}{3,5}\right] \sum_{i=1}^{n} \frac{x_{i} \lambda_{i}}{100}
$$

Onde:

$x_{p}$ : soma das concentrações dos componentes polares da mistura

- Viscosidade dinâmica:

$$
\mu_{i}=\mu_{o}\left(\frac{T}{273,15}\right)^{3 / 2} \frac{273,15}{T+C_{S}}
$$




$$
\mu=\sum_{i=1}^{n} \frac{x_{i} \mu_{i}}{100}
$$

- Calor específico:

$$
C_{P}=\sum_{i=1}^{n} \frac{x_{i} C_{P_{i}}}{100}
$$

- Densidade:

$$
\begin{aligned}
& \rho_{o}=\sum_{i=1}^{n} \frac{x_{i} \rho_{i}}{100} \\
& \rho=\rho_{o} \frac{273,15}{T}
\end{aligned}
$$

$\underline{\text { Ar }}$

As propriedades da água no estado líquido são válidas para temperatura entre $0^{\circ} \mathrm{C} \mathrm{e}$ $400^{\circ} \mathrm{C}$ e foram obtidas de correlacões geradas a partir de dados presentes em Holman (1992).

- Condutividade térmica

$$
\lambda=0,02428+6,939 \times 10^{-5} T+2,515 \times 10^{-8} T^{2}-7,194 \times 10^{-11} T^{3}
$$

- Calor específico:

$$
C_{P}=1,005-1,473 \times 10^{-5} T+2,515 \times 10^{-8} T^{2}-7,194 \times 10^{-11} T^{3}
$$

- Densidade:

$$
\rho=\frac{101,325}{0,287(T+273,15)}
$$


- Difusividade vapor de água no ar:

$$
\operatorname{Dif} f_{v, a r}=\frac{1,87 \times 10^{-10} \times T^{2,072}}{P}
$$

- Viscosidade dinâmica:

$$
\mu=10^{-7} T^{2}-0,00002 T+0,0014
$$

\section{$\underline{\text { Água líquida }}$}

As propriedades da água no estado líquido são válidas para temperatura entre $0^{\circ} \mathrm{C} \mathrm{e}$ $288^{\circ} \mathrm{C}$ foram obtidas de correlacões geradas a partir de dados presentes em Holman (1992).

- Condutividade térmica

$$
\lambda=0,56611+0,002048 T-1,0205 \times 10^{-5} T^{2}+1,1897 \times 10^{-8} T^{3}
$$

- Viscosidade

$$
\mu=\exp (-6,3933-0,026299 T+9,7341)
$$

- Calor específico

$C_{p}=\exp \left(1,4423-8,4025 \times 10^{-4} T-1,41 \times 10^{-5} T^{2}-7,3846 \times 10^{-8} T^{3}+\right.$ $\left.1,4856 \times 10^{-10} T^{4}\right)$

- Densidade

$$
\rho=1002,6-0,2177 T-0,0020099 T^{2}-1,6478 \times 10^{-6} T^{3}
$$

\section{$\underline{\text { Aço Inox }}$}

A condutividade térmica do aço inox AISI 316 foi obtida em Incropera (2011).

$$
\lambda=13,4 \quad(\text { a } 300 \mathrm{~K})
$$




\section{APÊNDICE D - Método numérico das diferenças finitas e discretização das equações de balanço constituintes do modelo numérico}

A primeira etapa para resolução de qualquer método numérico envolvendo as equações diferenciais parciais é discretizar a região onde se procura a solução. Para a discretização define-se uma malha, que é um conjunto finito de pontos pertencentes ao domínio, chamados nós da malha.

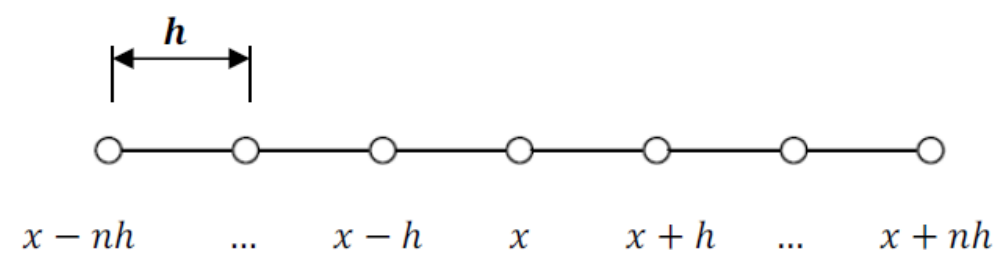

O método numérico das diferenças finitas é usado como uma abordagem alternativa para obter a aproximação da solução de uma equação diferencial parcial. A idéia básica desse método é transformar a resolução de uma equação diferencial em um sistema de equações algébricas, substituindo as derivadas por diferenças por meio da na discretização do domínio e da substituição das derivadas presentes na equação diferencial por aproximações utilizando apenas os valores numéricos da função. (Ruggiero e Rocha Lopes, 1996).

Por definição, a derivada de uma função $f(x)$ em um ponto $x_{i}$ é dada por:

$$
\frac{d f(x)}{d x}=\lim _{h \rightarrow 0} \frac{f\left(x_{i}+h\right)-f\left(x_{i}\right)}{h}
$$

Onde:

$$
h=\Delta x
$$

De forma aproximada, adotando-se h muito pequeno, pode-se escrever que:

$$
\frac{d f(x)}{d x} \approx \frac{f\left(x_{i}+h\right)-f\left(x_{i}\right)}{h}
$$


Esta aproximação é denominada como diferença progressiva, uma vez que se utiliza de um ponto a frente de $x_{i}$, o ponto $x_{i}+h$.

Alternativamente, pode-se deduzir a aproximação por meio de diferenças por meio da série de Taylor, conforme a seguir:

$$
f\left(x_{i}+h\right)=f\left(x_{i}\right)+h \frac{d f\left(x_{i}\right)}{d x}+\frac{h^{2}}{2 !} \frac{d^{2} f\left(x_{i}\right)}{d x^{2}}+\frac{h^{3}}{3 !} \frac{d^{3} f\left(x_{i}\right)}{d x^{3}}+\cdots \frac{h^{n}}{n !} \frac{d^{n} f\left(x_{n}\right)}{d x^{n}}+\cdots
$$

A expressão D3 pode ser reescrita como sendo:

$$
\frac{d f\left(x_{i}\right)}{d x}=\frac{f\left(x_{i}+h\right)-f\left(x_{i}\right)}{h}-\frac{h^{2}}{2 !} \frac{d^{2} f\left(x_{i}\right)}{d x^{2}}-\frac{h^{3}}{3 !} \frac{d^{3} f\left(x_{i}\right)}{d x^{3}}-\cdots \frac{h^{n}}{n !} \frac{d^{n} f\left(x_{n}\right)}{d x^{n}}-\cdots
$$

Logo, desprezando-se os termos relativos às derivadas de ordem igual ou superior a dois, também se obtém a aproximação com diferença progressiva.

Analogamente, a expansão da série de Taylor do valor $x=x i-h$ em torno de $x=x_{i}$.

$$
\begin{gathered}
f\left(x_{i}-h\right)=f\left(x_{i}\right)-h \frac{d f\left(x_{i}\right)}{d x}+\frac{h^{2}}{2 !} \frac{d^{2} f\left(x_{i}\right)}{d x^{2}}-\frac{h^{3}}{3 !} \frac{d^{3} f\left(x_{i}\right)}{d x^{3}}+\cdots+(-1)^{n} \frac{h^{n}}{n !} \frac{d^{n} f\left(x_{n}\right)}{d x^{n}} \\
+\cdots
\end{gathered}
$$

Reescrevendo a expressão:

$$
\begin{aligned}
\frac{d f\left(x_{i}\right)}{d x} & =\frac{f\left(x_{i}\right)-f\left(x_{i}+h\right)}{h}-\frac{h}{2 !} \frac{d^{2} f\left(x_{i}\right)}{d x^{2}}+\frac{h^{2}}{2 !} \frac{d^{2} f\left(x_{i}\right)}{d x^{2}}+\cdots+(-1)^{n} \frac{h^{n}}{n !} \frac{d^{n} f\left(x_{n}\right)}{d x^{n}} \\
& -\cdots
\end{aligned}
$$

Portanto, desprezando-se os termos relativos às derivadas de ordem igual ou superior a dois, se obtém a expressão da aproximação com diferença regressiva.

$$
\frac{d f\left(x_{i}\right)}{d x} \approx \frac{f\left(x_{i}\right)-f\left(x_{i}+h\right)}{h}
$$


Uma terceira alternativa pode ser considerada para aproximação da derivada de primeira ordem de $f\left(x_{i}\right)$, conhecida como aproximação centrada.

$$
\frac{d f\left(x_{i}\right)}{d x} \approx \frac{f\left(x_{i}+h\right)-f\left(x_{i}-h\right)}{2 h}
$$

A seguir, são apresentados o desenvolvimento e a discretização das equações para solução do modelo proposto:

$$
\begin{gathered}
d Q_{g}=-\dot{m}_{g} C p_{g} d T_{g} \\
d Q_{c}=-\dot{m}_{c} C p_{c} d T_{c} \\
d Q=U\left(T_{g}-T_{c}\right) d A \\
d Q=\left[h_{g}\left(T_{g}-T_{i}\right)+k_{g} h^{*}{ }_{l g}\left(x_{v, b}-x_{v, i}\right)\right] d A=U_{o}\left(T_{i}-T_{c}\right) d A
\end{gathered}
$$

Assumindo que $d Q_{g}=d Q_{c}$ :

$$
\begin{gathered}
d \Delta T=d\left(T_{g}-T_{c}\right)=d T_{g}-d T_{c} \\
=-(d Q)\left(\frac{1}{\dot{m}_{g} C p_{g}}-\frac{1}{\dot{m}_{c} C p_{c}}\right) \\
d T_{g}-d T_{c}=-\left[U\left(T_{g}-T_{c}\right) d A\right]\left(\frac{1}{\dot{m}_{g} C p_{g}}-\frac{1}{\dot{m}_{c} C p_{c}}\right) \\
\frac{d T_{g}}{d A}+U\left(\frac{1}{\dot{m}_{g} C p_{g}}-\frac{1}{\dot{m}_{c} C p_{c}}\right) T_{q}=\frac{d T_{f}}{d A}+U\left(\frac{1}{\dot{m}_{g} C p_{g}}-\frac{1}{\dot{m}_{c} C p_{c}}\right) T_{c} \\
\dot{m}_{g} C p_{g}\left(T_{g}-T_{g s}\right)=\dot{m}_{c} C p_{c}\left(T_{c}-T_{c e}\right) \\
T_{c}=T_{c e}+\frac{\dot{m}_{g} C p_{g}}{\dot{m}_{c} C p_{c}}\left(T_{g}-T_{g s}\right)
\end{gathered}
$$

Derivando: 


$$
\frac{d T_{c}}{d A}=\frac{\dot{m}_{g} C p_{g}}{\dot{m}_{c} C p_{c}} \frac{d T_{g}}{d A}
$$

Substituindo:

$$
a \frac{d T_{g}}{d A}+b T_{g}+c T_{g s}=d T_{c e}
$$

Onde:

$$
\begin{gathered}
a=\left(1-\frac{m_{g} C p_{g}}{\dot{m}_{c} C p_{c}}\right) \\
b=U\left(\frac{1}{\dot{m}_{g} C p_{g}}-\frac{1}{\dot{m}_{c} C p_{c}}\right) \cdot\left(1-\frac{m_{g} C p_{g}}{\dot{m}_{c} C p_{c}}\right) \\
c=U\left(\frac{1}{\dot{m}_{g} C p_{g}}-\frac{1}{\dot{m}_{c} C p_{c}}\right) \cdot\left(\frac{m_{g} C p_{g}}{\dot{m}_{c} C p_{c}}\right) \\
d=U\left(\frac{1}{\dot{m}_{g} C p_{g}}-\frac{1}{\dot{m}_{c} C p_{c}}\right) \\
d T_{g, n}=T_{g}(n \cdot A), n=0,1 \ldots . . N \\
T_{g, 0}=T_{g}(0)=T_{g e} \\
T_{g, N}=T_{g}(A)=T_{g s}
\end{gathered}
$$

Discretizando:

$$
\begin{gathered}
a_{n} \frac{T_{g, n}-T_{g, n-1}}{\Delta A}+b_{n} T_{g, n}+c_{n} T_{g, N}=d_{n} T_{c e} \\
-\frac{a_{n}}{\Delta A} T_{g, n-1}+\left(b_{n}+\frac{a_{n}}{\Delta A}\right) T_{g, n}+c_{n} T_{g, N}=d_{n} T_{c e}
\end{gathered}
$$

Se $n=N$

$$
-\frac{a_{n}}{\Delta A} T_{g, n-1}+\left(b_{n}+\frac{a_{n}}{\Delta A}\right) T_{g, n}+c_{n} T_{g, N}=d_{n} T_{c e}
$$

Para $n=1$ : 
190

$$
\begin{gathered}
-\frac{a_{1}}{\Delta A} T_{g, 0}+\left(b_{1}+\frac{a_{1}}{\Delta A}\right) T_{g, 1}+c_{1} T_{g, N}=d_{1} T_{c e} \\
\left(b_{1}+\frac{a_{1}}{\Delta A}\right) T_{g, 1}+c_{1} T_{g, N}=d_{1} T_{c e}+\frac{a_{1}}{\Delta A} T_{c e}
\end{gathered}
$$

Para $\mathrm{n}=2$ :

$$
-\frac{a_{2}}{\Delta A} T_{g, 1}+\left(b_{2}+\frac{a_{2}}{\Delta A}\right) T_{g, 2}+c_{1} T_{g, N}=d_{2} T_{c e}
$$

Para $n=3$ :

$$
\frac{-a_{3}}{\Delta A} T_{g, 2}+\left(b_{3}+\frac{a_{3}}{\Delta A}\right) T_{g, 3}+c_{3} T_{g, N}=d_{3} T_{c e}
$$

Para $n=N$ :

$$
-\frac{a_{N}}{\Delta A} T_{g, N-1}+\left(b_{N}+\frac{a_{N}}{\Delta A}+c_{N}\right) T_{g, N}=d_{N} T_{c e}
$$




\section{APÊNDICE E - Procedimento de cálculo}

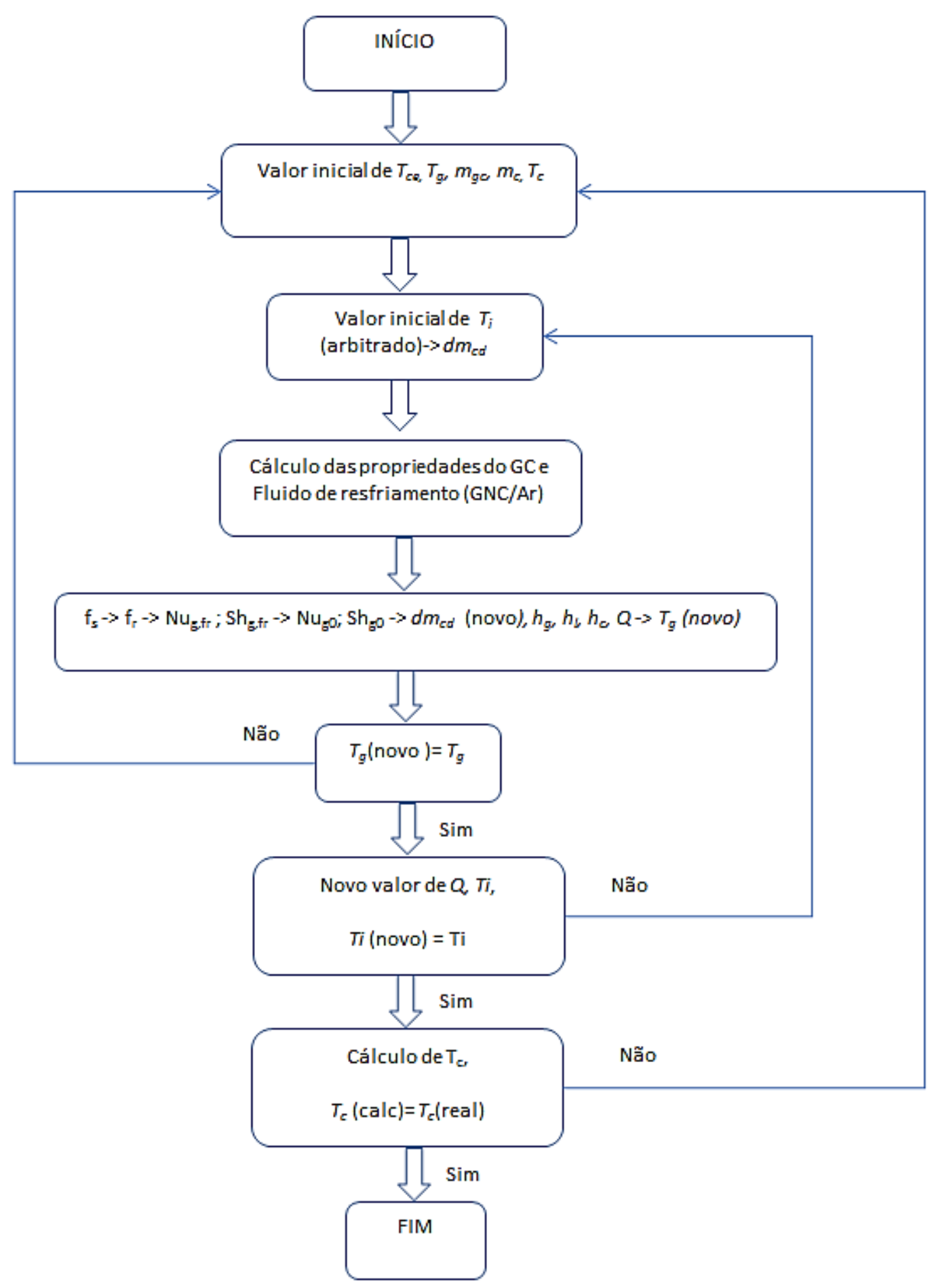

Figura E1 - Fluxograma relativo ao procedimento de cálculo empregado 